\title{
WestVirginiaUniversity
}

THE RESEARCH REPOSITORY @ WVU

Graduate Theses, Dissertations, and Problem Reports

2010

\section{Passive Thermal Management of Solar Heat Flux through Building Roof Structures}

\author{
Emily Deanna Pertl \\ West Virginia University
}

Follow this and additional works at: https://researchrepository.wvu.edu/etd

\section{Recommended Citation}

Pertl, Emily Deanna, "Passive Thermal Management of Solar Heat Flux through Building Roof Structures" (2010). Graduate Theses, Dissertations, and Problem Reports. 3089.

https://researchrepository.wvu.edu/etd/3089

This Dissertation is protected by copyright and/or related rights. It has been brought to you by the The Research Repository @WVU with permission from the rights-holder(s). You are free to use this Dissertation in any way that is permitted by the copyright and related rights legislation that applies to your use. For other uses you must obtain permission from the rights-holder(s) directly, unless additional rights are indicated by a Creative Commons license in the record and/ or on the work itself. This Dissertation has been accepted for inclusion in WVU Graduate Theses, Dissertations, and Problem Reports collection by an authorized administrator of The Research Repository @ WVU.

For more information, please contact researchrepository@mail.wvu.edu. 


\title{
Passive Thermal Management of Solar Heat Flux through Building Roof Structures
}

\author{
Emily Deanna Pertl \\ Dissertation submitted to the \\ College of Engineering and Mineral Resources \\ at West Virginia University \\ in partial fulfillment of the requirements \\ for the degree of \\ Doctor of Philosophy \\ in \\ Mechanical Engineering \\ Mary Ann Clarke, $\mathrm{PhD}$ \\ W. Scott Wayne, $\mathrm{PhD}$ \\ Eric Johnson, $\mathrm{PhD}$ \\ Kenneth Means, $\mathrm{PhD}$ \\ James E. Smith, PhD, Chair
}

Department of Mechanical and Aerospace Engineering

Morgantown, West Virginia

2010

Keywords: Heat Transfer, Energy Saving, Convective Flow

Copyright Emily D. Pertl 2010 


\title{
AbStract \\ Passive Thermal Management of Solar Heat Flux through Building Roof Structures
}

\author{
Emily Deanna Pertl
}

The impact of rising energy prices on household costs and the overall economy has increasingly become a focal point of public concern. During a typical summer day, solar radiation heats up a building for the majority of the day through the windows, walls, doors, and especially the roof. To maintain comfort in summer, the heat gained must be removed by a cooling system and similarly in winter, the heat lost must be replaced by a heating system. Heating and cooling are both major contributors to energy expenditures in most building structures, and as a result, energy savings focused on these sources need to be investigated.

The objective of the research was to evaluate through analytic and experimental techniques a novel type of passive thermal management system by determining the impact of natural convective air gaps driven by buoyancy effects and evaluating the interactive thermal properties. The properties considered included the convection heat transfer coefficient, thermal conductivity, radiation emissivity, thermal resistance, and thermal capacitance of each system component. To meet this objective, the governing classical thermal and flow equations were used to create a predictive tool for the development of a scaled physical test model. This structural test model and its similar control unit were set up to evaluate the direct effects that convective cooling has on sunlit days. For these experiments, temperature and air speed measurements were observed in the experimental units and compared against the analytic predictions. To validate the design, experimental tests were performed and compared to the predictive results. In addition, the experimental results were used to validate the prediction model and to investigate alternative design settings, parametrically.

This research assessed the thermal attributes of an add-on roof system for a single or multifamily residence or small business, with the goal of providing recommendations that can be employed in the design of new homes and businesses. Likewise, the roof system can be applied as a retro-fit to improve the efficiency of current home and business roof designs. The results of this evaluation show the effectiveness of the heat roof design for attic and home temperature reductions, as well as provide an experimentally based model for future roof design considerations. 


\section{ACKNOWLEDGEMENTS}

Though this dissertation is an individual work, achieving my goals relied on the help, support, guidance and efforts of several people. First, I would like to thank my supervisor, mentor and friend, Dr. James E. Smith for instilling in me the qualities of being an excellent engineer. His encouragement and support have been major driving forces through my graduate education and employment at West Virginia University. More importantly, he has demonstrated his faith in my ability to rise to the occasion and do the necessary. I would also like to thank each of my committee members, Dr. Mary Ann Clarke, Dr. Kenneth Means, Dr. Scott Wayne, and Dr. Eric Johnson for their guidance over the years.

I would also like to express my sincere gratitude to my friends and family for their encouragement, love and support, in particular to Jean Kopasko, Nicole Moran, and Davina Cirillo. I would also like to say thank you to Daniel Carder and Clifford Judy for their help with assembling the experimental units.

A very special thanks to the one person whom I owe everything I am today, my mother, Janna D. Nicholas. Her unwavering faith and confidence in my abilities and in me is what has shaped me to be the person I am today. Last, but not least, I most want to thank my husband, Andy for his love, patience and kind indulgence. His support and guidance allowed me to fulfill one of my greatest accomplishments. 


\section{DEDICATION}

I would like to dedicate this work to my late grandfather, Herman L. Nicholas, and late grandmother, Janna L. Kirkwood, both who unfortunately passed away during the time period while I was completing my dissertation work. Although they did not get to see me graduate, I know they are very proud of my accomplishments. 


\section{TABLE OF CONTENTS}

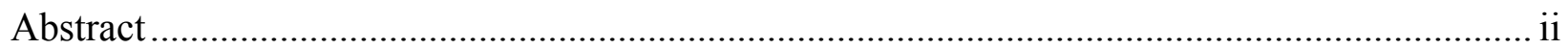

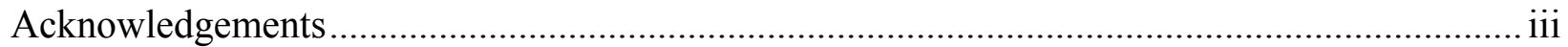

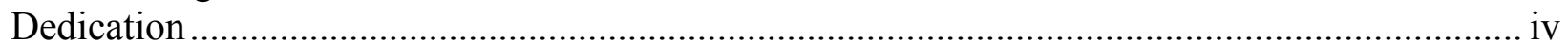

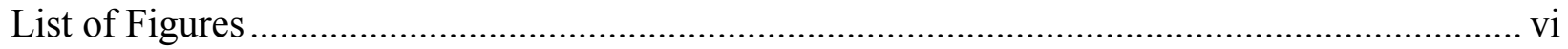

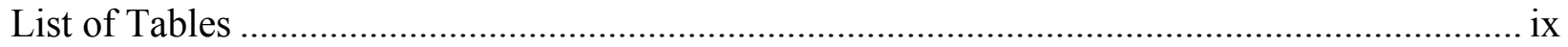

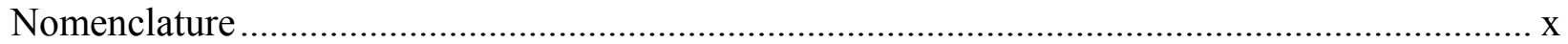

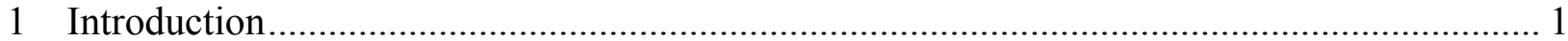

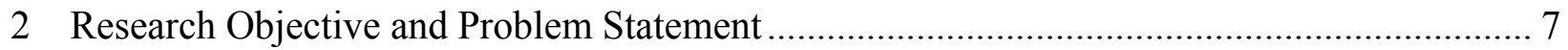

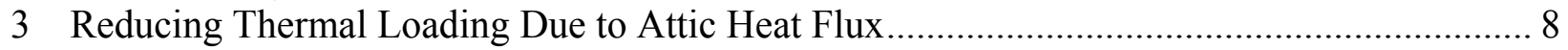

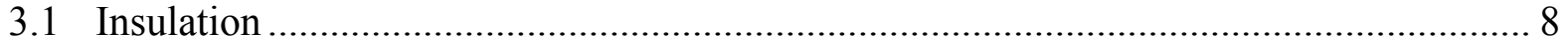

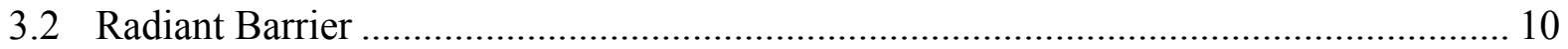

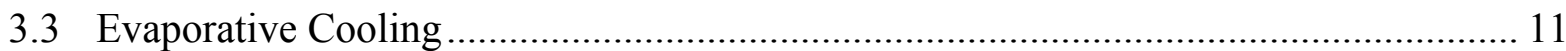

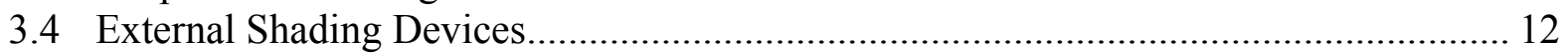

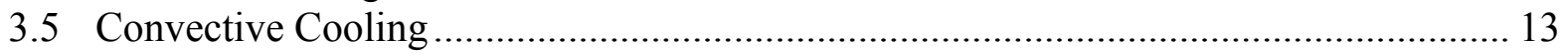

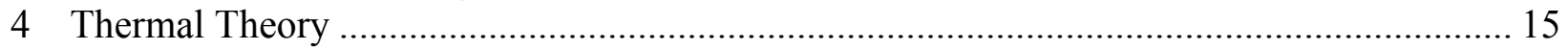

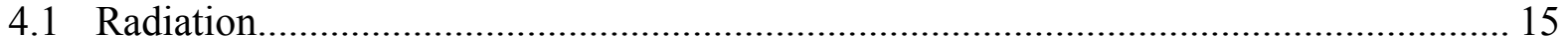

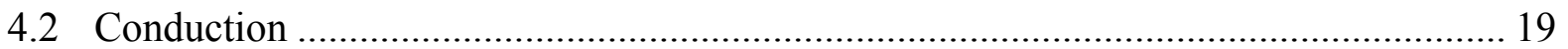

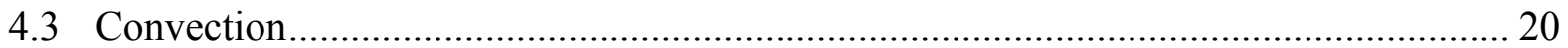

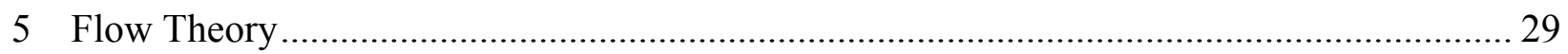

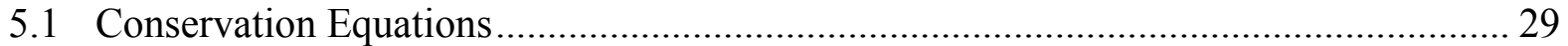

5.2 Flow Over and Between Parallel Plates ........................................................................ 32

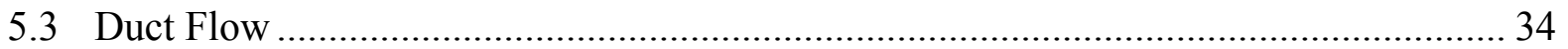

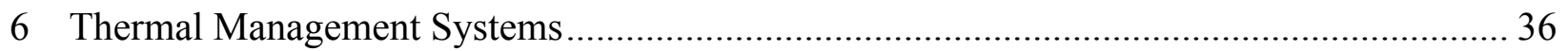

6.1 Feasibility Analysis of an Add-On Roof System for Standard Shipping Containers..... 36

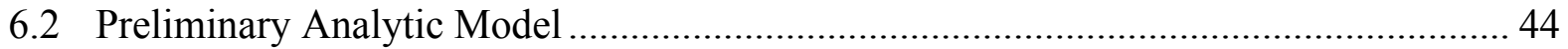

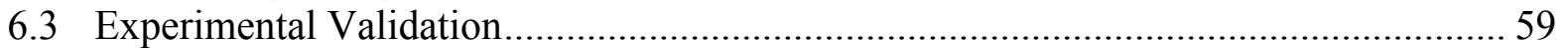

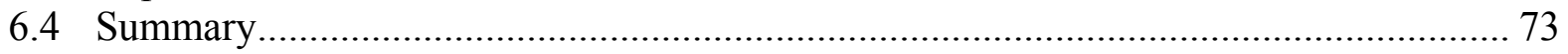

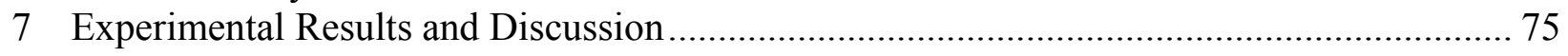

7.1 Controlled Environment Baseline ………….......................................................... 76

7.2 Environmentally Exposed Baseline.............................................................................. 79

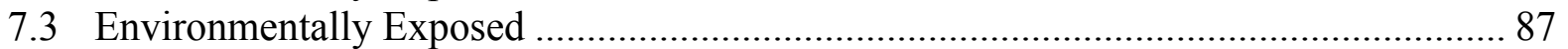

7.4 Analytic and Experimental Comparison ................................................................ 103

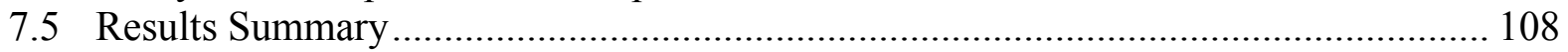

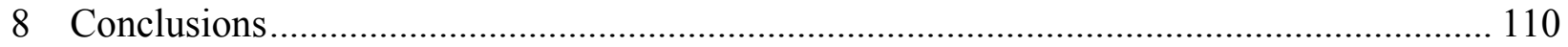

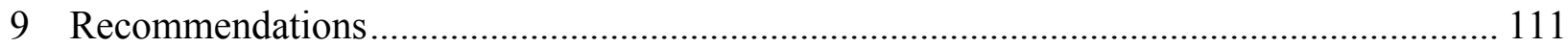

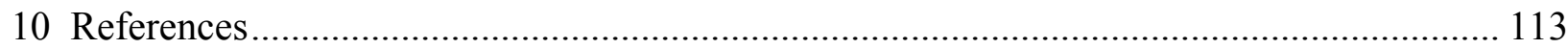

Appendix A - Mathematica ${ }^{\circledR}$ Code for Analytic Model......................................................... 117

Appendix B - Matlab ${ }^{\circledR}$ Code for Controlled Baseline Data ………........................................... 123

Appendix C - Matlab ${ }^{\circledR}$ Code for Environmental Baseline Data............................................... 129

Appendix D - Matlab ${ }^{\circledR}$ Code for Environmentally Exposed Data ............................................. 135 


\section{LIST OF FIGURES}

Figure 1 Space Heating Characteristics by Type of Housing Unit (Energy 2005)......................... 1

Figure 2 US Residential Electricity Consumption (Energy 2005)........................................... 2

Figure 3 US Electric Industry Residential Average Retail Prices of Electricity by State (Energy 2005) 2

Figure 4 US Department of Energy Recommendations for Insulation Levels (Energy 2005) ....... 4

Figure 5 Typical Insulation in a Pitched Roof (eHow 2008) .................................................... 8

Figure 6 Proper Batt Installation with Vapor Barrier (Kansas State University 2000) ................... 9

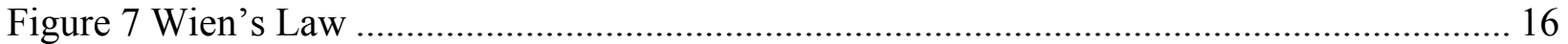

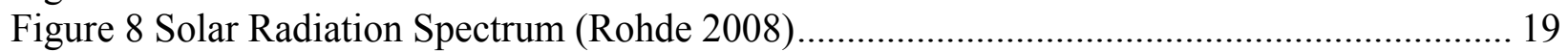

Figure 9 Convective Currents over a Vertical Flat Plate (Çengel 2007) ..................................... 24

Figure 10 Natural Convective Currents over an Inclined Plate (Çengel 2007) ........................... 25

Figure 11 Natural Convective Currents over the Upper and Lower Surfaces of a Horizontal Plate

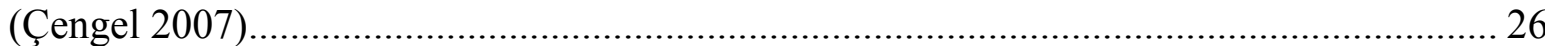

Figure 12 Mass Conservation on a Control Volume (Bejan 2004) ............................................. 29

Figure 13 Force Balance on a Control Volume (Bejan 2004) ...................................................... 30

Figure 14 First Law of Thermodynamics Applied to a Control Volume (Bejan 2004) ................ 31

Figure 15 Velocity Profiles Over and Between Flat Vertical Plates .............................................. 32

Figure 16 Velocity Profiles Over and Between Flat Inclined Plates ........................................... 33

Figure 17 Mobile Hospital (ECS MOGOS)(ECS MOGOS 2007) ……………………………...... 37

Figure 18 Container Corner Castings (Pacific Marine 2007) ………………….......................... 38

Figure 19. Shelter without Heat Roof (A), Exploded View Heat Roof Locking into Place (B),

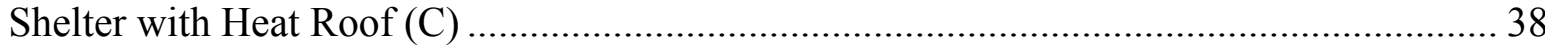

Figure 20 Thermal Schematic of Military Shelter Heat Transfer ................................................. 40

Figure 21 Thermal schematic of military shelter with modular heat roof .................................... 41

Figure 22 Temperature Error for Military Shelter …………………………………………...... 43

Figure 23 Temperature Error for Military Shelter with Modular Heat Roof................................. 43

Figure 24 Convective Currents for a Conventional Pitched Roof ............................................... 45

Figure 25 Convective Currents for a Conventional Pitched Roof with Add-on Roof Feature..... 45

Figure 26 Common Locations for Convective Heat Loss in a Typical Home (Energy Star New

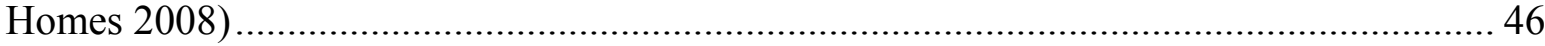

Figure 27 Heat Transfer Processes in a Residential Attic.......................................................... 47

Figure 28 Electrical Schematic of Control Unit ...................................................................... 48

Figure 29 Average Measured Daily Insolation on a Horizontal Surface in the United States

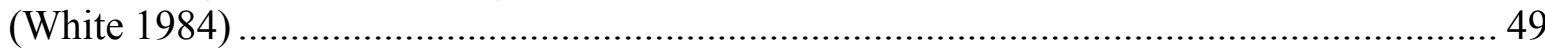

Figure 30 Heat Transfer Processes in a Residential Home with Add-On Roof Feature............... 52

Figure 31 Electrical Schematic of Control Unit with Add-on ................................................... 52

Figure 32 Convective Currents for a Conventional Pitched Roof with Add-on Roof Feature and

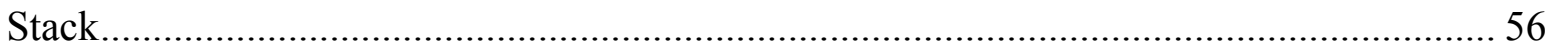

Figure 33 Predicted Air Velocity due to Buoyancy Effects …………........................................ 57

Figure 34 Predicted Results for Various Air Gap Heights ..................................................... 58

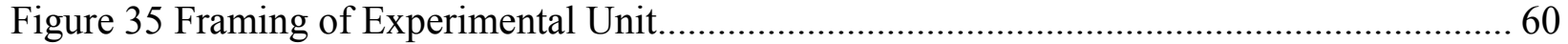

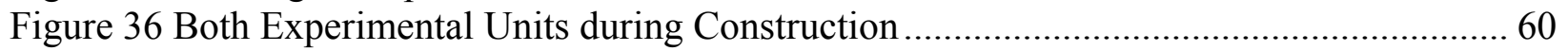

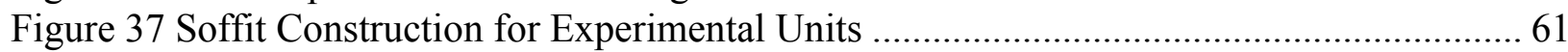

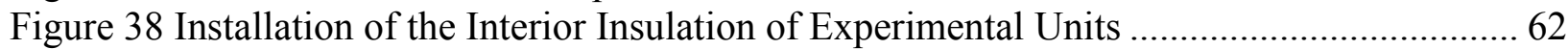

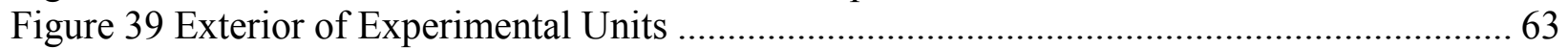




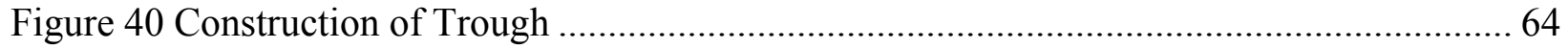

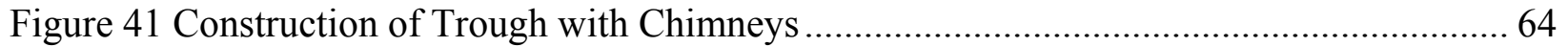

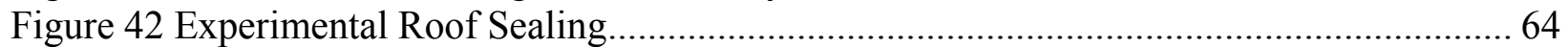

Figure 43 Computer Aided Drawing of External Roof Structure.............................................. 65

Figure 44 Computer Aided Drawing of Experimental Control Unit ............................................. 66

Figure 45 Resistance Temperature Detector Secured with Thermal Urethane................................. 67

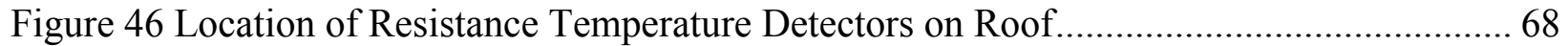

Figure 47 Location of Resistance Temperature Detectors Inside of Attic................................... 68

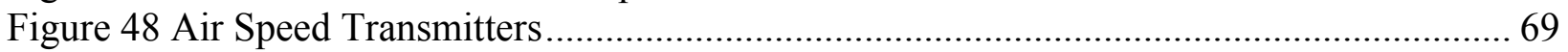

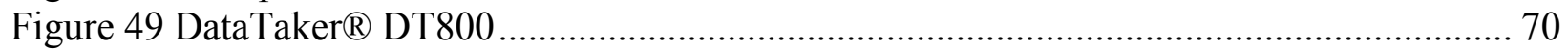

Figure 50 DataTaker ${ }^{\circledR}$ DT800 3-Wire Resistance Inputs Configuration....................................... 70

Figure 51 DataTaker ${ }^{\circledR}$ DT505 (left) and Channel Expansion Module (right) ............................. 71

Figure 52 Data Loggers Installed Inside of Each Unit ……………………………................ 71

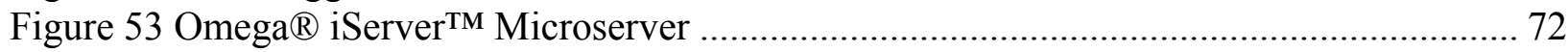

Figure 54 Channel Configuration for DT505 (left) and DT800 (right) Data Loggers ................. 73

Figure 55 Experimental and Control Units Inside of WVU Hangar ........................................... 76

Figure 56 Controlled Baseline Attic Temperatures (500 Unit) ………………………………..... 77

Figure 57 Controlled Baseline Attic Temperatures (800 Unit) .................................................. 78

Figure 58 Controlled Baseline Roof Temperatures (500 Unit) .................................................... 78

Figure 59 Controlled Baseline Roof Temperatures (800 Unit) .................................................... 79

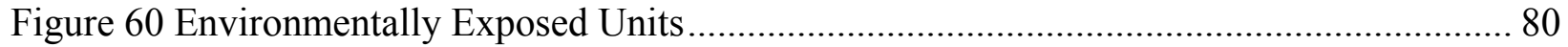

Figure 61 Environmentally Exposed Attic Temperatures (500 Unit) ....................................... 80

Figure 62 Environmentally Exposed Attic Temperatures (800 Unit).......................................... 81

Figure 63 Environmentally Exposed Attic Temperatures (500 Unit)........................................... 81

Figure 64 Environmentally Exposed Attic Temperatures (800 Unit)......................................... 82

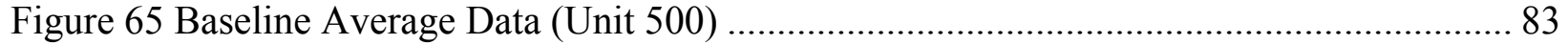

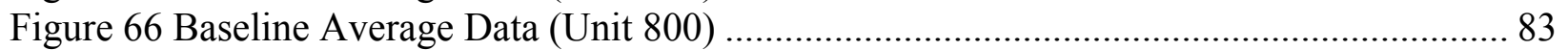

Figure 67 Environmentally Exposed Baseline Temperatures (500 Unit) ………...................... 84

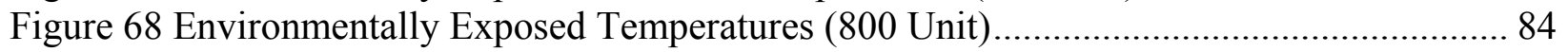

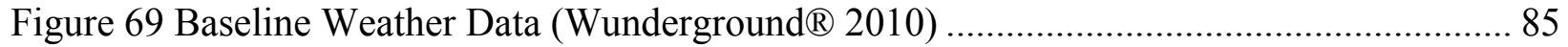

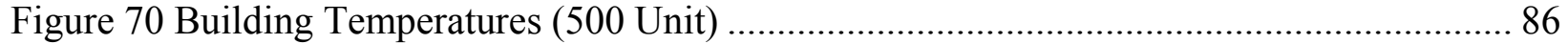

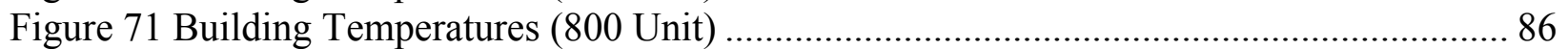

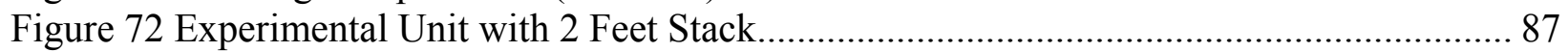

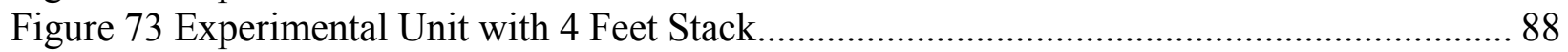

Figure 74 Environmentally Exposed Attic Temperatures (500 Unit)...................................... 88

Figure 75 Environmentally Exposed Roof Temperatures (500 Unit).......................................... 89

Figure 76 Environmentally Exposed Attic Temperatures (800 Unit)......................................... 90

Figure 77 Environmentally Exposed Roof Temperatures (800 Unit).......................................... 90

Figure 78 Environmentally Exposed Underneath External Roof Temperatures (800 Unit) ........ 91

Figure 79 Environmentally Exposed Topside External Roof Temperatures (800 Unit) .............. 91

Figure 80 Comparison of LHS Attic Temperatures.................................................................. 92

Figure 81 Comparison of RHS Attic Temperatures ………...................................................... 93

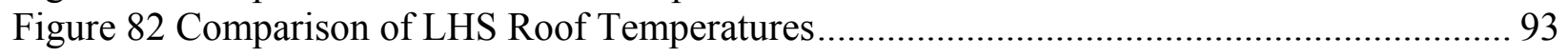

Figure 83 Comparison of RHS Roof Temperatures ……………………………….................... 94

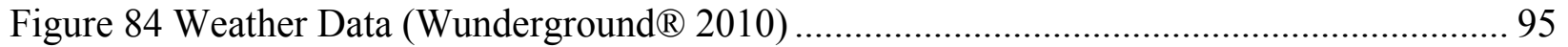

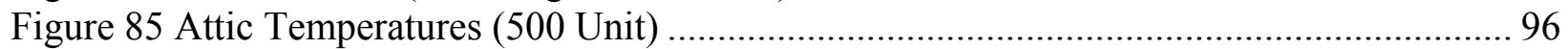




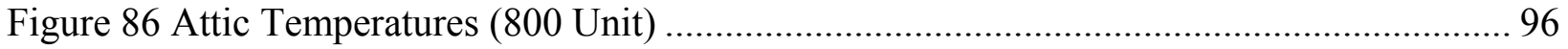

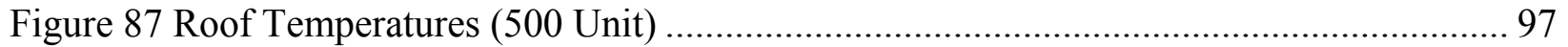

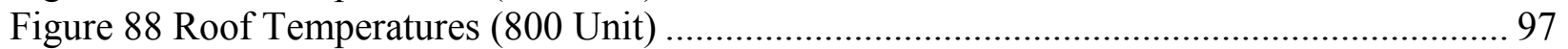

Figure 89 Topside Roof Temperatures (800 Unit) ................................................................ 98

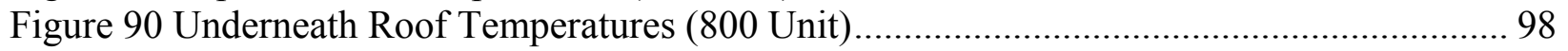

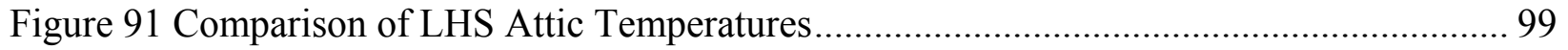

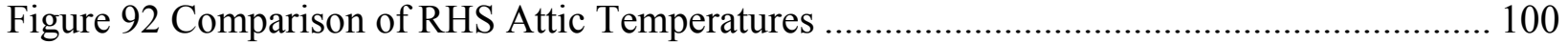

Figure 93 Comparison of LHS Roof Temperatures.......................................................... 100

Figure 94 Comparison of RHS Roof Temperatures ......................................................... 101

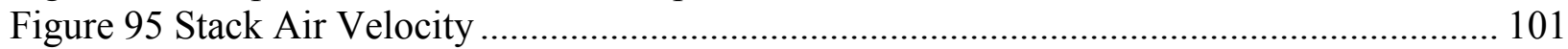

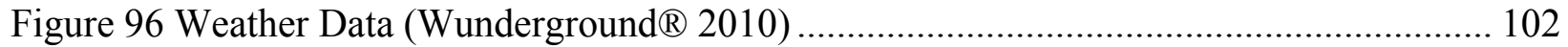

Figure 97 Hydrolynx Model 4015 Solar Photovoltaic Cell ................................................. 111

Figure 98 Oregon Scientific Professional Weather Station ................................................ 112 


\section{LIST OF TABLES}

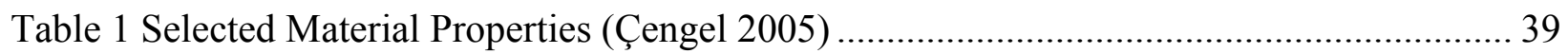

Table 2 Thermal Resistance Elements ............................................................................. 48

Table 3 R-Values of Building and Insulating Materials (Çengel 2005, ASHRAE 1997) ............. 49

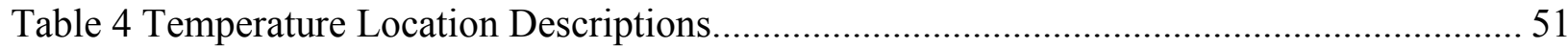

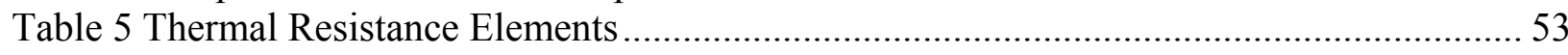

Table 6 Temperature Location Descriptions............................................................................... 54

Table 7 Matrix Configuration of Thermal Management System..................................................5 59

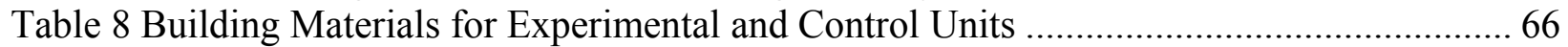

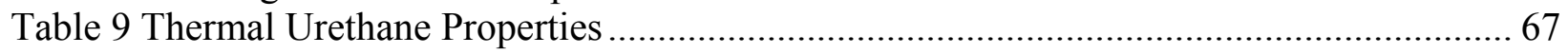

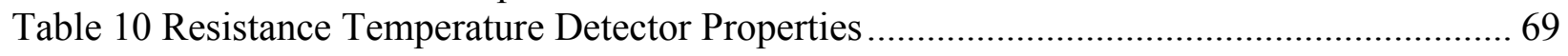

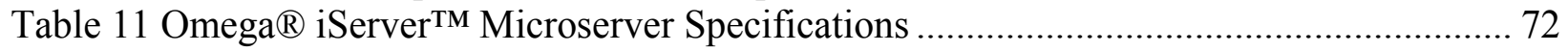

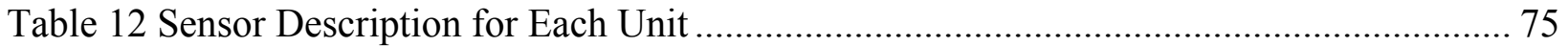

Table 13 Analytic and Experimental Comparison (1.5 inch air gap) ...................................... 103

Table 14 Analytic and Experimental Comparison (4 inch air gap) ............................................. 103

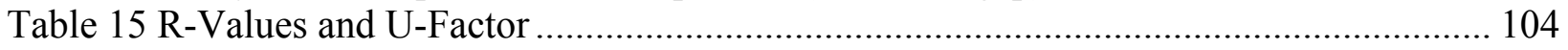

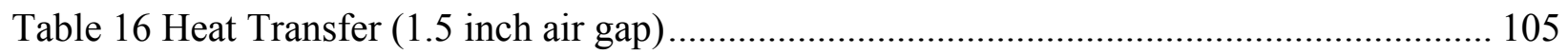

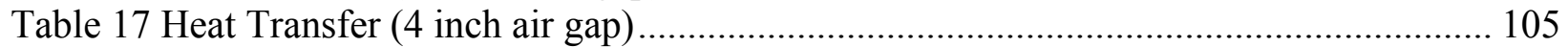

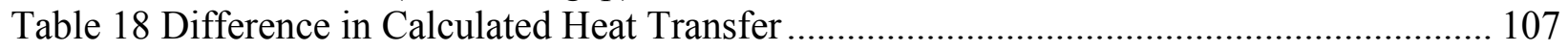

Table 19 Degree Day Method Calculations........................................................................ 108 


\section{NOMENCLATURE}

\begin{tabular}{|c|c|}
\hline$A$ & Area $\left[\mathrm{m}^{2}\right]$ \\
\hline$c$ & Speed of Light $[\mathrm{m} / \mathrm{s}]$ \\
\hline$C$ & Discharge Coefficient [-] \\
\hline$E_{e x t}, E_{s c}$ & Extraterrestrial Solar Illuminance, Solar Illuminance [Klux] \\
\hline$E_{d n}$ & Direct Normal Illuminance [Klux] \\
\hline$f$ & Frequency $[\mathrm{Hz}]$ \\
\hline$F$ & Force $[\mathrm{N}]$ \\
\hline$g$ & Gravity $\left[\mathrm{m} / \mathrm{s}^{2}\right]$ \\
\hline$G r$ & Grashof Number [-] \\
\hline$h_{\text {conv }}$ & Heat Transfer Coefficient $\left[\mathrm{W} /\left(\mathrm{m}^{2} \cdot \mathrm{K}\right)\right]$ \\
\hline$h$ & Planck Constant $[\mathrm{J} \cdot \mathrm{s}]$ \\
\hline$h_{c}, h_{a}$ & Chimney Height, Air Gap Height [m] \\
\hline$I$ & Spectral Radiance $\left[\mathrm{J} /\left(\mathrm{m}^{2} \cdot \mathrm{sr}\right)\right]$ \\
\hline$j^{*}$ & Irradiance $\left[\mathrm{W} / \mathrm{m}^{2}\right]$ \\
\hline$J_{d}$ & Julian Date \\
\hline$k$ & Thermal Conductivity $[\mathrm{W} /(\mathrm{m} \cdot \mathrm{K})]$ \\
\hline$L_{c}$ & Characteristic Length $[\mathrm{m}]$ \\
\hline $\mathrm{Nu}$ & Nusselt Number [-] \\
\hline$P, a$ & Pressure, Atmospheric Pressure [Pa] \\
\hline $\operatorname{Pr}$ & Prandtl Number [-] \\
\hline$R$ & Thermal Resistance [] \\
\hline$R a$ & Rayleigh Number [-] \\
\hline$\dot{Q}$ & Heat Transfer Rate $[\mathrm{W}]$ \\
\hline$T$ & Temperature $[\mathrm{K}]$ \\
\hline$V$ & Volume $\left[\mathrm{m}^{3}\right]$ \\
\hline$\dot{V}$ & Volumetric Flow Rate $\left[\mathrm{m}^{3} / \mathrm{s}\right]$ \\
\hline$\alpha$ & Thermal Diffusivity $\left[\mathrm{m}^{2} / \mathrm{s}\right]$ \\
\hline$\beta$ & Volume Expansion Coefficient $[1 / \mathrm{K}]$ \\
\hline$\varepsilon$ & Emissivity [-] \\
\hline$\rho, \rho_{\infty}$ & Density $\left[\mathrm{kg} / \mathrm{m}^{3}\right]$, Density of Fluid Far Away From Surface $\left[\mathrm{kg} / \mathrm{m}^{3}\right]$ \\
\hline$\sigma$ & Stephan-Boltzmann Constant $[\mathrm{J} / \mathrm{K}]$ \\
\hline$v$ & Kinematic Viscosity $\left[\mathrm{m}^{2} / \mathrm{s}\right]$ \\
\hline CIRA & Center for Industrial Research Applications \\
\hline MAE & Mechanical and Aerospace Engineering Department \\
\hline
\end{tabular}


LHS

Left Hand Side

RHS

Right Hand Side

RTD

Resistance Temperature Detector

WVU

West Virginia University 


\section{INTRODUCTION}

The impact of rising energy prices on household budgets and the overall economy has increasingly become a focal point of public concern. A significant portion of total energy costs can be attributed to heating and cooling. In 2005, approximately 111 million homes contained at least one heating unit with $65 \%$ of them for a single family detached dwelling (Energy 2005). For this type of home, the breakdown of the primary heating source is presented in Figure 1. This figure shows that the major heating sources for this type of home are electricity and natural gas.

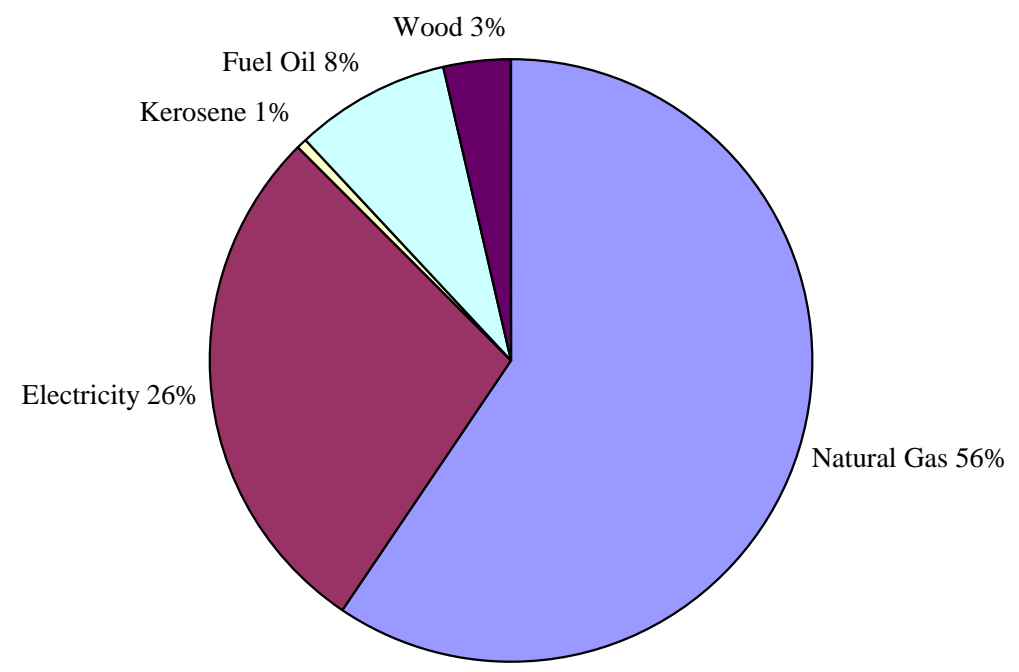

\section{Figure 1 Space Heating Characteristics by Type of Housing Unit (Energy 2005)}

A typical residence has numerous energy consuming appliances and devices. Major contributors include air conditioning, refrigeration, and heating. Figure 2 below shows the typical breakdown of residential consumption by the major types of uses for energy. Approximately $85 \%$ of homes have cooling equipment, $76 \%$ of which use central air, while the remaining 24\% have at least a window/wall unit (Energy 2005). 


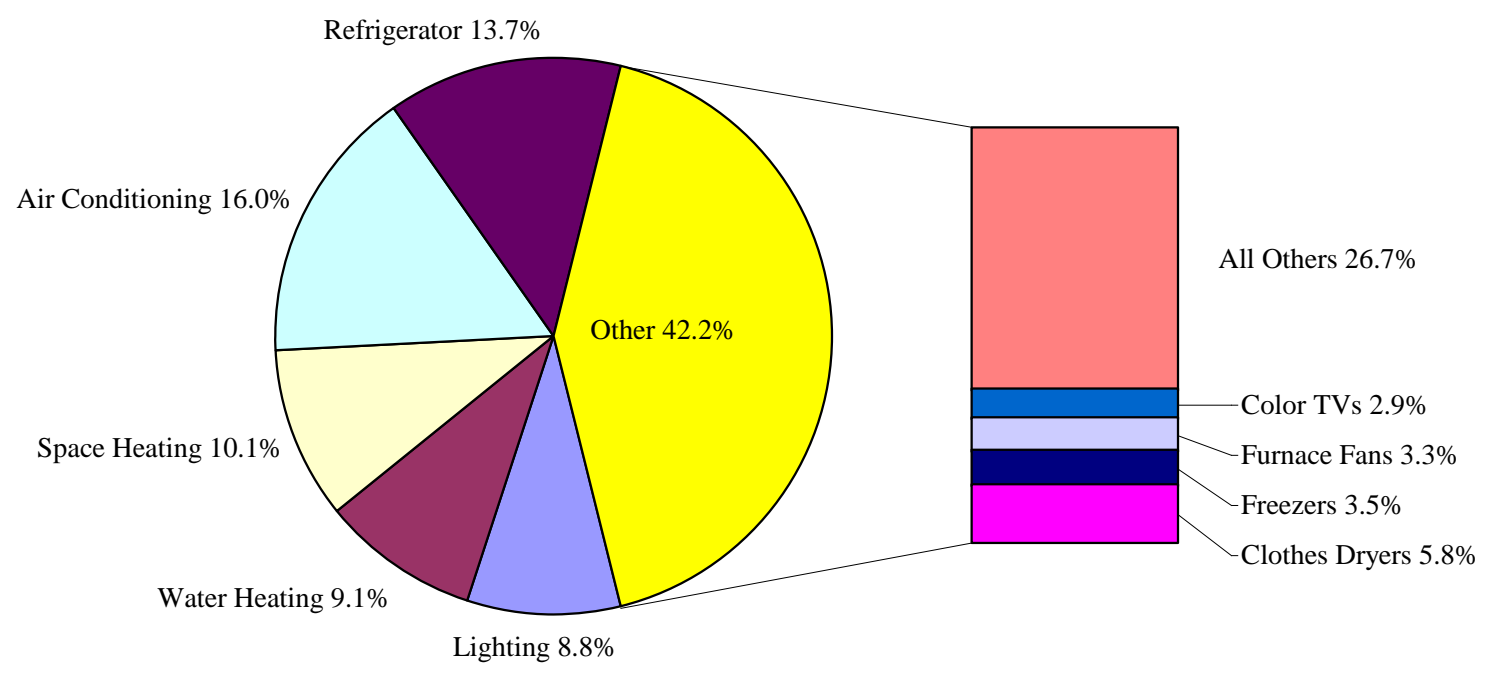

Figure 2 US Residential Electricity Consumption (Energy 2005)

Figure 3 shows the variability of the average retail price of electricity across the United States in 2004. In Kentucky, the average price of electricity was a little less than $\$ 0.06 / \mathrm{kWh}$. On the other hand, the average electricity price triples for the residents of Hawaii. Price differences by state are often related to the cost and availability of the fuels used to generate electricity, as well as the existence of any energy retail competition (Energy 2005). Note that the cost for energy has and will most likely continue to rise.

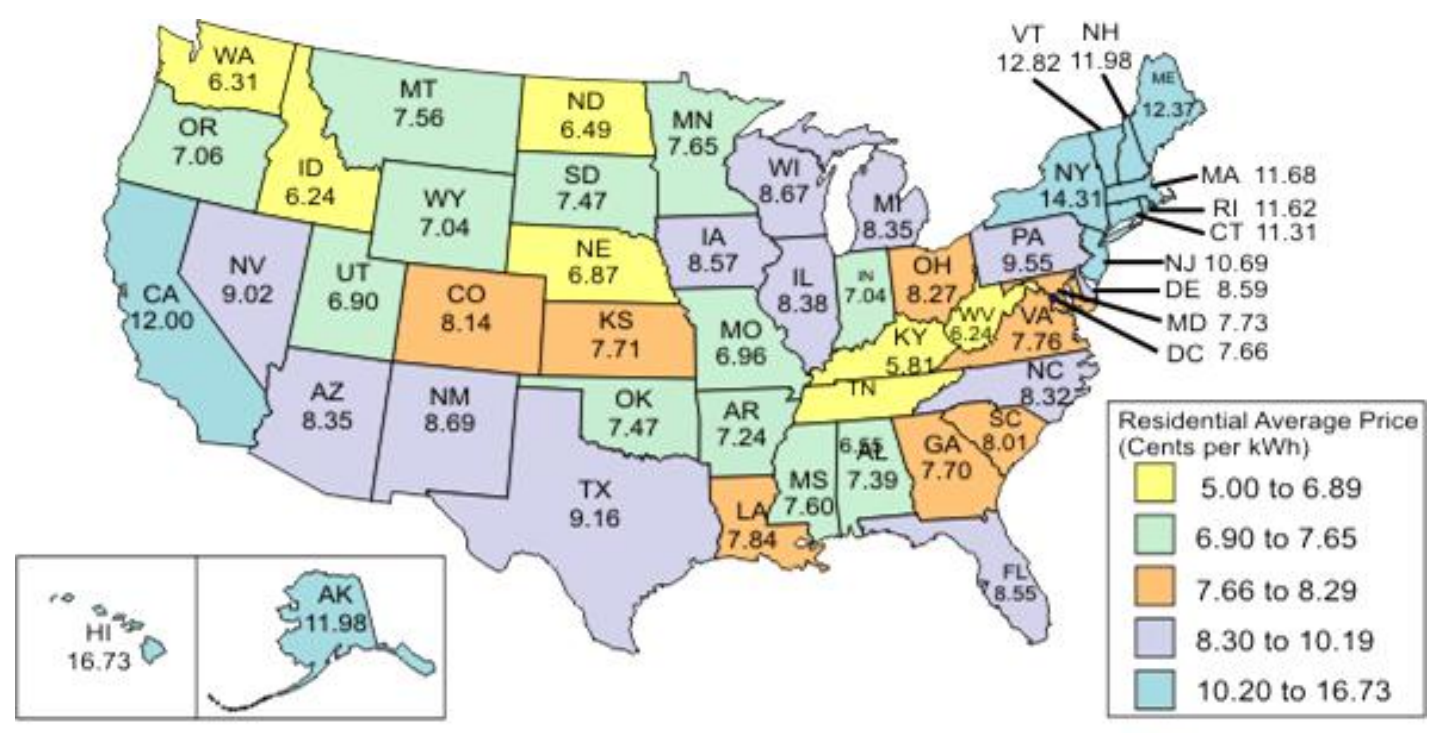

Figure 3 US Electric Industry Residential Average Retail Prices of Electricity by State (Energy 2005) 
With both heating and cooling being the major contributors to energy expenditures in most building structures, energy savings focused on these sources needs to be investigated. Currently, energy savings in a home can be accomplished in a variety of ways. One way is to replace normal window glass throughout the home with low emissivity (low-e) glass. Low-E glass has a special thin coating that will let visible light in, but helps to reduce the heat transfer between surfaces. Another alternative would include the planting of trees and/or shrubs to shade a building structure in summer and to provide a wind break in winter. It is also recommended that thermostats be adjusted to decrease energy used. In addition, shading room air conditioners from direct sun will reduce their workload. Such energy savings measures will translate into reduced heating and cooling electrical costs.

During a typical summer day, solar radiation heats up a building for the majority of the day through the windows, walls, doors, and especially the roof. According to studies performed by the Florida Solar Energy Center, attic temperature can easily reach over $140^{\circ} \mathrm{F}$ (Parker 2005). Attic heat will then work its way through the attic insulation and through the $\mathrm{A} / \mathrm{C}$ ductwork, if located in the attic, into the cooling system, and subsequently, the rest of the building. The A/C system has to offset this added heat load to maintain cool temperatures in the structure. For most residential and a majority of commercial structures the roof represents a major contributor to the infiltration of heat into a building. Most of these structures utilize either, or both, passive and active ventilation systems.

Residential home attic ventilation is important for two reasons. During the summer, excess heat that builds up in the attic during the day results in increased energy expenditures for cooling. Also, moisture produced within the home may move into the attic if ceiling vapor barriers are not properly installed. Moisture not exhausted from the attic can condense, and cause insulation and construction materials to deteriorate. Thus, temperature and moisture control are the major reasons for providing attic ventilation.

In a building with poor ceiling insulation (R-14 or less), compensating for heat flow through ceilings may account for $30 \%$ of the total cooling and heating cost, while for a home that is wellinsulated (R-19 or above) this number can drop to $15 \%$. Thus, attic ventilation rates are most important for poorly insulated ceilings during the hot seasons.

The US Department of Energy recommends ranges of R-values based on local heating and cooling costs and climate conditions in different areas of the nation, as shown in Figure 4. This 
map is divided into six sections with further subdivisions based upon the type of heating. State and local codes in some parts of the country may require lower R-values than the Department of Energy (DOE) recommendations, which are often based on cost-effectiveness; savings in energy versus the cost of materials and installation.
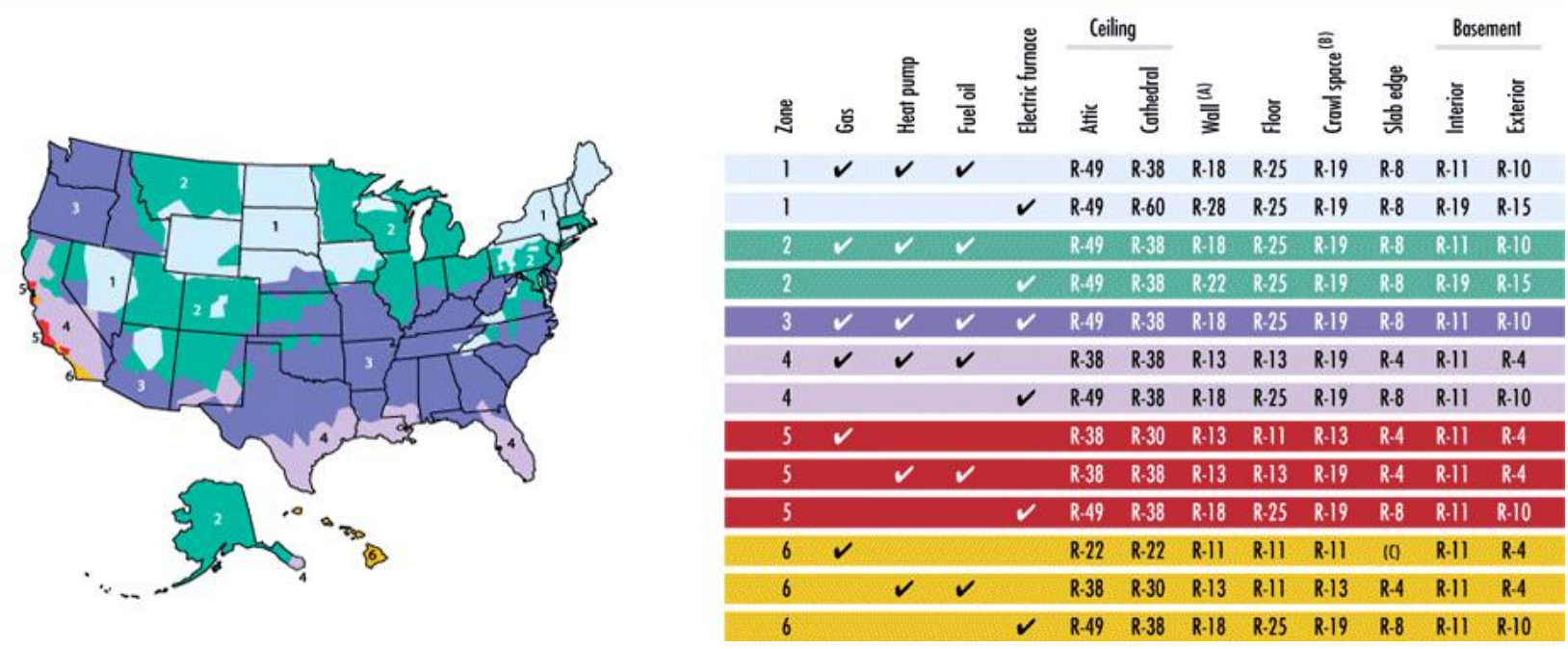

\section{Figure 4 US Department of Energy Recommendations for Insulation Levels (Energy 2005)}

Attic temperatures depend primarily on the amount of solar radiation, construction details, and the rate of ventilation. Winter attic ventilation must be sufficient to remove moisture vapor moving from the living space to the attic but kept to a minimum to reduce energy loss because of conduction. In general, passive ventilation adequate for summer cooling is more than adequate for winter ventilation. Thus any additional active ventilation is normally thermostatically controlled to not only minimize the energy use of the fan but to also control the temperature differential between the attic and the living space.

Whenever there is a temperature difference, heat flows naturally from a warmer space to a cooler space. To maintain comfort in summer, the heat gained through the roof must be removed by a cooling system and similarly in winter, the heat lost must be replaced by a heating system. Stewart showed that attics can reach temperatures up to $160^{\circ} \mathrm{F}$ during a summer day with the outside temperature being $97{ }^{\circ} \mathrm{F}$. The cooling load for an air conditioner depends on the difference in temperature between the inside, the attic, and outside air temperatures. A reduction from 160 to $110^{\circ} \mathrm{F}$ will result in a significantly lower cooling load and hence increased energy savings (Stewart 2008). 
Attic ventilation can be accomplished by gravity ventilators, wind assisted ventilators or power ventilators. The purpose of all of these is to provide uniform ventilation of the attic for proper temperature and moisture control.

Ventilation caused by wind pressure differences requires less vent area to achieve the same ventilation rate as ventilation by gravity. One problem with wind ventilation is that the areas of high and low pressures within the attic change with wind direction, causing difficulty in locating inlets and outlets so that ventilation will take place regardless of wind direction. The best system is one in which the outlet is near the ridge and the inlets are in the soffit area. Outlet vents can be provided by roof louvers, gable end louvers, turbine ventilators or continuous ridge vents.

Powered ventilation can be accomplished in two ways. In homes without air conditioners, the temperature can be controlled to some extent by the use of attic fans. Air conditioned homes can use powered attic ventilators by installing an exhaust fan through the roof or in the gable. The advantage of a powered ventilator is that they can provide good ventilation even when there is no wind, but they do require energy to operate and for well-insulated ceilings, the cost of a powered ventilator is often not justified.

However, there are some attics which cannot be ventilated by gravity or wind-assisted methods, and in these, the power vent is necessary for moisture and temperature control. Despite the inherent problems with natural ventilation, the cost benefits justify the further development of this type of temperature control.

Natural ventilation is the most common method of achieving reduced attic temperatures and moisture control. While this may initially be the most cost effective solution when considering the overall lifecycle energy cost of a structure it will, in many cases, not be the most energy efficient. Because of its simplicity, any enhancements in the control and quantity of this process could up the balance away from active systems in many, if not the majority of the situations.

The natural ventilation method takes advantage of two principles. First, as air is heated it becomes less dense and rises. Second, wind movement over and around a home creates areas of high and low pressure. If a space has high air outlets in conjunction with low inlets, ventilation occurs as the air within the space is heated, rises and escapes though the high outlets to be replaced by cooler air entering at the lower inlets. The greater the temperature difference between the outlet and inlet, the greater the ventilation rate. This is a natural result of buoyancy effects. Additionally, the structure serves as a differential pressure driven by creating a slightly 
higher pressure around the windward side of the structure. As the air passes over the ridge or top of the structure, which creates a slightly lower than ambient pressure, the Bernoulli effect, and thus encouraging mass flow through the structure.

Enhancing and exploiting this buoyancy effect and taking advantage of the wind/structure interaction for convective ventilation is the goal of the current research. Traditional natural ventilation occurs in the interior of the attic. On the other hand, this research aims to enhance natural buoyancy driven convection in an exterior space immediately along the top most surface of a building to reduce attic temperatures. This could be accomplished with a variety of structures and control schemes retrofitted on top of an existing roof, or the design of a new roof structure with an air gap between the additional structure and the existing roof. This add-on structure will be termed "heat roof" in this research. 


\section{ReSearch ObJective ANd Problem Statement}

The objective of the research was to evaluate through analytic and experimental techniques a novel type of thermal management system by determining the impact of thermal material properties and natural convective air gaps driven by buoyancy effects. The properties considered included the convection heat transfer coefficient, thermal conductivity, radiation emissivity, thermal resistance, and thermal capacitance of the system components.

To meet this objective, the governing classical thermal and flow equations were used to create a predictive tool for the development of a scaled physical test model. This structural test model and its similar control unit were set up to evaluate the direct effects that convective cooling has on sunlit days. For these experiments, temperature and air speed measurements were observed in the experimental units and against the analytic predictions. The results of this evaluation show the effectiveness of the heat roof design for attic and home temperature reductions, as well as provide an experimentally based model for future roof design considerations.

To validate this design, experimental tests were performed and compared to the results of the predictive analysis. In addition, the experimental results were used to validate the predictions and to investigate alternative design settings, parametrically.

This research assesses the thermal attributes of an add-on roof system for a single or multifamily dwelling or small business, with the goal of providing recommendations that can be employed in the design of new homes and businesses or can be applied to improve the efficiency of current home and business roof designs. 


\section{Reducing Thermal Loading Due to AtTic Heat Flux}

In order to set up valid experimental conditions, attic thermal management will be briefly reviewed. Five common strategies exist for blocking heat gain due to solar radiation in a residential home which includes the following:

- insulating heavily,

- installing a radiant barrier,

- installing an evaporative roof cooling system,

- $\quad$ shading surfaces, and/or

- convective cooling.

\subsection{Insulation}

When insulation is installed properly, it reduces the heat transfer through the envelope of a building. To maintain comfort in the summer, any heat gained must be removed by an airconditioning unit. On the other hand, any heat lost in the winter must be replaced by a heating system. For either case, an external source of energy needs to be employed. Typical insulation practice in a pitched roof is shown below in Figure 5.

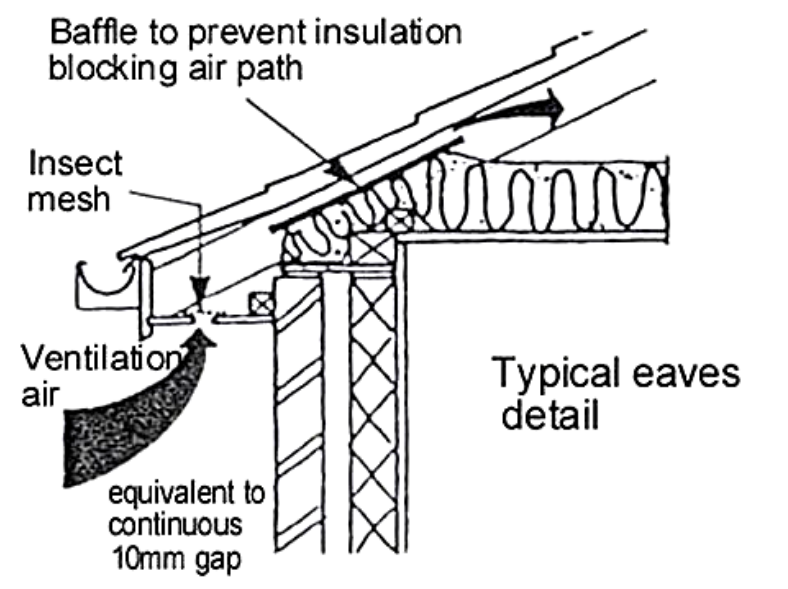

Figure 5 Typical Insulation in a Pitched Roof (eHow 2008)

Although insulation can be made from a variety of materials, it usually comes in batts, rolls, loose-fill or rigid foam boards. Each type is made to fit in a different part of a home. Batts, usually constructed of fiber glass or rock wool, are made to fit between the studs in the walls or between the joists of the ceilings or floors, as shown in Figure 6. Fiber glass is manufactured from sand and recycled glass, and rock wool is made from basaltic rock and recycled material 
from steel mill wastes. Rolls or blankets are also usually made of fiber glass and can be laid over the floor in the attic. Loose-fill insulation, usually made of fiber glass, rock wool or cellulose, can be blown into the attic or walls. Cellulose is made from recycled materials and is normally treated with fire-retardant chemicals.

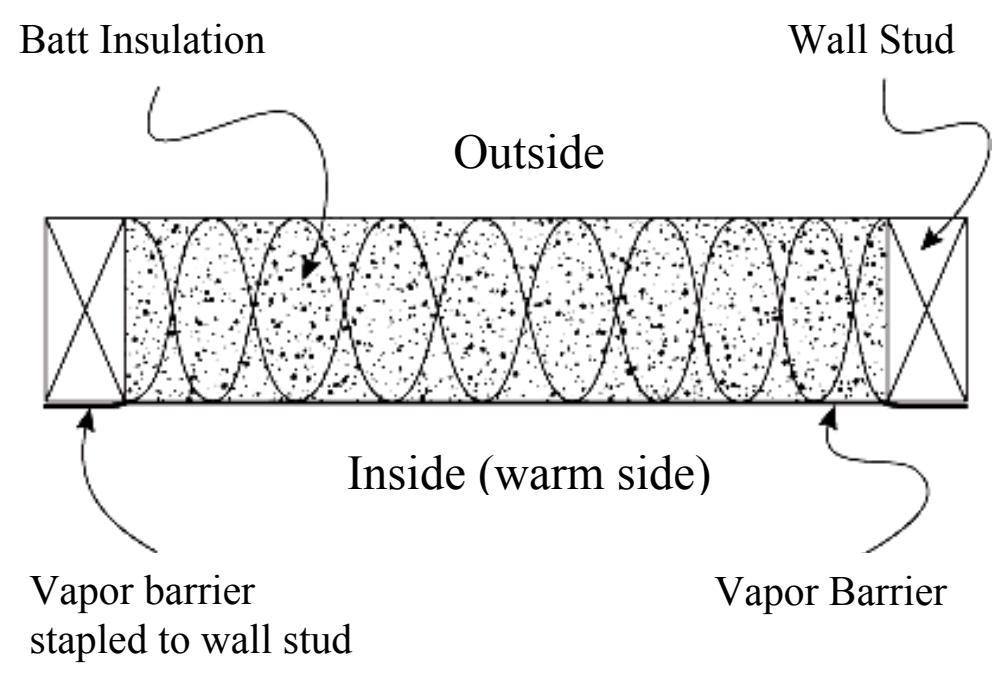

Figure 6 Proper Batt Installation with Vapor Barrier (Kansas State University 2000)

There are several types of insulation that will reduce the cooling loads in a home, as mentioned previously. Another type includes a spray-on open-cell foam insulation. This type of insulation is good for adding insulation to existing finished areas, irregularly shaped areas, and around obstructions. It does not have to be ventilated and can be used under flat roof decks. However, the roof deck would need to be removed for installation, if the structure of the home already existed.

Reflective insulation is defined as a thermal insulation consisting of one or more low emittance (or high reflectance) surfaces, bounding one or more enclosed spaces (RIMA 2002). This type of insulation uses layers of aluminum, paper, and/or plastic to trap air. The performance of the system is determined by the emittance of the materials and the size of the enclosed air spaces.

All insulation products, including reflective insulation, are measured by R-values; the higher the R-value, the greater the insulating or thermal performance of the material which will impede the heat flow. 


\subsection{Radiant Barrier}

A radiant barrier system is a reflective material(s) (emittance is 0.10 or less) that intercepts the flow of radiant energy to and from the building components. For example, in older homes, aluminum foil shields are installed behind radiators to block radiant heat from the radiator to the exterior wall.

Attics are the most common location for a radiant barrier system. In an attic, the benefits of a radiant barrier system is significantly affected by the amount of attic ventilation. A vented attic with a radiant barrier is a very different system from an unvented attic with the same radiant barrier (RIMA 2002). Radiant barriers are not insulation, and hence do not have an R-value. However, there are some radiant barrier products that have entrapped air spaces (bubble pack or multilayer films) where an R-value may be available for the product. In these situations, the product is operating as insulation as well. Radiant barriers are mainly sold in areas with warmer climates because radiant barriers may reduce heat gains from the sun in colder climates.

Wilkes modeled residential attics with horizontal radiant barriers laid on top of insulation and radiant barriers attached to the bottom of the top chords of the attic trusses. The models included features such as a radiation interchange analysis within the attic space, convective coupling with the ventilation air, and absorption/desorption of moisture at surfaces facing the attic enclosure.

An analytic model was previously developed and compared to the experimental data collected at Oak Ridge National Laboratory. All surfaces within the model were assumed to be isothermal. Conduction through each of the surfaces was handled using thermal response factors which relate the surface heat fluxes to the present and previous temperatures at the two surfaces of the component. Convection heat transfer coefficients were taken from the literature based upon isothermal flat plates. For radiation, the surfaces were assumed to be plane, gray, and isothermal. The radiation interchanges were calculated using view factors accounting for all inter-reflections, and allowing each of the surfaces to have a different emittance. Approximations were built into the models to account for the latent heat effects from absorption and desorption of moisture at the wood surfaces that face the attic space.

The truss radiant barrier configuration installed on the interior of the attic space required additional heat balances for the analytic model. An extra ventilation air space was created between the radiant barrier surface and the roof. 
For the analytic model, each of the nonlinear heat balance equations were factored into a linear form. The predicted attic temperatures were within a few degrees of the experimental values obtained for the basic model only. Experimental verification was not performed with the radiant barrier. (Wilkes 1988)

\subsection{Evaporative Cooling}

Another method to decrease the outside roof temperature is a technique called evaporative cooling. Simply stated, a light spray of water is dispersed onto a roof, which lowers the temperature through the latent heat of evaporation from the roof and the resultant flow of heat. However, if not enough water is applied, roof temperatures can rise above the desired limit, and if too much water is applied, the positive effects of evaporation can be reversed. In addition, these systems rely on a constant supply of water which is an added cost. In some areas, excess water is not an available resource. A history of evaporative cooling techniques is presented below.

This type of technology has been around for about a century. In 1910, William CrawfordFrost received a patent for a system that sprayed water on a roof, cooling the roof, and hence cooling the interior of the building. He also utilized the run-off water to sprinkle water on the lawn and water flowers in the garden to avoid unnecessary waste (Crawford 1910).

Thirty years later, Holder was issued United States Patent No. 2,266,321 which addresses the prevention of excessive heat accumulation in exposed surfaces, such as roofs. He recognized that evaporative cooling efficiently removes thermal energy while the excessive application of fluid on the surface decreases that effect. He also noted that to obtain any appreciable cooling from this effect would require large quantities of water and hence would be deemed impracticable except in those instances where large quantities of water are readily available. His invention incorporated a controlled evaporative cooling system to maintain roof surface temperatures within a predetermined narrow range substantially equivalent to normal summer room temperature conditions on a flat roofing system. The system would automatically shut off when a

predetermined temperature drop occurred, to prevent puddling or streams from forming (Holder 1941).

In 1950, Murray was issued United States Patent No. 2,506,936 which suggested cooling flat roofs by periodically applying water to the exposed roof surface and utilizing evaporation which would occur naturally. An attempt was made to overcome supplying excess water by utilizing 
spray heads that only dispersed a very small amount of water. Small orifices become clogged either by mineral deposits or foreign particles in the water and hence would require frequent maintenance. Instead, large orifices were utilized and controlled as to not damage the roof with the effects of flooding. He concluded that the evaporation is highly accelerated if a small amount of water is placed on the roof (Murray 1950).

Three years later, United States Patent No. 2,660,863 was issued to Gerhart which described a porous hose to effectively drip irrigate a roof for a one-story ranch type house because of the favorably large ratio of roof area to cubage. The gutters collected and delivered the portion of the water that did not evaporate to a sump from which a circulating pump drew cooling water, passed it through a condenser, and again, delivered it to the roof through the diffusing hose (Gerhart 1953).

In 1988, Viner was issued United States Patent No. 4,761,965 which described a very specific arrangement of an evaporative roof cooling system. The system included a water distribution piping system and nozzles to supply a uniform spray of water on the roof surface. A thermistor monitored and measured the actual roof temperature that interacted with a control system for the roof cooling system. The system was designed for roof surfaces, both flat and pitched, exposed to relatively high levels of solar radiation (Viner 1988).

\subsection{External Shading Devices}

Another strategy to reduce thermal loading in an attic is to use external shading devices, whether by way of natural or artificial means. External shading devices play an important role in controlling the amount of direct solar radiation entering the interior of a building when specialty windows or window films cannot be installed. This strategy can also be a good strategy to prevent occupants from having to lower shades or close blinds perpetually. However, there are numerous factors to consider with such a system, and simply affixing a shade over a window does not guarantee a reduced heat gain. The type of shading device, climate, and where on the building the device is used all contribute to the effectiveness of this approach.

A natural way to create external shading would be to simply plant a shrub or tree in a specific location with respect to the home. Shrubs can effectively block early morning and late afternoon sunlight on eastern and western exposures, respectively. Small-leafed, open-branched shrubs provide shade without unduly restricting air movement for passive cooling in the spring and fall. Also, trees are some of the most valuable landscaping tools for passively increasing the interior 
comfort of a home. Once established, most trees require little maintenance and represent an appreciating investment in the home's value. Trees are effective providers of shade, as well as modifiers of air movement. How a particular tree species performs these functions depends on how tall it grows, whether or not the leaves stay on the tree all year, and the shape and density of the canopy. Trees that grow thirty or more feet tall are capable of casting shadows over the roof of a typical single family house (Robinson and Eddington 2001).

Unfortunately, new plantings of most large growing trees require twenty or more years to reach full size. Also, large trees overhanging the roof of a house do present the risk of damage from falling limbs, as well as the nuisance of clogging rain gutters with leaves and twigs, and foundation problems due to tree root systems.

The planting sites of new trees must be carefully considered to optimize future shade benefits while minimizing these potential problems. If a solar water heating or electric system is on the roof, careful attention must be paid to positioning shade trees so that the efficiency of the system is not reduced.

Carmody and Haglund conducted a study that focused on external shading devices and their impact on energy use and glare control in a commercial building. The study took into account five types of shading conditions: none, vertical fins, shallow overhangs, deep overhangs, and a combination of overhangs and fins which was coupled with six types of performance glazings, six geographic climates, and windows facing east, south, and west (Carmody and Haglund 2006).

As expected, the results varied widely by system and climate, however, the presence of shading devices on south facing windows showed the most promise in reducing energy usage. While many estimated savings were in the single digits, energy reductions were estimated as high as $38.5 \%$ with a south facing shading system in Phoenix, Arizona.

However, adding external shading to the building envelope means there is another element added to the maintenance list. Plus, in a climate where it snows, there may be dripping or icing issues on the shades.

\subsection{Convective Cooling}

To exhaust hot air from an attic, powered attic ventilators (PAV) are installed typically either on the rooftop or sidewall. PAVs can lower overall attic temperature; however, secondary effects, such as extracting cool air from a house or the possible introduction of combustion gases 
into your living spaces can sometimes offset any benefit. When a PAV is turned on to exhaust hot attic air, it can move large quantities of air. Smaller fans can easily move 1,000 cfm while more powerful or multiple fans can extract many thousands of cfms of air.

This movement of air creates natural low pressure inside the attic space. To equalize this pressure difference, air begins to rush into the attic space from multiple points. If there are many passive roof vents, large side gable vents, and/or unobstructed soffit vents, then there is a good chance that most of the make-up air will originate from outside the home. If there are only a few passive attic ventilation inlets, then a significant portion of the replacement air can come from inside the home thereby affecting the overall value of the fan.

If an air conditioner is running at the same time as a PAV, then expensive cooled air might move from the living space into the attic. This air seeps into the attic through the attic access panel and hidden holes in the interior wall top plates where plumbing vent pipes and electrical wires enter the attic. Air also can easily slip between the space between bowed wall plates and drywall. To complete the circle, hot and humid exterior air enters the living space. The air conditioner now has to work harder and longer to keep the space cool while the PAV is dumping some of the conditioned air to the exterior of the house.

The other problem with using a PAV is the danger of drawing combustion gases from hot water heaters and any other combustion appliance into the attic or living spaces. To feed the fluid/air appetite of the PAVs, air will enter the home at the point of least resistance, often a chimney or hot water heater metal B-vent pipe. The latest and most compelling findings by Natural Florida Retrofit and the AEC Applied Building Science Center found that in all homes they studied, powered attic ventilators offered no benefits, and sometimes caused serious health and safety problems (Dominion 2008).

All of these strategies can reduce thermal loading due to attic solar heat flux, but the cost benefits are often unclear. Each type of system has its advantages and disadvantages as mentioned previously. A passive rather than an active convective cooling system, such as the research described herein, has the potential to decrease energy costs during both the winter and summer months. This is demonstrated in the results of the analytic model and verified with experimental units for modifying existing homes or businesses. 


\section{THERMAL THEORY}

The key to maintaining a comfortable temperature in a home is to reduce the heat transfer out during the winter and reduce the heat transfer in during the summer. Heat transfer occurs when a temperature gradient exists. Heat is transmitted across confined air spaces by radiation, conduction and convection. Each of these types of heat transfer methods will be discussed in the next three sections.

\subsection{Radiation}

Radiation is the transfer of heat (generally infrared radiant energy) from a hot surface to a cold surface through air or vacuum by electromagnetic waves. When these waves strike another surface, they are partially absorbed which increases the temperature of that surface.

Emittance and reflectance are two terms used when discussing radiant heat transfer. Emittance refers to the ability of a material's surface to emit radiant energy. As a quantity, emittance ranges from zero to one. The lower a material's emittance, the lower the energy radiated from its surface. On the other hand, reflectance refers to the fraction of incoming radiant energy that is reflected from the surface rather than being absorbed which also has a value range from zero to one.

The characteristics of the thermal radiation emitted from the surface of an object are a function of the object's temperature. Infrared radiation from a common household radiator or electric heater is generally at infrared wavelengths, where as light emitted by a glowing incandescent light bulb is at visible wavelengths. Thermal radiation is generated when the movement of charged particles within atoms emit electromagnetic radiation. The emitted wave frequency distribution of thermal radiation is dependent on temperature and material characteristics (emittance, reflectance, etc.). The Wien approximation, shown in Equation (1), was originally proposed as a description of the spectrum of thermal radiation emitted by a blackbody, although it failed to accurately describe long wavelength (low frequency) emission (Love 1968, Wielbelt 1966).

$$
I(f, T)=\frac{2 h f^{3}}{c^{2}} e^{-\frac{h f}{\sigma T}},
$$

where $I$ is the spectral radiance $\left[\mathrm{J} /\left(\mathrm{s} \cdot \mathrm{m}^{2} \cdot \mathrm{sr} \cdot \mathrm{m}\right)\right], f$ is the frequency $[\mathrm{Hz}], T$ is the temperature of the blackbody $[\mathrm{K}], h$ is the Planck constant $[\mathrm{J} \cdot \mathrm{s}], c$ is the speed of light $[\mathrm{m} / \mathrm{s}], \sigma$ is the Stephan- 
Boltzmann constant $[\mathrm{J} / \mathrm{K}]$. Wien's Law infers that objects of different temperatures emit spectra that peak at different wavelengths, as shown in Figure 7. Hotter objects emit most of their radiation at shorter wavelengths and cooler objects emit most of their radiation at longer wavelengths. Furthermore, at any wavelength, a hotter object radiates more than a cooler one.

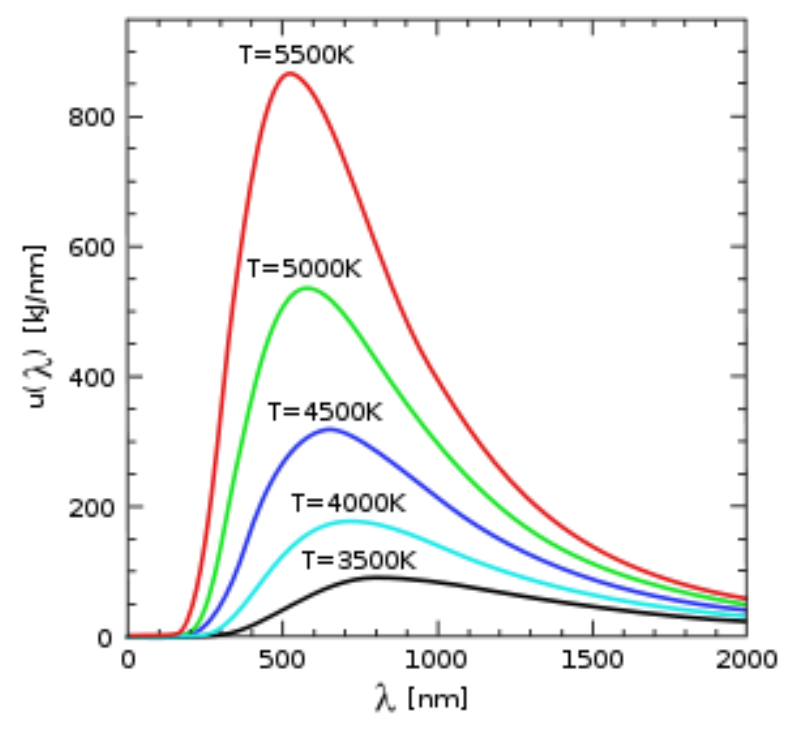

Figure 7 Wien's Law

Later, Max Planck developed Planck's law, which superseded Wein's law. Unlike the Wien approximation, Planck's law accurately describes the complete spectrum of thermal radiation for a genuine blackbody, shown in Equation (2):

$$
I(f, T)=\frac{2 h f^{3}}{c^{2}} \frac{1}{e^{\frac{h f}{\sigma T}}-1}
$$

Additionally, a general case of a grey body can be described by the Stephan-Boltzmann law, shown in Equation (3), where $j^{*}$ is the irradiance of a blackbody $\left[\mathrm{W} / \mathrm{m}^{2}\right]$. This equation includes emissivity $\varepsilon$ that indicates how much is radiating. For a blackbody, the value of emissivity is one, or $100 \%$. The Stephan-Boltzmann constant $\sigma$ is derived from other constants of nature, as shown in Equation (4). It equals a constant value of $5.67 \times 10^{-8} \mathrm{~J} /\left(\mathrm{s} \cdot \mathrm{m}^{2} \cdot \mathrm{K}^{4}\right)$. In order to determine the total absolute power of energy radiated from an object, the surface area $A\left[\mathrm{~m}^{2}\right]$ is taken into account, as shown in Equation (5).

$$
j^{*}=\varepsilon \sigma T^{4}
$$




$$
\begin{gathered}
\sigma=\frac{2 \pi^{5} k^{4}}{15 c^{2} h^{3}} \\
P=A j^{*}=A \varepsilon \sigma T^{4}
\end{gathered}
$$

For the problem at hand, radiation from the sun strikes the outer surfaces of a building (i.e. roof and walls) and is absorbed. This causes the building's surface to heat up. Then, via conduction, heat flows from the outer wall to the inner wall. Heat is then reradiated and convected through the air spaces in the home. Altogether, this describes a heating cycle from the outside to the inside of a home.

Solar radiation is often blocked from entering buildings by walls, windows, blinds, awnings or curtains. The average solar heat flux at the earth's surface varies inversely with the square of the distance between the sun and the Earth, and as the cosine of the angle between the radiation and the surface. The Earth's orbit and obliquity change with time (over thousands of years), sometimes forming a nearly perfect circle, and at other times stretching out to an orbital eccentricity of $5 \%$ (currently $1.67 \%$ ). The total insolation, measure of solar radiation energy received on a given surface area in a given time, remains almost constant, but the seasonal and latitudinal distribution, and intensity of solar radiation received at the Earth's surface also varies (Berger 1991). For example, at latitudes of 65 degrees, the change in solar energy in summer and winter can vary by more than $25 \%$ as a result of the Earth's orbital variation. Because changes in winter and summer tend to offset the change in the annual average insolation at any given location to nearly zero, the redistribution of energy between summer and winter does strongly affects the intensity of seasonal cycles.

The spectrum of the sun's solar radiation, with a temperature of 5,800 K, is close to that of a blackbody. This is divided into several parts: the visible short-wave part of the electromagnetic spectrum, the other in the near-infrared part and the remainder that lies in the ultraviolet part of the spectrum (Folland 2001). The spectrum of electromagnetic radiation striking the Earth's atmosphere is 100 to $10^{6} \mathrm{~nm}$. This can be divided into five regions in increasing order of wavelengths (Naylor 1995):

- Ultraviolet C (UVC) range spans 100 to $280 \mathrm{~nm}$. The term ultraviolet refers to the fact that the radiation is at higher frequency than violet light. Owing to absorption by the atmosphere, very little reaches the Earth's surface, through the Lithosphere. 
- The ultraviolet B (UVB) range spans 280 to $315 \mathrm{~nm}$. It is also greatly absorbed by the atmosphere, and along with UVC is responsible for the photochemical reactions leading to the production of the ozone layer.

- Ultraviolet A (UVA) range spans 315 to $400 \mathrm{~nm}$. It has been traditionally held to be less damaging to DNA, and hence is used in tanning and PUVA therapy for psoriasis.

- The visible range or light spanning 400 to $700 \mathrm{~nm}$ is visible to the naked eye.

- The infrared range that spans $700 \mathrm{~nm}$ to $10^{6} \mathrm{~nm}$, is largely responsible for the warmth or heat that sunlight carries. It is divided into three types on the basis of wavelength:

- Infrared-A: $700 \mathrm{~nm}$ to $1,400 \mathrm{~nm}$

- Infrared-B: $1,400 \mathrm{~nm}$ to $3,000 \mathrm{~nm}$

- Infrared-C: $3,000 \mathrm{~nm}$ to $1 \mathrm{~mm}$.

The solar constant is the amount of incoming solar electromagnetic radiation per unit area, measured on the outer surface of Earth's atmosphere in a plane perpendicular to the rays. The solar constant includes all types of solar radiation, not just visible light. It is measured by satellite and fluctuates by about $6.9 \%$ during a year (from $1,412 \mathrm{~W} / \mathrm{m}^{2}$ in early January to $1,321 \mathrm{~W} / \mathrm{m}^{2}$ in early July). The variations caused by the earth's elliptical orbit around the Sun, and by a few parts per thousand from day to day. Thus, for the whole Earth, the solar energy is $1.7 \times 10^{17} \mathrm{~W}$ $\pm 3.5 \%$. The solar constant also fluctuates and does not remain stable for long periods of time. The approximate average is $1,366 \mathrm{~W} / \mathrm{m}^{2}$, or $1.96 \mathrm{Ly} / \mathrm{min}$ (Heckert 2008).

The Earth receives a total amount of radiation determined by its cross section $\left(\pi \cdot R_{E}^{2}\right)$, but this energy is distributed across the half sphere surface area $\left(2 \pi \cdot R_{E}^{2}\right)$. Hence the average incoming solar radiation (sometimes called the solar irradiance), taking into account the angle at which the rays strike and that at any one moment half the planet does not receive any solar radiation, this then becomes one-half the solar constant (approximately $684 \mathrm{~W} / \mathrm{m}^{2}$ ). At any given moment, the amount of solar radiation received at a location on the Earth's surface depends on the state of the atmosphere and the location's latitude (Stickler 1999). Figure 8 shows radiation at sea level (red) and the small amount of ultraviolet (UV) radiation reaching the earth relative to the visible spectrum (Rohde 2008). 


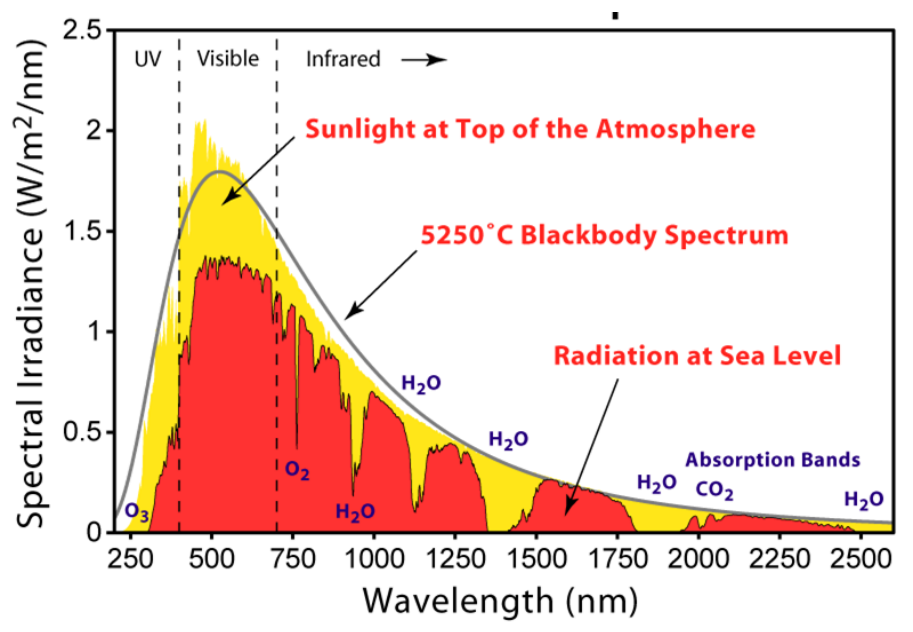

Figure 8 Solar Radiation Spectrum (Rohde 2008)

To calculate the amount of sunlight reaching the ground, both the elliptic orbit of the earth and the earth's atmosphere has to be taken into account. The extraterrestrial solar illuminance $E_{\text {ext }}$ corrected for the elliptic orbit by using the day number of the year, is known as the Julian date $J_{d}$ and is expressed by:

$$
E_{e x t}=E_{s c}\left(1+0.034 * \cos \left(\frac{2 \pi\left(J_{d}-2\right)}{365}\right)\right)
$$

The solar illuminance constant $E_{s c}$ is equal to 128 klux. The direct normal illuminance $E_{d n}$ corrected for the attenuating effects of the atmosphere is given by:

$$
E_{d n}=E_{e x t} e^{-c m},
$$

where $c$ is the atmospheric extinction coefficient and $m$ is the relative optical air mass.

\subsection{Conduction}

Heat transferred from the exterior roof surface to the interior attic is due to conduction. Conduction is the direct flow of heat through a material resulting from physical contact. The transfer of heat by conduction is caused by molecular motion whereupon molecules transfer their energy to adjoining molecules and thus increase their temperature. Heat transfer by conduction is governed by Fourier's Law of Conduction, as shown in Equation (8):

$$
\dot{Q}_{\text {cond }}=-k A \frac{d T}{d x},
$$


where $k$ is thermal conductivity $[\mathrm{W} /(\mathrm{m} \cdot \mathrm{K})], A$ is the area normal to $x$-direction through which heat flows $\left[\mathrm{m}^{2}\right]$, and $d T / d x$ is the temperature gradient in the $x$-direction $[\mathrm{K} / \mathrm{m}]$ (Myers 1998, Çengel 2007). Thermal conductivity is a characteristic of material that varies with temperature, density, and composition. A high value for thermal conductivity indicates a material is a good heat conductor, or in other words, a poor insulator.

\subsection{Convection}

Convection is the transfer of heat with the movement of a fluid. In a home, warm air rises and cold air settles to create a convection loop. This process is called free or natural convection. Forced convection is when a mechanical device, such as a fan, induces flow. Convection is described by Newton's Law of Cooling, shown in Equation (9):

$$
\dot{Q}_{\text {conv }}=h_{\text {conv }} A\left(T_{s}-T_{\infty}\right) \text {, }
$$

where $h_{\text {conv }}$ is the heat transfer coefficient $\left[\mathrm{W} / \mathrm{m}^{2} \mathrm{~K}\right], A$ is the surface area evaluated $\left[\mathrm{m}^{2}\right], T_{s}$ is the surface temperature $[\mathrm{K}]$, and $T_{\infty}$ is the fluid temperature away from the surface $[\mathrm{K}]$. The heat transfer coefficient is defined as the rate of heat transfer between a solid surface and a fluid, per unit surface area, per unit temperature difference (Bejan 2004, Çengel 2007).

Typical examples of heat transfer through convection include warm air rising from a fan driven heat register (forced convection), warm air rising from surfaces on a radiator (after air in contact with radiator has been heated by conduction), or warm air rising from a chimney (natural or free convection).

Natural convection occurs due to gas expansion and gravitation. In a gravitational field, there is a net force that pushes upward on a less dense fluid pocket placed in a denser fluid. The upward force exerted by a fluid on a volume completely immersed is called the buoyancy force $F_{\text {buoy }}$, shown in Equation (10):

$$
F_{\text {buoy }}=\rho g V
$$

where $\rho$ is the density of the fluid $\left[\mathrm{kg} / \mathrm{m}^{3}\right], g$ is the gravitational acceleration $\left[\mathrm{m} / \mathrm{s}^{2}\right]$, and $V$ is the volume of the portion of the body immersed in the fluid $\left[\mathrm{m}^{3}\right]$ (Çengel 2007).

The chimney effect, or stack effect, which induces the upward flow of hot gases through a chimney is due to this buoyancy effect. The upward force acting on the gases in the chimney is 
proportional to the difference in densities of the hot gases within the chimney and the cooler air outside.

The chimney effect occurs in tall buildings, chimneys, gas flue stacks, and is driven by buoyancy. Differences in indoor-to-outdoor air density result from temperature and moisture variation. The result is either a positive or negative buoyancy force; the greater the thermal difference combined with the height of a structure, the greater the buoyancy force, and thus the chimney effect. The pressure difference $\Delta P$ can be calculated using Equation (11) (Çengel 2007):

$$
\Delta P=0.342 a h_{c}\left(\frac{1}{T_{o}}-\frac{1}{T_{i}}\right),
$$

where $a$ is the atmospheric pressure [Pa], $h_{c}$ is the chimney height [m], $T_{o}$ and $T_{i}$ are the absolute outside and inside temperatures $[\mathrm{K}]$, respectively. The volumetric flow rate induced by the stack effect can be calculated with Equation (12) (Çengel 2007):

$$
\dot{V}=C A \sqrt{2 g h_{c} \frac{T_{i}-T_{o}}{T_{i}}},
$$

where $A$ is the chimney cross-sectional flow area $\left[\mathrm{m}^{2}\right], C$ is the unitless discharge coefficient [-], and $g$ is gravity $\left[\mathrm{m} / \mathrm{s}^{2}\right]$.

The stack effect will cause air infiltration since buildings are not totally sealed. During the heating season, warmer indoor air rises up through a building and escapes at the top either through open windows, ventilation openings, or leaks. Rising warm air reduces the pressure in the base of a building, forcing cold air to infiltrate through either open doors, windows, or other openings and leaks. During cooling, the stack effect is reversed, but is typically weaker due to lower temperature differences.

To express net buoyancy force in terms of temperature differences, the volume expansion coefficient $\beta[1 / \mathrm{K}]$ represents the variation of the density of a fluid with temperature at constant pressure, as in Equation (13) (Çengel 2007):

$$
\beta=\frac{1}{v}\left(\frac{\partial v}{\partial T}\right)_{P}=-\frac{1}{\rho}\left(\frac{\partial \rho}{\partial T}\right)_{P} \approx-\frac{1}{\rho}\left(\frac{\rho_{\infty}-\rho}{T_{\infty}-T}\right)_{P},
$$

where $\rho_{\infty}\left[\mathrm{kg} / \mathrm{m}^{3}\right]$ is the density and $T_{\infty}[\mathrm{K}]$ is the temperature of the quiescent fluid away from the surface. Using the ideal gas relation, the volume expansion coefficient for an ideal gas is 
inversely proportional to the thermodynamic temperature $T[\mathrm{~K}]$ as presented in Equation (14) (Çengel 2007):

$$
\beta_{\text {idealgas }}=\frac{1}{T}
$$

The ratio of buoyancy to viscous forces acting on a fluid can be approximated by utilizing the Grashof number $G r$. In particular, the Grashof number for flow over a vertical flat plate is represented by Equation (15) (Çengel 2007):

$$
G r_{L}=\frac{g \beta\left(T_{s}-T_{\infty}\right) L_{c}^{3}}{v^{2}},
$$

where $T_{s}$ is the surface temperature $[\mathrm{K}], L_{c}$ is the characteristic length [m], and $v$ is the kinematic viscosity $\left[\mathrm{m}^{2} / \mathrm{s}\right]$. In natural convection, the Grashof number also provides the main criterion in determining whether the fluid flow is laminar or turbulent. For example, the critical Grashof number is observed to be about $10^{9}$ for flat vertical plates whereupon the flow becomes turbulent.

Natural convection on a surface depends on several factors including the geometry of the surface, orientation, variation of surface temperatures, and thermophysical properties of the fluid involved. Due to the complexities of fluid motion, it is very difficult to obtain simple analytic relations for heat transfer by solving the governing equations of energy and motion. Therefore, heat transfer relations are based on experimentally determined empirical relations.

In natural convection, the simple empirical correlations for the Prandtl number $P r$, average Nusselt number $N u$, and Raleigh number $R a$ are each presented below in Equations (16), (17), and (18), respectively (Çengel 2007):

$$
\begin{gathered}
\operatorname{Pr}=\frac{v}{\alpha}=\frac{\mu c_{p}}{k}, \\
N u=\frac{h_{c o n v} L_{c}}{k}=C\left(G r_{L} \operatorname{Pr}\right)^{n}=C\left(R a_{L}^{n}\right) \text { and } \\
R a=G r_{L} \operatorname{Pr}=\frac{g \beta\left(T_{s}-T_{\infty}\right) L_{c} P r}{v^{2}},
\end{gathered}
$$

where $\alpha$ is the thermal diffusivity $\left[\mathrm{m}^{2} / \mathrm{s}\right], h_{\text {conv }}$ is the heat transfer coefficient $\left[\mathrm{W} / \mathrm{m}^{2} \cdot \mathrm{K}\right]$, and $k$ is the thermal conductivity of air $[\mathrm{W} / \mathrm{m} \cdot \mathrm{K}]$. The values of $C$ and $n$ depend on the geometry of the 
surface and the flow regime, which is characterized by the range of the Rayleigh number. The value of $C$ is normally less than one. The value of $n$ is usually $1 / 4$ or $1 / 3$ for laminar or turbulent flows, respectively.

The Nusselt number is described as the ratio of convective to conductive heat transfer across the boundary. The Prandtl number describes the relationship between momentum diffusivity and thermal diffusivity, and hence the Rayleigh number can also be viewed as the ratio of buoyancy forces and the product of thermal and momentum diffusivities.

Çengel explains the simple relations for the average Nusselt number for various geometries. For this research, three representative geometries were selected to include flat vertical, inclined, and horizontal plates. Although these are all flat plates, their orientation varies, and hence their characteristic lengths, Nusselt number, and Rayleigh number also vary.

For a flat vertical isothermal plate, the upper surface is considered the cold surface, the lower surface is the hot surface, and the characteristic length is the plate height. Figure 9 shows the typical velocity and temperature profiles for natural convective flow over a hot vertical plate at temperature $T_{s}$ inserted in a fluid at temperature $T_{\infty}$. The empirical relations for the average Nusselt number for natural convection over a flat vertical plate surface are shown in Equations (19) to (21). The first two relations cover only specific ranges of the Rayleigh number, while the third relation covers the entire range. Despite its complexity, Churchill and Chu recommend using the third relation primarily in the range of $10^{-1}<R a_{L}<10^{9}$ (Churchill and Chu 1975, Çengel 2007).

$$
\begin{gathered}
N u=0.59 R a_{L}^{1 / 4} \text { for } 10^{4}<R a_{L}<10^{9}, \\
N u=0.1 R a_{L}^{1 / 3} \text { for } 10^{20}<R a_{L}<10^{13}, \text { and } \\
N u=\left(0.825+\frac{0.387 R a_{L}^{1 / 4}}{\left[1+(0.492 / \mathrm{Pr})^{9 / 16}\right]^{8 / 27}}\right)^{2} \text { for the entire range. }
\end{gathered}
$$




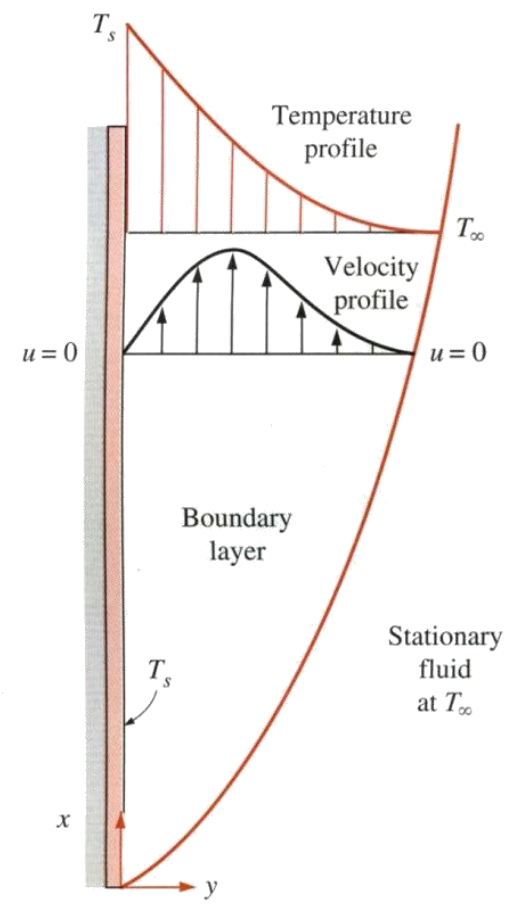

\section{Figure 9 Convective Currents over a Vertical Flat Plate (Çengel 2007)}

For a constant surface heat flux on a vertical plate, the rate of heat transfer is known; however, the surface temperature increases with height along the plate. According to Churchill and $\mathrm{Chu}$, the Nusselt number relations for the constant surface temperature and constant surface heat flux cases are nearly identical (Churchill and Chu 1975). Therefore, the relations for isothermal plates can also be used for plates subjected to uniform heat flux provided that the plate midpoint temperature $T_{L / 2}$ is used for the surface temperature in the evaluation of the film

temperature, Rayleigh number, and Nusselt number. The midpoint temperature is determined by iteration so that the Nusselt numbers are determined from Equations (21) and (22).

$$
N u=\frac{h_{c o n v} L_{c}}{k}=\frac{\dot{q} L_{c}}{k\left(T_{L / 2}-T_{\infty}\right)}
$$

Figure 10 shows the natural convective flows on the upper and lower surfaces of an inclined hot plate. The net force acting on a unit volume of fluid in the boundary layer is always in the vertical direction. If the force that drives the motion is reduced, then it is expected that the convective currents will be weaker and the rate of heat transfer will be lower relative to the vertical plate case. 


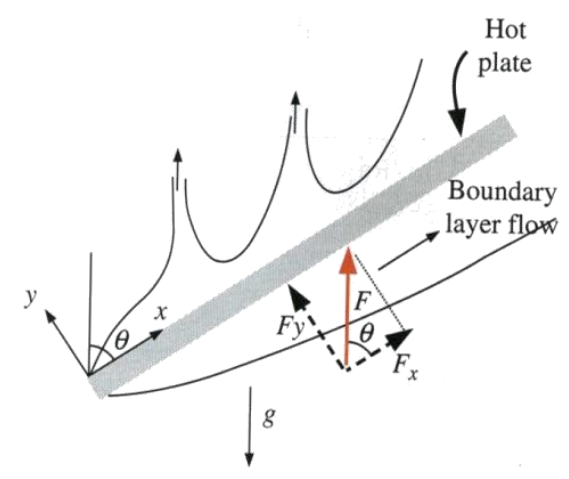

Figure 10 Natural Convective Currents over an Inclined Plate (Çengel 2007)

This theory works for the lower surface of a hot plate, but cannot be confirmed experimentally for the upper surface. On the upper surface, the y-component of the force initiates upward motion in addition to the parallel motion along the plate, and thus the boundary layer breaks up and forms plumes. As a result, the thickness of the boundary layer and thus the resistance to heat transfer decreases, and the rate of heat transfer increases relative to the vertical orientation.

In the case of a cold plate in a warm environment, the opposite occurs. The boundary layer on the upper surface remains intact with weaker boundary layer flow, and thus a lower rate of heat transfer. In addition, the boundary layer on the lower surface breaks apart and thus enhances the heat transfer.

When the boundary layer remains intact, the Nusselt number can be determined from the vertical plate relations discussed previously. Also, the Rayleigh number, Equation (18), is slightly modified to incorporate the angle from the horizontal axis of the inclined plate $\theta$, as shown in Equation (23). Fujii and Imura determined Nusselt number relations for the upper surface of a hot plate or the lower surface of a cold plate (Fujii and Imura 1975).

$$
R a_{\theta}=G r_{L} \operatorname{Pr}=\frac{g \cos \theta \beta\left(T_{s}-T_{\infty}\right) L_{c} P r}{v^{2}} \text { for } \theta>60^{\circ}
$$

The rate of heat transfer to or from a horizontal surface depends on which way the hot (or cold) surface is facing. For a hot surface in a cooler environment, the net force acts upward, forcing the heated fluid to rise. If the hot surface is facing upward, the heated fluid rises freely, 
inducing strong natural convection currents which thus affects the heat transfer, as shown in Figure 11.

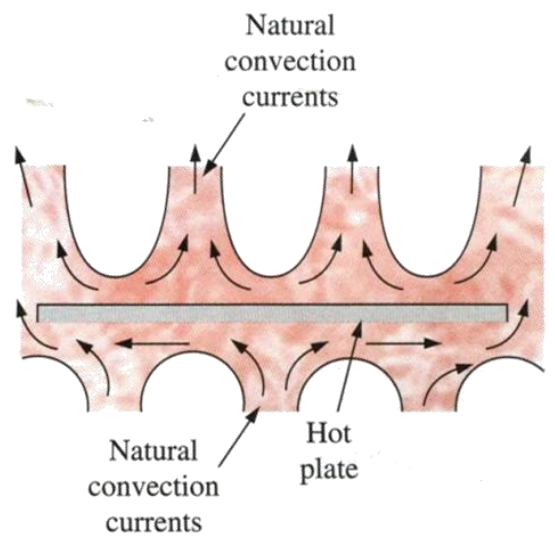

\section{Figure 11 Natural Convective Currents over the Upper and Lower Surfaces of a Horizontal Plate (Çengel 2007)}

The empirical relations for the average Nusselt number for this type of heat transfer are shown in Equations (24) and (25) (Çengel 2007):

$$
\begin{gathered}
N u=0.54 R a_{L}^{1 / 4} \text { for } 10^{4}<R a_{L}<10^{7} \text { and } \\
N u=0.15 R a_{L}^{1 / 3} \text { for } 10^{7}<R a_{L}<10^{11}
\end{gathered}
$$

On the other hand, if the hot surface is facing downward, the plate blocks the heated fluid that tends to rise, impeding the heat transfer. The opposite is true for a cold plate in a warmer environment since the net force (weight minus buoyancy force) acts downward, and the cooled fluid near the plate tends to descend. The average Nusselt number for this type of horizontal plate is shown in Equation (26):

$$
N u=0.27 R a_{L}^{1 / 4} \text { for } 10^{5}<R a_{L}<10^{11}
$$

Whether the horizontal surface is facing upward or downward, the characteristic length is determined by Equation (27):

$$
L_{c}=\frac{A_{s}}{p} \text {, }
$$

where $A_{s}$ is the surface area $\left[\mathrm{m}^{2}\right]$ and $p$ is the perimeter $[\mathrm{m}]$. The magnitude of the natural convection heat transfer is directly related to the mass flow rate of the fluid which is established by buoyancy and friction effects. 
A very common problem encountered in various applications is the prediction of the heat exchange rate between two fluid streams separated by a wall. Three limiting situations are possible: forced convection on both sides; forced convection on one side and natural convection on the other; and natural convection on both sides. This research work includes convective heat transfer between horizontal, vertical and inclined plates which has been studied by Vistanta and Lankford, Onur et al., and Elenbaas, as described below.

Vistanta and Lankford considered the problem of thermal coupling by conduction through a wall separating two fluid reservoir cells at different temperatures. Experiments were performed and a simple analysis developed to predict the extent of the thermal interaction between the two fluid streams separated by a wall. The experiments were conducted with air in natural convection systems and comparisons made with the predication of heat transfer through the wall made by commonly accepted procedures in the heat transfer literature (Vistanta 1981).

The cell consisted of an adiabatic double-wall chamber divided into two equal parts by a balsa wood vertical wall. The temperatures were controlled independently by circulating water from a constant temperature bath through the double walls of the chamber. Depending on the temperatures in the chamber, it took about 12 hours to reach steady-state conditions. At that time, thermocouple readings were recorded and interference fringe patterns were photographed. Brass, glass, and copper were used for the vertical separating wall to cover a wide range of thermal conductivities.

The predictions for the brass plate were very close to those for the copper plate. The results show that the difference between the calculated and the measured surface temperatures is greatest near both ends mainly due to the two-dimensional heat conduction effects in the plate. The measured natural convection heat transfer coefficients are at most 5\% lower than the predicted values and $12 \%$ higher than those expected for a constant temperature wall. There was reasonably good agreement between the analytic and experimental results.

Vistanta and Lankford concluded that the natural convective heat transfer coefficients on the two sides of the separating wall are interdependent, but a good agreement for the local heat transfer along the wall can be obtained by neglecting thermal interaction and using average values of wall temperature. In general, for ordinary fluids, the thermal interaction between two laminar convection systems separated by a wall is only moderate. 
Onur et al. presented the results of natural convective heat transfer between inclined parallel plates. The lower plate was heated isothermally while the upper plate was both unheated and insulated. Plate inclinations were 0 degrees, 30 degrees, and 45 degrees measured from the vertical position. Experiments were carried out for various temperature differences in air to determine the effect of plate spacing and plate inclination on heat transfer. It was found that the heat transfer rate depends on plate spacing and inclination (Onur et al. 1997).

Extensive analytic and experimental work was carried out on this problem since 1942, when Elenbaas first introduced the problem of natural convection between vertical parallel plates. However, almost all of the work has treated the cases of vertical parallel plates under different heating conditions.

In this chapter, all three heat transfer methods were discussed. Heat can be transferred by way of conduction, convection and/or radiation in which all of these heat transfer modes require the existence of a temperature difference. All modes are from a higher to lower temperature medium and the energy transfer stops when the two mediums reach the same temperature. In general, radiation is usually significant relative to conduction or natural convection, but negligible relative to forced convection. For this research, solar radiation is the driving force for the natural convection between the add-on structure and the existing roof which in addition is being driven by the effects of stack enhanced convection. In turn, this add-on structure will reduce the heat transfer into a residential house or a commercial building.

Heat transfer rates are critical in design and evaluation in research and development projects. The thermal theory presented in this chapter was incorporated into the preliminary analytic model which was verified by an experimental analysis to ensure consistency with the observed nature of the problem at hand. 


\section{FLOW THEORY}

The temperature distributions which result from convective heat transfer are related to velocity characteristics. For this research, three types of natural convection flows were considered. This included flow over a plate, flow between two parallel plates and flow through a conduit or ducted flow. Each of these types of flows will be discussed next three sections.

\subsection{Conservation Equations}

This section presents the differential equations that describe the convective heat transfer process using a control volume analysis. These include the continuity (conservation of mass), Navier-Stokes (momentum), and energy (enthalpy) equations, each of which will be discussed.

Conservation of mass requires that the change in mass of a control volume with respect to time equals the difference of the mass flows into and out of a control volume. In convective heat transfer, the velocity and temperature distribution are of particular interest and hence a control volume is drawn around an infinitesimally small region around a fixed location in the flow field, as shown in Figure 12.
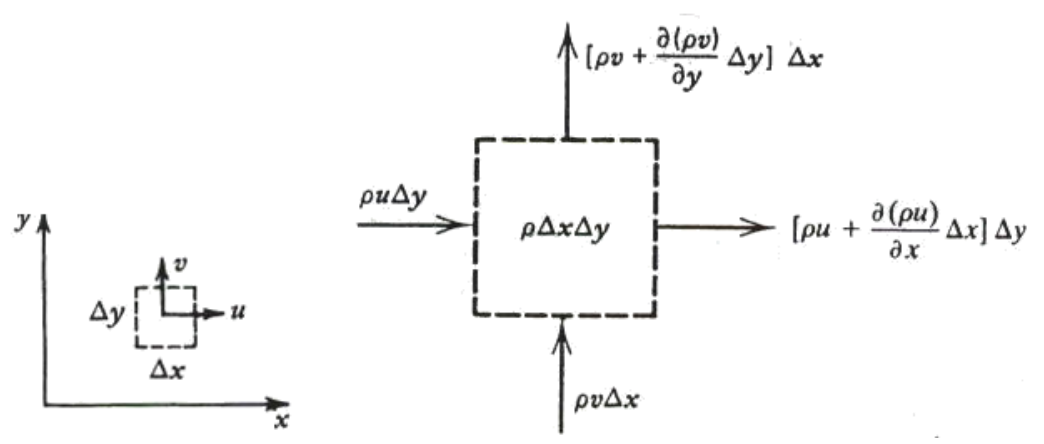

Figure 12 Mass Conservation on a Control Volume (Bejan 2004)

For a 2-D, unsteady, compressible flow field, conservation of mass is represented in the equation below (Bejan 2004, Turner and Bradshaw 1988).

$$
\frac{\partial p}{\partial t}+\frac{\partial(\rho u)}{\partial x}+\frac{\partial(\rho v)}{\partial y}=0,
$$

where $\rho$ is density, $u$ and $v$ are the velocity components in the $x$ and $y$ directions, respectively.

The conservation of momentum can be derived by similar use of control volume concepts, from which there is a momentum equation for each direction. The momentum equations are 
based on a force balance, which includes the body and surface forces, as shown in Figure 13 for the $\mathrm{x}$-direction.

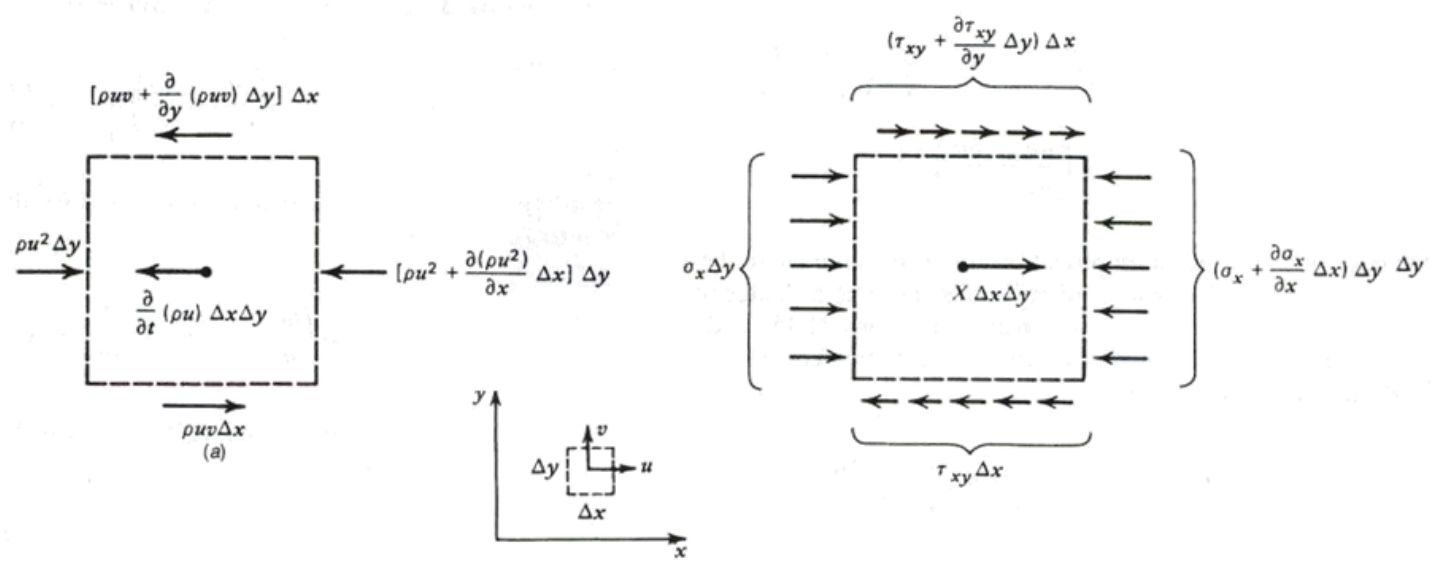

Figure 13 Force Balance on a Control Volume (Bejan 2004)

If each of the forces from Figure 13 are formulated into the conservation of momentum equation and utilizing the result from Equation (28), the momentum equation for the $x$-direction would be reduced to Equation (29). The normal stress $\sigma_{x}$ and tangential stress $\tau_{x y}$ are shown in Equations (30) and (31), respectively (Bejan 2004, Turner and Bradshaw 2008):

$$
\begin{gathered}
\rho \frac{D u}{D t}=-\frac{\partial \sigma_{x}}{\partial x}+\frac{\partial \tau_{x y}}{\partial y}+X \\
\sigma_{x}=P-2 \mu \frac{\partial u}{\partial x}+\frac{2}{3} \mu\left(\frac{\partial u}{\partial x}+\frac{\partial v}{\partial y}\right) \\
\tau_{x y}=\mu\left(\frac{\partial u}{\partial y}+\frac{\partial v}{\partial x}\right)
\end{gathered}
$$

where $P$ is the pressure, $D u / D t$ is the substantial derivative of the velocity component in the $\mathrm{x}$ direction and $X$ is the $\mathrm{x}$-direction body force per unit volume.

The conservation of mass and momentum equations discussed previously will solve for the flow part of convective heat transfer. However, when the natural flow is driven by the heat administered to the flowing fluid, the heat transfer part also needs to be determined. This will require the temperature distribution, through the flow, especially in close vicinity of the walls. The last conservation equation is the energy equation or the first law of thermodynamics. 
Utilizing a control volume of finite size, as shown in Figure 14, the first law states that the increase of internal energy in a system is equal to the amount of energy added by heating the system, minus the amount lost as a result of the work done by the system on its surroundings.
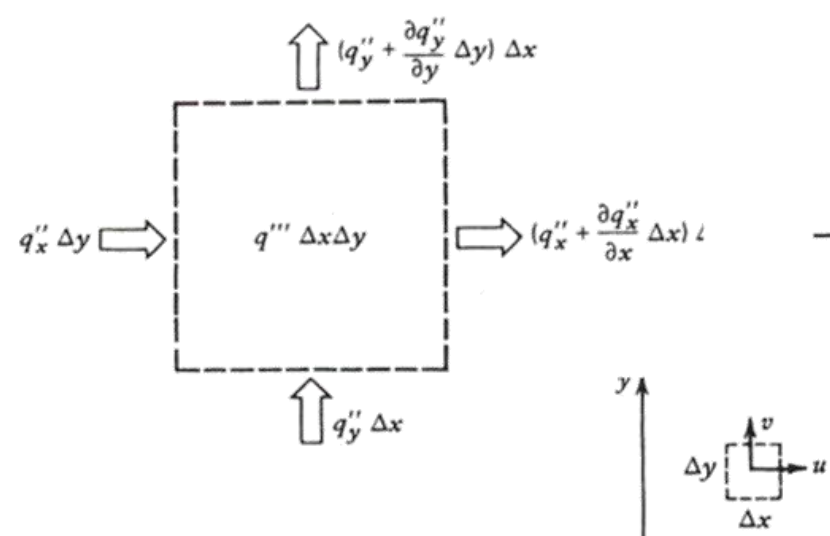

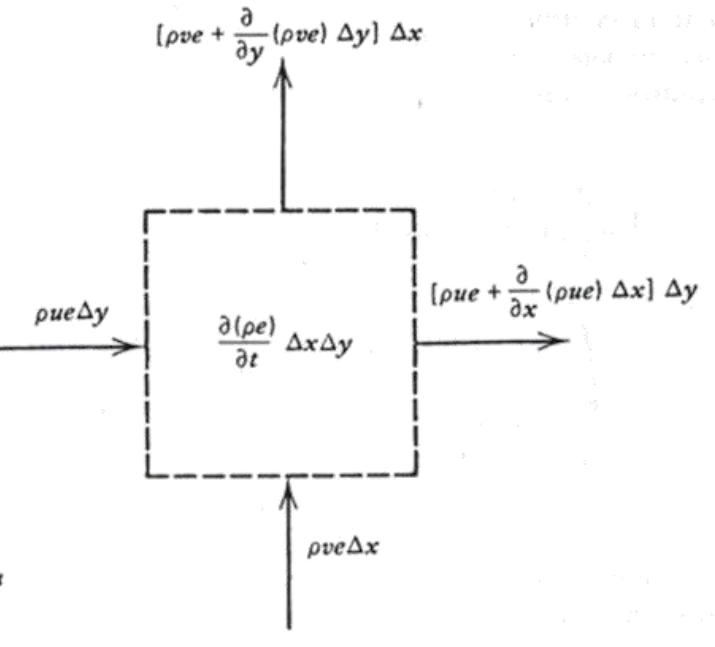

Figure 14 First Law of Thermodynamics Applied to a Control Volume (Bejan 2004)

Inserting Eqs. (30) and (31) into the energy conservation equation yields the following expression.

$$
\rho \frac{D e}{D t}+e\left(\frac{D \rho}{D t}+\rho \nabla \bullet v\right)=-\nabla \bullet q^{\prime \prime}+q^{\prime \prime \prime}-P \nabla \bullet v+\mu \Phi
$$

where $e$ is the specific internal energy, $q^{\prime \prime}$ is the heat flux vector $\left(q_{x}{ }^{\prime \prime} q_{y}{ }^{\prime \prime}\right)$ as described by Fourier's law of heat conduction, $q_{x}{ }^{\prime \prime}$ is the heat flux in the x-direction, $q_{y}{ }^{\prime \prime}$ is heat flux in the y-direction, $\mu$ is the viscosity, $q^{\prime \prime \prime}$ is the dissipation rate (or internal heat generation), and $\Phi$ is the viscous dissipation function, as shown in Equation (33):

$$
\Phi=2\left[\left(\frac{\partial u}{\partial x}\right)^{2}+\left(\frac{\partial v}{\partial y}\right)^{2}\right]+\left(\frac{\partial u}{\partial x}+\frac{\partial v}{\partial y}\right)^{2}
$$

Equation (32), the energy equation can now be expressed utilizing the enthalpy equation and conservation of mass, as shown in Equations (34) and (35), respectively. 


$$
\begin{gathered}
h=e+\frac{P}{\rho} \\
\rho \frac{D h}{D t}=\nabla \bullet(k \nabla T)+q^{\prime \prime \prime}+\frac{D P}{D t}+\mu \Phi
\end{gathered}
$$

\subsection{Flow Over and Between Parallel Plates}

Convective heat transfer theory is based on defining a heat transfer coefficient that operates on surfaces. Figure 15 shows some typical velocity profiles for natural convection over a flat vertical plate and between two vertical plates. There are clearly two distinct cases: one in which the velocity profile does not interact with any nearby surface and the other in which this is indeed the case. All heat transfer relations for natural convection between parallel plates are based on this observation and they can all simply be said to map a weighted average between these two extremes. In addition, plate spacing plays an important role. For the flow between two plates, two cases are shown. For the plates that are spaced far apart (b), the velocity profile is symmetric about the center with a maximum velocity near each wall. For the plates spaced close together (c), the velocity profile is also symmetric about the center but with a single velocity maximum at the center.

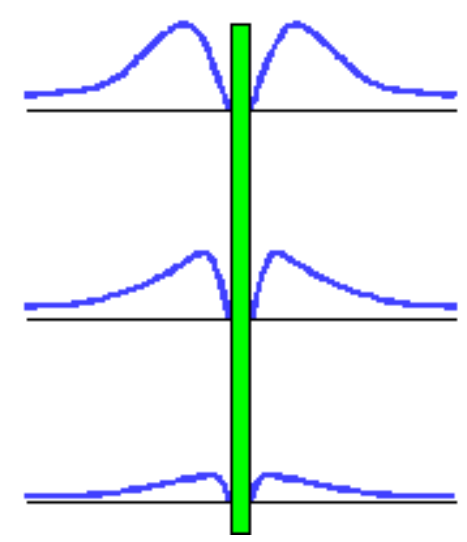

(a)

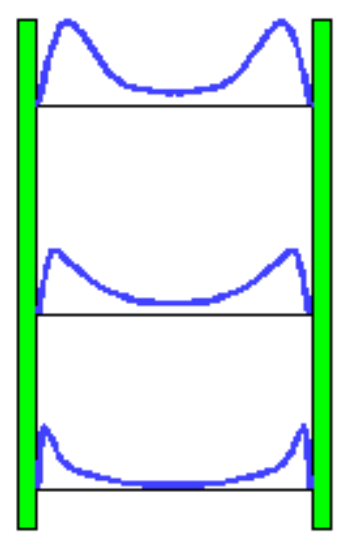

(b)

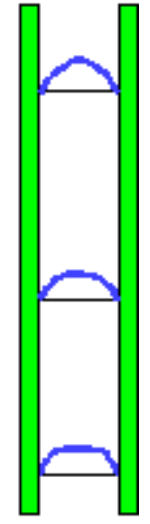

(c)

Figure 15 Velocity Profiles Over and Between Flat Vertical Plates

Bodoia and Osterle studied the development of free convection between heated vertical plates. Their study focused on the flow and heat transfer characteristics of channels with a height that did not reach fully developed flow. Results were obtained for the velocity and temperature distributions throughout the channel assuming the fluid entered with ambient temperature and a flat velocity profile. Their research work is compared to well known research experiments, such 
as Elenbaas. The results compared favorably except for at low Grashof numbers, or laminar flow, where the close plate separation resulted in side leakage effects causing an increase in the convective heat dissipation and consequently a higher Nusselt number (Bodoia and Osterle 1962).

Basic heat transfer theory reveals that angular orientation has a rather limited impact on the cooling of a single plate. For parallel plates, the angle does not have much impact either for angles less than sixty degrees (White 1988). However, this angular restriction does not hold for inclined plates that are closely spaced.

A particular difficulty when dealing with inclined parallel plates is the asymmetry in the velocity profile, as shown in Figure 16. For single plates (a) and parallel plates separated by a large distance (b), it is apparent that the velocity gradient is higher on the downward side than on the upward side. However, for closely spaced plates (c), the viscous forces are strong enough to prevent the formation of any significant asymmetry.

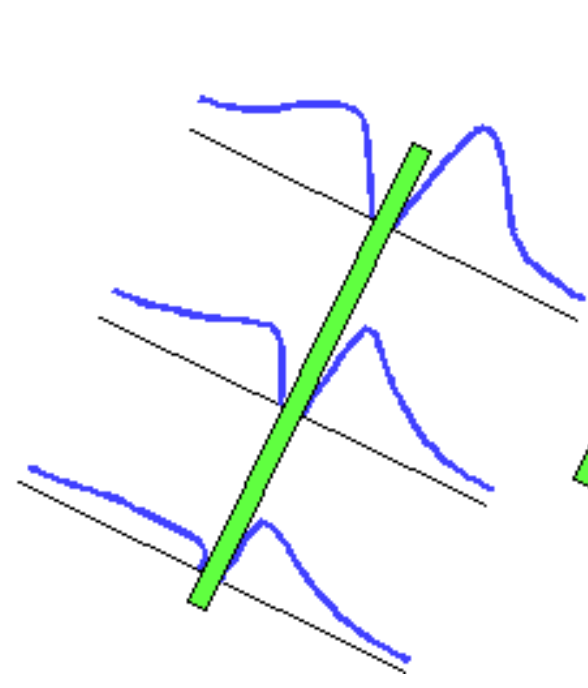

(a)

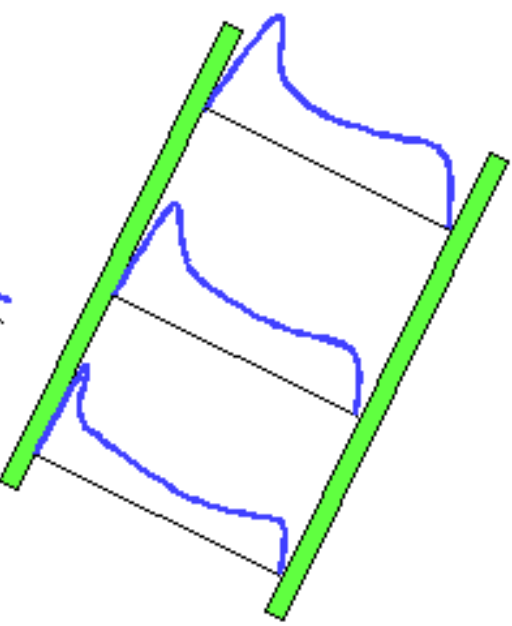

(b)

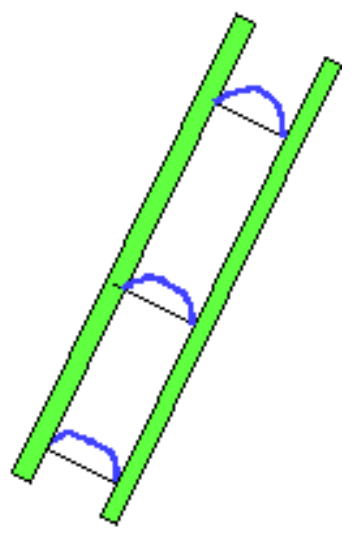

(c)

Figure 16 Velocity Profiles Over and Between Flat Inclined Plates

For inclined and vertical parallel plates with large spacing, the characteristic equations are independent of any inclination angle. However, for plates with smaller spacing, the velocity profile is angle dependent and symmetric. The characteristic equations are the same as for vertical plates but with the difference that gravity is replaced by the gravity component in the plate direction. 
Lin performed a numerical study of the formation of longitudinal vortices in natural convection flow over horizontal and inclined surfaces. The results showed that the onset position characterized by the Grashof number depends on the Prandtl number, relative geometry, and the inclination angle of the plates/surfaces. The vortex mode of flow was found to become more dominant as the angle increased, due to a decrease in buoyancy force in the normal direction of the plate/surface. The numerical results agreed with the experimental data presented in the literature (Lin 2001).

\subsection{Duct Flow}

Poiseuille flows are generated by pressure gradients, and are generally applied to duct flow. For a straight duct of an arbitrary shape, there is an entrance effect, a thin initial shear layer and core acceleration. The shear layers grow and meet and the core disappears, within a fairly short entrance length, $L_{e}$. Shah and London showed that regardless of shape, the entrance length can be correlated for laminar flow, as shown in Equation (36). This equation is dependent on the hydraulic diameter $D_{h}$ and the Reynolds $R e$ number based from this diameter, as shown in Equations (37) and (38) (Shah and London 1978, White 1991):

$$
\begin{gathered}
\frac{L_{e}}{D_{h}}=0.5+0.5 \operatorname{Re}_{D_{h}}, \\
D_{h}=\frac{4 A}{P}, \text { and } \\
R e_{D_{h}}=\frac{\rho V D_{h}}{\mu},
\end{gathered}
$$

where $A$ is the area, $P$ is the perimeter, $\rho$ is the density, $V$ is the volume, and $\mu$ the dynamic viscosity of the fluid .

Berker reviewed various noncircular shapes for fully developed duct flow, one of which is flow in a rectangular section with radial widths of $a$ and $b$ (Berker 1971). For this type of rectangular section with $-a \leq y \leq a$ and $-b \leq z \leq b$, velocity distribution $u(y, z)$ and volume rate of flow $Q$ are shown in Equations (39) and (40), respectively (White 1991):

$$
u(y, z)=\frac{16 a^{2}}{\mu \pi^{3}}\left(-\frac{d \hat{p}}{d x}\right) \sum_{i=1,3,5, \ldots}^{\infty}(-1)^{(i-1) / 2}\left[1-\frac{\cosh (i \pi z / 2 a)}{\cosh (i \pi b / 2 b)}\right] \frac{\cos (i \pi y / 2 a)}{i^{3}} \text { and }
$$




$$
Q=\frac{4 b a}{3 \mu}\left(-\frac{d \hat{p}}{d x}\right)\left[1-\frac{192 a}{\pi^{5} b} \sum_{i=1,3,5, \ldots}^{\infty} \frac{\tanh (i \pi b / 2 a)}{i^{5}}\right]
$$

where $d \hat{p} / d x$ is the pressure gradient, $\mu$ is the coefficient of viscosity of a Newtonian fluid and $i$ is the summation index.

Flow characteristics, as described by the previous three sections, directly relate to convective heat transfer, which is a primary component for this research. The flow theory utilized in this research includes flow over a plate, flow between two parallel plates and duct flow. All of these theories were included in the analytic and experimental calculations. 


\section{Thermal MANagement Systems}

Initially, this research area focused on reducing the energy requirements for ISO military containers using a retrofit design for flat roofs. Subsequently, the research included inclined roof designs, such as those on residential buildings, in which an analytic model was developed. A stack was added to the inclined roof design to enhance and take advantage of the buoyancy effect. To corroborate the analytic results, two experimental units were built and tested.

This chapter is divided into four sections, the first of which describes the preliminary analytic model developed to determine the feasibility of a thermal management system. The second section discusses the predictive analytic model that determined the parameters for the experimental setup described in the third section. Lastly, the heat transfer through the building structures was analyzed based upon the analytic results.

\subsection{Feasibility Analysis of an Add-On Roof System for Standard Shipping Containers}

Conduction, convection, and radiation all play a part in increasing the heat loads on a structure, but the radiant load from the sun is the largest load incurred during this research. It has been shown that the addition of a solar shade can reduce the solar loading on a given structure. Solar shades, such as the modular heat roof (MHR), can decrease the radiant heat load on an ISO container, used by the military as a shelter, by up to $50 \%$, which provides for a decrease in the amount of energy required to cool the shelter (Riemer 2003).

There are approximately 20,000 shelters in use in the Middle East where the average daytime temperature reaches $45{ }^{\circ} \mathrm{C}$ (ASHRAE 1997). The United States military uses air-conditioned cargo container shelters for field hospitals, offices, and to house electronic equipment. The advantages of these shelters is that they can be preconfigured in the US to meet their specific mission requirements including the shipment of goods, and then be rapidly shipped anywhere to meet the soldiers' needs. Figure 17 shows a cargo container-type shelter that is configured to be a mobile hospital. 


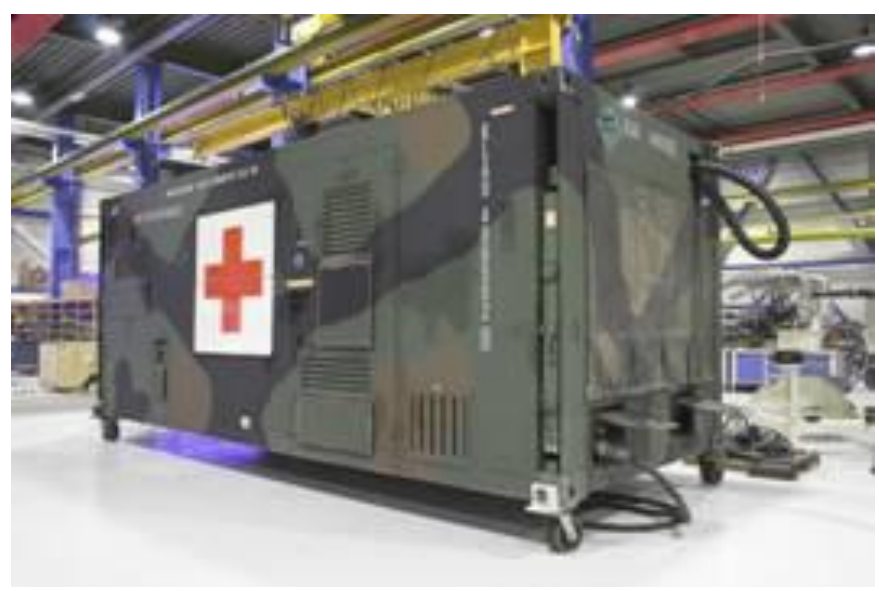

Figure 17 Mobile Hospital (ECS MOGOS) (ECS MOGOS 2007)

There are maximum temperatures for which these shelters can be operate effectively and fulfill their purpose. With the high heat index of locations, such as Iraq and Afghanistan, the cost of cooling the working space of the armed service personnel is extremely high. In addition to the extreme weather conditions that the shelter's air-conditioning units must offset, they are powered by generators that require fuel to be transported into the remote regions where the troops are operating, which further adds to the cost of cooling.

Several solutions exist to reduce the heat loads in US military containers located in the Middle East. This could include replacing existing shelters with a more energy efficient design and/or modifying the current shelters. Replacing or modifying the current shelters present a logistical challenge in that the containers will need to be shipped to and from the manufacturing facility resulting in substantial down time. In addition, this would result in a surplus in military shelters and/or possible undesirable permanent modifications.

An alternative method for adding insulation is to design and implement an aftermarket addon roof structure to help reduce the heat loads. This add-on Modular Heat Roof (MHR) could be installed in the field, and would require no modification to the existing shelter design. This smaller and lightweight design would be easy to transport to most remote locations. In addition, it would be simple to manufacture and replace if damaged. Mounting a MHR to the shelter would be accomplished through use of the corner castings located at the corners of the shelters, as shown in Figure 18. 


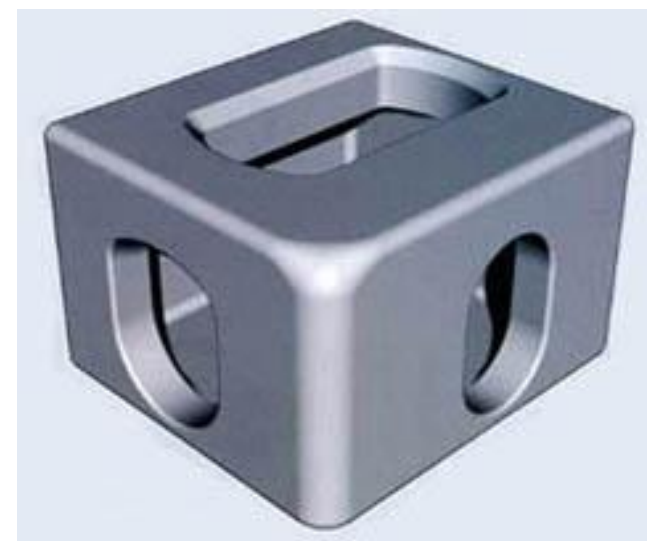

Figure 18 Container Corner Castings (Pacific Marine 2007)

These corner castings are of standard dimensions, and are intended for use in stacking the containers during storage or shipping. Figure 19 shows the mounting of the MHR through use of these corner castings.

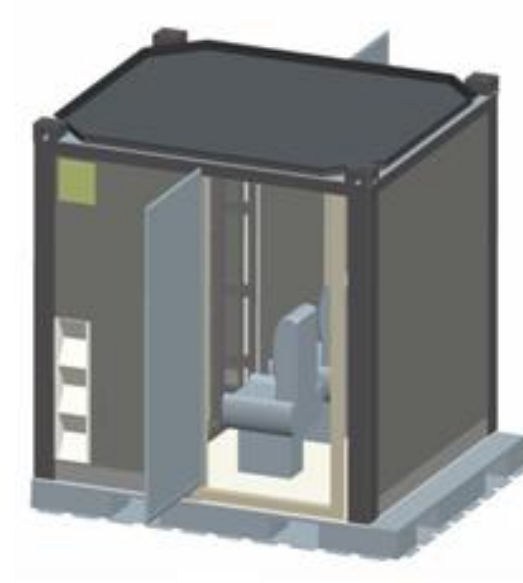

A

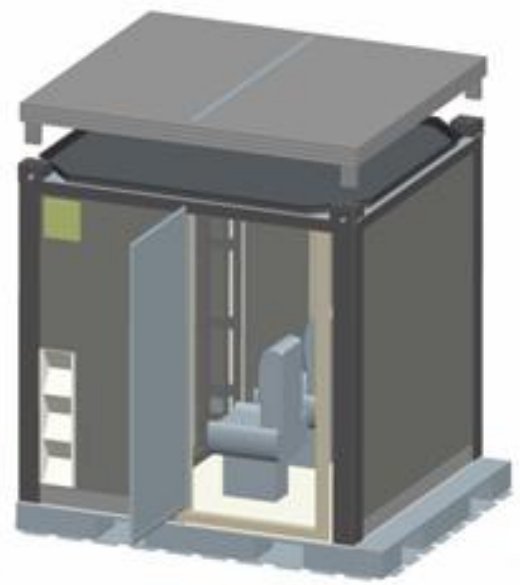

B

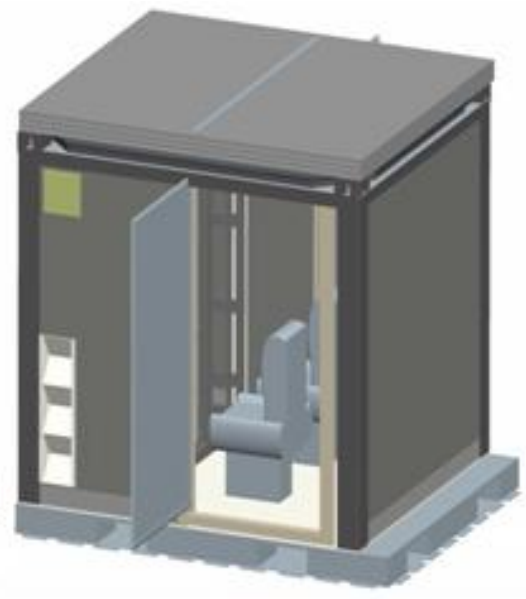

C

Figure 19. Shelter without Heat Roof (A), Exploded View Heat Roof Locking into Place (B), Shelter with Heat Roof $(C)$

The MHR needs to be cost-effective to manufacture, and durable enough for field usage. To meet these requirements the MHR would consist of a thin layer of brushed aluminum set over an insulating material layer which is then laid over a thin layer of plywood to give the heat roof added strength and durability. In addition to the insulation added by the MHR materials, the air gap created between the MHR and the shelter's roof, will provide additional insulation to the shelter and add cooling via natural convection. 
The top of a typical military shelter is constructed out of four materials. From the inside of the shelter, the first layer is a thin layer of plastic sheathing followed by a layer of insulation. The shelter is encased in an aluminum housing that is usually externally powder coated. The properties for each material are shown in Table 1.

Table 1 Selected Material Properties (Çengel 2005)

\begin{tabular}{|c|c|c|}
\hline Material & Thickness $[\mathbf{m m}]$ & $\begin{array}{c}\text { Thermal Conductivity } \\
{\left[\mathbf{W} / \mathbf{m}^{\circ} \mathbf{C}\right]}\end{array}$ \\
\hline Powder coating & 3 & 0.75 \\
\hline Aluminum & 10 & 250 \\
\hline Insulation & 80 & 0.78 \\
\hline Plastic & 10 & 0.03 \\
\hline
\end{tabular}

The overall system was assumed to be a steady one-dimensional heat flow through a composite wall of combined thickness, area, and thermal conductivity exposed to convection on both sides to fluids at temperatures with heat transfer coefficients. The temperature varies linearly in the wall, and asymptotically approaches the outside temperature and inside temperature in the fluids as the distance increases away from the wall. Overall, the rate of heat convection into the wall equals the rate of heat conduction through the wall which equals the rate of heat convection from the wall.

The thermal design was analyzed and the base energy savings were calculated for the new design and compared to the general energy costs of current shelters. The data was then crossreferenced with well established heat transfer models and final calculations were based on accurate system specifications. A computer program was developed to predict the heat flow for the specified conditions using Fourier's law of heat conduction, Newton's law of cooling and the Stephan-Boltzmann law.

An electrical analogy was utilized to calculate the steady state heat loss through the ceiling of a military shelter as a function of the outside surface temperature with the inside being maintained at the specified temperature. Figure 20 represents the electrical circuit analogy for each of the heat transfer modes. The result of this circuit will determine the amount of heat flow through the ceiling of a military shelter. The circuit below represents the heat transfer through the ceiling of the shelter which includes the natural convective currents both outside and inside of the shelter, as well as the conduction through the ceiling materials. In addition, the thermal 
solar radiation, represented as a current source, is assumed to be a constant $700 \mathrm{~W} / \mathrm{m}^{2}$ for the Middle East area (ASHRAE 1997, Çengel 2005).

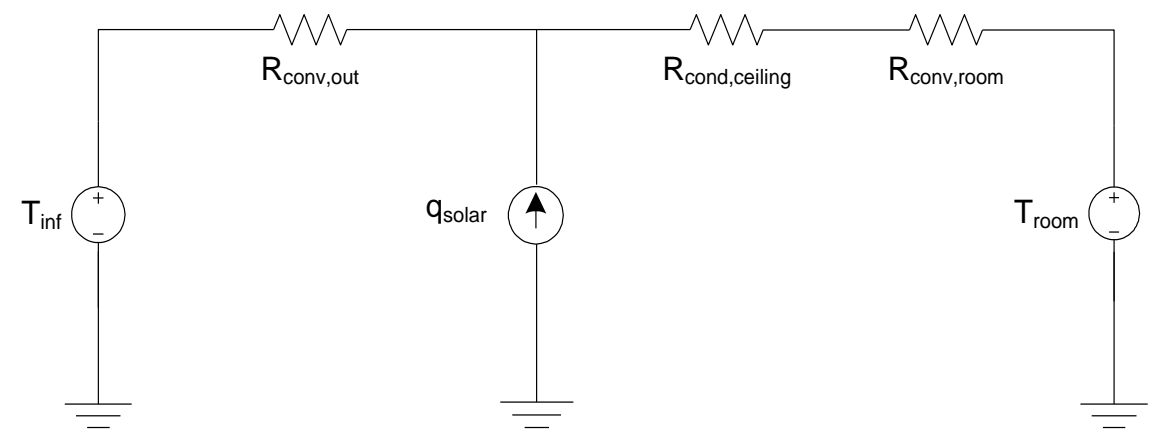

Figure 20 Thermal Schematic of Military Shelter Heat Transfer

The resistance for the conduction and the convection, inside and outside of the shelter, are shown in Equation (41) and (43), respectively. The top of the shelter was assumed to be completely horizontal and hence Equation (42) was used to determine the characteristic length (Çengel 2005).

$$
\begin{gathered}
R_{\text {cond }}=\frac{L_{c}}{A_{s} k}, \\
L_{c}=\frac{A_{s}}{p}, \text { and } \\
R_{\text {conv }}=\frac{1}{A_{s} h},
\end{gathered}
$$

where $L_{c}$ is the characteristic length, $A_{s}$ is the surface area, $p$ is the perimeter, $k$ is the thermal conductivity of each material, and $\mathrm{h}$ is the heat transfer coefficient. This coefficient is based on the flow characteristics of the fluid and is represented by

$$
h=\frac{k N u}{L_{c}},
$$

where $k$ is the thermal conductivity of air and $N u$ is the Nusselt number for a hot upper surface horizontal plate calculated using Equation (45) or Equation (46). This dimensionless number varies based on the orientation of the plate and the calculated Rayleigh number, as shown in Equation (47). (Çengel 2005)

$$
N u=0.54 R a^{1 / 4} \text { for } 10^{4}<R a<10^{7}
$$




$$
\begin{gathered}
N u=0.15 R a^{1 / 3} \text { for } 10^{7}<R a<10^{11} \\
R a=\frac{g \beta\left(T_{s}-T_{\text {inf }}\right) L_{c} P r}{v^{2}}
\end{gathered}
$$

where $\operatorname{Pr}$ is the Prandtl number, $R a$ is the Rayleigh number, $g$ is gravity, $T_{s}$ is the surface temperature, $T_{\text {inf }}$ is the temperature at infinity, $v$ is kinematic viscosity, and $\beta$ and the film temperature $T_{f}$ calculated using Equation (48) and Equation (49), respectively. (Çengel 2007)

$$
\begin{gathered}
\beta=\frac{1}{T_{f}} \\
T_{f}=\frac{T_{s}+T_{i n f}}{2}
\end{gathered}
$$

Once the individual thermal resistances were evaluated, the total resistance and the total rate of heat transfer were determined through the ceiling was determined using Equation (50).

$$
i=\frac{\Delta V}{\sum R}=\frac{\left(\frac{T_{\text {inf }}}{R_{\text {conv }, \text { out }}}+\dot{q}_{\text {solar }}\right) R_{\text {conv }, \text { out }}-T_{\text {room }}}{R_{\text {conv }, \text { out }}+R_{\text {cond }, \text { shelter }}+R_{\text {conv }, \text { room }}}
$$

The schematic is slightly modified with the addition of the modular heat roof. The number of resistances doubles to six compared to the original electrical schematic. The air gap between the MHR and top of the shelter produces a natural convection and radiation, and the MHR thickness adds another conduction term.

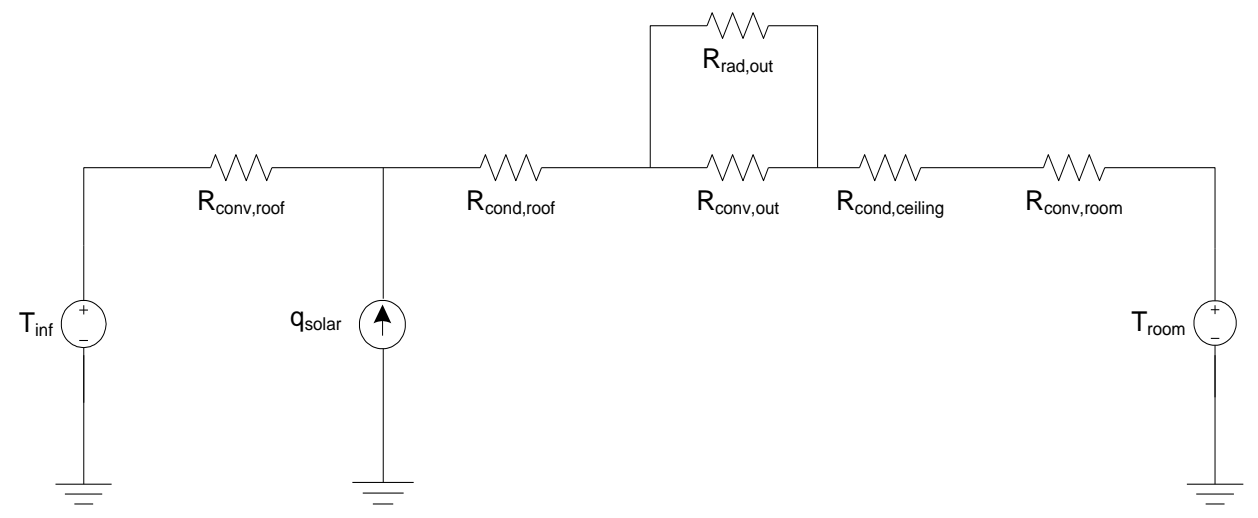

Figure 21 Thermal schematic of military shelter with modular heat roof 
The resistances for the conduction and convection will utilize the previously discussed Equation (41) through Equation (49). For the radiation that will occur between the MHR and the top of the shelter, the thermal resistance was calculated using Equation (51).

$$
R_{\text {rad }}=\frac{1}{A_{s} \sigma \varepsilon\left(T_{s}+T_{\text {surr }}\right)\left(T_{s}^{2}+T_{\text {surr }}^{2}\right)},
$$

where $A_{s}$ is the surface area, $\sigma$ is the Stephan-Boltzmann constant, $\varepsilon$ is the emissivity, $T_{s}$ is the surface temperature and $T_{\text {surr }}$ is the temperature of the surroundings. Once each of the thermal resistances were evaluated, the total resistance and the total rate of heat transfer through the ceiling and modular heat roof was determined using Equation (52).

$$
i=\frac{\Delta V}{\sum R}=\frac{\left(\frac{T_{\text {inf }}}{R_{\text {conv }, \text { roof }}}+\dot{q}_{\text {solar }}\right) R_{\text {conv }, \text { roof }}-T_{\text {room }}}{R_{\text {conv }, \text { roof }}+R_{\text {cond }, \text { roof }}+\frac{R_{\text {rad }} R_{\text {conv }, \text { out }}}{R_{\text {rad }}+R_{\text {conv }, \text { out }}}+R_{\text {cond }, \text { room }}+R_{\text {conv }, \text { room }}}
$$

To determine the total heat flow for the shelter with and without the modular heat roof, several assumptions were made. The room and outside temperatures were held constant at $20^{\circ} \mathrm{C}$ and $45^{\circ} \mathrm{C}$, respectively. To calculate the total energy, it was assumed that the shelter would endure this condition in direct sun for 10 hours.

For the initial resistance calculations, the surface temperature was varied from $75^{\circ} \mathrm{C}$ to $45^{\circ} \mathrm{C}$ in decrements of $0.25^{\circ} \mathrm{C}$ and all of the resistances were iterated simultaneously. Figure 22 shows the temperature error for this setup which was calculated by taking the difference of the iterated and the initial value of the surface temperature. The temperature on the top surface was iterated to be approximately $47^{\circ} \mathrm{C}$ and the total heat transfer through all surfaces equated to $12.6 \mathrm{~kW}$. 


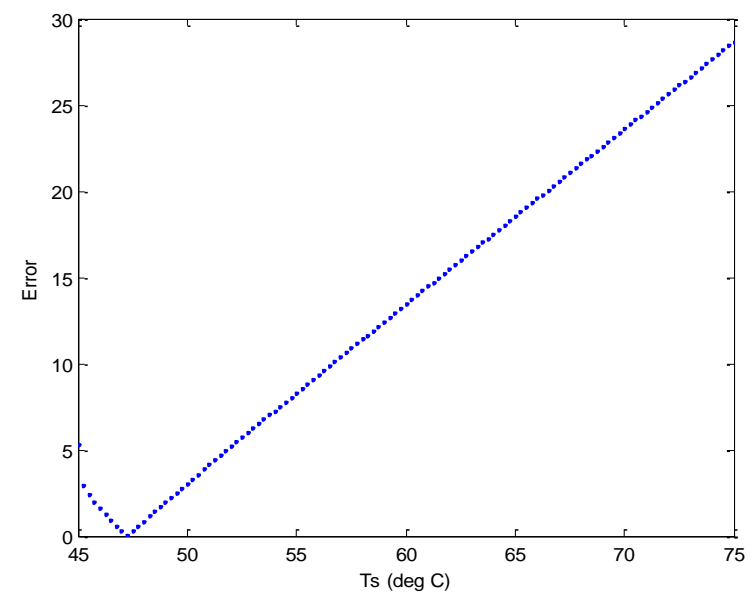

Figure 22 Temperature Error for Military Shelter

After adding the MHR, the surface temperature of the shelter and roof were each varied from $20^{\circ} \mathrm{C}$ to $100^{\circ} \mathrm{C}$ in increments of $0.5^{\circ} \mathrm{C}$ and all resistances were iterated simultaneously. Figure 23 shows the temperature error for this modified setup calculated by adding the square of each iterated surface temperature. The surface temperature on the shelter and roof were iterated to be approximately $74^{\circ} \mathrm{C}$ and $37^{\circ} \mathrm{C}$, respectively. The total heat transfer through all surfaces with the modular heat roof was determined to be $7.5 \mathrm{~kW}$ with an energy cost of $\$ 6.00$ per day for each shelter.

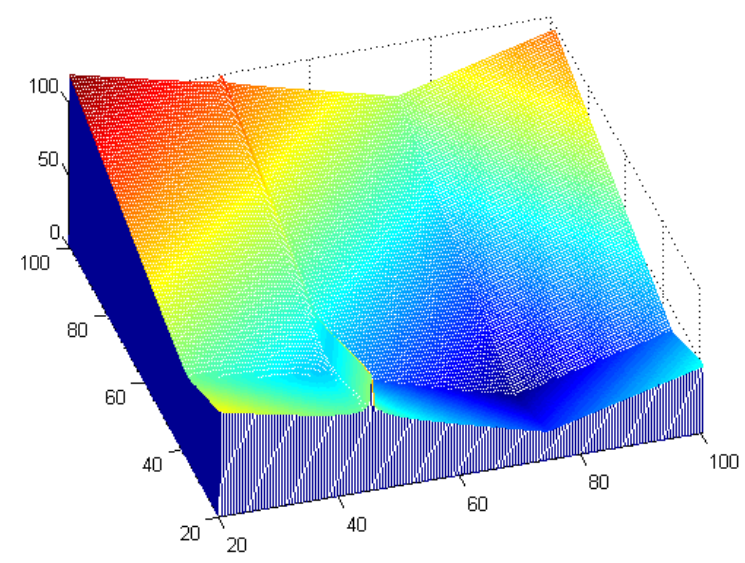

Figure 23 Temperature Error for Military Shelter with Modular Heat Roof

While this example is very simple and not representative of the actual environment these shelters will be subjected to, it is clear that a full design study will yield a range of values that reflect this assumed scenario. The MHR can reduce heating and cooling loads which in turn 
yields energy cost savings. The air gap is an effective insulator and allows the radiation transfer to decrease. Increasing the air gap is a cost effective method of controlling cooling costs. Although the temperature on the uppermost surface increased, the resulting surface temperature of the shelter dropped by $10^{\circ} \mathrm{C}$ and preliminary estimations can yield a total energy savings of $40 \%$ in the Middle East.

Additional research will be necessary to verify the current findings. A major component of the future research will be to verify the calculations with simulated conditions. Once the model is verified, a general heat roof design can be created for any shelter/container susceptible to high heat loads.

\subsection{Preliminary Analytic Model}

The results from the feasibility analysis indicated that an additional heat roof can reduce the heat flux into a structure, and as such a preliminary analytic model for residential buildings was developed in two stages. The first of which included an analytic model for an inclined heat roof, similar to a residential roof line. Secondly, to enhance the buoyancy effect created from the separated surfaces, a stack was added to the ridge.

There are several types of ceiling and roof configurations for residential homes. These include an interior cathedral ceiling, an occupied living space on the top floor with no attic space above and a conventional attic space that is not occupied. The third type of configuration, which is typical of the majority of residential and small business roof structures, was selected for this research. This configuration was evaluated using heat transfer and flow equations through the predictive analysis and then experimentally verified.

For an unfinished, unoccupied attic, the interior of the attic is generally constructed of lumber and does not have insulation on the interior of the walls leading up the ridge vent. On the other hand, insulation is normally installed in between the ceiling joists. In addition, the roof normally contains vented soffits on either side or all the way around to allow natural convection and air flow up toward the ridge vent. A conventional pitched roof with this type of configuration is depicted in Figure 24 where the air flow follows the interior roof line from the soffit located at the bottom to the ridge vent located at the peak of the roof. 


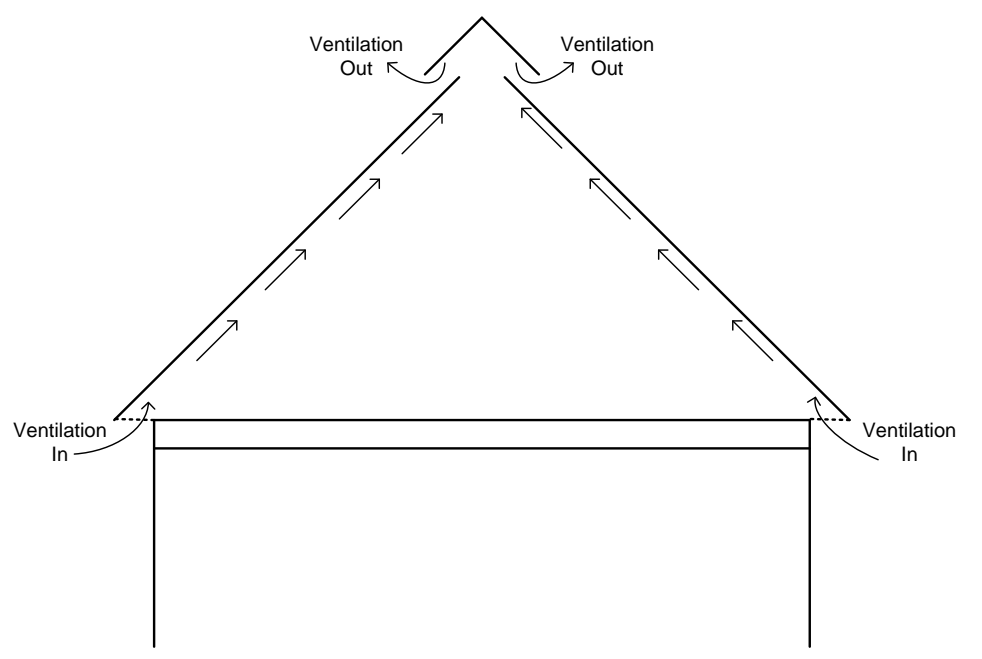

Figure 24 Convective Currents for a Conventional Pitched Roof

A study was performed to analyze the addition of a thermal management system to the exterior of the configuration described previously. This system exploits the buoyancy force created between the upper surface of the existing roof and the bottom surface of the add-on roof system. Convective currents will naturally form and air will flow upward towards the top of the roof and vent through the ridge area. Figure 25 shows the expected convective air currents after the add-on roof feature is installed over a conventional vented roof.

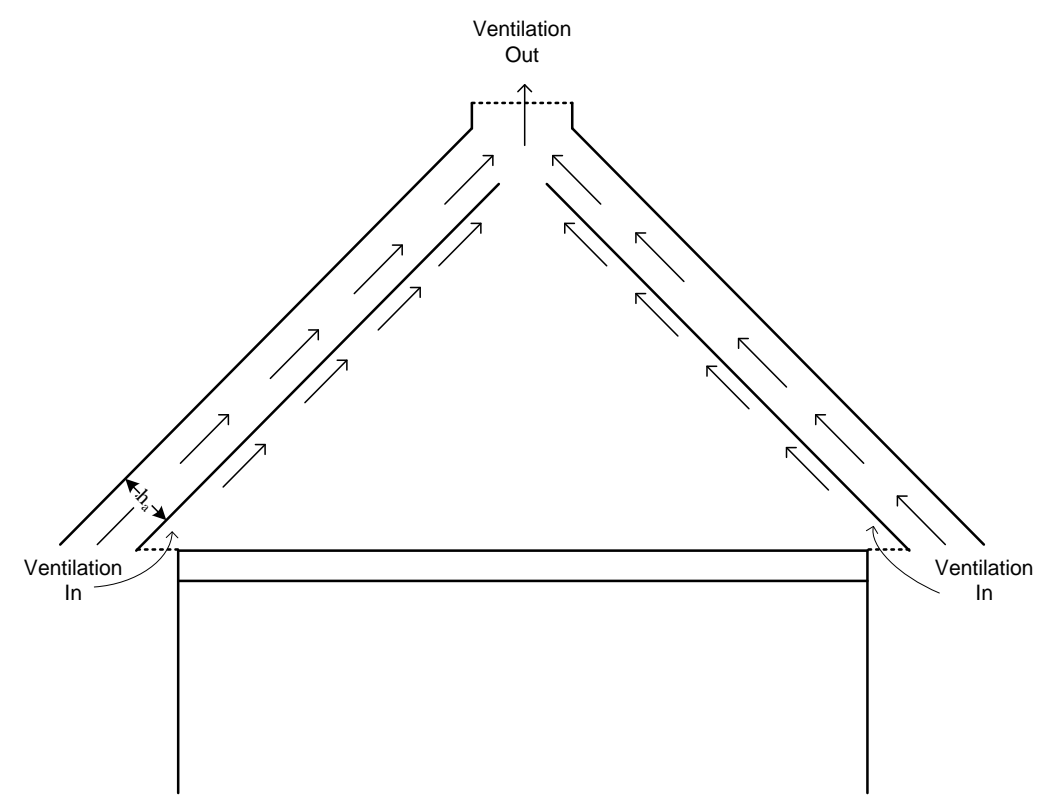

\section{Figure 25 Convective Currents for a Conventional Pitched Roof with Add-on Roof Feature}

The add-on roof system will provide shading, as well as an additional insulation layer to a residential home. The air gap created between the add-on roof and the residential roof will 
provide additional insulation to the home and add cooling via natural convection. This combination of thermal resistances provides the necessary conditions to lower the residential roof temperature by removing radiant heat through natural convection, which in turn will lower the temperature in the attic and hence lower the cooling energy requirements during summertime.

During the warmer months, as the sun radiates heat onto a roof, the roof's shingles or tile become very hot. This heat is transferred through the roof via conduction and in turn heats up the air inside the attic. If the insulation covering the ceiling does not effectively resist this heat, then the interior ceiling will become increasingly warm. Even with the recommended insulation, the heat in the attic on bright sunny days may encourage this heat buildup to transfer through the living space.

Heat is also conducted through the ceilings, walls and floors of homes. Effective insulation slows conduction by keeping the heat out. In addition, natural convection occurs on the inside and outside layers of the roof and throughout the structure. Convective heat loss also occurs through cracks and holes in the home through gaps and voids in the ceilings, walls, floors and insulation, as shown in Figure 26.

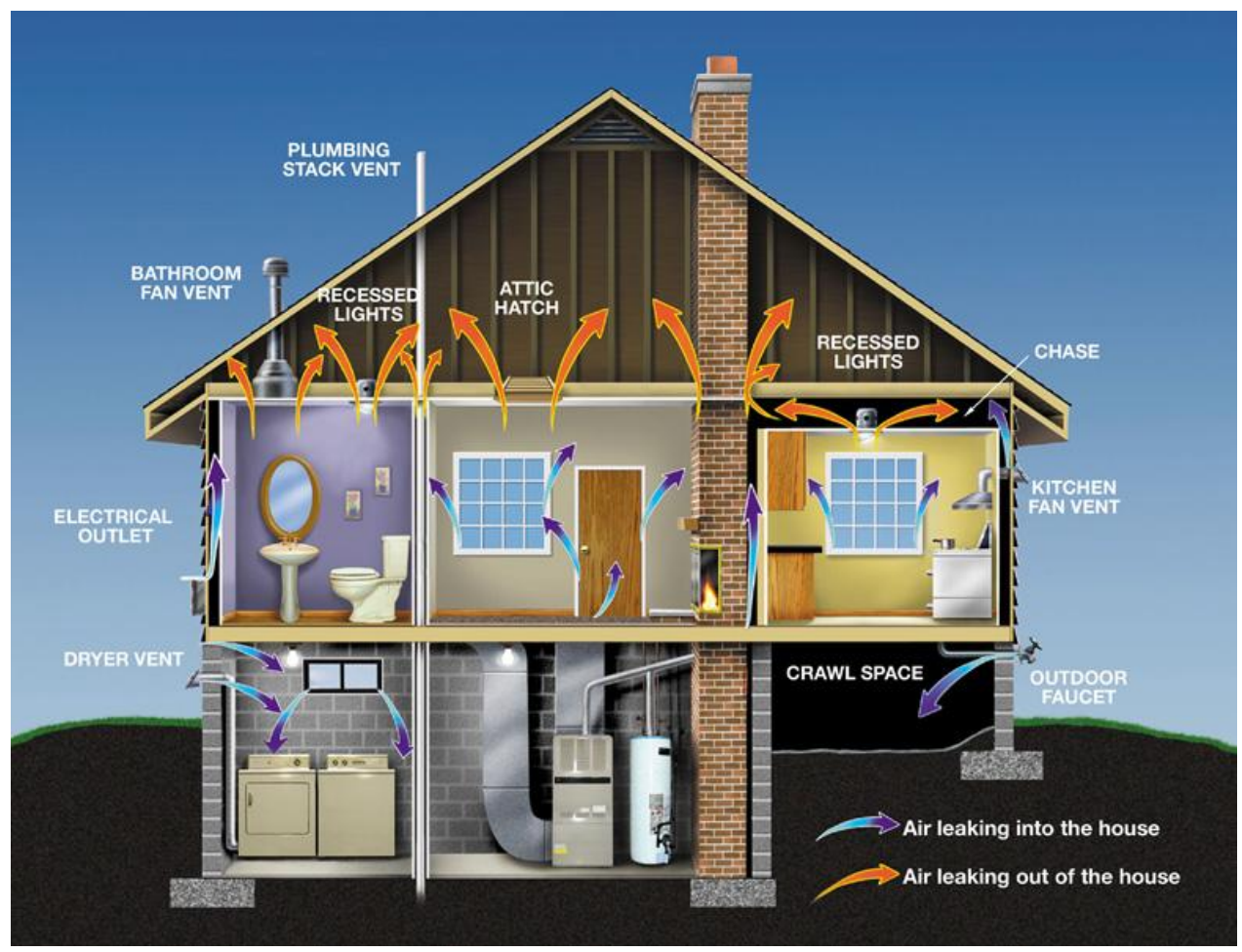

Figure 26 Common Locations for Convective Heat Loss in a Typical Home (Energy Star New Homes 2008) 
By removing or reducing the hot air within the attic, the process of heat transfer into the home is minimized. The less attic heat that is transferred into the home, the less an airconditioner will need to work resulting in energy savings. Figure 27 shows the various heat transfer processes that occur within an attic. This preliminary model treats all of these phenomena through a system of heat balance equations at the interior and exterior surfaces of the ceiling, roof sections, and the ridge vent, as well as a heat balance on the air mass within the attic.

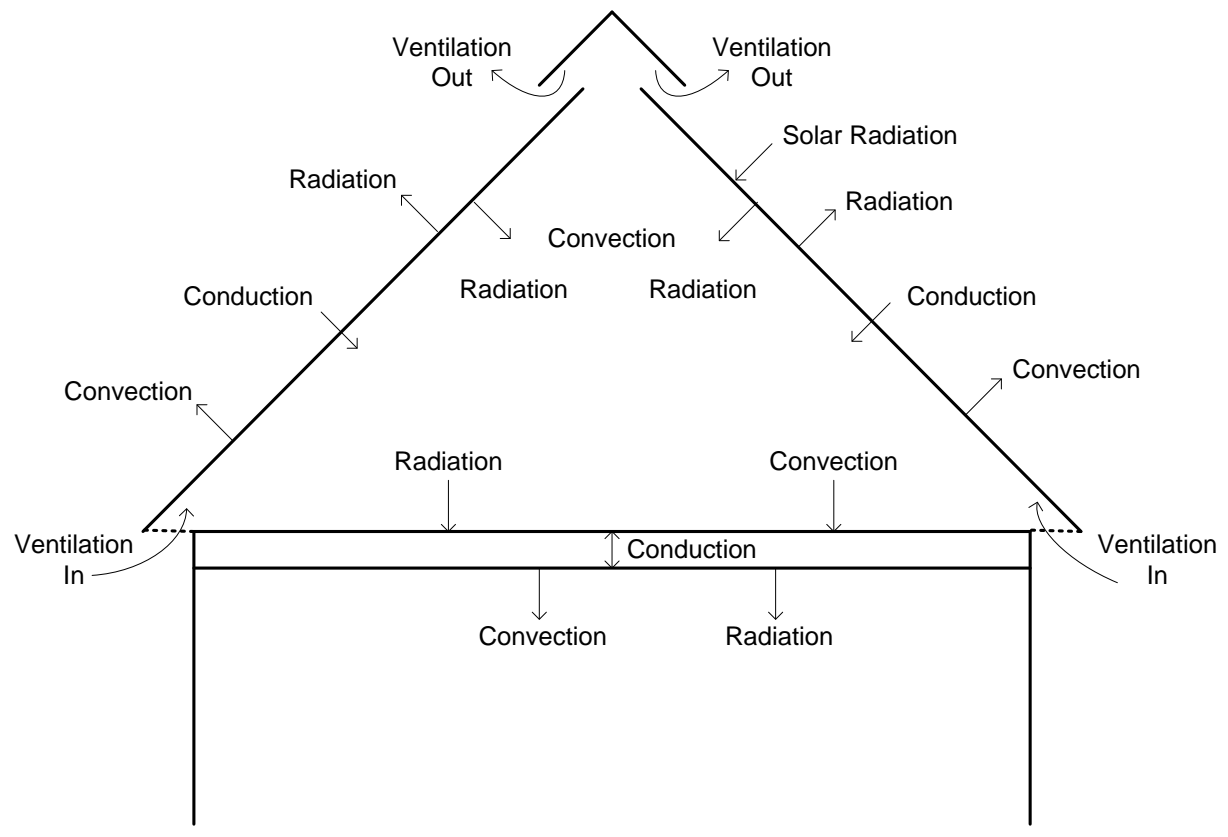

Figure 27 Heat Transfer Processes in a Residential Attic

The conduction heat transfer through the two roof sections and the ceiling surfaces was treated by an exact solution of the heat conduction equation for a one-dimensional heat flow through a multilayer slab and the temperatures were approximated to vary linearly. Convection heat transfer through the interior and exterior of the two roof sections and ceiling surfaces were calculated from the empirical relationships found in the literature (Çengel 2007, Bejan 2004). Several approximations are made in the treatment of the radiation within the attic. Each of the surfaces are assumed to be plane, gray and diffusely emitting and reflecting, as well as having a uniform radiant heat flux over the surface.

Figure 28 represents the electrical circuit analogy for each of the heat transfer modes described previously in Figure 27 for a conventional attic. Table 2 displays each element for Figure 28. This analogy was utilized to calculate the steady state heat loss through the ceiling 
and roof as a function of the outside surface temperature with the inside being maintained at the specified temperature. The result of this circuit determines the amount of heat flow through the roof and ceiling from the natural convection, conduction and radiation.

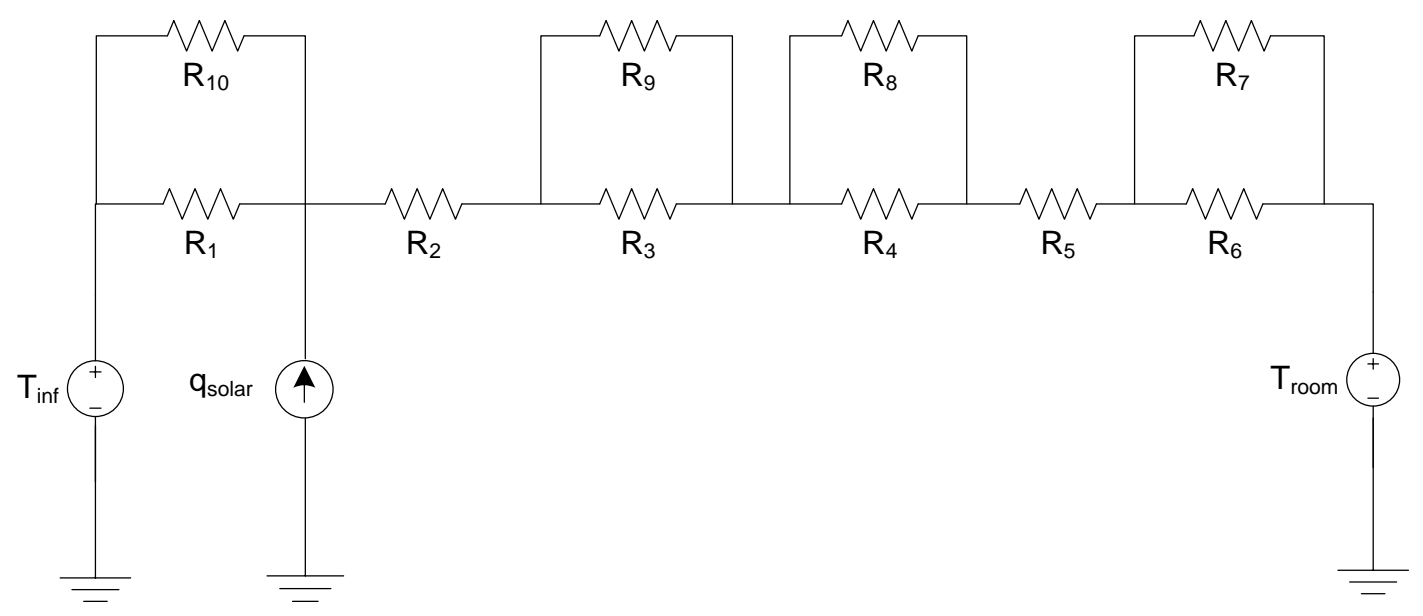

Figure 28 Electrical Schematic of Control Unit

Table 2 Thermal Resistance Elements

\begin{tabular}{|c|l|}
\hline Element & Description \\
\hline$R_{1}$ & Convection outside of shingled roof \\
\hline$R_{2}$ & Conduction through shingled roof \\
\hline$R_{3}$ & Convection inside of attic underneath shingled roof \\
\hline$R_{4}$ & Convection on attic floor \\
\hline$R_{5}$ & Conduction through ceiling \\
\hline$R_{6}$ & Convection on ceiling \\
\hline$R_{7}$ & Radiation on ceiling \\
\hline$R_{8}$ & Radiation on attic floor \\
\hline$R_{9}$ & Radiation inside of attic underneath shingled roof \\
\hline$R_{10}$ & Radiation outside of shingled roof \\
\hline
\end{tabular}

In addition, the thermal solar radiation, represented as a current source, is assumed to be a constant 550 langleys, as depicted in Figure 29 (White 1984) for the northern part of West Virginia. The average intensity of insolation in this area during the summertime months with 14 hours of sunlight results is approximately $450 \mathrm{~W} / \mathrm{m}^{2}$. 


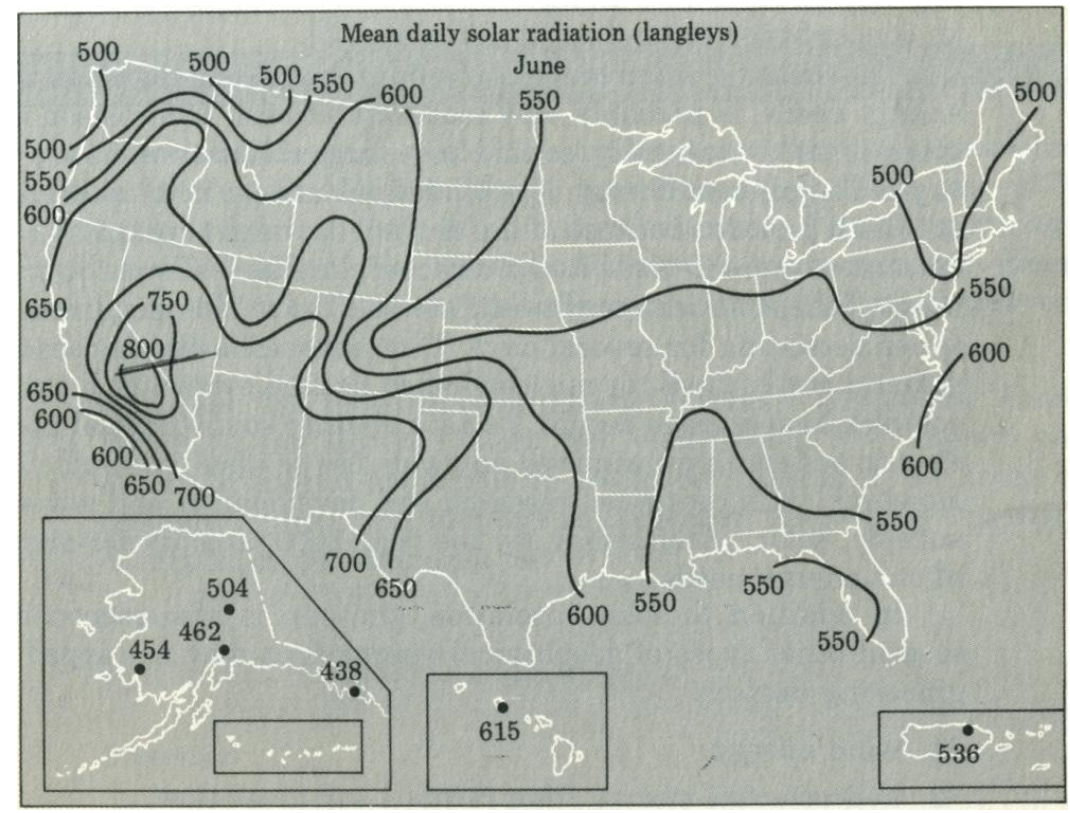

Figure 29 Average Measured Daily Insolation on a Horizontal Surface in the United States (White 1984)

The resistance for the conduction through the roof and ceiling were calculated from the Rvalues (Çengel 2005, ASHRAE 1997), as shown in Table 3. The total R-value for the roof and ceiling were $0.218 \mathrm{~m}^{2} \cdot{ }^{\circ} \mathrm{C} / \mathrm{W}$ and $0.09 \mathrm{~m}^{2} \cdot{ }^{\circ} \mathrm{C} / \mathrm{W}$, respectively. Each total R-value was divided by the surface areas to calculate the conduction thermal resistance for the roof and ceiling at 0.039 and $0.016^{\circ} \mathrm{C} / \mathrm{W}$, respectively.

Table 3 R-Values of Building and Insulating Materials (Çengel 2005, ASHRAE 1997)

\begin{tabular}{|l|c|}
\hline Material & R-Value $\left[\mathbf{m}^{2} \cdot{ }^{\circ} \mathbf{C} / \mathbf{W}\right]$ \\
\hline Drywall & 0.057 \\
\hline R-30 Insulation (ceiling) & 0.033 \\
\hline Plywood & 0.083 \\
\hline Asphalt Shingles & 0.077 \\
\hline Asphalt Roll Roofing & 0.026 \\
\hline
\end{tabular}

The convection thermal resistance at various locations was determined using Equation (53) with the surface area $A_{s}$ and heat transfer coefficient $h$. This coefficient was calculated using Equation (54) based on the flow characteristics of the fluid at the film temperature.

$$
R_{\text {conv }}=\frac{1}{A_{s} h}
$$




$$
h=\frac{k N u}{L_{c}}
$$

The thermal conductivity of air is represented by $k$ with the characteristic lengths of the respective surfaces. The Nusselt number $N u$ is calculated by Equation (55) to cover all Rayleigh numbers in the vertical or inclined orientation up to 60 degrees (Çengel 2005). As stated previously, this dimensionless number varies based on the orientation of the plate and the calculated Rayleigh number. The Rayleigh number and film temperature calculations were determined from Equation (48) and Equation (49), respectively.

$$
N u=\left(0.825+\frac{0.387 R a_{L}^{1 / 4}}{\left[1+(0.492 / \mathrm{Pr})^{9 / 16}\right]^{8 / 27}}\right)^{2}
$$

For this system, the ambient and room temperatures were held constant with all remaining temperatures left as unknown. Equation (56) calculates the temperature on the shingled roof surface $T_{1}$. However, since each resistance was a function of two temperatures, additional equations were necessary, as shown in Equation (57) to Equation (60). Each temperature description is shown in Table 4. Once the individual thermal resistances were evaluated, the temperatures at various locations were determined using an iterative process (see Appendix A).

$$
\begin{gathered}
T_{1}=\frac{T_{\infty} R_{\text {total }}+q_{s}\left(\frac{R_{1} R_{10}}{R_{1}+R_{10}}\right) R_{\text {total }}+T_{\text {room }}\left(\frac{R_{1} R_{10}}{R_{1}+R_{10}}\right)}{\left(\frac{R_{1} R_{10}}{R_{1}+R_{10}}\right)+R_{\text {total }}} \\
R_{\text {total }}=\left(R_{2}+\frac{R_{3} R_{9}}{R_{3}+R_{9}}+\frac{R_{8} R_{4}}{R_{8}+R_{4}}+R_{5}+\frac{R_{7} R_{6}}{R_{7}+R_{6}}\right) \\
\frac{T_{1}-T_{2}}{R_{2}}=\left(T_{2}-T_{3}\right)\left(\frac{R_{3}+R_{9}}{R_{3} R_{9}}\right) \\
\frac{T_{1}-T_{2}}{R_{2}}=\left(T_{3}-T_{4}\right)\left(\frac{R_{4}+R_{8}}{R_{4} R_{8}}\right) \\
\frac{T_{1}-T_{2}}{R_{2}}=\frac{T_{4}-T_{5}}{R_{5}} \\
\frac{T_{1}-T_{2}}{R_{2}}=\left(T_{5}-T_{\text {room }}\right)\left(\frac{R_{7} R_{6}}{R_{7}+R_{6}}\right)
\end{gathered}
$$




\section{Table 4 Temperature Location Descriptions}

\begin{tabular}{|c|l|}
\hline Element & Description \\
\hline $\mathrm{T}_{\text {inf }}$ & Ambient temperature $[\mathrm{K}]$ \\
\hline $\mathrm{T}_{1}$ & Shingled roof surface temperature $[\mathrm{K}]$ \\
\hline $\mathrm{T}_{2}$ & Attic temperature underneath shingled roof $[\mathrm{K}]$ \\
\hline $\mathrm{T}_{3}$ & Attic air temperature $[\mathrm{K}]$ \\
\hline $\mathrm{T}_{4}$ & Attic floor temperature $[\mathrm{K}]$ \\
\hline $\mathrm{T}_{5}$ & Ceiling temperature $[\mathrm{K}]$ \\
\hline $\mathrm{T}_{\text {room }}$ & Room temperature $[\mathrm{K}]$ \\
\hline
\end{tabular}

The ambient and room temperatures were held constant at $305 \mathrm{~K}$ and $295 \mathrm{~K}$, respectively. A constant solar heat flux of $450 \mathrm{~W} / \mathrm{m}^{2}$ due to solar radiation was used for the analysis. The radiation emissivities were $0.91,0.82$ and 0.67 for the shingled roof, attic wall and floor, and ceiling surfaces, respectively. After the iteration converged, this resulted in $346 \mathrm{~K}, 331 \mathrm{~K}, 323 \mathrm{~K}$, $314 \mathrm{~K}$, and $306 \mathrm{~K}$ for $\mathrm{T}_{1}, \mathrm{~T}_{2}, \mathrm{~T}_{3}, \mathrm{~T}_{4}$, and $\mathrm{T}_{5}$, respectively.

Figure 30 shows the heat transfer process for a typical home with the add-on roof feature which requires additional heat balances. Similar to the heat flow process mentioned previously, the solar radiation seeps through the add-on roof feature, radiates and convecs between the heat roof and shingled roof and then conducts through the construction materials with natural convection that will occur on both sides. Then the heat conducts through the construction materials of the existing roof and natural convection occurs on the inside of the attic. Lastly, the heat transfer conducts through the ceiling and then convecs and radiates into the building.

The natural convection and heat energy transport by the flow that occurs between the add-on roof feature and the existing roof is the key to this research. Not only will the add-on roof provide shading to the existing roof, it will also allow the air to heat up reducing its density which will promote the air movement to the crest of the roof. This air movement will extract the heat from outside of the existing roof which allows less heat flow to enter the attic. In turn, this will reduce the amount of heat entering the home and reduce the amount of energy required to maintain the home at a comfortable temperature. On a cold day, optional louvers placed at the bottom or the top could be closed to trap the air so it can act like an additional air gap insulator while still allowing for moisture removal. 


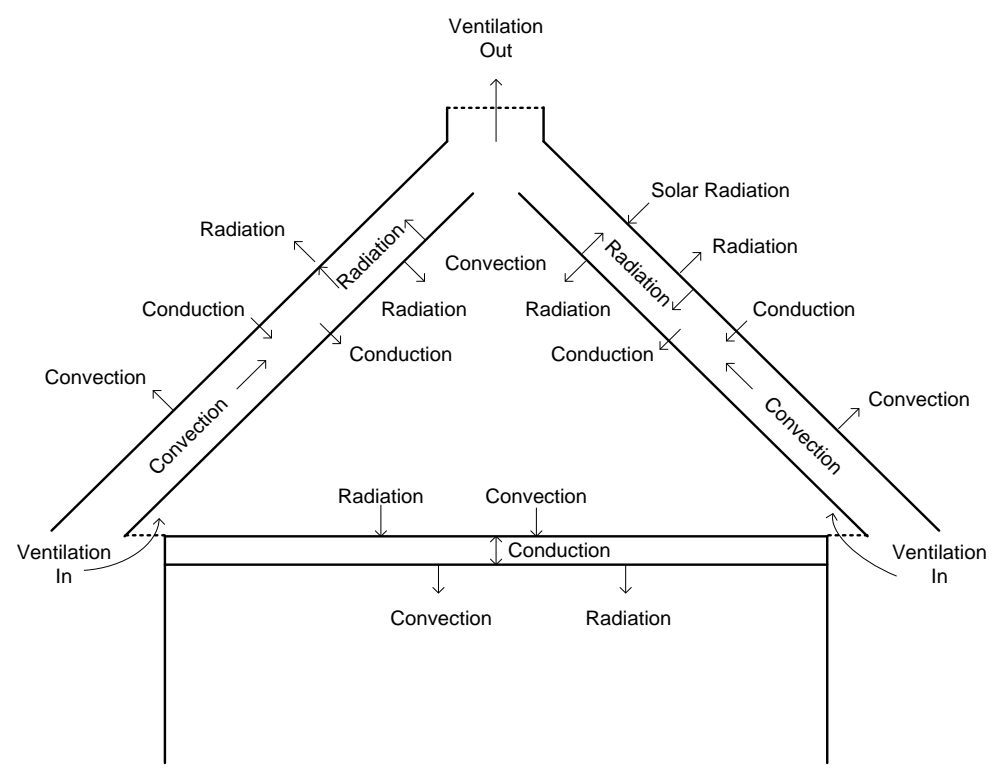

Figure 30 Heat Transfer Processes in a Residential Home with Add-On Roof Feature

The electrical circuit analogy for each of the heat transfer modes, depicted in Figure 30 with the add-on roof feature, is shown in Figure 31. This analogy was utilized to calculate the steady state heat loss through the ceiling and roof as a function of the outside surface temperature with the inside being maintained at the specified temperature. The result of this circuit will determine the amount of heat flow through the roof, ceiling and additional heat roof feature from natural convection, conduction and radiation.

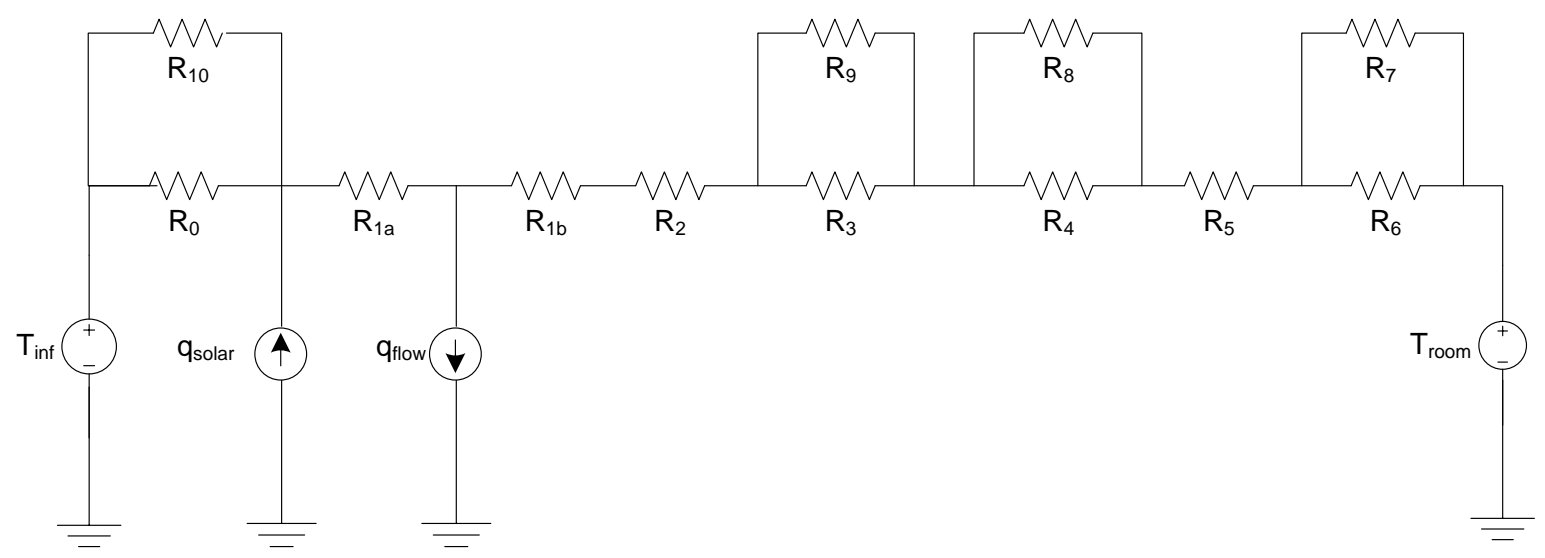

Figure 31 Electrical Schematic of Control Unit with Add-on

The addition of the heat roof increases the number of thermal resistances by two. The natural convection between the heat roof and shingled roof were added as $R_{1 a}$ and $R_{1 b}$. The heat flux from the solar radiation is now directed on this new surface instead of the shingled roof and the 
convective air flow is represented as a current source $q_{\text {flow }}$ in the opposing direction. As with the previous model, the ambient and room temperatures were held constant with all remaining temperatures unknown. Table 5 briefly describes each of the thermal resistant elements.

\section{Table 5 Thermal Resistance Elements}

\begin{tabular}{|c|l|}
\hline Element & Description \\
\hline$R_{0}$ & Convection outside of heat roof \\
\hline$R_{1 \mathrm{a}}$ & Convection underneath heat roof \\
\hline $\mathrm{R}_{1 \mathrm{~b}}$ & Convection on top of shingled roof \\
\hline $\mathrm{R}_{2}$ & Conduction through shingled roof \\
\hline $\mathrm{R}_{3}$ & Convection inside of attic underneath shingled roof \\
\hline $\mathrm{R}_{4}$ & Convection on attic floor \\
\hline $\mathrm{R}_{5}$ & Conduction through ceiling \\
\hline $\mathrm{R}_{6}$ & Convection on ceiling \\
\hline $\mathrm{R}_{7}$ & Radiation on ceiling \\
\hline $\mathrm{R}_{8}$ & Radiation on attic floor \\
\hline $\mathrm{R}_{9}$ & Radiation inside of attic underneath shingled roof \\
\hline $\mathrm{R}_{10}$ & Radiation outside of heat roof \\
\hline
\end{tabular}

Equations (61) and (62) calculate the temperature on the heat roof surface $T_{0}$ and convective air $T_{\text {gas. }}$ Equations (63) to (70) are the equations necessary to solve all the temperatures and heat flow through the channel $q_{\text {flow }}$ which were solved through an iterative process.

$$
\begin{gathered}
\left(T_{\infty}-T_{0}\right)\left(\frac{R_{10}+R_{0}}{R_{0} R_{10}}\right)+q_{\text {solar }}+\frac{T_{\text {gas }}-T_{0}}{R_{1 a}}=0 \\
\frac{T_{\text {gas }}-T_{0}}{R_{1 a}}-q_{\text {flow }}+\frac{T_{\text {room }}-T_{\text {gas }}}{R_{\text {total }}}=0 \\
R_{\text {total }}=\left(\begin{array}{c}
\left.R_{1 b}+R_{2}+\frac{R_{3} R_{9}}{R_{3}+R_{9}}+\frac{R_{8} R_{4}}{R_{8}+R_{4}}+R_{5}+\frac{R_{7} R_{6}}{R_{7}+R_{6}}\right) \\
\frac{T_{1}-T_{2}}{R_{2}}=\frac{T_{g a s}-T_{1}}{R_{1 b}} \\
\frac{T_{1}-T_{2}}{R_{2}}=\left(T_{2}-T_{3}\right)\left(\frac{R_{3}+R_{9}}{R_{3} R_{9}}\right) \\
\frac{T_{1}-T_{2}}{R_{2}}=\left(T_{3}-T_{4}\right)\left(\frac{R_{4}+R_{8}}{R_{4} R_{8}}\right)
\end{array}\right.
\end{gathered}
$$




$$
\begin{gathered}
\frac{T_{1}-T_{2}}{R_{2}}=\frac{T_{4}-T_{5}}{R_{5}} \\
\frac{T_{1}-T_{2}}{R_{2}}=\left(T_{5}-T_{\text {room }}\right)\left(\frac{R_{7}+R_{6}}{R_{7} R_{6}}\right) \\
T_{\text {gas }}=\frac{T_{\infty}+T_{\text {out }}}{2} \\
q_{\text {flow }}=\rho_{\text {air }} A_{\text {channel }} C_{D} \sqrt{2 g h\left(\frac{T_{\text {out }}-T_{\infty}}{T_{\infty}}\right)} \\
q_{\text {flow }}=\frac{T_{o}-T_{\text {gas }}}{R_{1 a}}+\frac{T_{1}-T_{\text {gas }}}{R_{1 b}}
\end{gathered}
$$

Table 6 Temperature Location Descriptions

\begin{tabular}{|c|l|}
\hline Element & Description \\
\hline $\mathrm{T}_{\text {inf }}$ & Ambient temperature $[\mathrm{K}]$ \\
\hline $\mathrm{T}_{0}$ & Heat roof surface temperature $[\mathrm{K}]$ \\
\hline $\mathrm{T}_{\text {gas }}$ & Convective air temperature $[\mathrm{K}]$ \\
\hline $\mathrm{T}_{1}$ & Shingled roof surface temperature $[\mathrm{K}]$ \\
\hline $\mathrm{T}_{2}$ & Attic temperature underneath shingled roof $[\mathrm{K}]$ \\
\hline $\mathrm{T}_{3}$ & Attic air temperature $[\mathrm{K}]$ \\
\hline $\mathrm{T}_{4}$ & Attic floor temperature $[\mathrm{K}]$ \\
\hline $\mathrm{T}_{5}$ & Ceiling temperature $[\mathrm{K}]$ \\
\hline $\mathrm{T}_{\text {room }}$ & Room temperature $[\mathrm{K}]$ \\
\hline
\end{tabular}

The model with the addition of the heat roof was evaluated with the same constant ambient and room temperatures of $305 \mathrm{~K}$ and $295 \mathrm{~K}$, respectively, as well as a constant solar heat flux of $450 \mathrm{~W} / \mathrm{m}^{2}$. The radiation emissivities were $0.970 .91,0.82$ and 0.67 for the black heat roof, shingled roof, attic wall and floor, and ceiling surfaces, respectively. The convective air temperature between the heat roof and shingled roof was calculated as the average of the inlet ambient air and the exit temperatures. After the iteration converged, the temperatures of the heat roof surface, average convective and exit air were $338 \mathrm{~K}, 310 \mathrm{~K}$, and $315 \mathrm{~K}$, respectively. The convective buoyancy between the heat roof and shingled roof resulted in a flow rate of $0.72 \mathrm{~m} / \mathrm{s}$ and heat flow of $110 \mathrm{~W} / \mathrm{m}^{2}$. The remaining temperatures were $305 \mathrm{~K}, 303 \mathrm{~K}, 301 \mathrm{~K}, 299 \mathrm{~K}$, and $297 \mathrm{~K}$ for $\mathrm{T}_{1}, \mathrm{~T}_{2}, \mathrm{~T}_{3}, \mathrm{~T}_{4}$, and $\mathrm{T}_{5}$, respectively. 
The objective of the computational model was to predict the projected temperature differentials with the thermal management system design. The inputs to the computer model included several factors based upon the thermal theory presented previously. For the conduction, convection and radiation heat flows, the dimensions of the roof and material composition were required. The material composition included the R-values and temperatures located on either side of the material it conducts through. The outputs of the preliminary mathematical computer model include the inside temperature of the attic, the varying surface temperatures and mass flows. The resultant set of heat balance equations are a system of simultaneous nonlinear algebraic equations with the unknowns being the various surface and air temperatures. Since many of the coefficients in the equations depend upon the unknown temperatures, the system of equations was solved iteratively until they converged. The heat flows were calculated after the temperatures were determined.

The addition of the heat roof creates a convective air channel between the shingled roof and the heat roof. The preliminary analytic model showed that the convective air flow rate between these two surfaces will reduce the heat flow into the attic by approximately $25 \%$. In turn, the shingled roof surface, attic air, and interior ceiling surface temperatures were reduced by $41 \mathrm{~K}$, $22 \mathrm{~K}$, and $9 \mathrm{~K}$, respectively.

A stack was added to enhance the natural convective buoyancy effect occurring between the shingled roof and the heat roof feature, as shown in Figure 33. The critical components of this add-on system are the chimney height $h_{c}$, air gap height $h_{a}$ and chimney diameter $w_{c}$. If the height of air gap is too small, the convective air currents will not form and the gap will act as an air insulator. On the other hand, if the gap is too large, then the natural convective currents will form vortices and re-circulate and not allow air flow uniformly upwards towards the gap located at the top. Either scenario detracts from the chimney effect along the width of the roof. The presence of the chimney at the top of the roof is predicted to enhance the stack effect and provide a predictor for added roof height. 


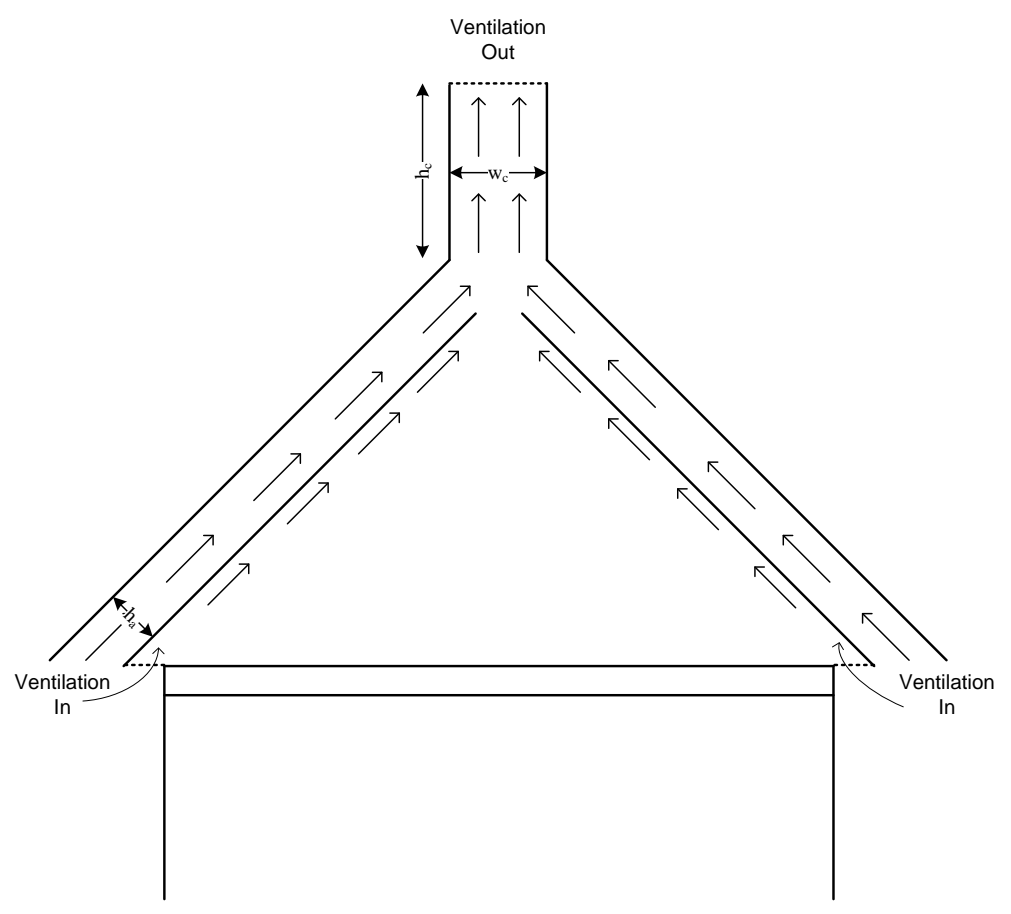

\section{Figure 32 Convective Currents for a Conventional Pitched Roof with Add-on Roof Feature and Stack}

In addition, the chimney dimensions are critical. If the chimney height is too short, then convective currents will not benefit from any additional buoyancy effects. If the chimney diameter is too small, it may also restrict the air flow rate, thereby increasing the conduction between the roofs and retarding any convection effects. In addition, the system should also be aesthetically pleasing to the eye, cost-effective to manufacture, durable enough for transportation, as well as be able to survive all types of weather and other environmental conditions. The relationship between all of these components is very important to the appeal and the performance of the add-on roof system.

An estimate of the air speed is made by dividing the ventilation volume flow rate by an average cross sectional area for the attic and for the flows over the interior surfaces. The rate of ventilation air flow is determined from a combination of stack and wind pressure effects. The ventilation rate was calculated from the vent area, discharge coefficient, and density induced pressure differential. The buoyancy effect was calculated using the outdoor temperature and the average temperature between the existing roof and add-on structure.

Prior to heat transfer to the air stream, the flow is assumed to enter the flow channel with the outdoor air temperature. It then flows along a path where it picks up heat by convection from 
each of the surfaces. From this, the exit air temperature is determined, as well as the average air temperature. The convective heat transfer due to the buoyancy flow was calculated using Equation (71) with the air mass flow rate and velocity as calculated from Equation (72) and Equation (73), respectively.

$$
\begin{gathered}
Q_{\text {conv }, \text { buoy }}=\dot{m} c_{p} \Delta T \\
\dot{m}=\rho A V \\
V=C_{D} \rho \sqrt{g L_{c} \frac{\Delta T}{T}}
\end{gathered}
$$

Figure 33 shows the calculated velocity as a function of the air temperature difference between the entrance and exit of the stack which corresponds to the ambient and exit air temperatures. Three different stack heights were incremented by two feet intervals for this research. As expected, with a small change in temperature, the corresponding air velocity is minimal. As the change in temperature increases, the air velocity also increases due to buoyancy effects. In addition, as the stack height and change in temperature both increase, the air flow velocity difference between each stack height also increases. As such, three stack heights were selected for the experimental testing.

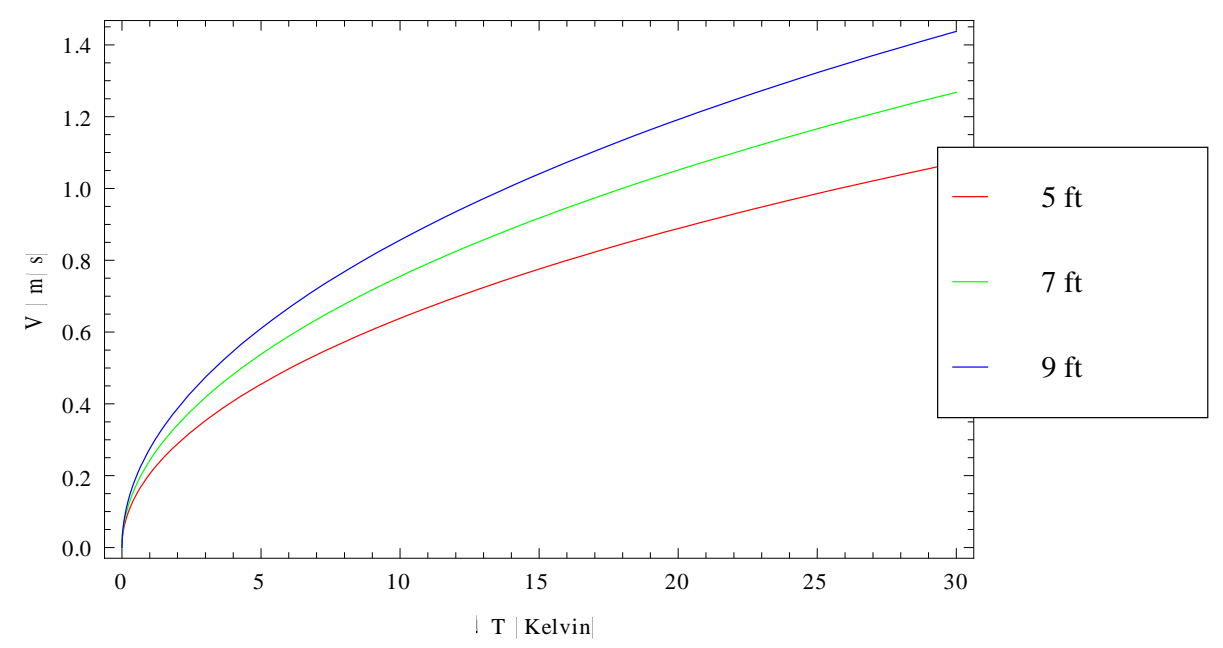

Figure 33 Predicted Air Velocity due to Buoyancy Effects 
Figure 34 illustrates air temperature difference between the inlet and outlet as a function of the net heat flux which is the solar heat flux less the convective losses on the outside of the additional roof. In steady state, the surface temperature of the existing roof will be no greater than the temperature of the air exiting the stack. Toward the inlet, the temperature will be lower. As an illustrative example, two different air gap heights were selected for the analytic model. The analysis shows that a small heat flux results in a low change in temperature. Conversely, as the change in temperature increases, the solar heat flux also increases. This predicts the temperature rise for a given net heat flux. As such, three stack heights were selected for the experimental research.

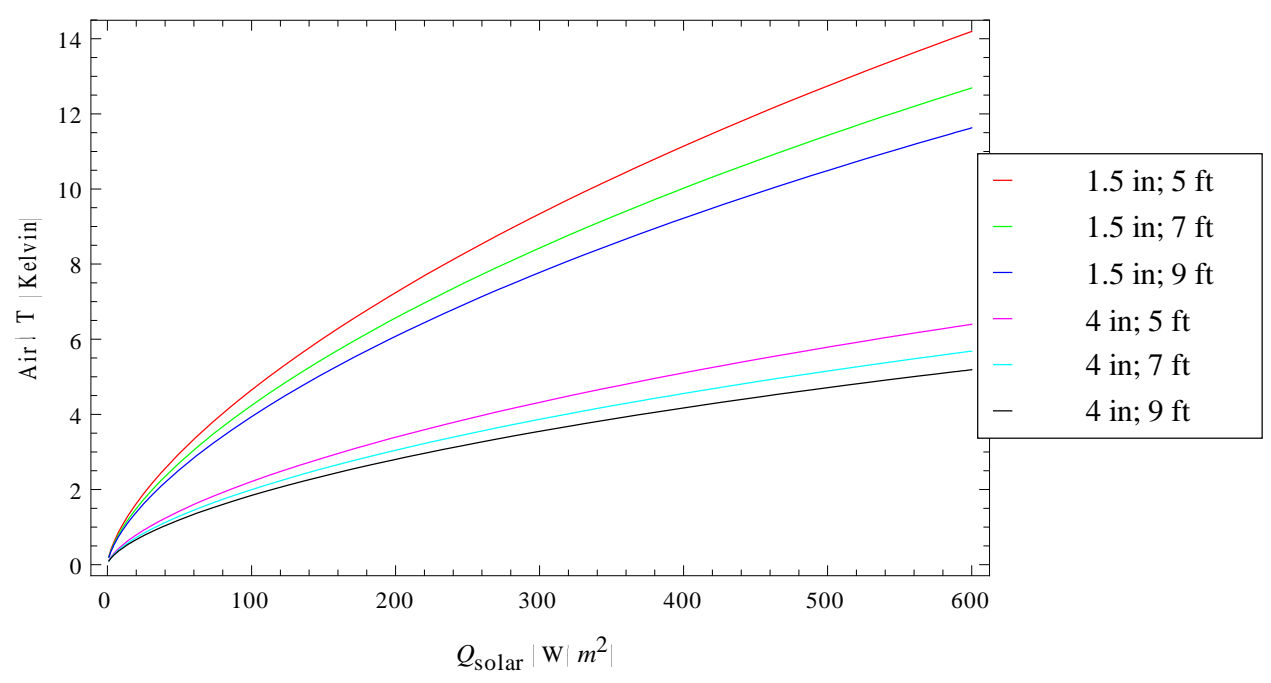

Figure 34 Predicted Results for Various Air Gap Heights

Figure 33 and Figure 34 are intended to be used in conjunction with one another. First, the net heat flux is calculated and then a temperature difference for selected air gap heights can be determined. The net heat flux is determined by the geographical location and the temperature difference can be used in Figure 33 to determine the corresponding velocity for selected air stack heights.

This preliminary analytic model was used to anticipate the results of this design. The equations presented were utilized to predict the results of the experimental units. For this research, a heat flux of $450 \mathrm{~W} / \mathrm{m}^{2}$ was selected for the Morgantown, WV area where the experimental units were tested (White 1984). Two air gap heights and three stack heights were 
selected for the experimental part of this research, as shown in Table 7, based upon the analytic model previously described.

Table 7 Matrix Configuration of Thermal Management System

\begin{tabular}{|c|c|}
\hline Air Gap Height [in] & Chimney Height (from ridge) [ft] \\
\hline 1.5 & 36 \\
\hline 1.5 & 60 \\
\hline 4 & 12 \\
\hline 4 & 36 \\
\hline 4 & 60 \\
\hline
\end{tabular}

\subsection{Experimental Validation}

Experimental verification plays an important role in evolving scientific endeavors and can produce evidence to confirm or refute theoretical concepts. However, the results of experimentation are subject to the conditions under which the experiment was performed and the constraints of the actual experimental design. To determine the validity of the mathematical model, a comparison between the mathematical model's predictions to the data measured on the experimental model was necessary as described in the preceding text.

Two units were constructed for experimental verification testing. The two units, one for control and the other as experimental, were equipped with sensors to monitor the thermal attributes inside and outside of each unit, as well as the air velocity inside the stack. The base construction of each unit is identical with the only difference being that second unit has the addon roof feature. The construction of each building, as well as the experimental testing setup, is described below.

The attic test module is a gabled attic built with roof pitch of 45 degrees. The frame of the unit is constructed out of two-by-six pieces of lumber, placed 16 inches on center, and covered on the outside with plywood sheets for rigidity and strength, as shown in Figure 35 and Figure 36. Tar paper was placed directly over the plywood sheets and $1 / 8$ inch thick asphalt shingles were layered on both sides of the roof. 


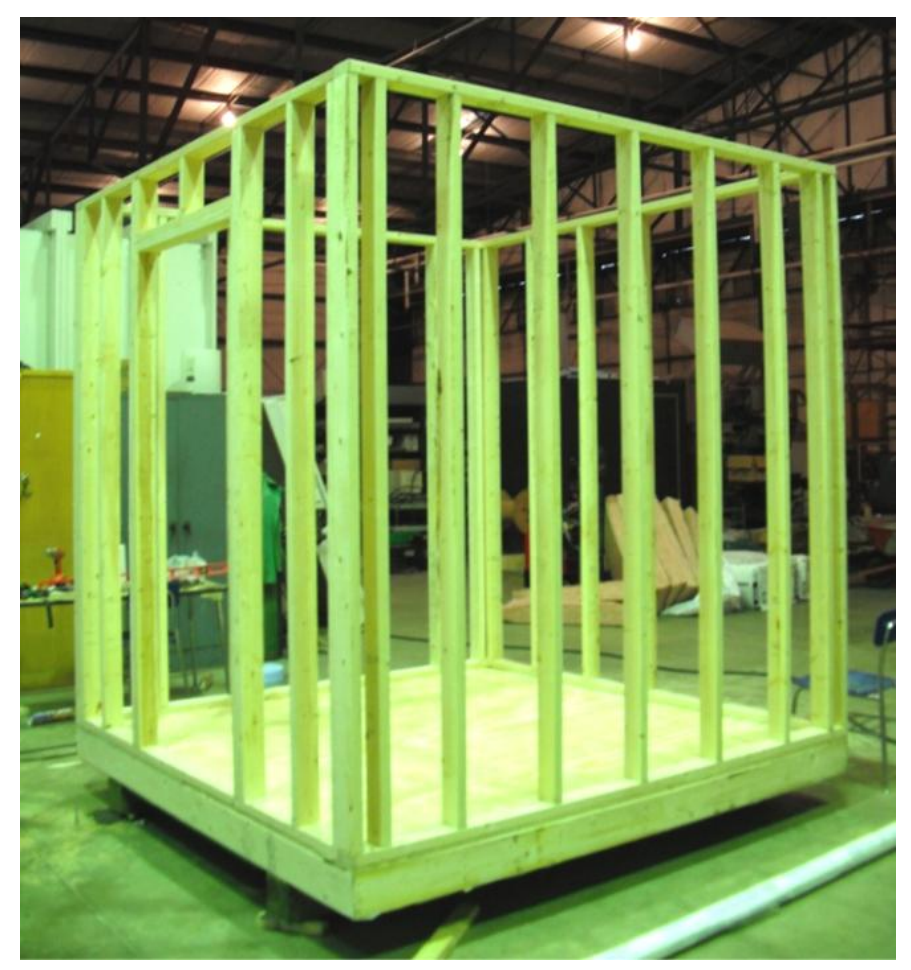

Figure 35 Framing of Experimental Unit

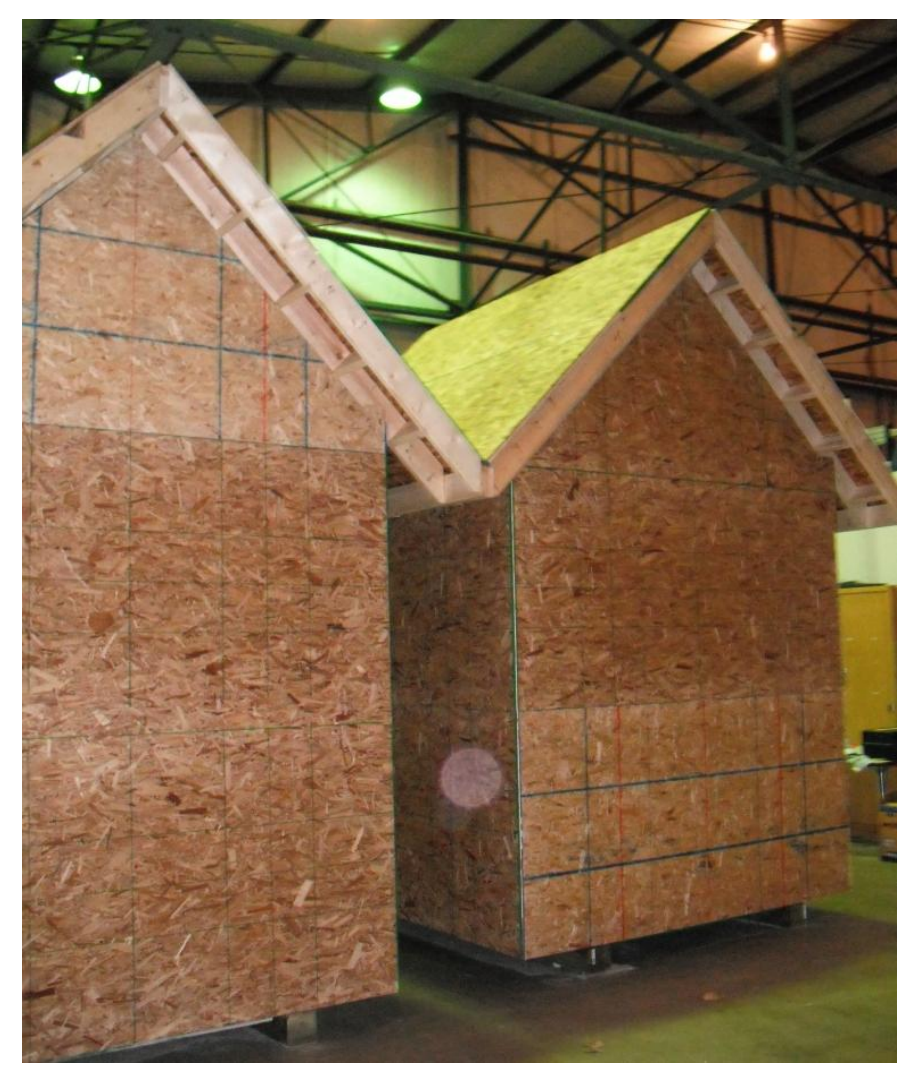

Figure 36 Both Experimental Units during Construction 
In addition, the roof has an overhang located on both sides to create a 12 inch soffit vent and a gable on the front side of each building. The soffit vent was constructed of one porous vent located in the middle with a solid piece on either side with the same pattern to the ends of the overhang, as shown in Figure 37.

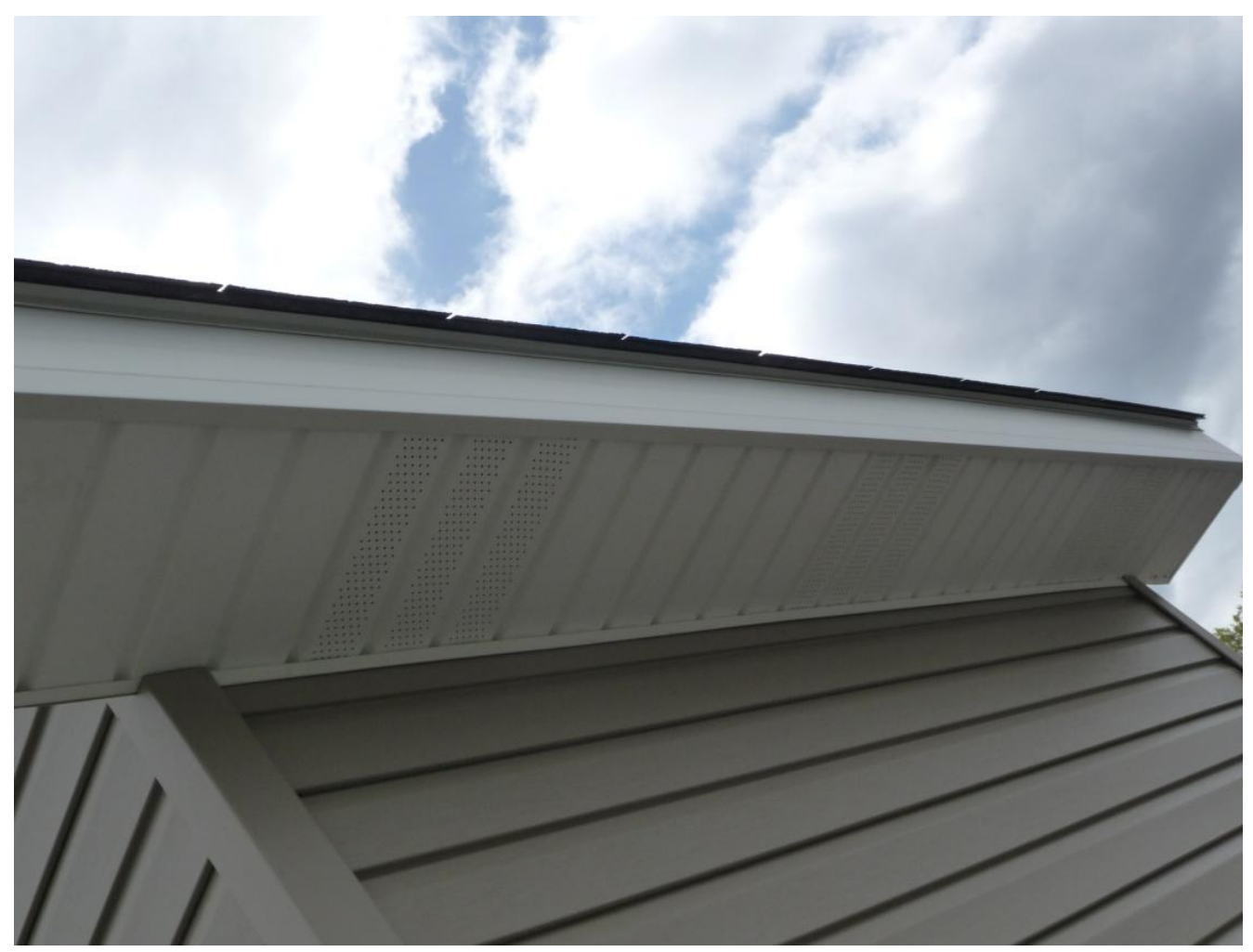

Figure 37 Soffit Construction for Experimental Units

The exterior of the building has standard tan vinyl siding, thin ( $2 \mathrm{~mm}$ thick), installed over the house wrap which was attached directly against the plywood. Typical R-13 fiberglass home insulation was installed in between each of the two-by-four studs with drywall installed in the interior of the unit. A layer of thin plastic was placed over the insulation to create a vapor barrier. The interior ceiling consisted of R-30 insulation between the two-by-six ceiling joists and drywall, as shown in Figure 38. Both the ceiling and each wall was painted white to maintain a steady temperature inside of each building. The interior floor was constructed in a similar fashion as the exterior walls without vinyl siding on the exterior. 


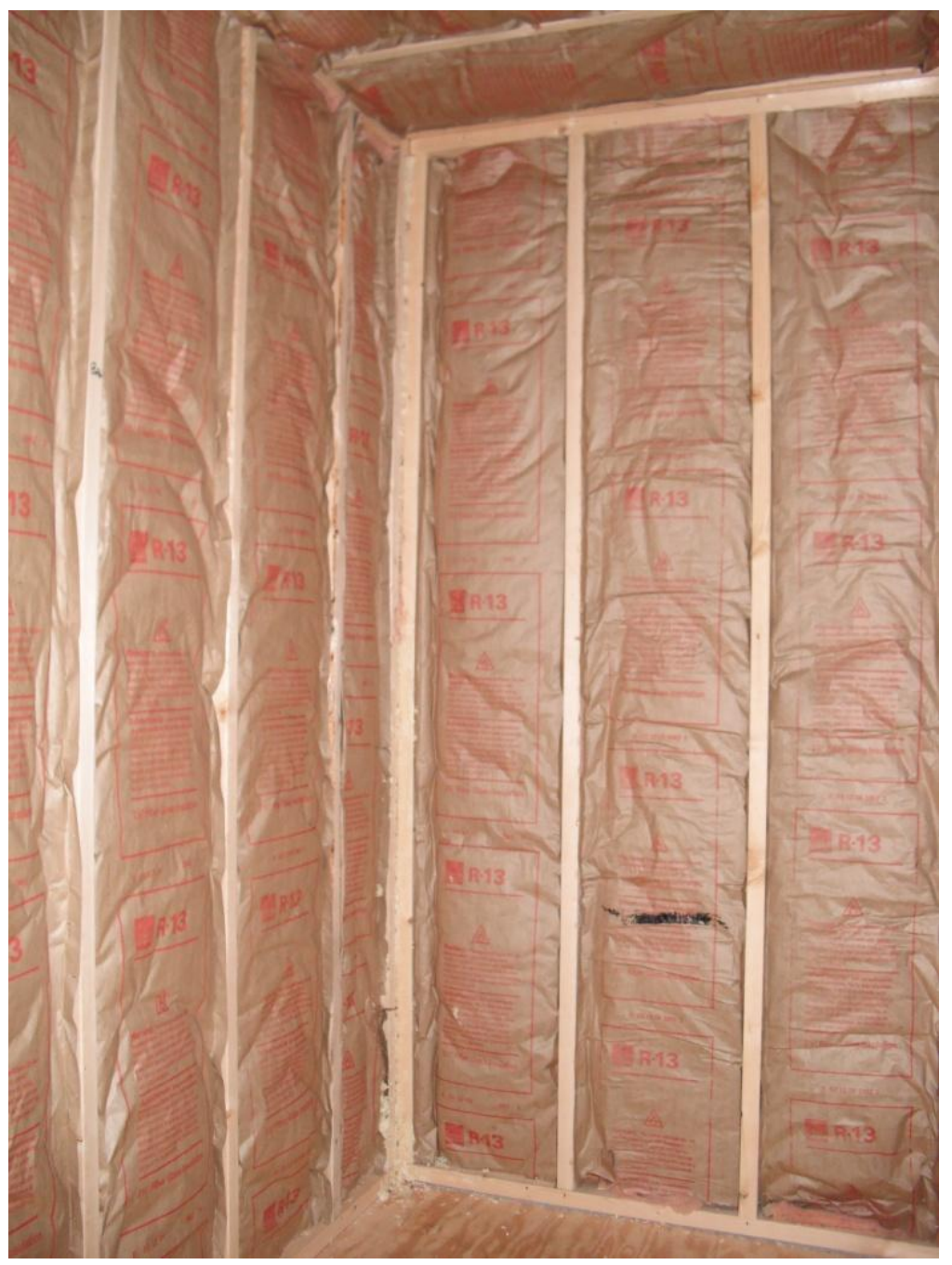

Figure 38 Installation of the Interior Insulation of Experimental Units

A $7 \mathrm{ft}$ steel exterior door was installed on the front side of each building to mimic the effect of typical building openings. In addition, a hexagon-shaped gable was installed directly over the exterior door to allow access to the attic area, as shown in Figure 39. During testing, the exterior door was closed and the gable was sealed shut. In order to analyze the impact of the convective heat roof and to keep the influence of the roof between experimental and control the same, the ridge vent was excluded in this research. 


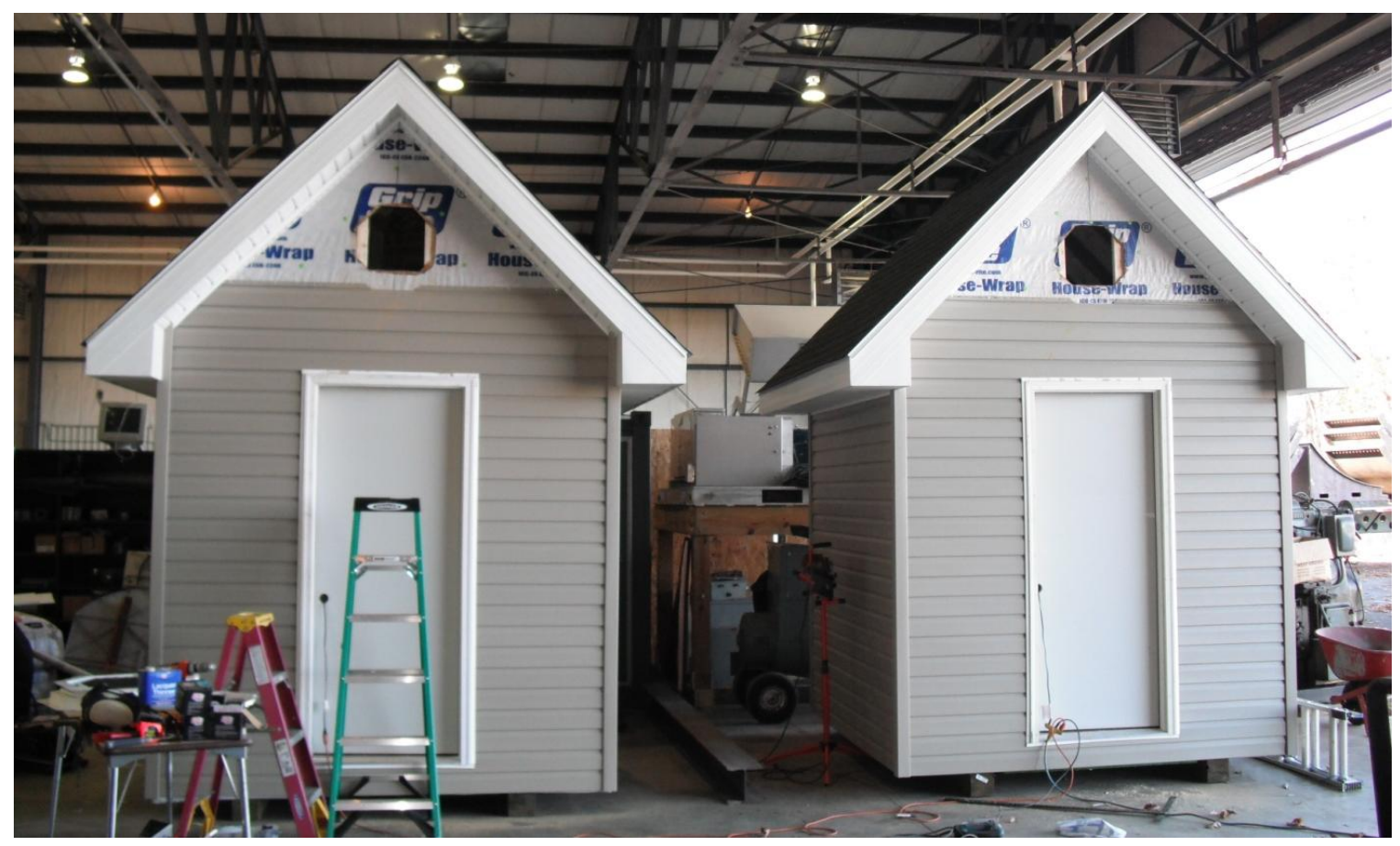

Figure 39 Exterior of Experimental Units

Holes were drilled through the ceiling to the attic, as well as out the rear side of the building near the ridge for the wiring of each sensor. In addition, one hole was drilled in the back corner of the floor for the power cord and Ethernet cable, with lengths of approximately 200 feet and 100 feet, respectively. Each hole was plugged with insulation to be consistent with the remainder of the ceiling and floor construction.

The add-on roof feature was constructed out of 0.04 inch aluminum and 12 inch diameter stove pipe for the chimney. The roof was divided into three main parts: trough located at the peak and the two panels on each side. The trough frame was constructed out of aluminum square tubing and overlaid with aluminum sheets. Two 12 inch diameter holes were cut in the trough 30 inches from the edge to the center of the each stack with 1 inch on either side from the edge, as shown in Figure 40. The chimney base consisted of a 4 inch height and 12 inch diameter aluminum stove pipe. The stack height was increased with 2 feet sections of additional aluminum stove pipe. A 6 inch $\times 50$ inch slot was removed from the trough on either side to allow the airflow from between the roofs to flow into the trough, as shown in Figure 41. The opposing side was secured to the existing roof and sealed to not allow air to escape from trough, as shown in Figure 29. 


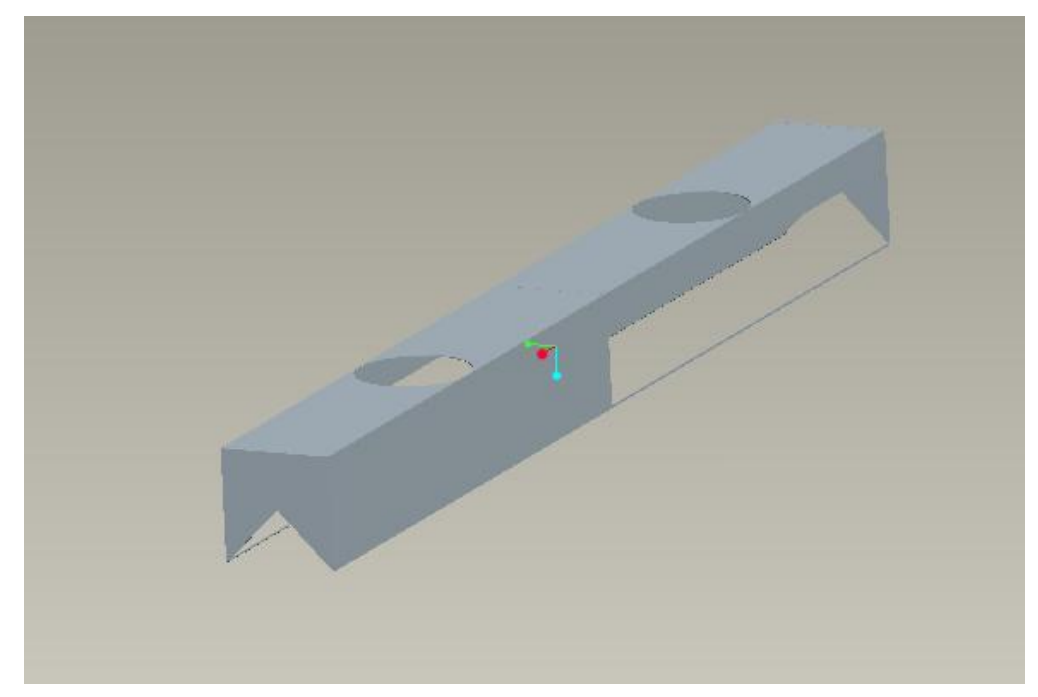

Figure 40 Construction of Trough

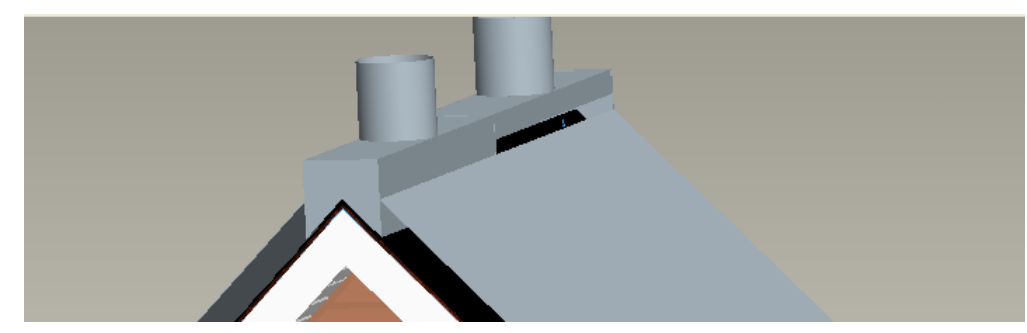

Figure 41 Construction of Trough with Chimneys

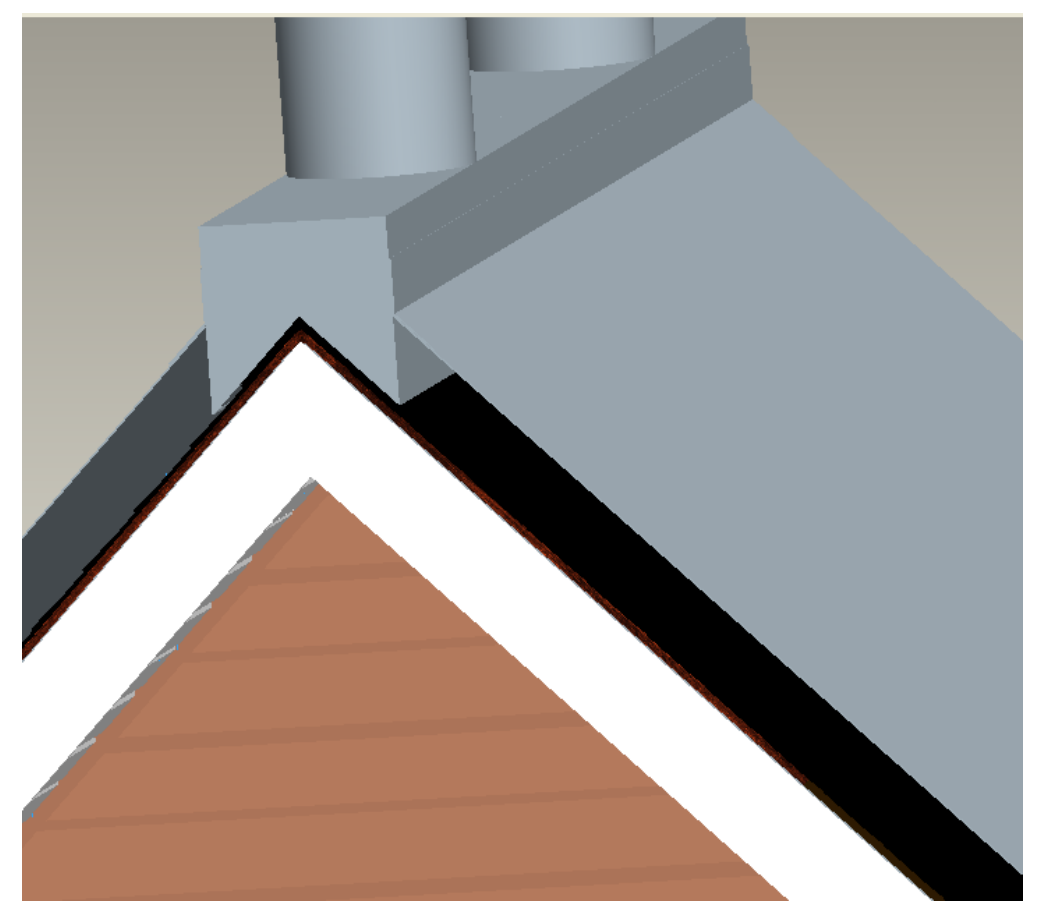

Figure 42 Experimental Roof Sealing 
The add-on roof was constructed in two halves, one for each side of the existing roof to analyze the effects from each side of the roof with a split trough along the ridge. In addition, the sides of the add-on structure were sealed with accordion gaskets and angle iron to mimic duct flow. The entire add-on roof system was black on the outside and white on the underside, except for the stack. The color difference enhances the natural convection effect. The roof was attached at various locations on top of the existing roof where it would not interfere with the natural convention flow in the channel, as desired in this research. The final drawing is depicted in Figure 43.

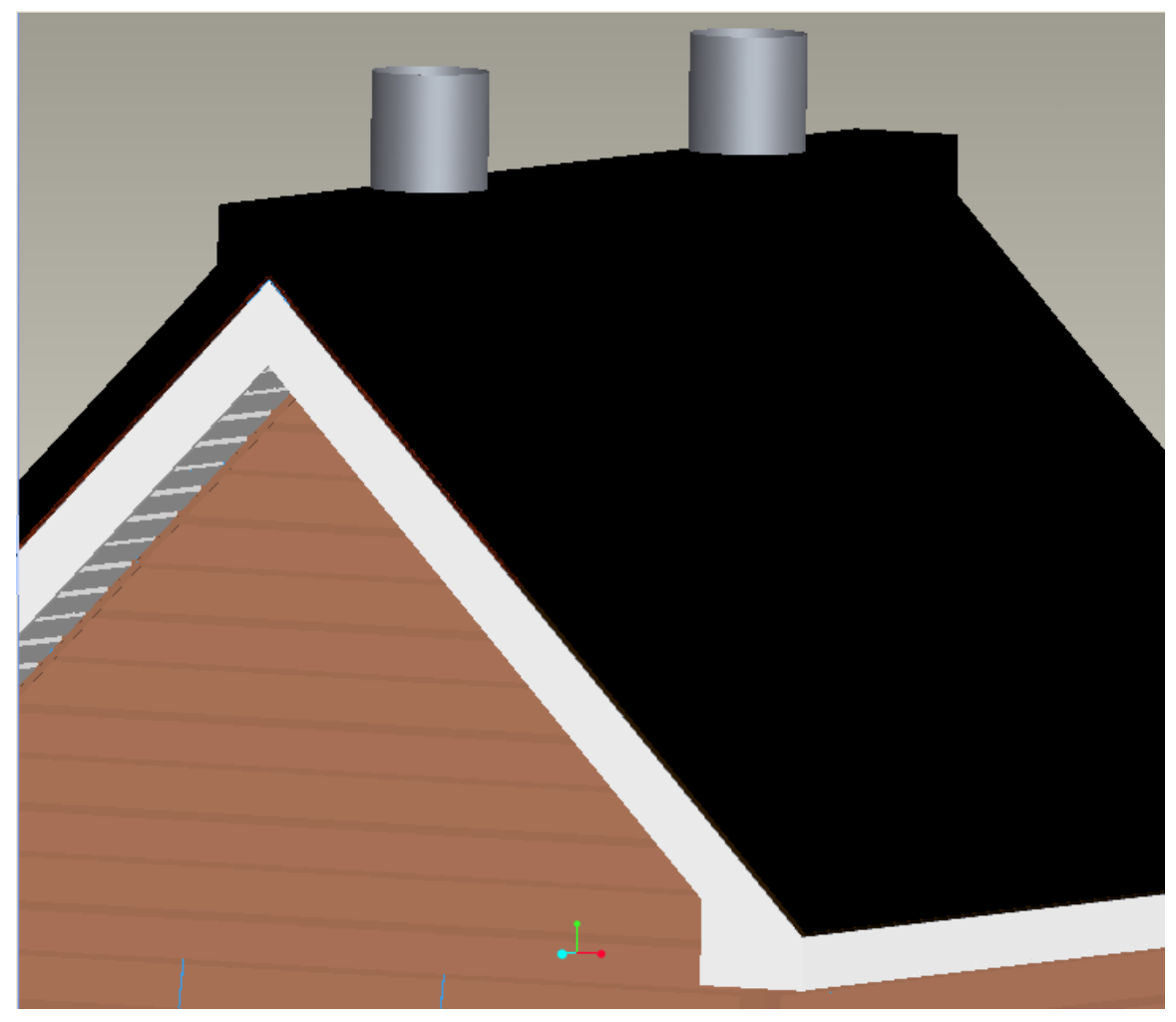

Figure 43 Computer Aided Drawing of External Roof Structure

The construction materials for the both the experimental and control units were chosen to represent a typical home. The dimensions of each building were selected to be a smaller scaled version of a typical home, as shown in Table 8 . The interior of each building is an 8 cubic feet with a 45 degree pitched roof. The exterior roof dimensions were 10 feet long with approximately 6 feet to the ridge on each side, as shown in Figure 44 . 
Table 8 Building Materials for Experimental and Control Units

\begin{tabular}{|c|c|c|}
\hline Material & Nominal Size & Actual Size \\
\hline Drywall & $1 / 2$ in thickness, $8 \mathrm{ft} \times 4 \mathrm{ft}$ sheets & $8 \mathrm{ft} \times 4 \mathrm{ft}$ \\
\hline Wall Studs $(2 \times 4)$ & 2 in $x 4$ in $x 925 / 8 \mathrm{ft}$ & 1.5 in $x 3.5$ in \\
\hline Floor Joists $(2 \times 6)$ & 2 in $x 6$ in $x 8 \mathrm{ft}$ & 1.5 in $x 5.5$ in \\
\hline R-30 Insulation & Rolls & 15 in width \\
\hline R-13 Insulation & Rolls & 15 in width \\
\hline Housewrap & Rolls & $9 \mathrm{ft} \times 150 \mathrm{ft}$ \\
\hline Plywood & 0.75 in thick, $8 \mathrm{ft} \times 4 \mathrm{ft}$ sheets & 0.75 in $x 4 \mathrm{ft} \times 8 \mathrm{ft}$ \\
\hline Asphalt Shingles & $1 / 8$ in thickness, 36 in $\times 12$ in & 13.25 in $x 38.75$ in \\
\hline Tar Paper & \#15 Rolls & 36 in $x 144$ in \\
\hline Oriented Strand Board (OSB) & 0.625 in $\times 4 \mathrm{ft} \times 8 \mathrm{ft}$ & 0.625 in $x 4 \mathrm{ft} \times 8 \mathrm{ft}$ \\
\hline Door & 30 in Steel & 31 in $x 79$ in \\
\hline Vinyl Siding & D4 Dutch-Lap & 8 in $x 150$ in \\
\hline Soffit (porous) & 12 in $x 12 \mathrm{ft}$ & 12.1 in $\times 144$ in \\
\hline Soffit (solid) & 12 in $\mathrm{x} 12 \mathrm{ft}$ & 12.1 in $x 144$ in \\
\hline
\end{tabular}

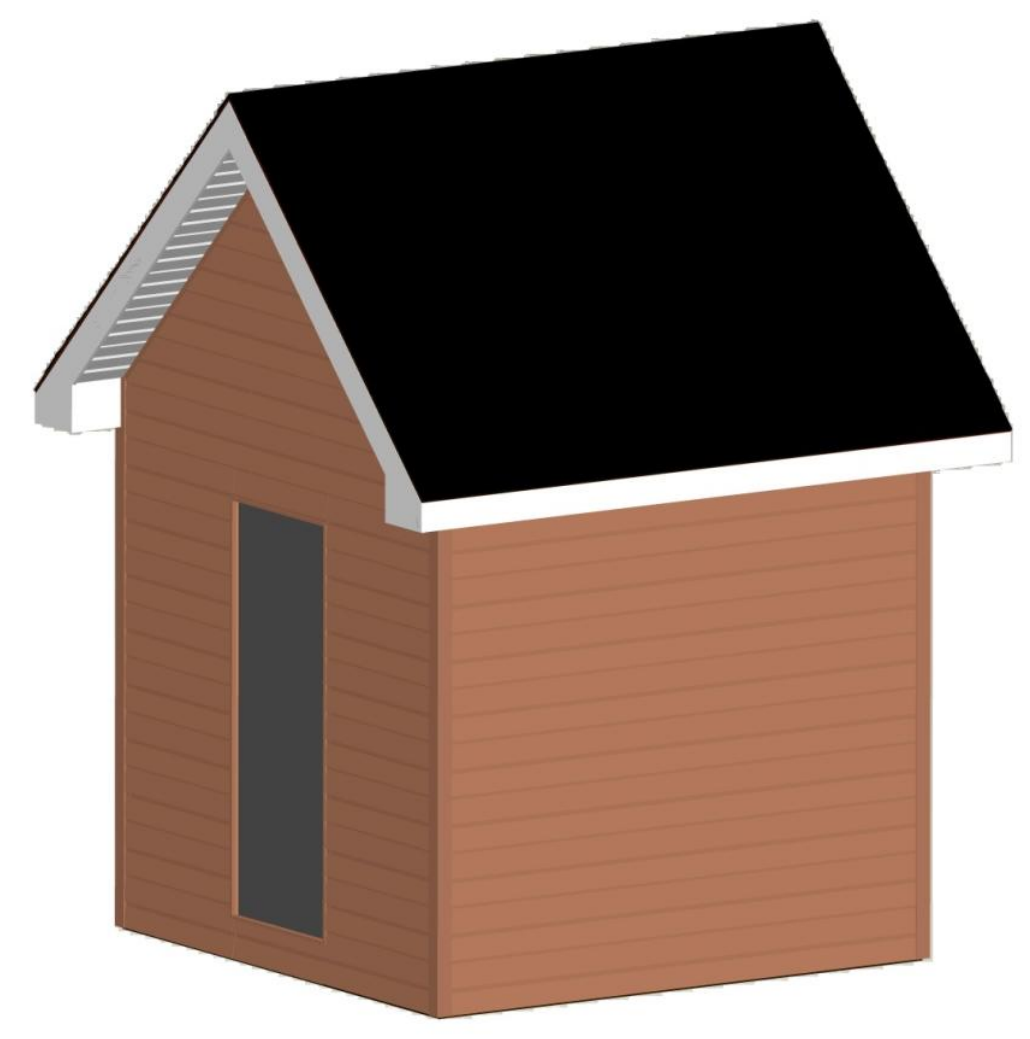

Figure 44 Computer Aided Drawing of Experimental Control Unit

Environmental monitoring was used to determine which method provided the best protection against temperature elevation caused by exposure to solar radiation. This was accomplished by 
using two data loggers, 44 resistance temperature detectors, one air speed transmitters, and downloading the weather for the Morgantown airport.

Test data collection was performed using two data loggers setup to monitor 15 and 29 temperature sensors for the 500 and 800 data units, respectively. Temperature sensors were placed in identical positions on each test unit to minimize the effects that varying the probe position could have on the test data. The test points for each unit are located twelve inches from the ridge (top), twelve inches from the attic floor (bottom), and in the middle of the top and bottom sensors $(\sim 30$ inches from ridge) on both the exterior and interior of each roof surface. Each sensor was encased with a flame retardant, thermal urethane, as depicted in Figure 45. Table 9 displays the properties of the thermal urethane applied with a 4:1 mixing nozzle used in this research. Every exposed lead was also covered with this thermal urethane to negate radiation effects.
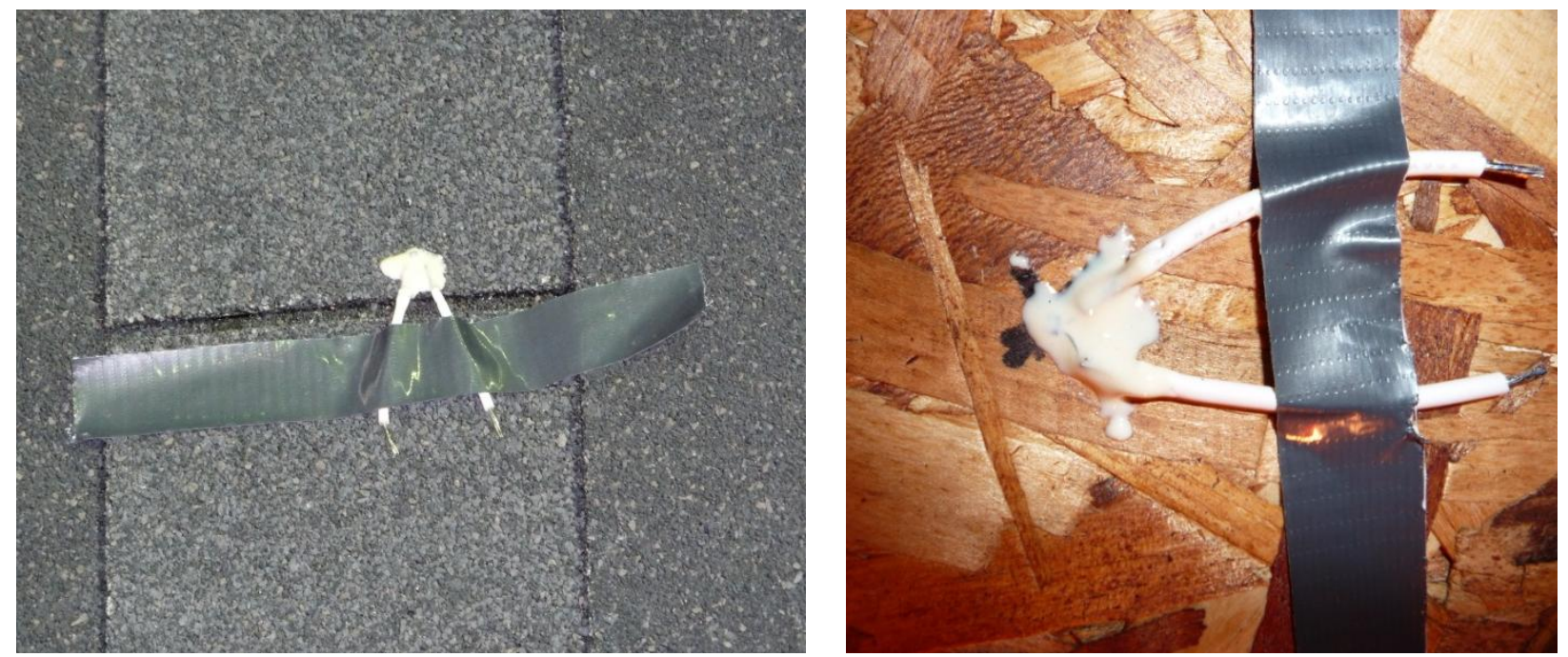

Figure 45 Resistance Temperature Detector Secured with Thermal Urethane

Table 9 Thermal Urethane Properties

\begin{tabular}{|c|c|}
\hline Loctite $\AA$ Brand & Hysol® \\
\hline Loctite $\AA$ Product Number & US2650 \\
\hline Package Size & $1.69 \mathrm{oz}(50 \mathrm{ml})$ dual cartridge \\
\hline Color & Tan \\
\hline Temperature Range & $-85^{\circ} \mathrm{F}$ to $+257^{\circ} \mathrm{F}$ \\
\hline Begins to Harden & $5-10 \min$ \\
\hline Reaches Full Strength & 16 hours \\
\hline Thermal Conductivity & $0.47 \mathrm{~W} / \mathrm{m} \cdot \mathrm{K}$ \\
\hline
\end{tabular}


In addition, one resistance temperature detector (RTD) sensor is placed vertically twelve inches from the ridge to measure the temperature of the attic air. Two temperature sensors were placed inside of each unit. One RTD was mounted directly on the center of the ceiling and the other was placed twelve inches vertically down from the center of the ceiling, as shown in Figure 46 and Figure 47. A total of 16 and 27 temperature sensors were installed in the control and experimental units, respectively.

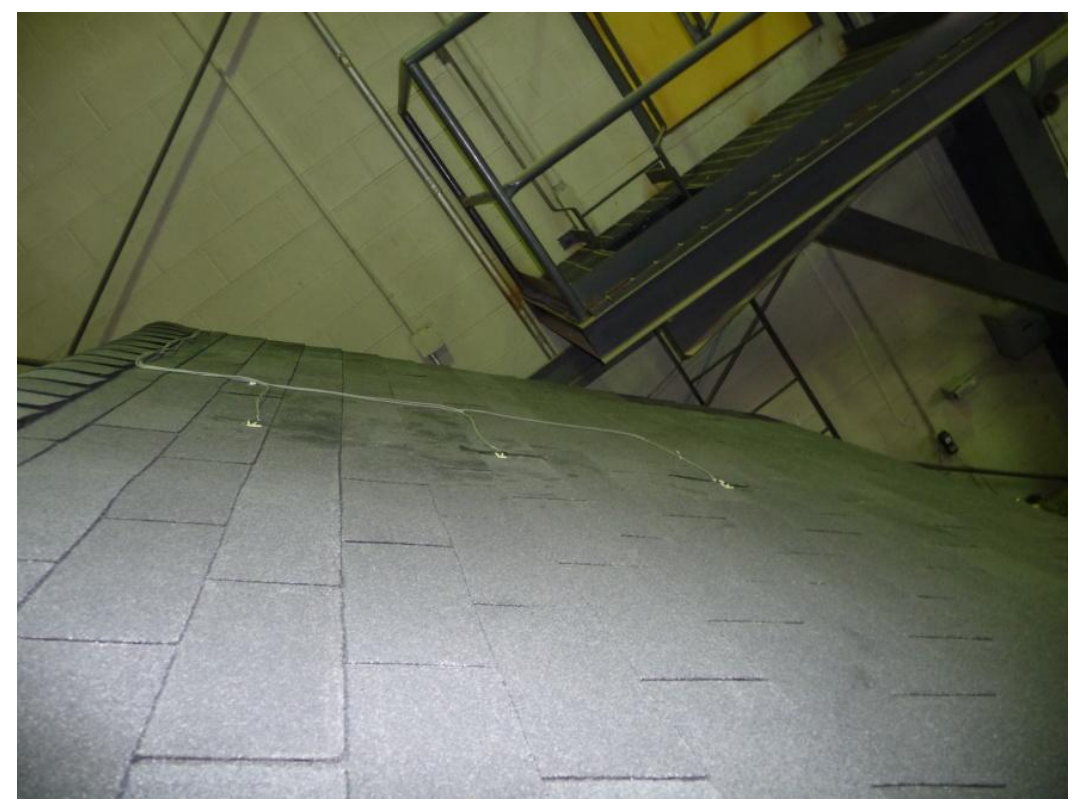

Figure 46 Location of Resistance Temperature Detectors on Roof

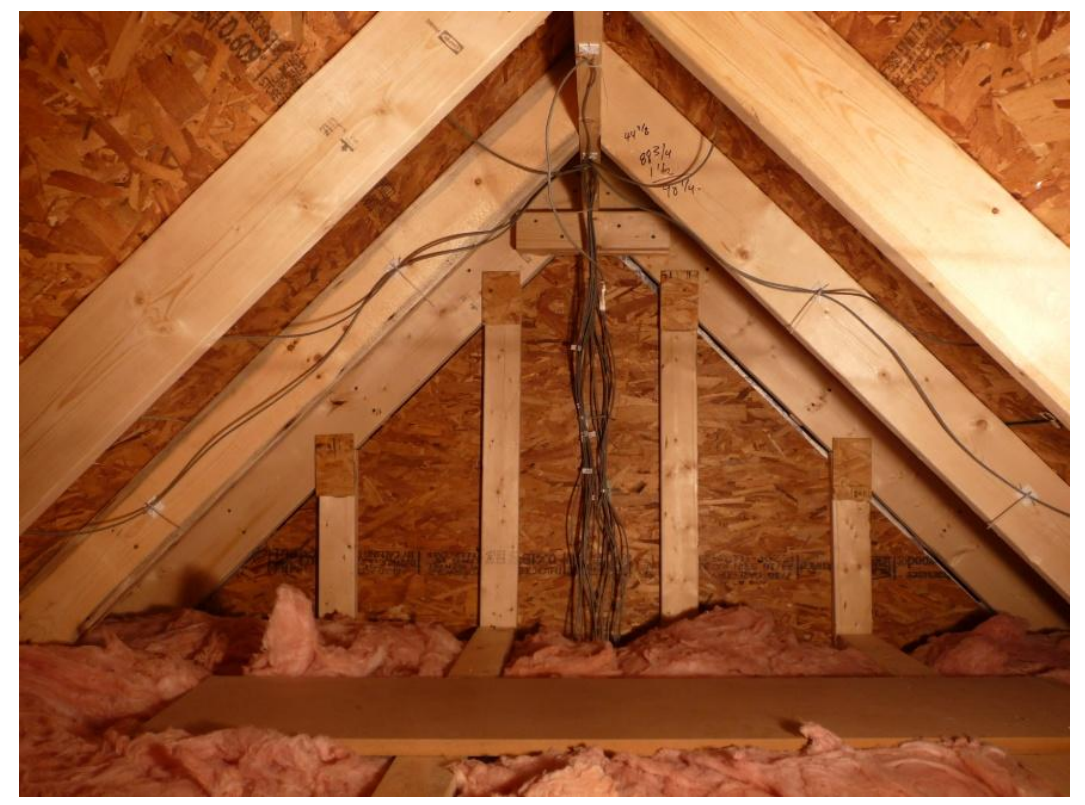

Figure 47 Location of Resistance Temperature Detectors Inside of Attic 
OMEGAFILM ${ }^{\circledR}$ Platinum resistance temperature detectors (RTD) sensors (Model No.: F2020-100-1/3B-100) were selected for this research for their flat, low profile and accuracy of temperature measurements. The specifications for the RTDs used in this research are listed below in Table 10.

Table 10 Resistance Temperature Detector Properties

\begin{tabular}{|l|l|}
\hline Tolerance & $\pm(0.1+0.0017 \mathrm{t})^{\circ} \mathrm{C}$ \\
\hline Resistance at $0^{\circ} \mathrm{C}$ & \pm 0.04 ohms \\
\hline Temperature Range & -50 to $250^{\circ} \mathrm{C}$ \\
\hline Size & $2.0 \mathrm{~mm} \times 2.0 \mathrm{~mm} \times 0.8 \mathrm{~mm}$ \\
\hline Nominal Resistance & $100 \mathrm{ohms}$ \\
\hline Platinum Clad Nickel Wire Leads & $10 \mathrm{~mm} \mathrm{~L} \times 0.2 \mathrm{~mm} \mathrm{D}$ \\
\hline
\end{tabular}

The OMEGA ${ }^{\circledR}$ FMA-900 air velocity mass flow transducers, as shown in Figure 48, were selected to measure the airflow exiting each chimney. The FMA-900 employs two rugged glasscoated RTD elements, protected by a 0.25 inch diameter $304 \mathrm{SS}$ tube with a window cut out. One RTD is the velocity sensor, while the other RTD provides ambient air temperature compensation. The velocity sensor is heated to maintain a constant (approximately $30^{\circ} \mathrm{C}$ ) temperature differential above the ambient air temperature, as measured by the second RTD element. The cooling effect of the air flow experienced by the velocity sensor is measured and converted to an electrical output signal proportional to air velocity.

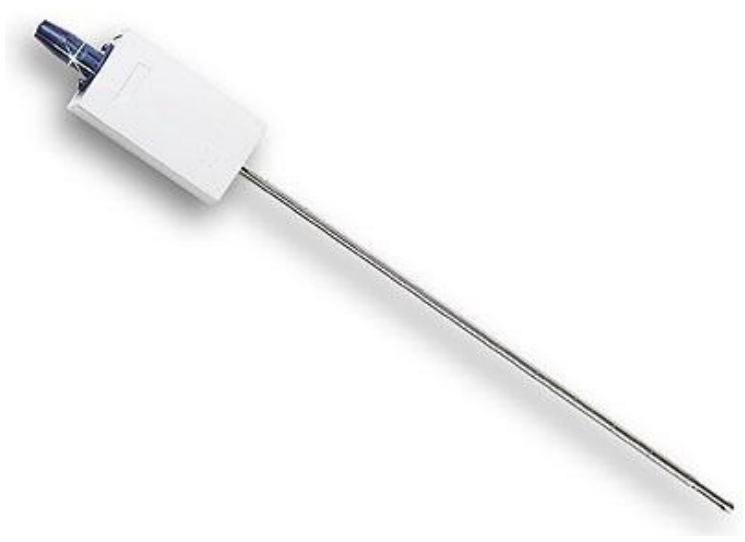

Figure 48 Air Speed Transmitters

The temperature and flow sensors were monitored using two data loggers. The dataTaker® DT800 data acquisition and logging instrument, as shown in Figure 49, is a tool to measure 12 analog channel pairs in various configurations and has built-in Ethernet capabilities. 


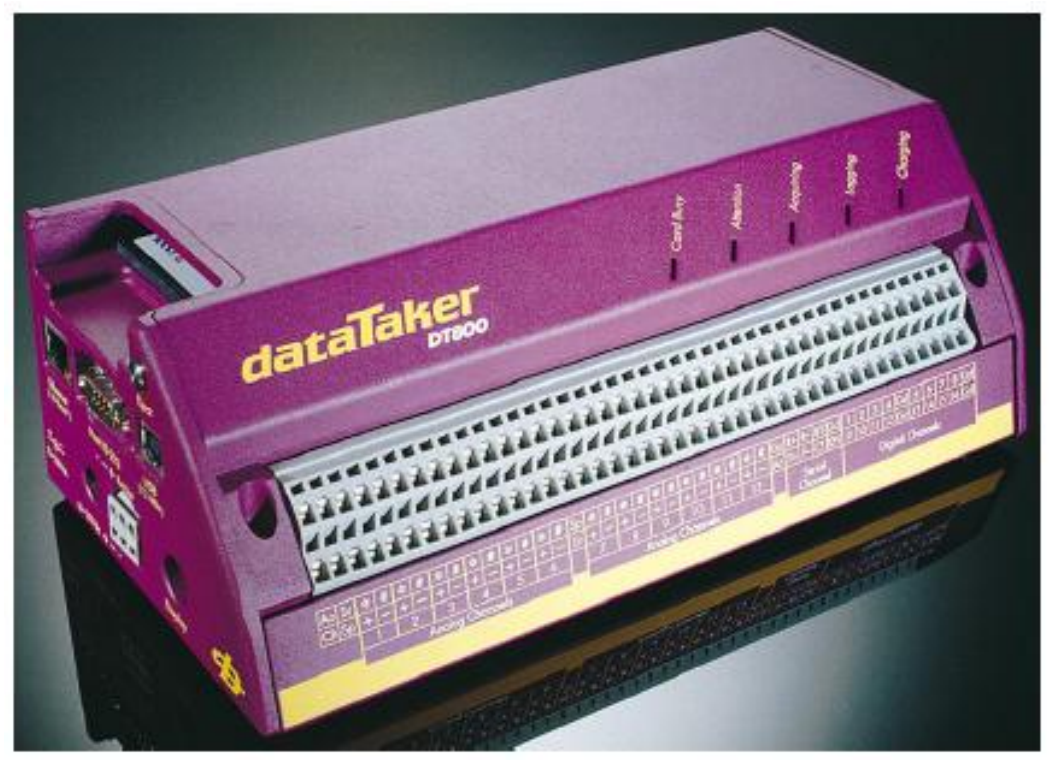

Figure 49 DataTaker ${ }^{\circledR}$ DT800

A 3-wire RTD configuration was used in the DT800 with six sensors sharing a common return to increase the amount of sensors to be measured, as depicted in Figure 50. One lead resistance sensing loop was used for each set of six sensors necessitating each wire in the set to be the same length.
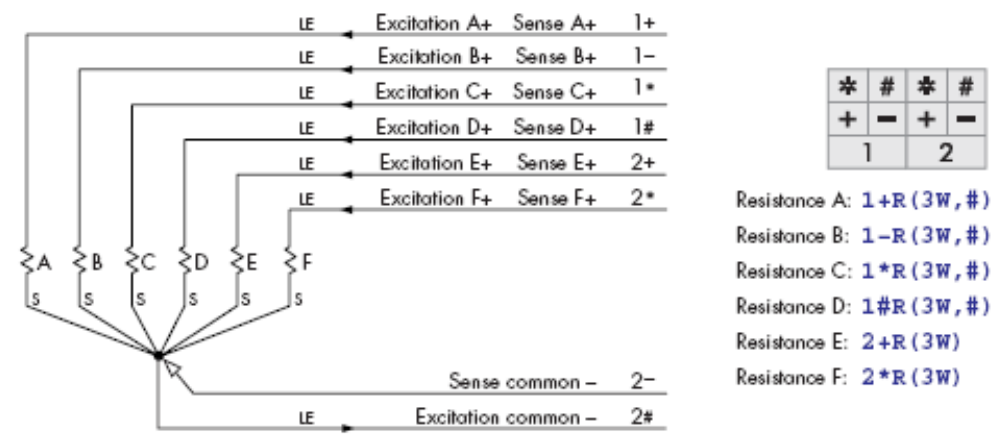

Figure 50 DataTaker ${ }^{\circledR}$ DT800 3-Wire Resistance Inputs Configuration

The second data logger utilized in this research was the dataTaker ${ }^{\circledR}$ DT505 data acquisition and logging instrument, as shown in Figure 51. This is a low power, general purpose unit with a card relay selector, removable memory and expansion module for added capabilities. This unit measures up to 30 analog channel pairs in various configurations and an additional 10 RTD channels with the expansion module. 

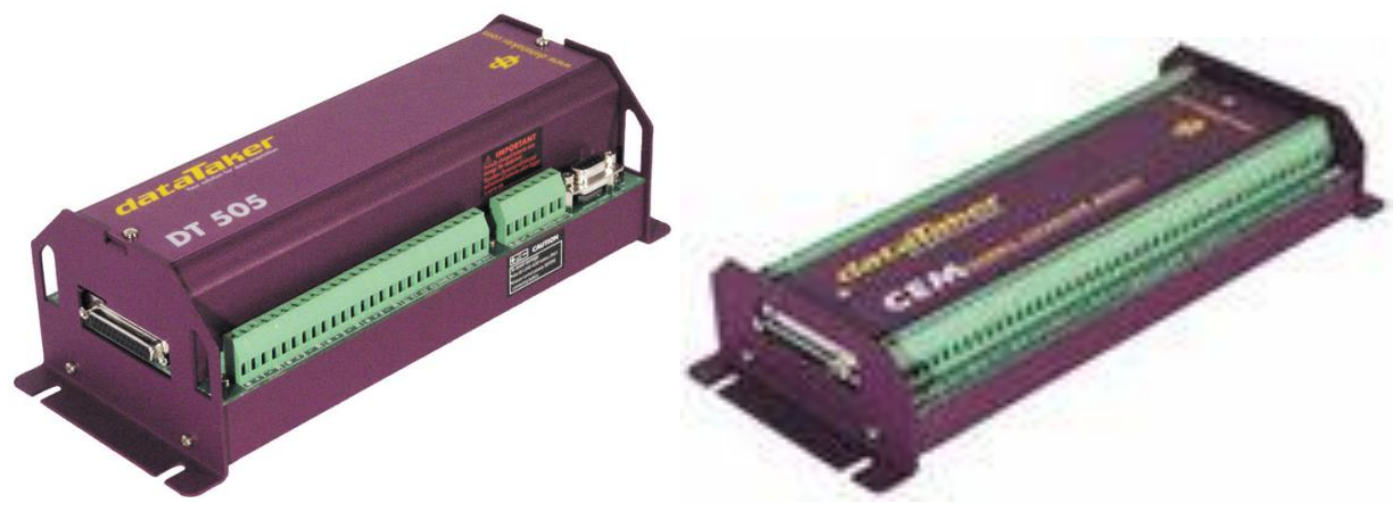

Figure 51 DataTaker ${ }^{\circledR}$ DT505 (left) and Channel Expansion Module (right)

The DataTaker® DT505 was setup with a 4-wire configuration which used two wires to supply a constant current to the sensor while the other two wires carried no current and therefore can sense the exact voltage across the resistor without any voltage drop in the wire. The dataTaker ${ }^{\circledR}$ DT505 and DT800 were installed in the control and experimental units, respectively, as shown in Figure 52. The 6-outlet power supply is on the far left with the data logger located in the middle.
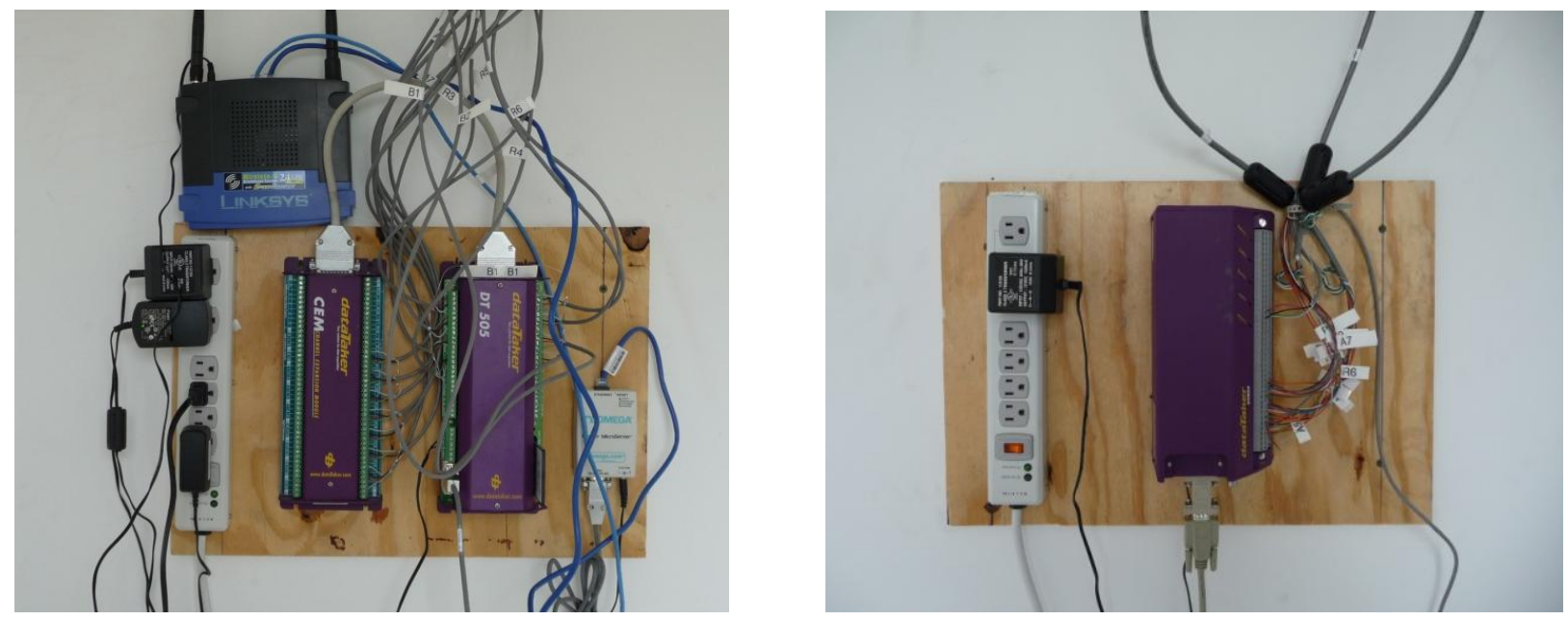

Figure 52 Data Loggers Installed Inside of Each Unit

The dataTaker® DT505 did not have onboard Ethernet so an external device was purchased for this reason, as shown in Figure 53. The Omega ${ }^{\circledR}$ iServer ${ }^{\mathrm{TM}}$ Microserver converts a serial DB9 connection to an Ethernet RJ45 connection. The specifications for this unit are shown in Table 11. The heat load from each datalogger was relatively small $(5 \mathrm{~W})$ and hence considered negligible for this research. 


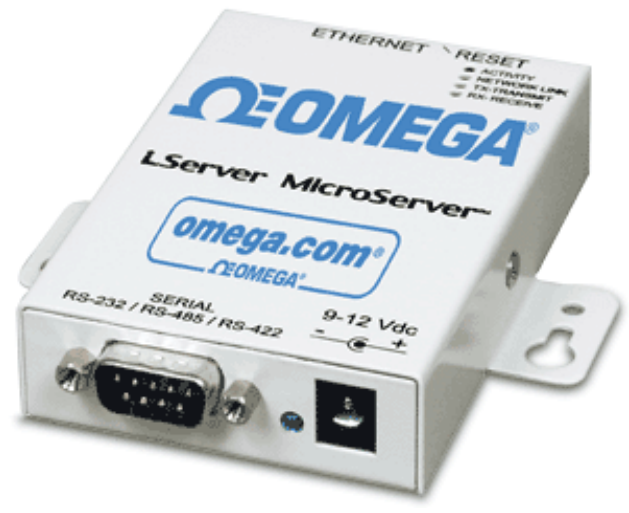

Figure 53 Omega ${ }^{\circledR}$ iServer ${ }^{\mathrm{TM}}$ Microserver

Table 11 Omega ${ }^{\circledR}$ iServer ${ }^{\mathrm{TM}}$ Microserver Specifications

\begin{tabular}{|l|l|}
\hline Serial Interface & $\begin{array}{l}\text { Software selectable RS-232, RS-422 or RS-485 (2 wire) with DB- } \\
9 \text { (male DTE) connector }\end{array}$ \\
\hline Data Rates & 300 to $115.2 \mathrm{kbps}$ \\
\hline Network Interface & Ethernet 10Base-T with RJ45 connector \\
\hline Protocols & $\begin{array}{l}\text { TCP/IP, UDP/IP, ARP, ICMP, DHCP, DNS, HTTP, Telnet, and } \\
\text { MODBUS/TCP }\end{array}$ \\
\hline Input Power & $9-12$ VDC \\
\hline Consumption & $2 \mathrm{~W}$ maximum \\
\hline Operating Temperature & 0 to $70^{\circ} \mathrm{C}\left(32\right.$ to $\left.158^{\circ} \mathrm{F}\right)$ \\
\hline Dimensions & $20.8 \mathrm{H} \times 61.6 \mathrm{~W} \times 90.3 \mathrm{D} \mathrm{mm}(0.83 \mathrm{H} \times 2.93 \mathrm{~W} \times 3.56 \mathrm{D}$ in $)$ \\
\hline
\end{tabular}

The dataTaker® software was utilized to configure, set schedules and download data from each data logger unit. The configuration included channel selection, sensor type, data logger, and label for each sensor, as shown in Figure 54. The labels started with the number one and were preceded with a letter for the type of location (e.g. A1 indicated attic sensor in position location one). In addition, each data logger was programmed to have Schedule A take data once a minute for each sensor. The data from each unit was downloaded at least twice per week in a comma separated values (.csv) file format over the internet or Ethernet configurations. 

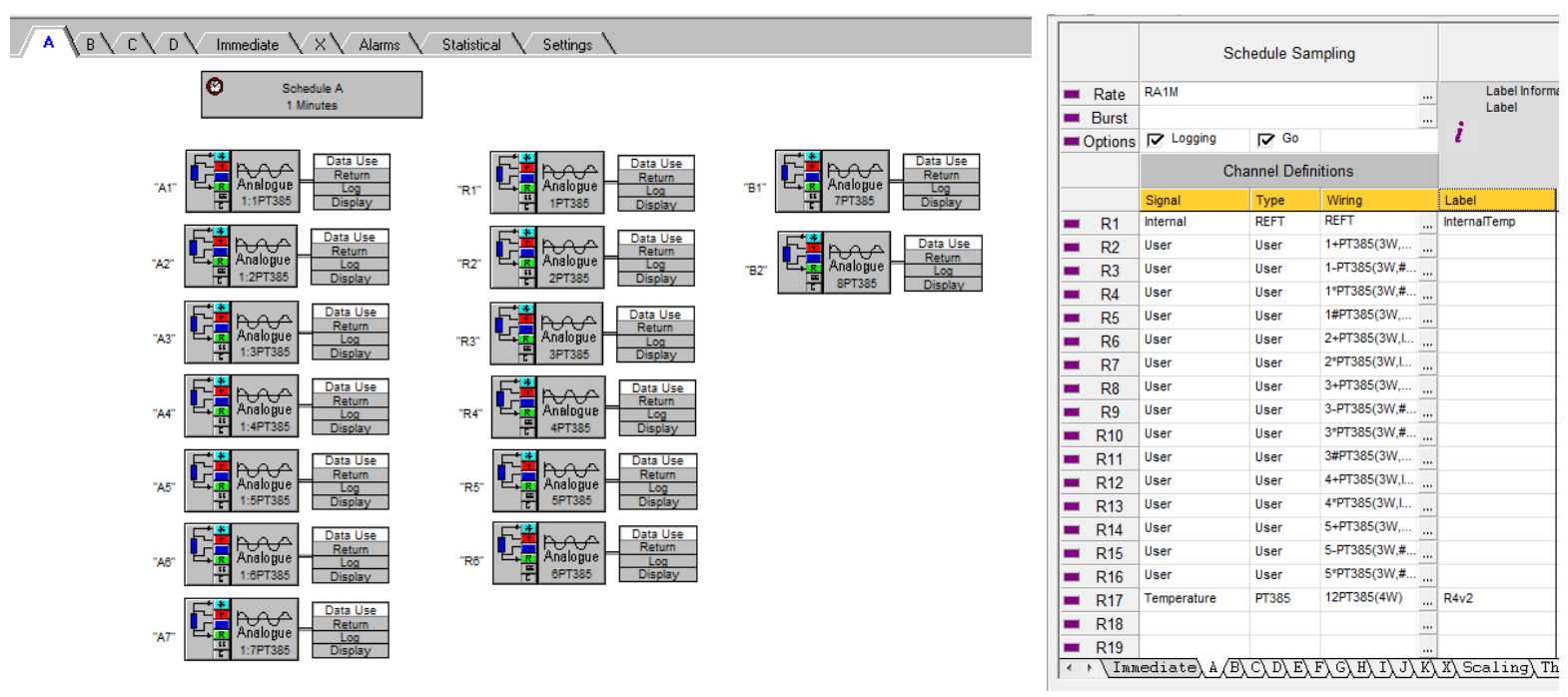

\section{Figure 54 Channel Configuration for DT505 (left) and DT800 (right) Data Loggers}

\subsection{Summary}

To verify the experimental setup, each unit was initially monitored inside of the West Virginia University Hangar in Morgantown, West Virginia. The two building units were placed in a non-shaded area in order to receive the most sunlight possible. The location was asphalt covered and on the tarmac located directly outside of the WVU Hangar. The control unit was used as a reference while the test unit had the heat roof design prototype attached to the top. Each unit was placed close enough to each other to experience similar environmental conditions, but far enough from each other as to be independent and prevent shading from one another at any point during the day. No internal heat loads or heat removal were employed in the units to minimize potential differences between them.

The instrumentation included several resistance temperature detectors (RTD) and hot wire anemometers to measure the natural convective mass flow currents in the air gap. The sensor data was recorded continuously with data logging equipment previously described. The data collection system and sensors were checked regularly to ensure proper functionality. The environmental conditions were monitored using a professional weather station.

After the data sets were collected, it was analyzed to establish the performance of the heat roof setup relative to the experimental control building. A simple theoretical thermal analysis of the buildings was also performed as a check of the measurements. These calculations and the measurements may enable the derivation of a simple thermal model that would allow for the prediction of the thermal behavior of the buildings in different environments. 
The data loggers were programmed to sample the ambient gauges and external thermocouples every minute. The average value was transmitted to a data storage module and downloaded onto a laptop computer two times per week where the environmental data sets were analyzed. 


\section{EXPERIMENTAL RESULTS AND DISCUSSION}

This chapter is divided into three main sections with selected representative continuous data periods. The baseline line data sets were divided into controlled and environmentally exposed environments with the remaining section covering the completed experimental data.

Experimental data sets were collected for a total of 5 months which covered a variety of weather conditions. Table 12 gives a brief description of the location of each sensor installed in each unit. Each RTD sensor label starts with the number one from left side of the building (facing the door) to the right side of the building ending with the number six (e.g. Roof 2 "R2" represents the temperature in the middle of the left side of the roof). Additional temperature sensors were installed in various locations and labeled accordingly (e.g. Attic 7 "A7" represents the temperature in the middle of the attic), as well as the air velocity in the stack (e.g. AIR1 represents the velocity of the air located at the bottom of the stack, $\sim 10$ in from the ridge). The experimental and control units were constructed identically, and as such, the sensor placement was also identical.

Table 12 Sensor Description for Each Unit

\begin{tabular}{|c|c|c|c|}
\hline Label & Area & Location No. & Location Description \\
\hline A1 & Attic & 1 & 12 in from exterior ridge left side along roofline \\
\hline A2 & Attic & 2 & 30 in from exterior ridge left side along roofline \\
\hline A3 & Attic & 3 & 48 in from exterior ridge left side along roofline \\
\hline A4 & Attic & 4 & 12 in from exterior ridge right side along roofline \\
\hline A5 & Attic & 5 & 30 in from exterior ridge right side along roofline \\
\hline A6 & Attic & 6 & 48 in from exterior ridge right side along roofline \\
\hline A7 & Attic & 7 & 12 in from the ridge in the center of the attic \\
\hline R1 & Roof & 1 & 12 in from interior ridge left side along roofline \\
\hline R2 & Roof & 2 & 30 in from interior ridge left side along roofline \\
\hline R3 & Roof & 3 & 48 in from interior ridge left side along roofline \\
\hline R4 & Roof & 4 & 12 in from interior ridge right side along roofline \\
\hline R5 & Roof & 5 & 30 in from interior ridge right side along roofline \\
\hline R6 & Roof & 6 & 48 in from interior ridge right side along roofline \\
\hline B1 & Building & 1 & 12 in from center backwall on interior ceiling surface \\
\hline B2 & Building & 2 & 12 in from backwall, \\
\hline B3 & Building & 3 & Right hand side of exterior (in the shade) \\
\hline TR1 & Top & 1 & 34 in from soffit on left side \\
\hline TR2 & Top & 2 & 52 in from soffit on left side \\
\hline TR3 & Top & 3 & in from soffit on left side \\
\hline & & & \\
\hline
\end{tabular}




\begin{tabular}{|c|c|c|c|}
\hline TR4 & Top & 4 & 34 in from soffit on right side \\
\hline TR5 & Top & 5 & 52 in from soffit on right side \\
\hline TR6 & Top & 6 & 70 in from soffit on right side \\
\hline UR1 & Bottom & 1 & 34 in from soffit on left side \\
\hline UR2 & Bottom & 2 & 52 in from soffit on left side \\
\hline UR3 & Bottom & 3 & 70 in from soffit on left side \\
\hline UR4 & Bottom & 4 & 34 in from soffit on right side \\
\hline UR5 & Bottom & 5 & 52 in from soffit on right side \\
\hline UR6 & Bottom & 6 & 70 in from soffit on right side \\
\hline AIR1 & Stack & 1 & Air velocity inside stack \\
\hline
\end{tabular}

\subsection{Controlled Environment Baseline}

After each unit was fully constructed, each unit remained inside the WVU Hangar for a period of 2 months to establish baseline data in a controlled environment, as shown in Figure 55. During this time period, the gable was open and hence natural convective air currents would flow in through the soffit and exit through the gable. A representative set of data for the attic temperatures is shown in Figure 56 and Figure 57 for the 500 and 800 units, respectively. In addition, the same time period is shown as a representative set of data for the roof temperatures shown in Figure 58 and Figure 59 for the 500 and 800 units, respectively.

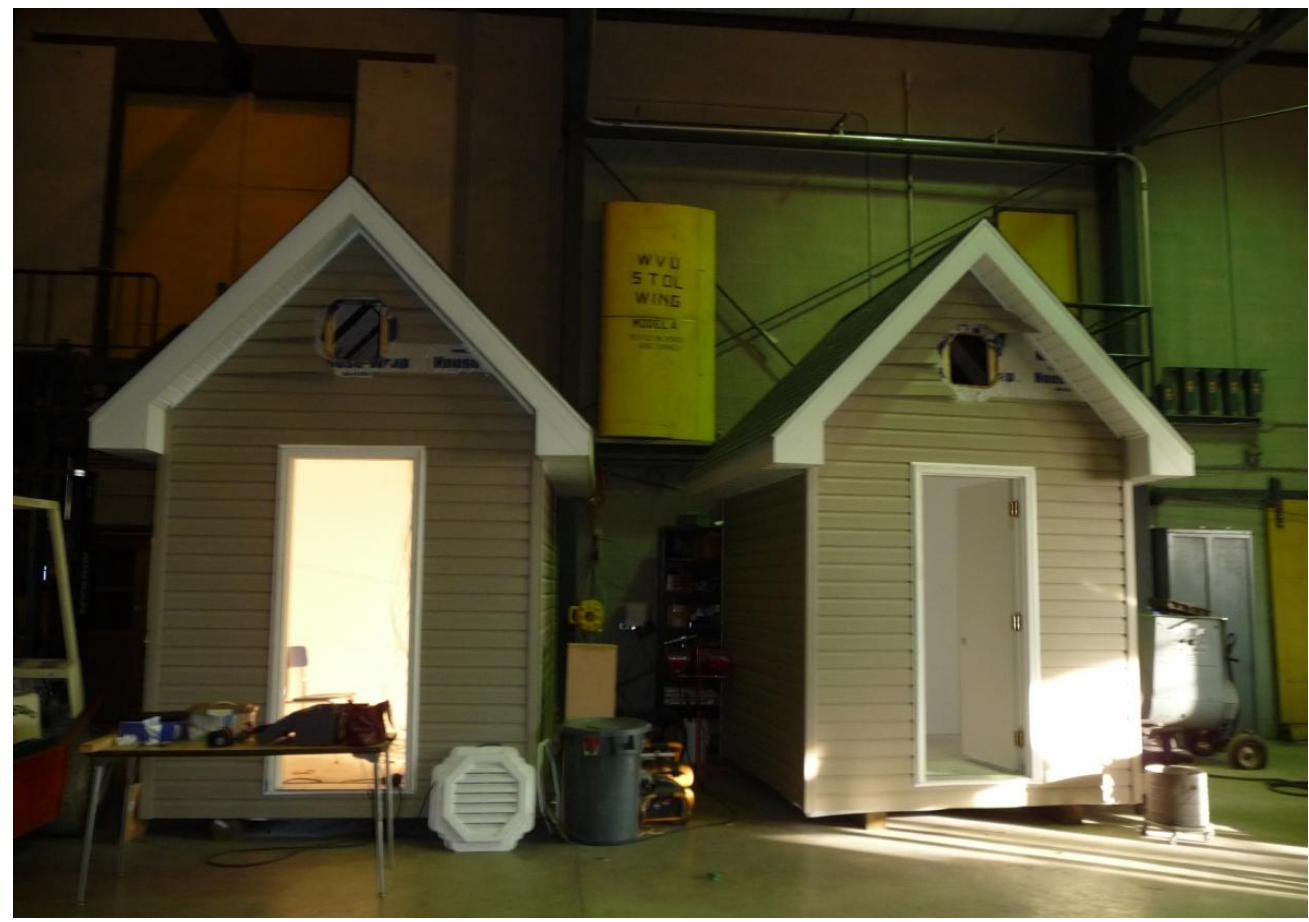

Figure 55 Experimental and Control Units Inside of WVU Hangar 
Each unit was located 20 feet from the hangar bay doors and raised 6 in from the floor by 6 inch square wood blocks for the controlled environment baseline testing. A series of representative tests were executed and the results were analyzed. The first test analyzed the effects of the automatic heaters located on the left and right above each of the units. The multitude of peaks in Figure 56, Figure 57, Figure 58, and Figure 59 clearly indicate when the heaters were operating.

A second test was also performed to show the opposite effect. This included fully opening the hangar bay door to allow the significantly cooler air to naturally flow into the hangar bay. There are six valleys shown in Figure 56, Figure 57, Figure 58, and Figure 59 on January $11^{\text {th }}$, $12^{\text {th }}, 14^{\text {th }}, 15^{\text {th }}, 19^{\text {th }}$, and $20^{\text {th }}$, which clearly indicate when this event occurred. In both tests, all of the temperature sensors responded in a similar fashion in the controlled environment. The maximum difference from each of the sensors was one degree Celsius. In addition, there were minimal differences between each unit on both the roof and inside the attic.

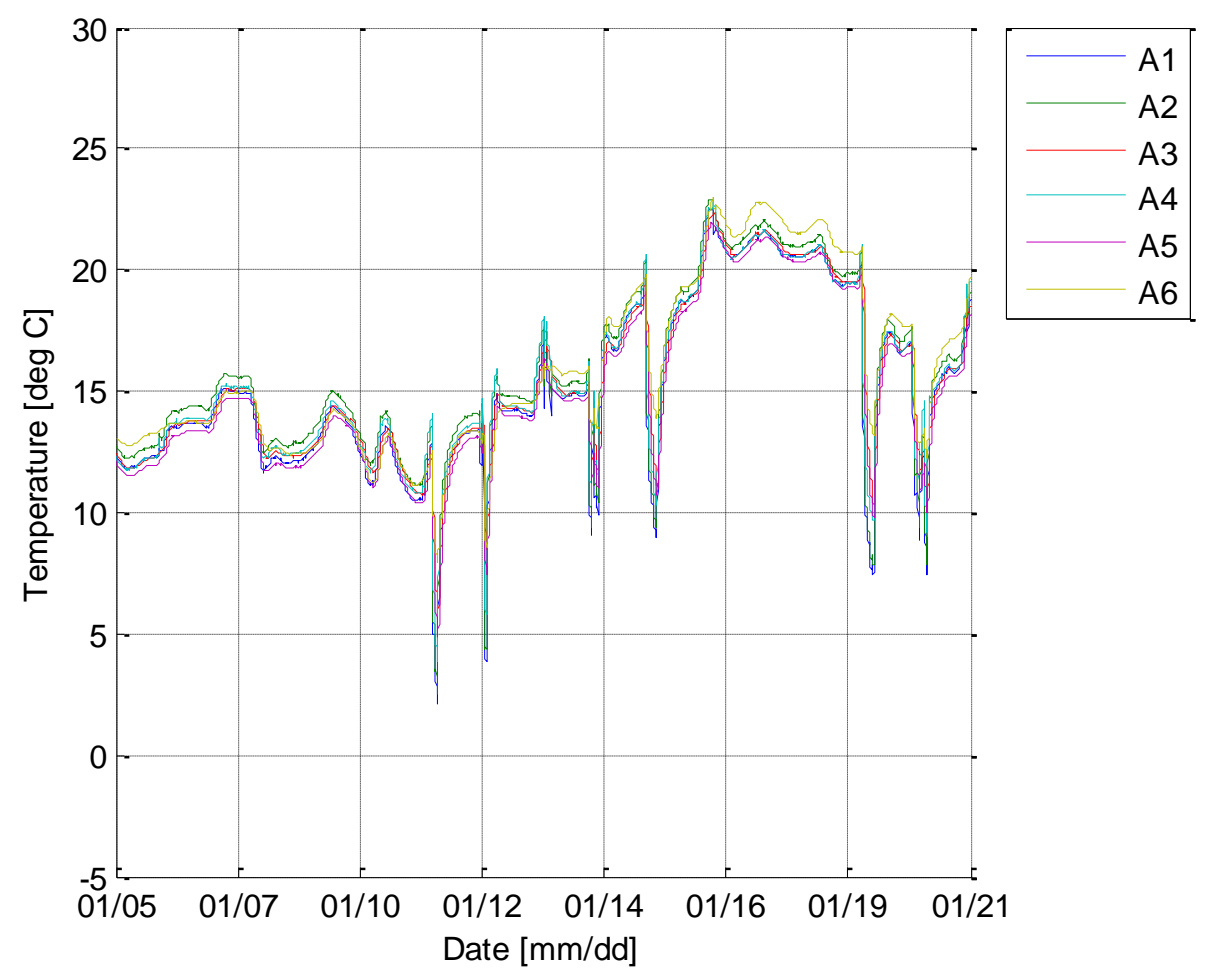

Figure 56 Controlled Baseline Attic Temperatures (500 Unit) 


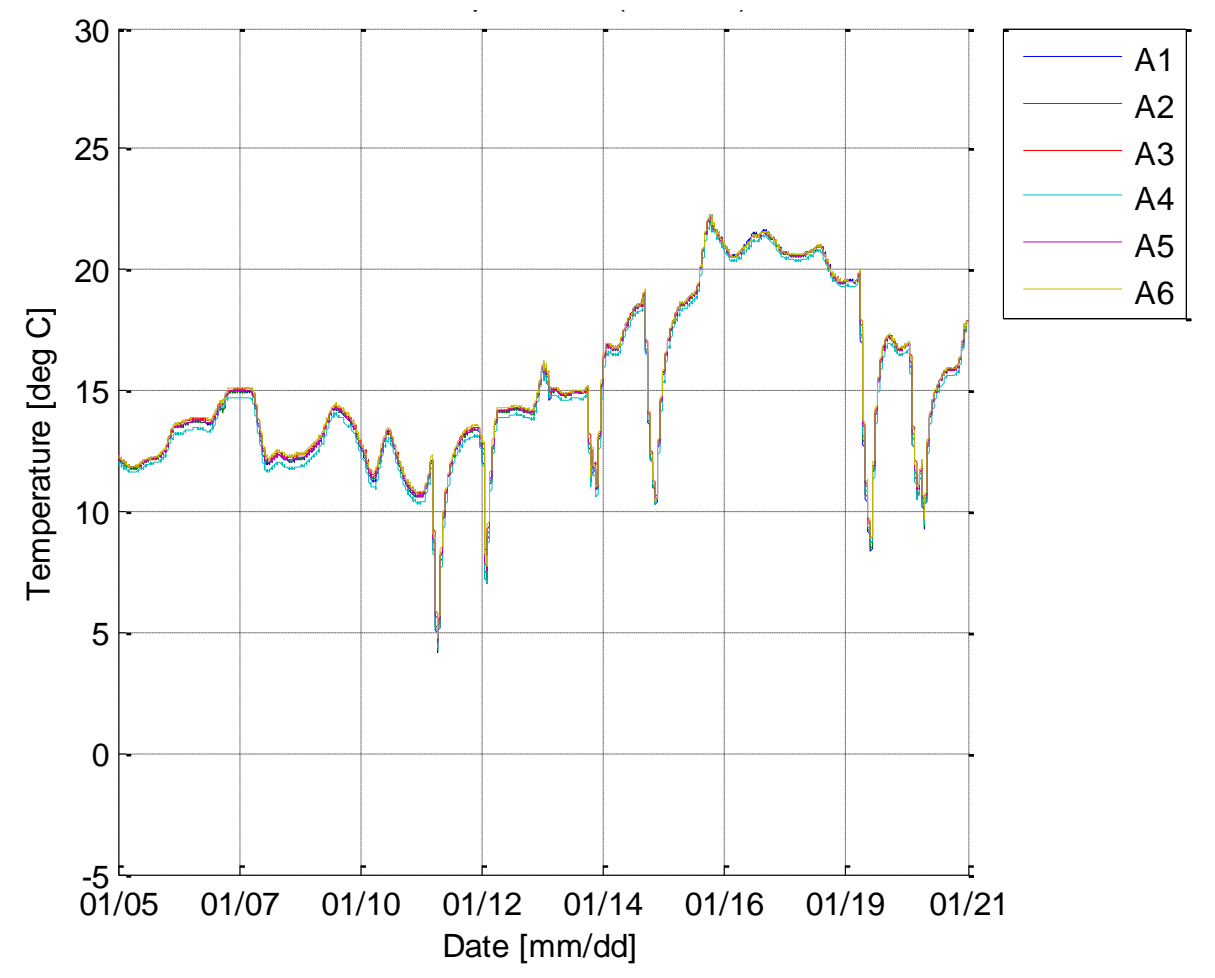

Figure 57 Controlled Baseline Attic Temperatures (800 Unit)

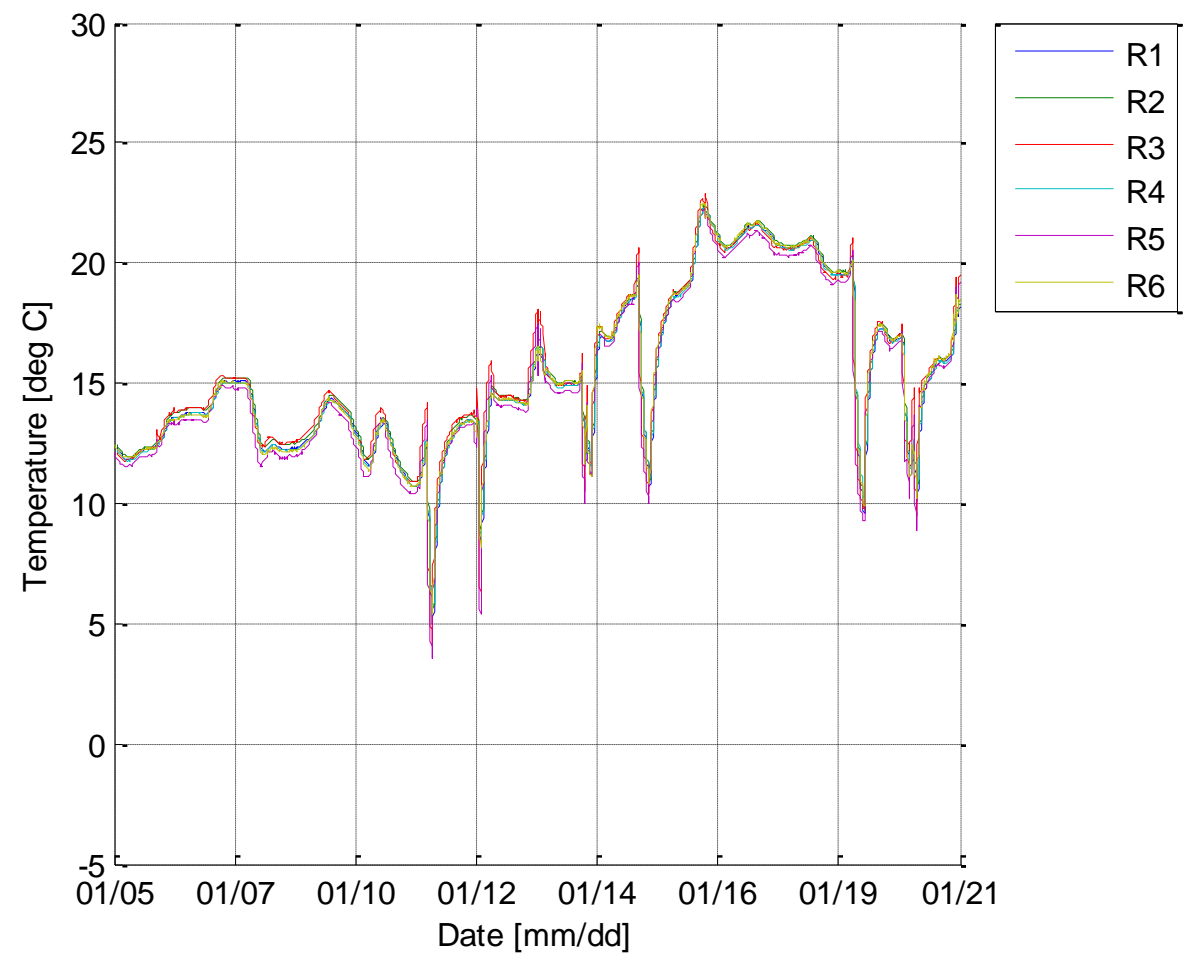

Figure 58 Controlled Baseline Roof Temperatures (500 Unit) 


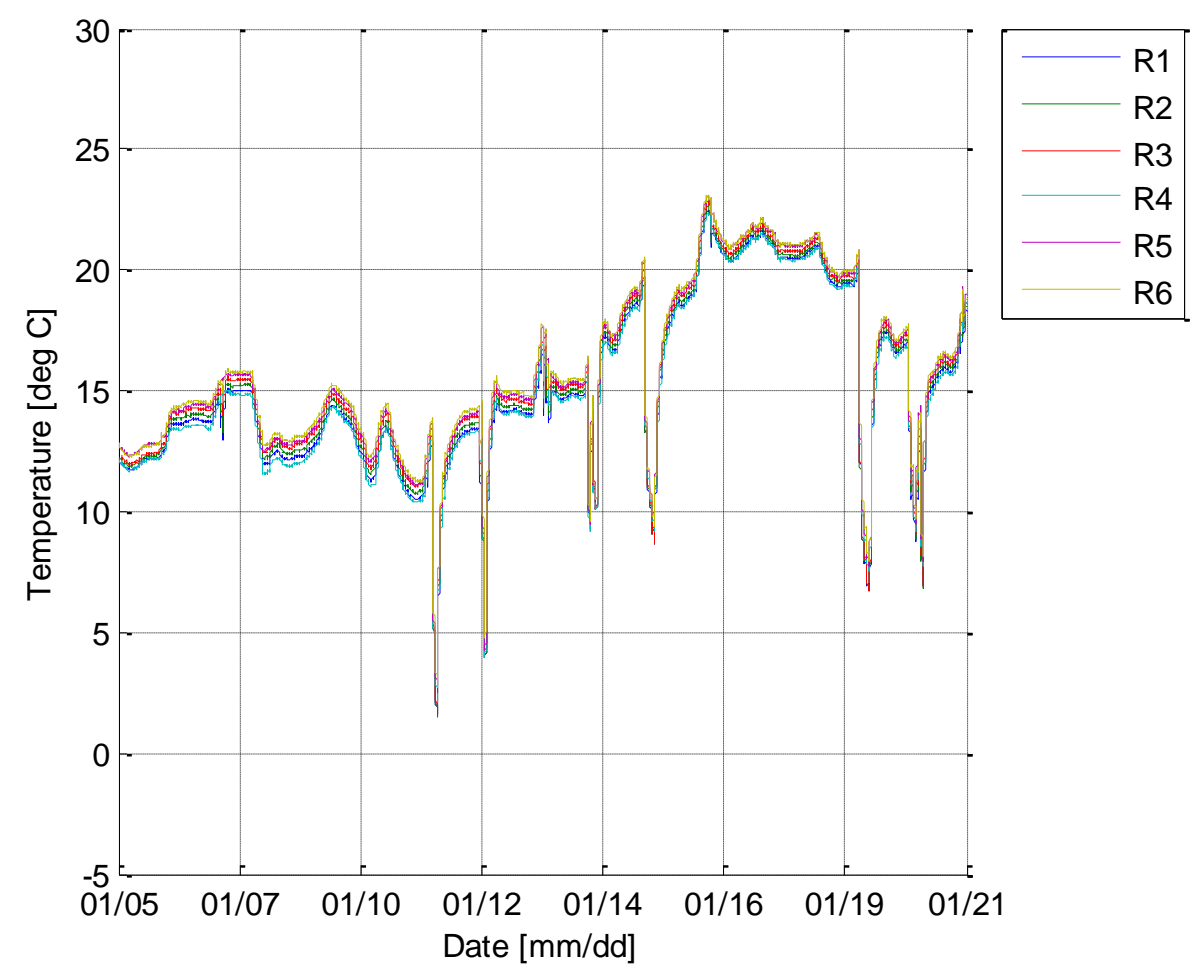

Figure 59 Controlled Baseline Roof Temperatures (800 Unit)

\subsection{Environmentally Exposed Baseline}

The gable on each unit was sealed with an octagon shaped particle board to minimize the convective currents in the attic. After the successful baseline testing inside of the WVU hangar, each unit was moved to the tarmac area, outside of the WVU Hangar, as shown in Figure 60. Testing commenced for a period of 2 months under various environmental conditions. A representative set of data for the attic temperatures are shown in Figure 61 and Figure 62 for the 500 and 800 units, respectively. In addition, the same time period is shown as a representative set of data for the roof temperatures shown in Figure 63 and Figure 64 for the 500 and 800 units, respectively. 


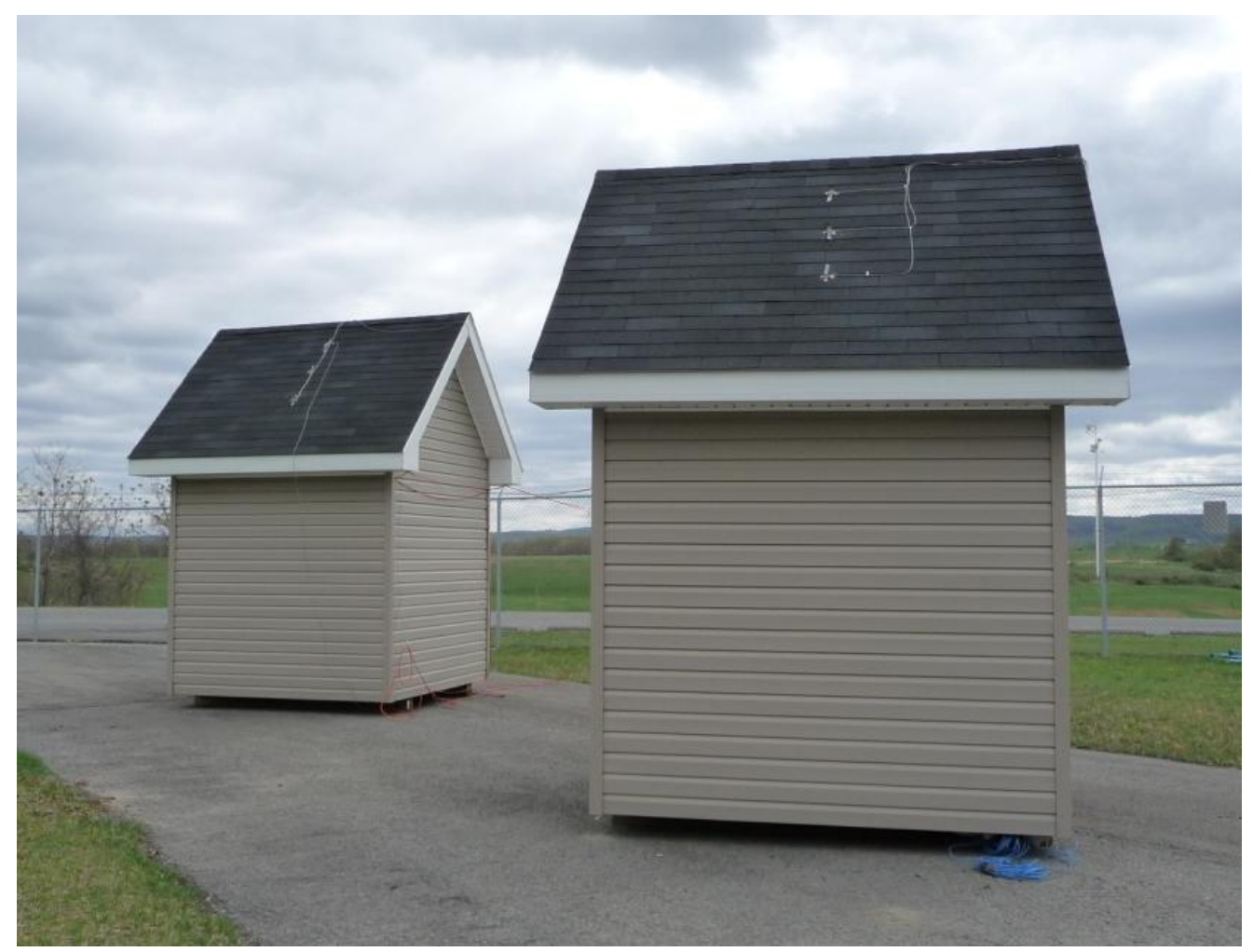

Figure 60 Environmentally Exposed Units

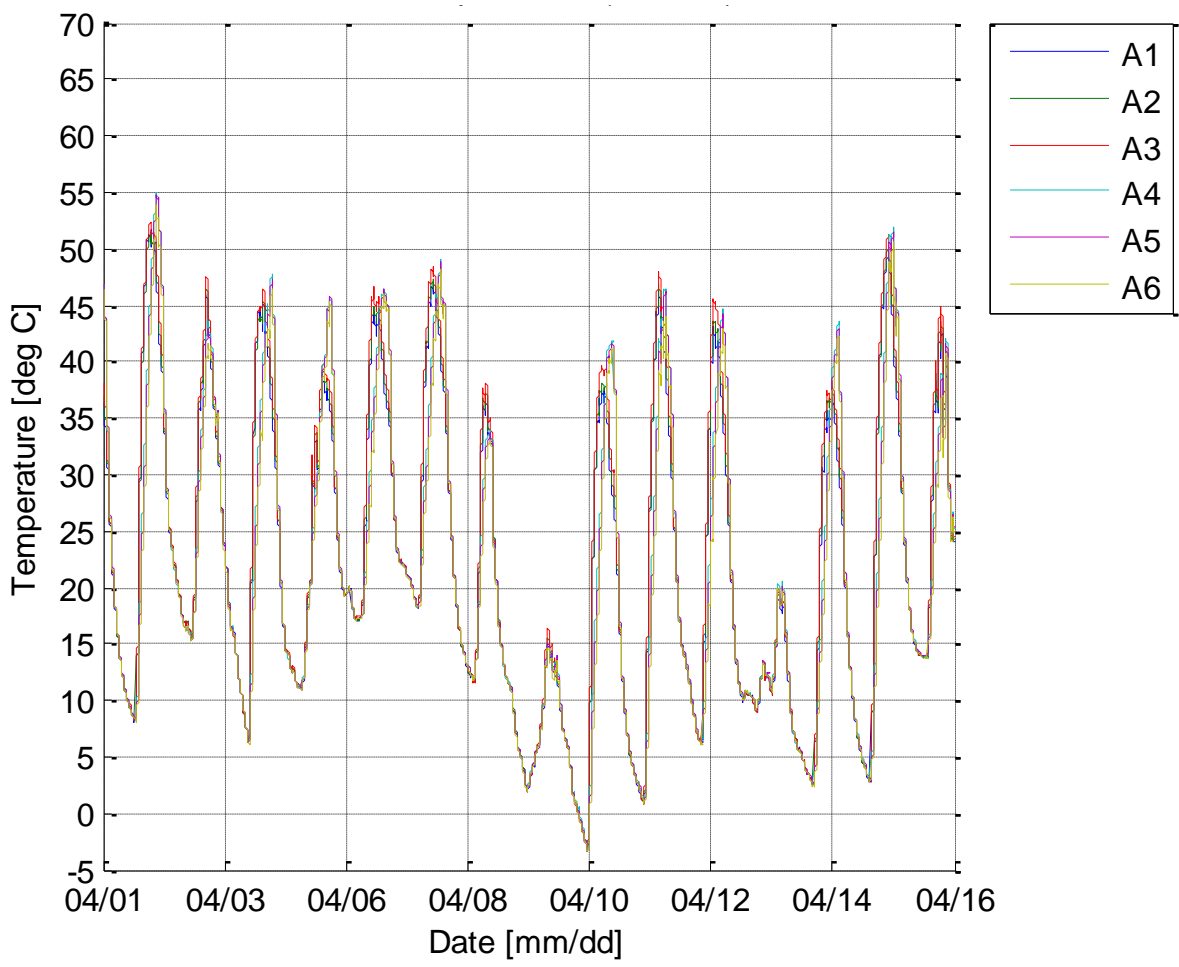

Figure 61 Environmentally Exposed Attic Temperatures (500 Unit) 


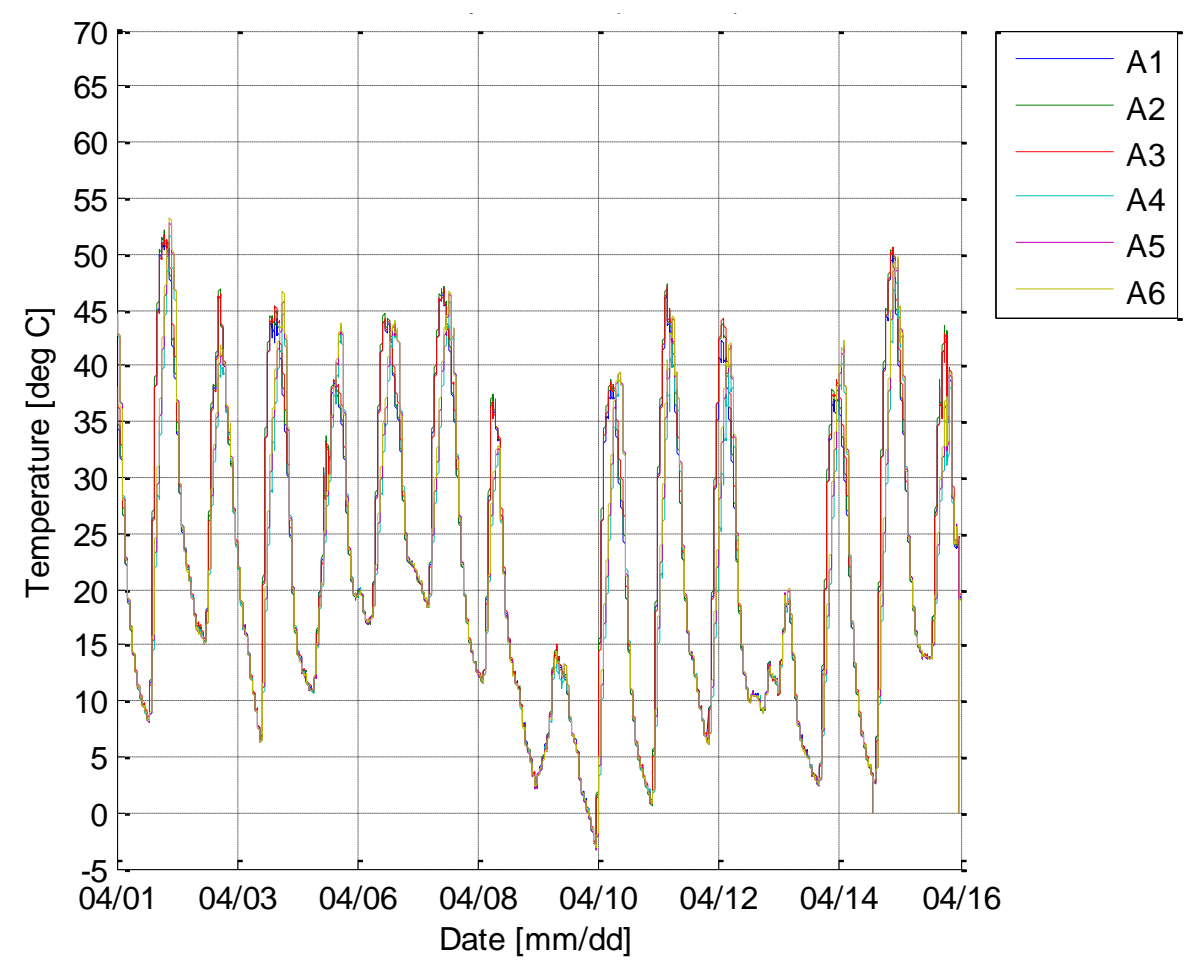

Figure 62 Environmentally Exposed Attic Temperatures (800 Unit)

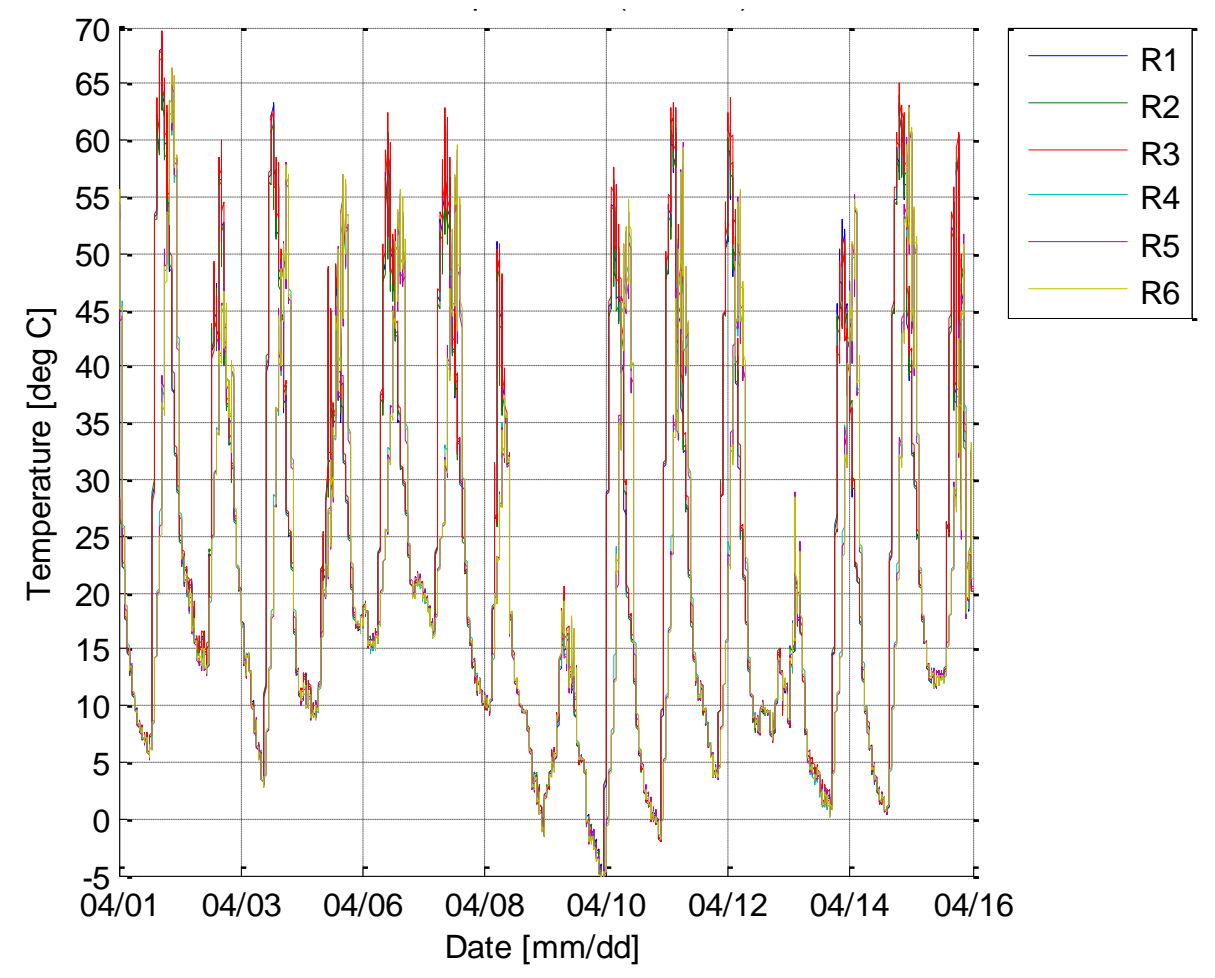

Figure 63 Environmentally Exposed Attic Temperatures (500 Unit) 


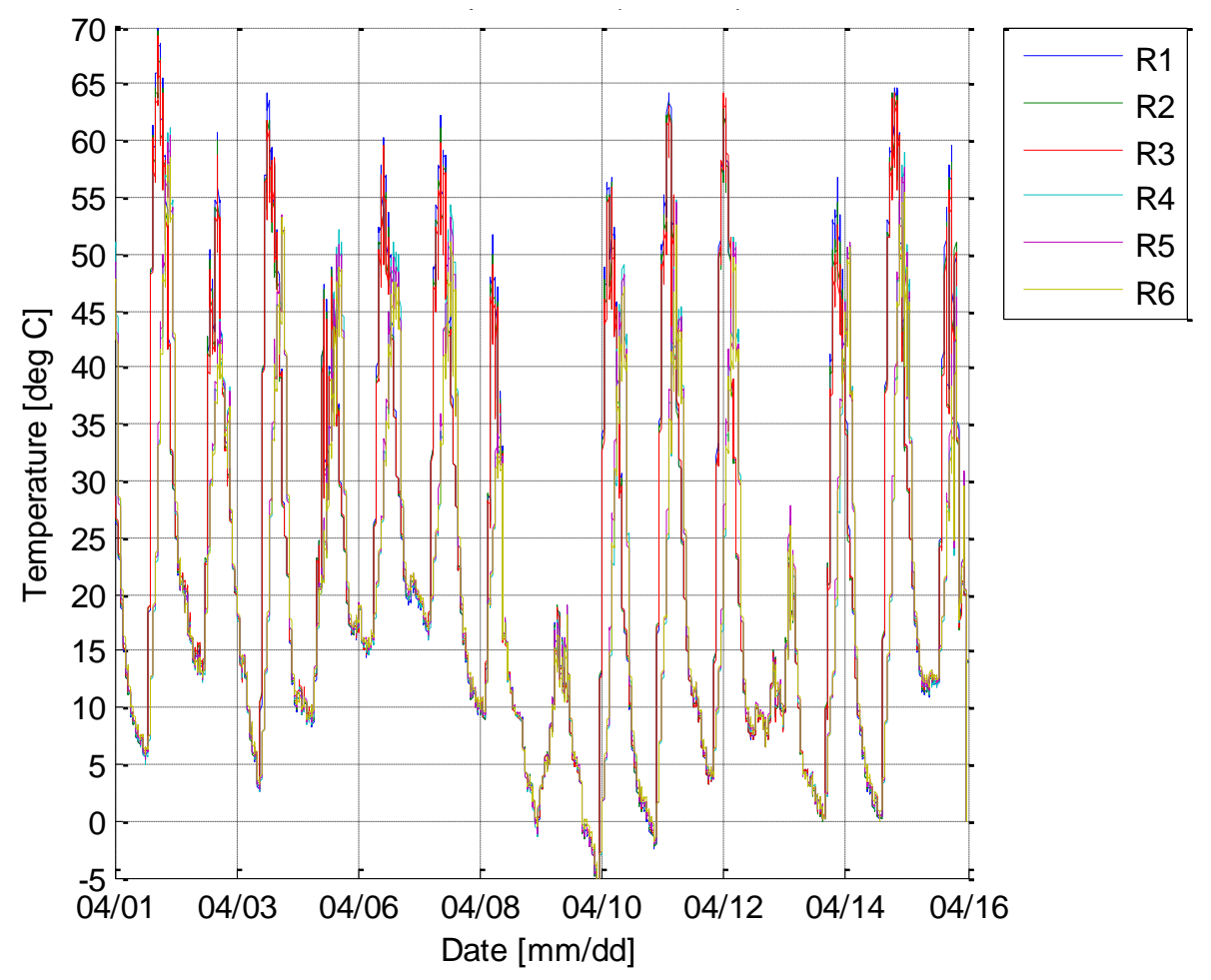

Figure 64 Environmentally Exposed Attic Temperatures (800 Unit)

Each unit was located 150 feet from the front of the hangar and placed such that they were not in the shadows of any structure for the environmentally exposed testing. The temperatures on the left hand side and right hand side of the roof and attic were within one degree Celsius, so an average of each side was calculated and shown in Figure 65 and Figure 66 for the 500 and 800 units, respectively. In addition, the ambient temperature for that time period is shown on each figure. As expected, both sides of each unit increased as the ambient temperature increased. The left hand side (LHS) reached its peak temperature first, after which the right hand side (RHS) followed, but did not reach the same peak temperature. In this data set, there were two days (April $9^{\text {th }}$ and $13^{\text {th }}$ ) in which the ambient temperature was significantly lower and most of the day was cloudy and hence the peak for both the RHS and LHS were similar and lower than the other testing days.

In addition, the data for the LHS and RHS both follow the ambient temperature trend. For example, when there were noticeable ambient temperature fluctuations, the LHS and RHS exhibited the same pattern, as shown in Figure 67 and Figure 68, for the time period of April $13^{\text {th }}$ through the April $15^{\text {th }}$ when both cloudy and sunny days were observed. 


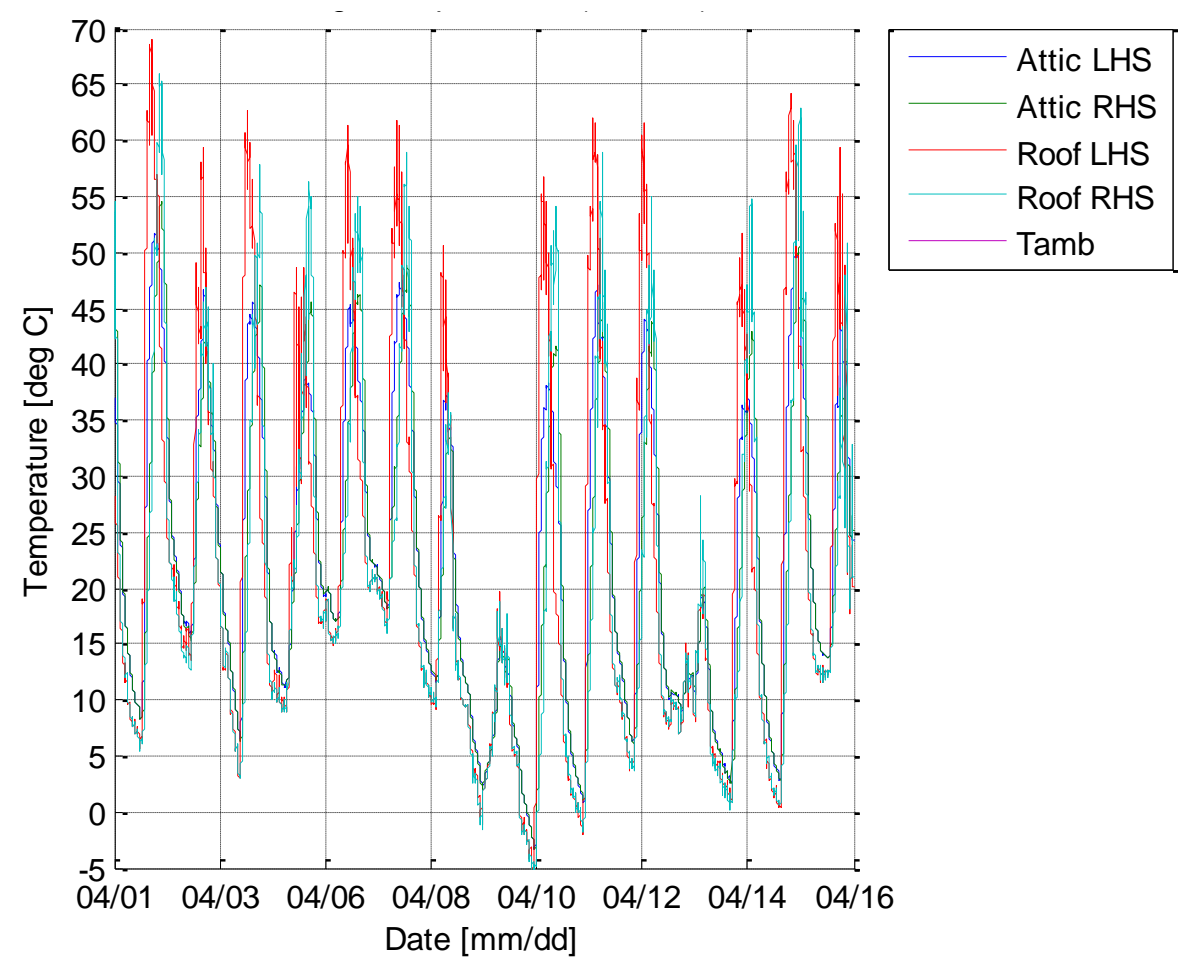

Figure 65 Baseline Average Data (Unit 500)

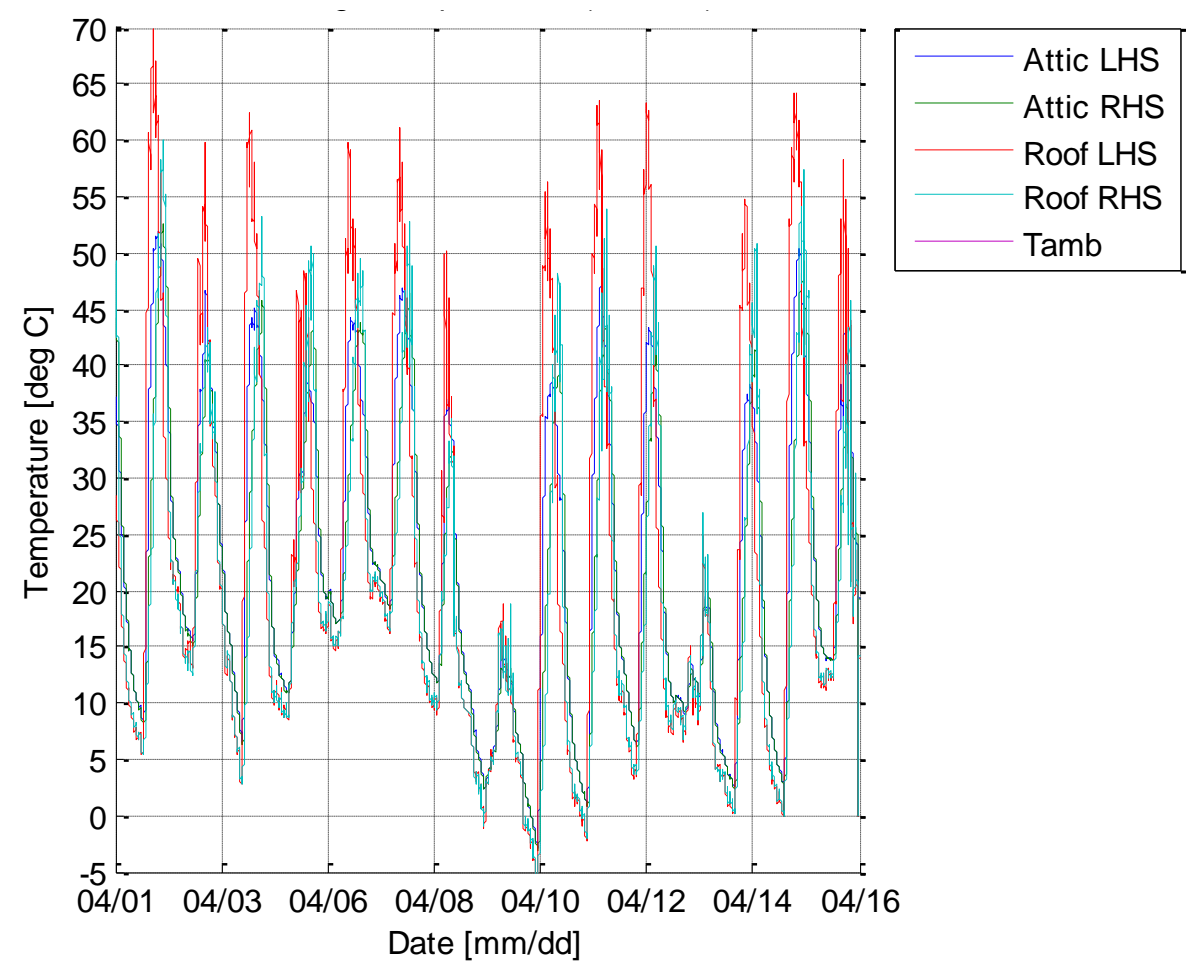

Figure 66 Baseline Average Data (Unit 800) 


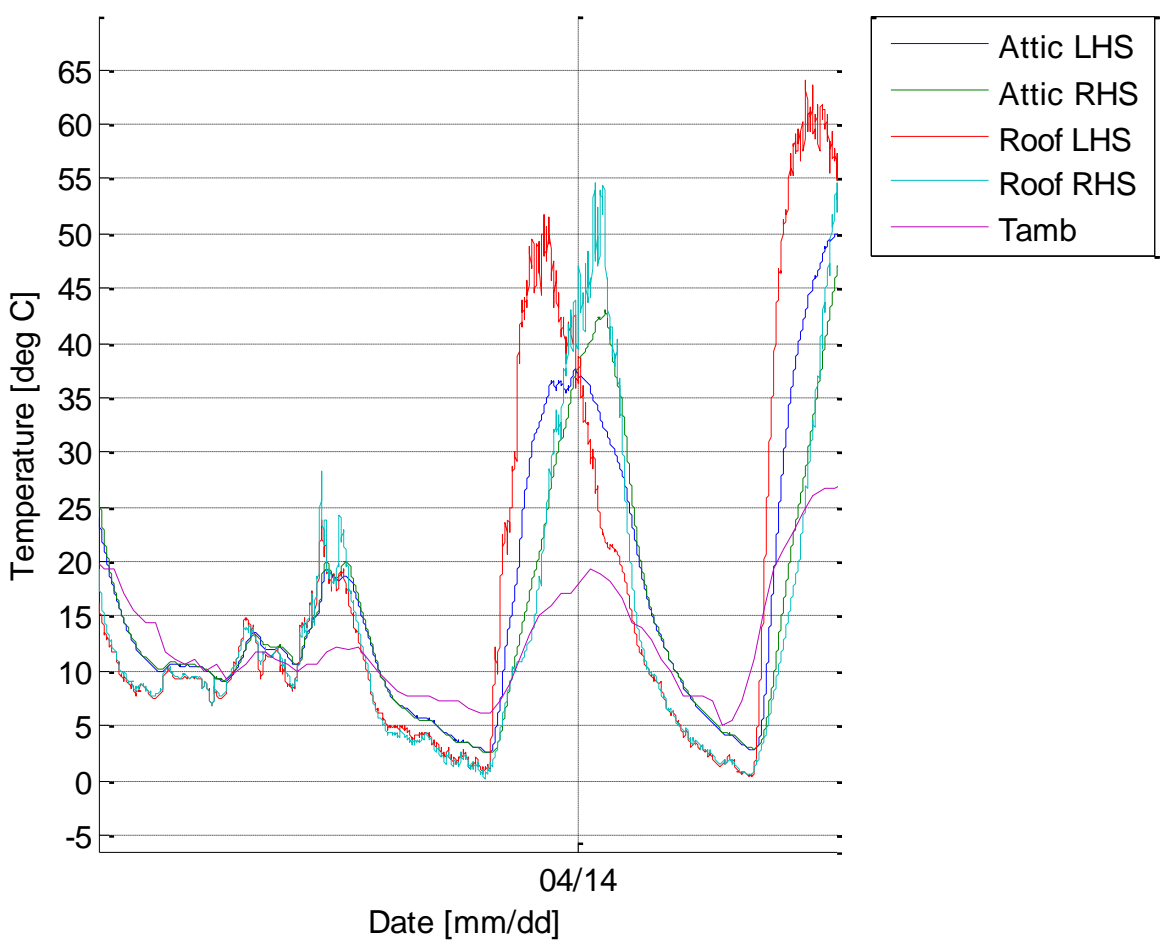

Figure 67 Environmentally Exposed Baseline Temperatures (500 Unit)

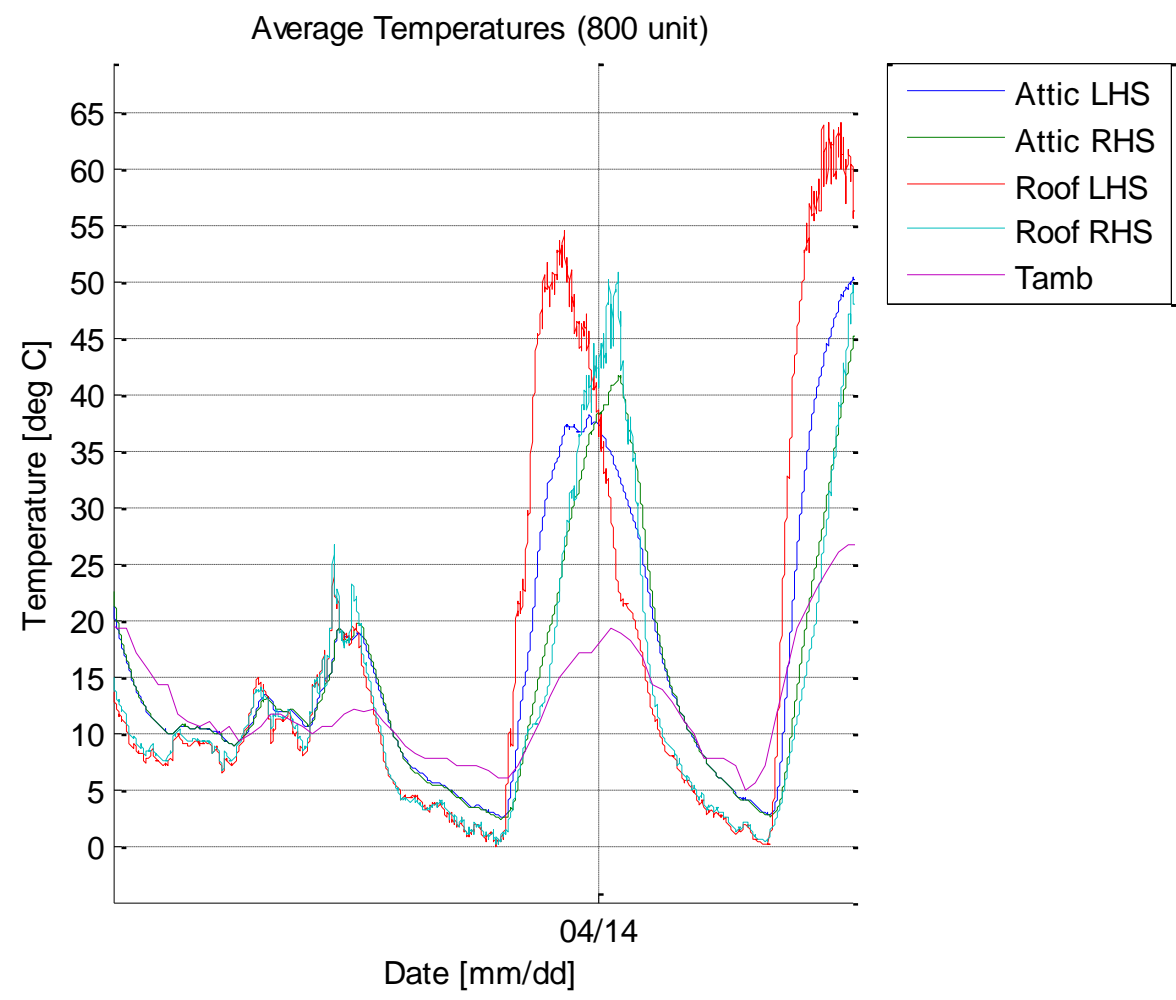

Figure 68 Environmentally Exposed Temperatures (800 Unit) 
Figure 69 displays the weather data for each day during the given time period (Weather 2010). This weather data included the ambient and dew point temperatures, as well as the barometric pressure and humidity.
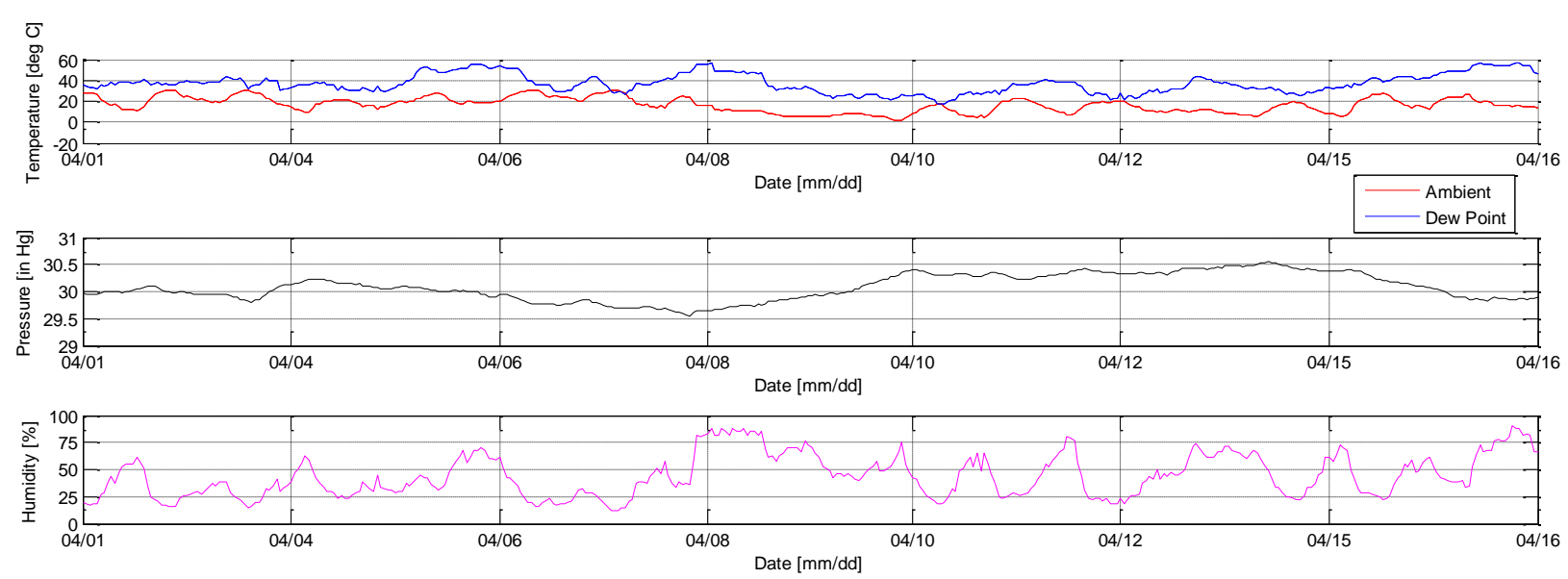

Figure 69 Baseline Weather Data (Wunderground $\left.{ }^{\circledR} 2010\right)$

To monitor the temperature inside of each building, two RTDs were added to the configuration, as shown in Figure 70 and Figure 71 for the 500 and 800 units, respectively. The difference between the two building temperatures, B1 and B2, was negligible for each unit.

Both the experimental and control units exhibited the same temperature pattern in the controlled and environmentally exposed environments inside of the attic and building, as well as on the roof top surfaces. 


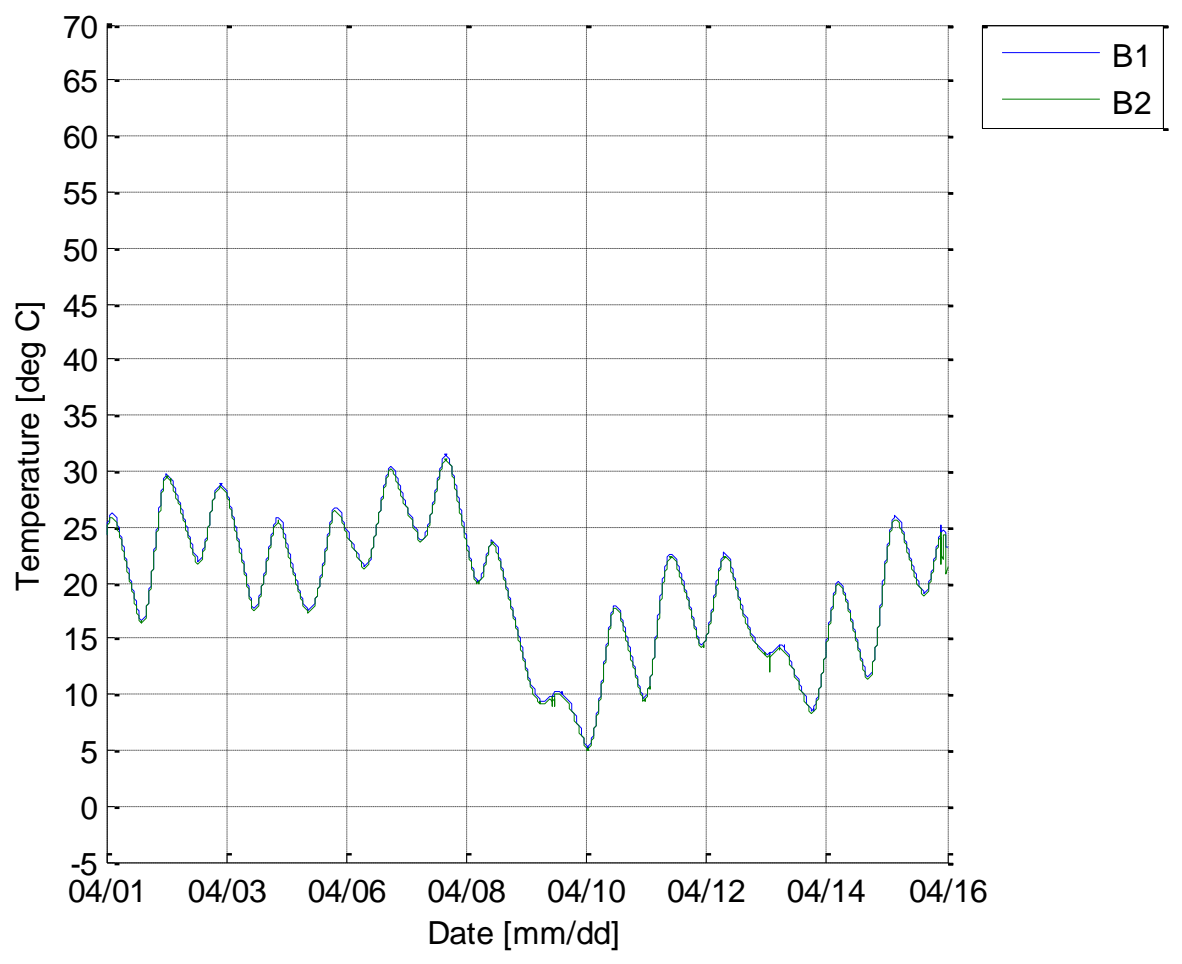

Figure 70 Building Temperatures (500 Unit)

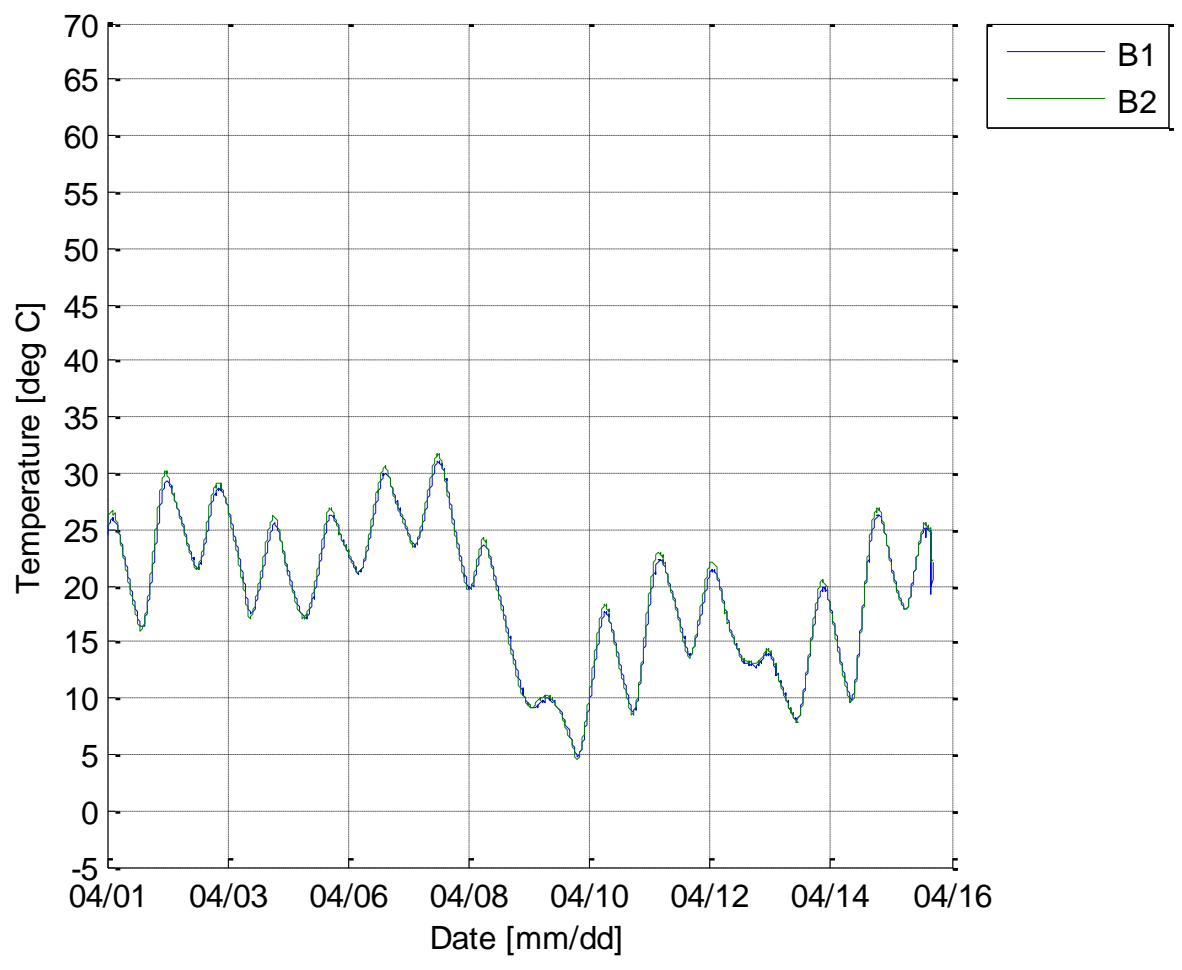

Figure 71 Building Temperatures (800 Unit) 


\subsection{Environmentally Exposed}

After the baseline testing under various environmental conditions commenced, the additional roof feature was constructed and mounted to the existing roof of the building with the 800 data logger unit only. Six RTD sensors were installed on each side of the roof for a total of twelve additional temperature sensors. The natural convective currents on the left hand side were channeled to the stack located in the front of the building, while the stack located in the back was for the right hand side of the roof.

For the remaining time period, the units remained outside under various weather conditions with a 1.5 inch air gap and 2 and 4 feet stack heights which were alternated approximately once per hour, as shown in Figure 72 and Figure 73. Figure 74 and Figure 75 display the temperatures of the attic and roof for the 500 unit only, respectively.

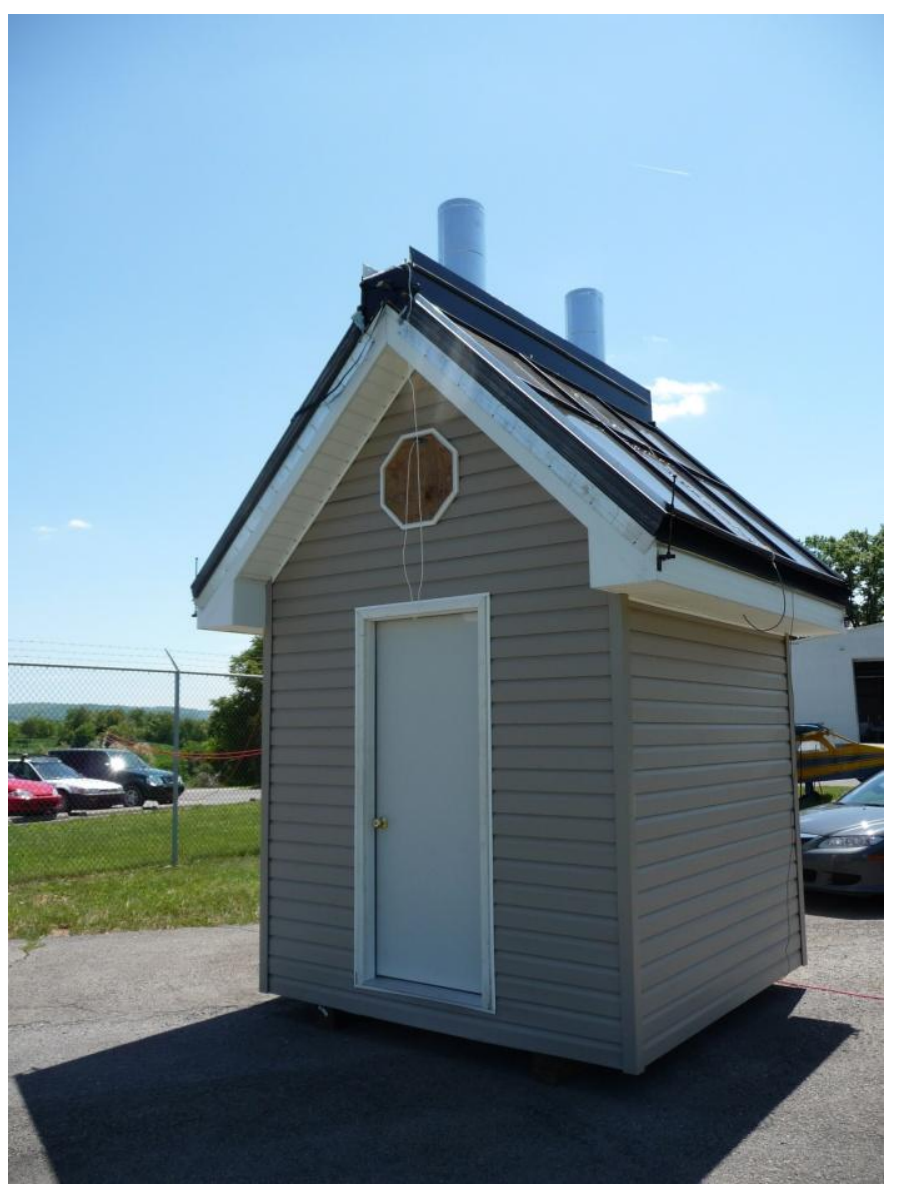

Figure 72 Experimental Unit with 2 Feet Stack 


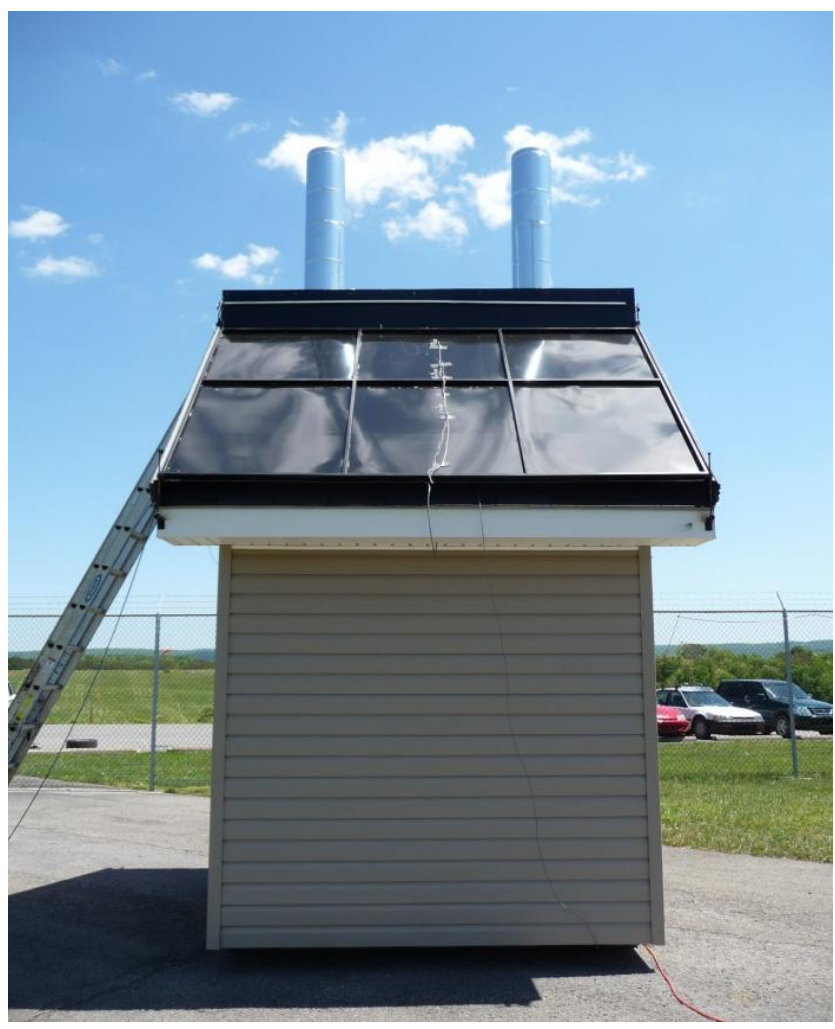

Figure 73 Experimental Unit with 4 Feet Stack

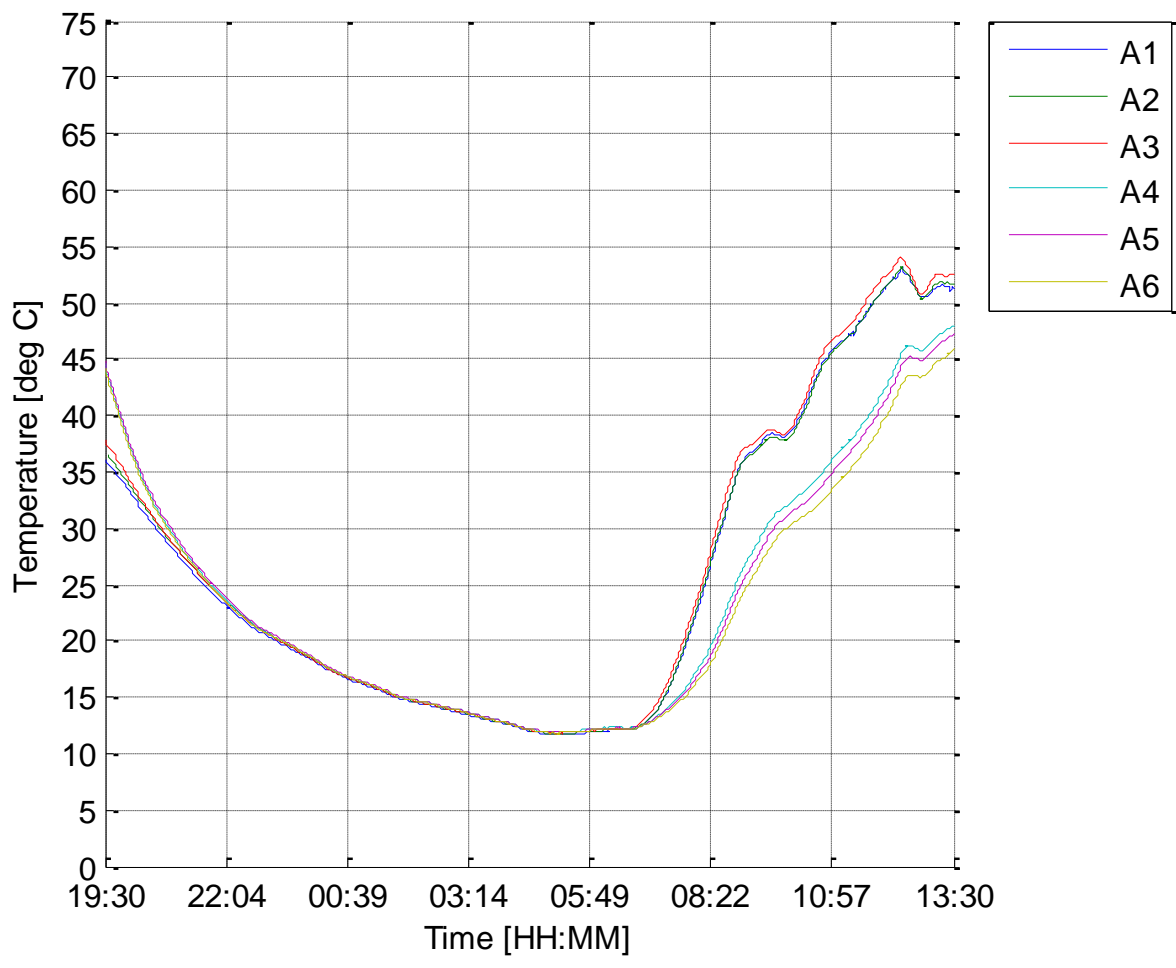

Figure 74 Environmentally Exposed Attic Temperatures (500 Unit) 


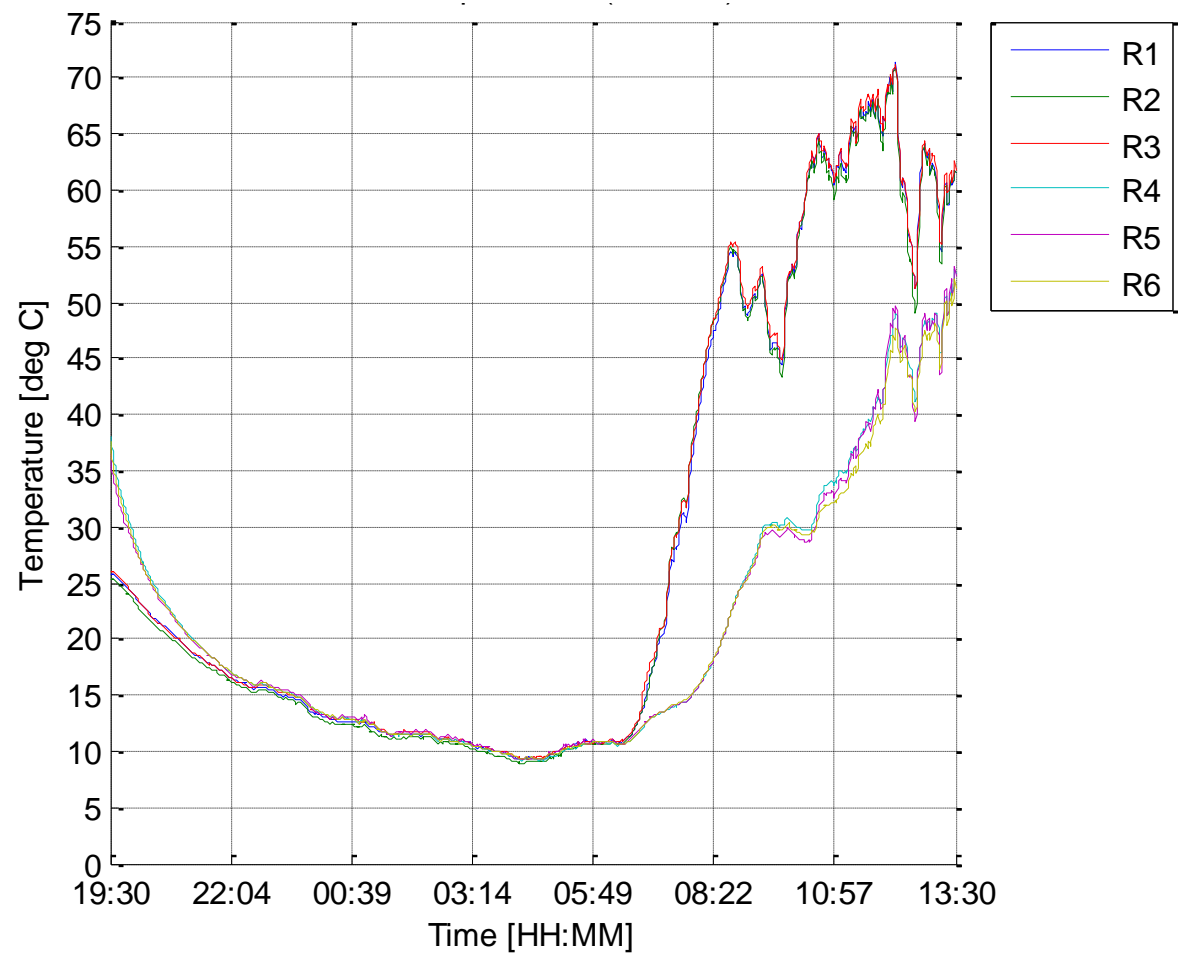

Figure 75 Environmentally Exposed Roof Temperatures (500 Unit)

Initially, a test matrix was configured to evaluate the optimal configuration for the 800 unit. The air gap heights were configured to 1.5 and 4 inches with stack heights of 2 and 4 feet tall, plus the initial 4 inch for the base stack where the air velocity sensor is mounted and a trough height of 10 inches. The results from each test configuration were analyzed and the 4 inch air gap height and $2 \mathrm{ft}$ stack height were selected for further analysis. These results are shown in Figure 76, Figure 77, Figure 78, and Figure 79 for the attic, existing roof, underneath of external roof and topside of external roof surfaces, respectively.

It should be noted that there is an increased temperature difference $\left(\sim 2^{\circ} \mathrm{C}\right)$ from the baseline data between the bottom and middle temperature sensors (R1 and R2; R6 and R5) on the existing roof. In addition, there is an even larger $\left(\sim 4^{\circ} \mathrm{C}\right)$ increase between the middle and top sensors (R2 and R3; R5 and R6). With these increased temperature differences, it is clear that the additional roof structure with the stack is providing a channel for convective flows, as opposed to just providing a shading device. 


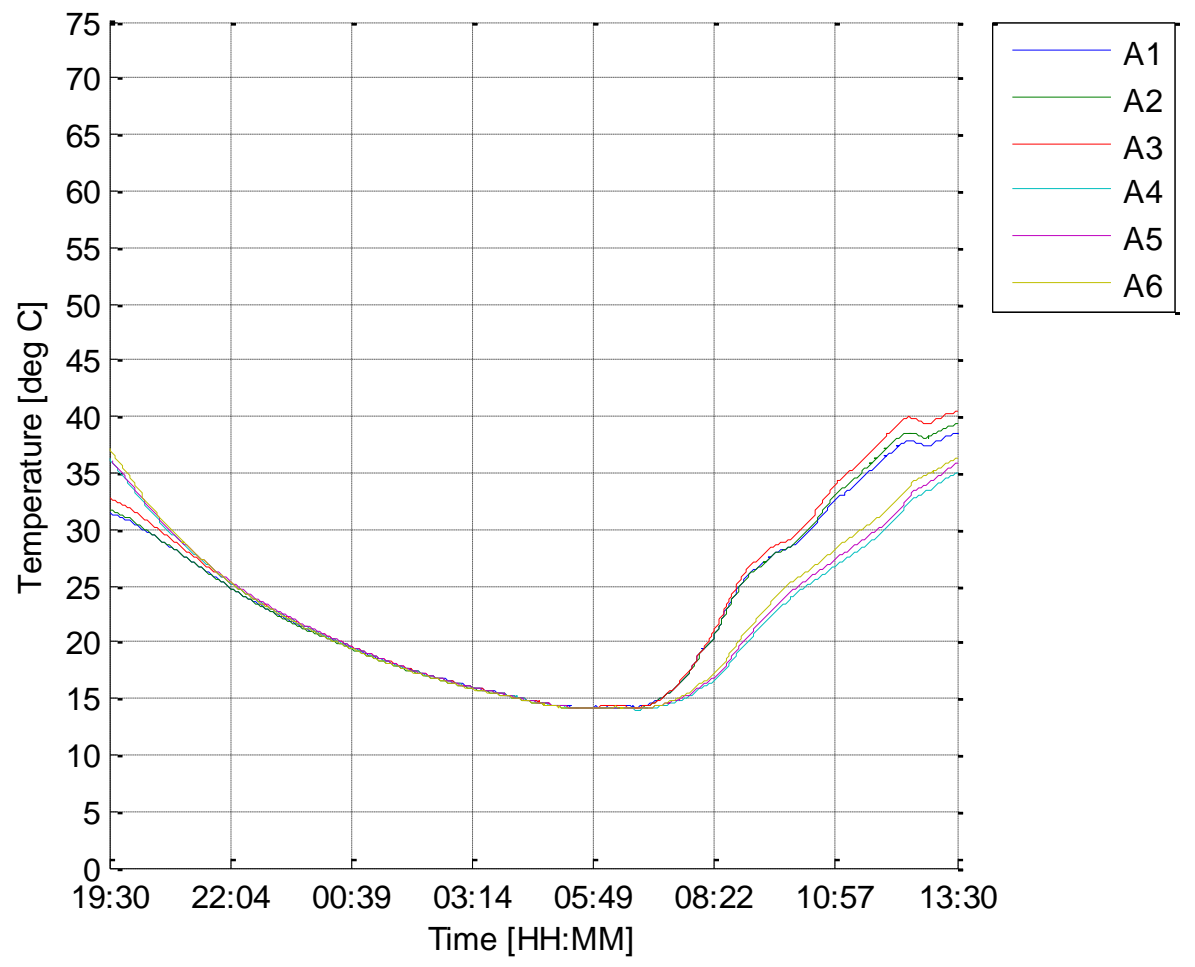

Figure 76 Environmentally Exposed Attic Temperatures (800 Unit)

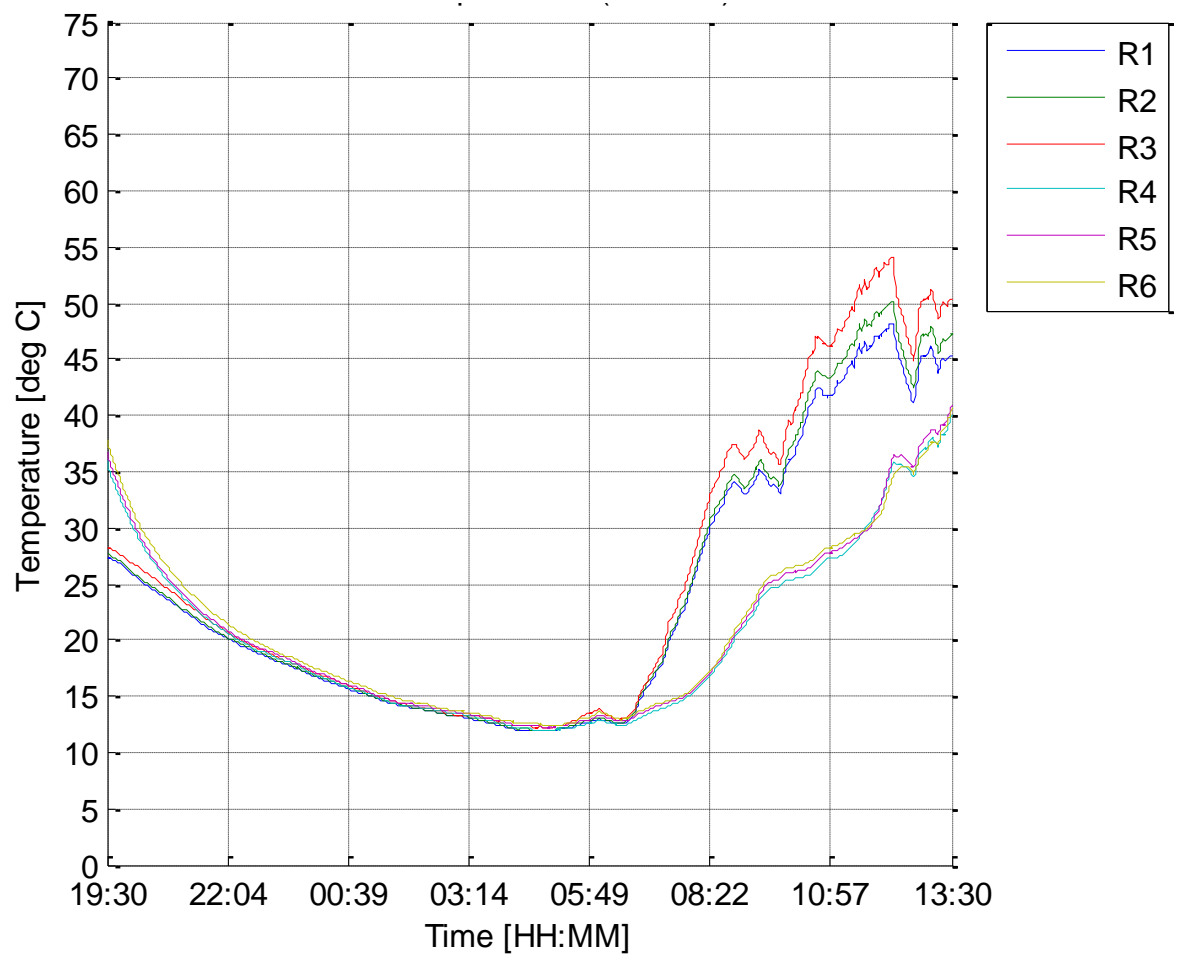

Figure 77 Environmentally Exposed Roof Temperatures (800 Unit) 


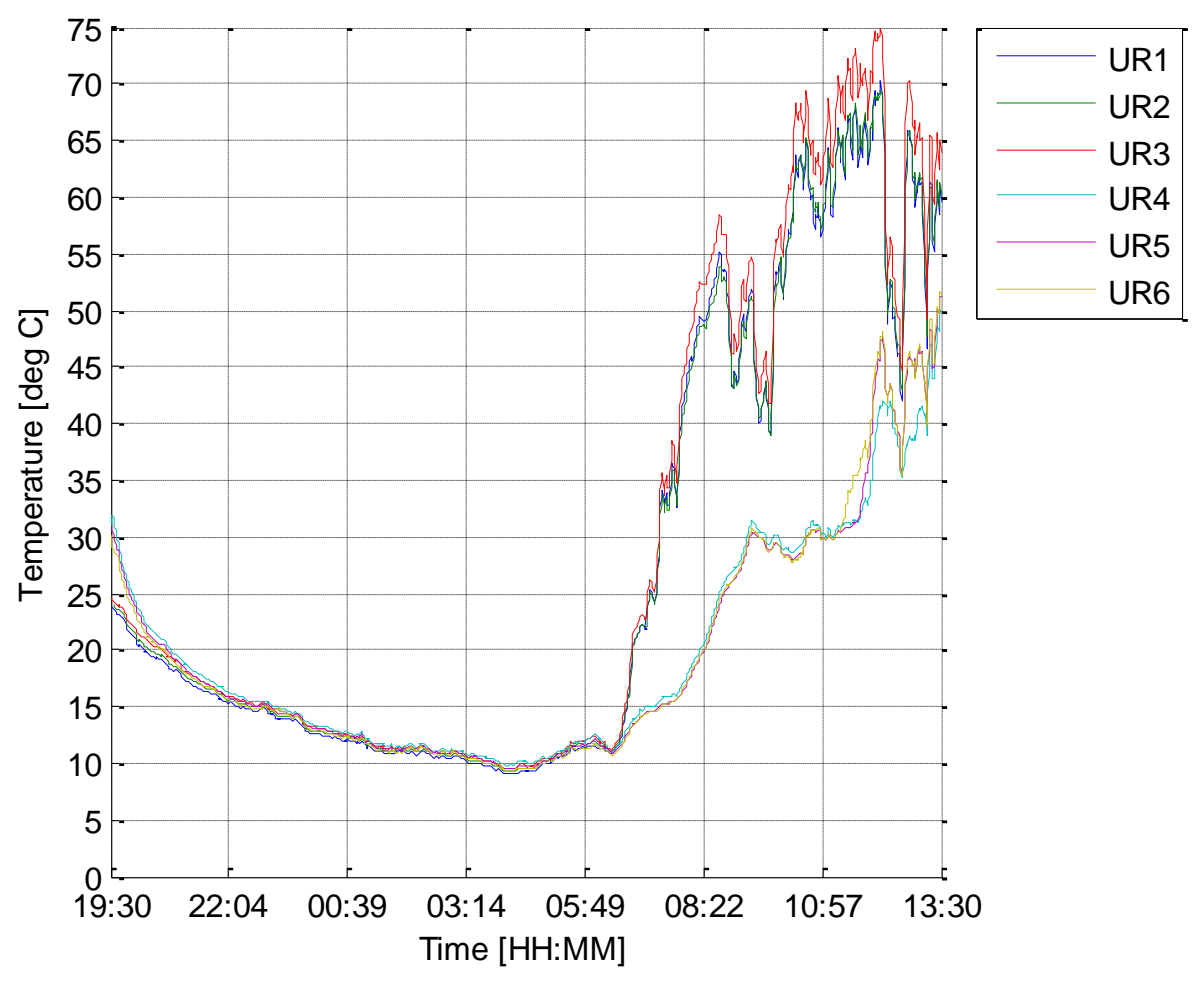

Figure 78 Environmentally Exposed Underneath External Roof Temperatures (800 Unit)

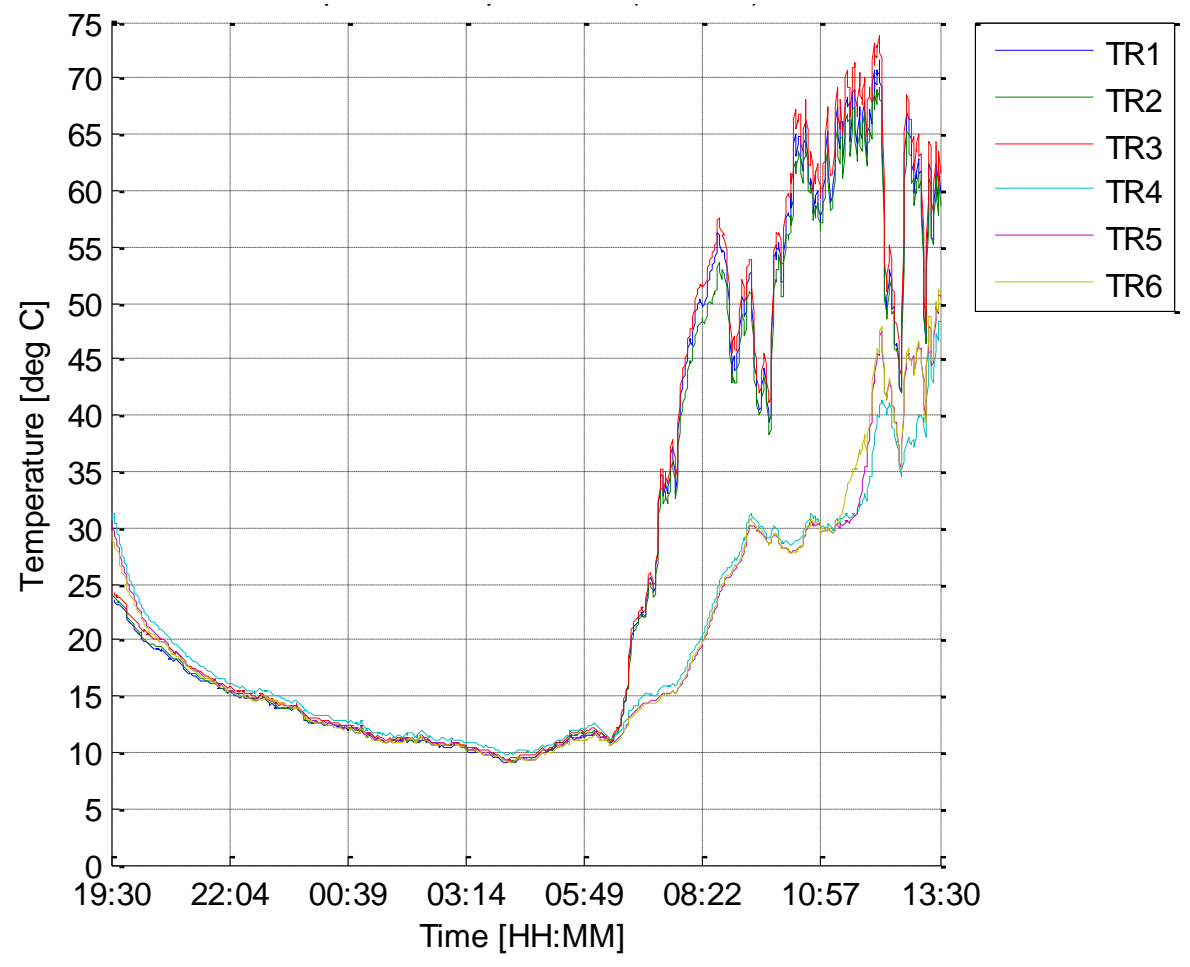

Figure 79 Environmentally Exposed Topside External Roof Temperatures (800 Unit) 
Under the two baseline environments, the attic and roof temperatures in both units were within one degree Celsius. After the additional roof structure was added to the 800 unit, the attic (Figure 74 and Figure 75) and roof (Figure 76 and Figure 77) temperatures between the two experimental units were no longer within one degree Celsius. A temperature difference of approximately 15 degrees Celsius for both the LHS and RHS of the attic is shown in Figure 80 and Figure 81. The increased stack from 2 to 4 feet increased the temperature difference between each unit. Reduced attic temperatures resulted from the decreased existing roof temperatures. A comparison between the LHS and RHS of the existing roof temperatures are shown in Figure 82 and Figure 83.

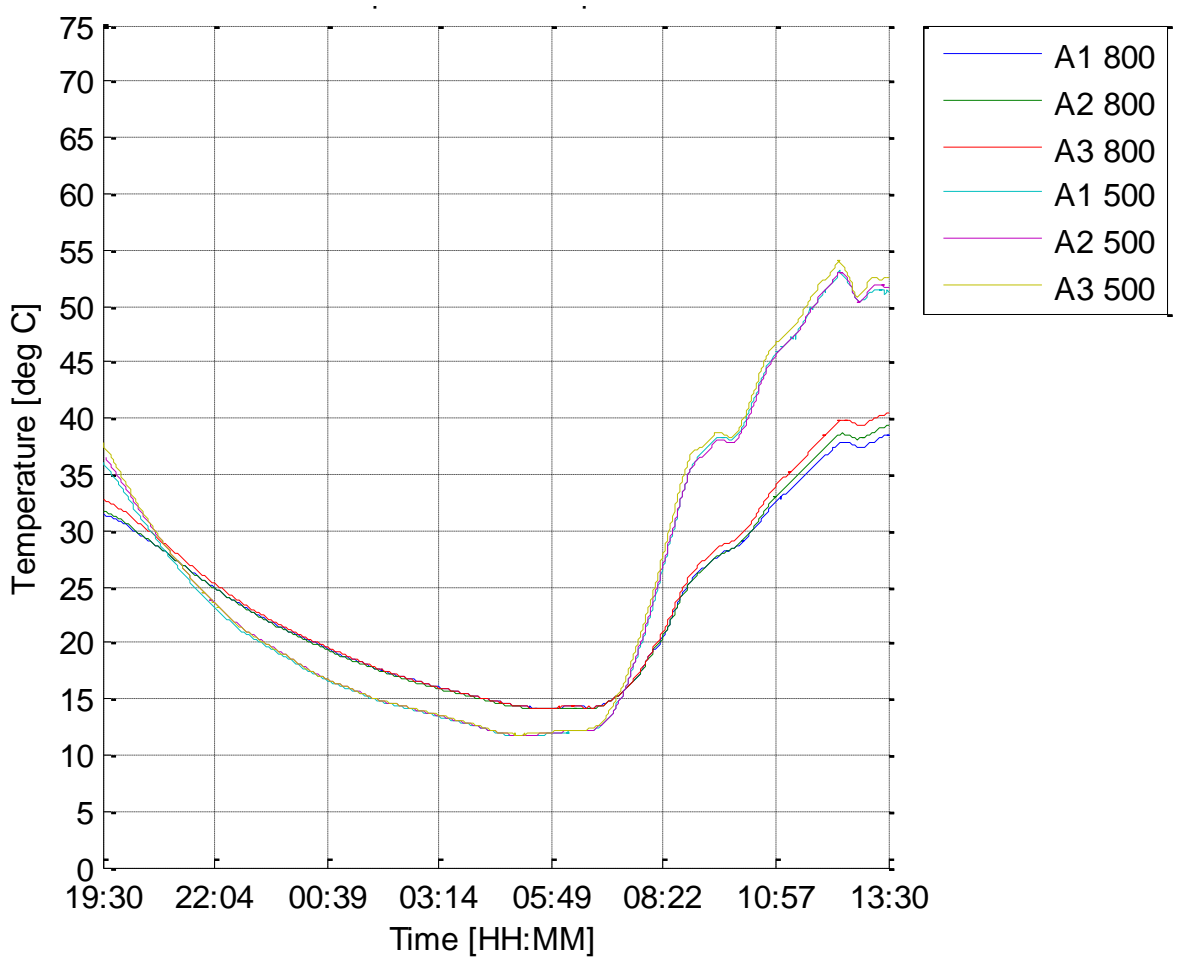

Figure 80 Comparison of LHS Attic Temperatures 


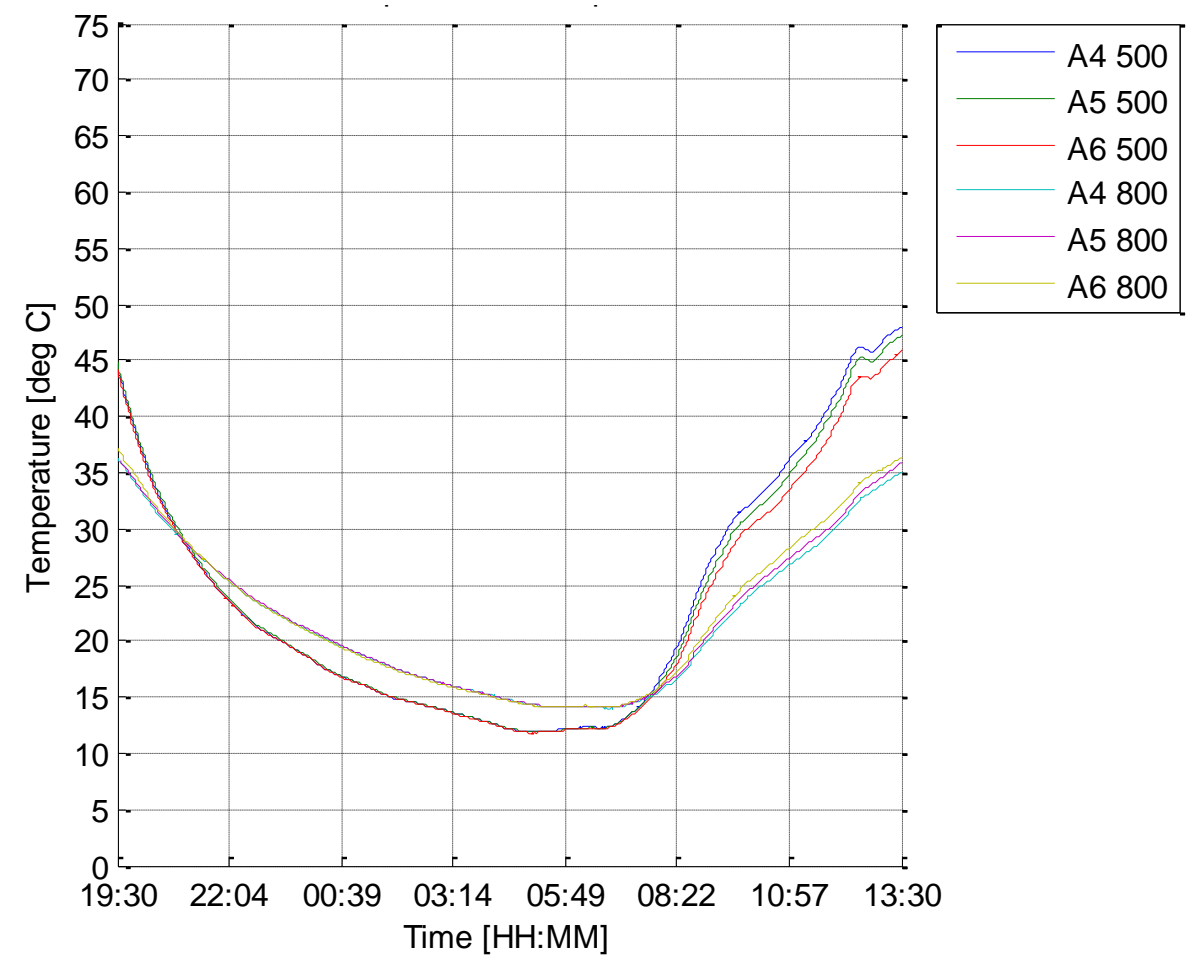

Figure 81 Comparison of RHS Attic Temperatures

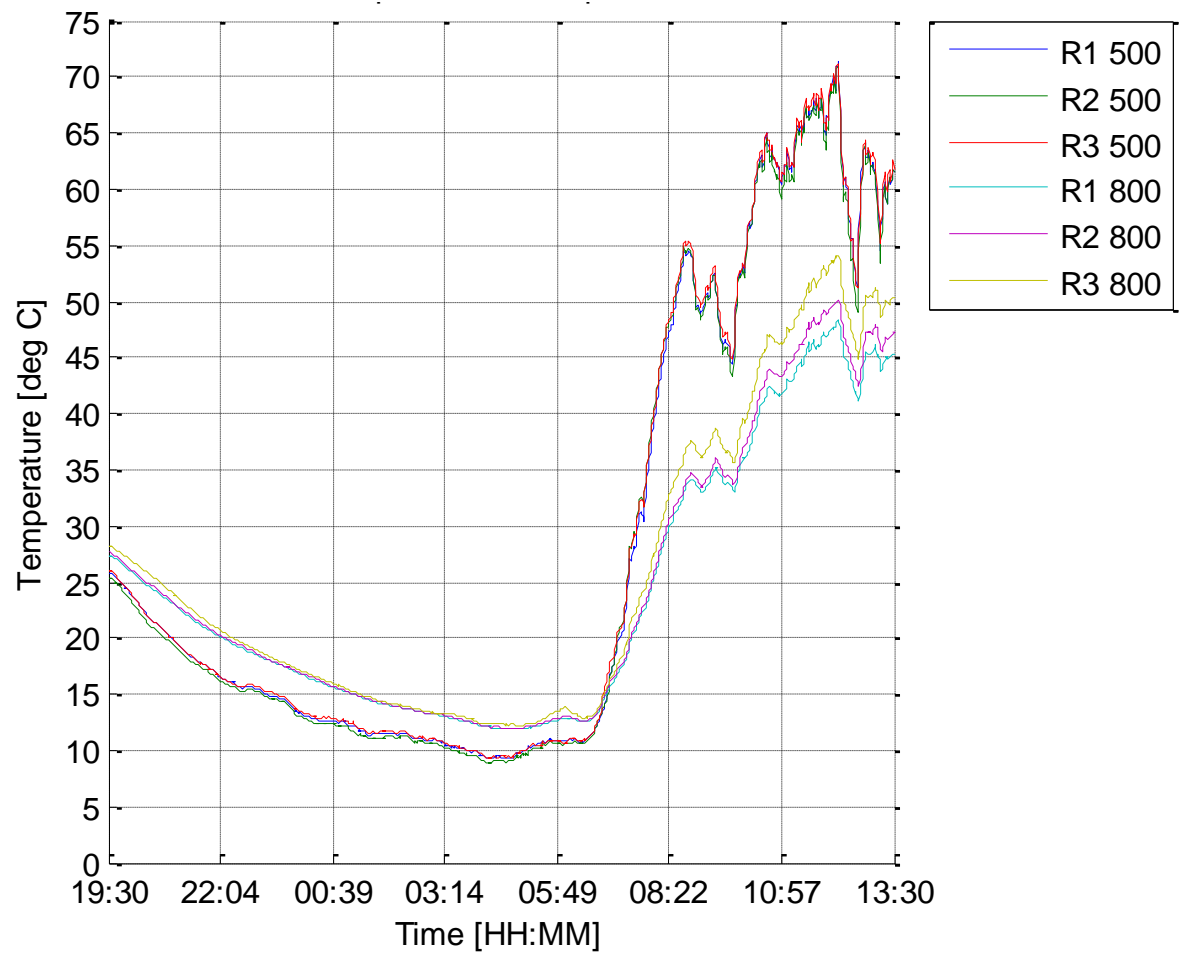

Figure 82 Comparison of LHS Roof Temperatures 


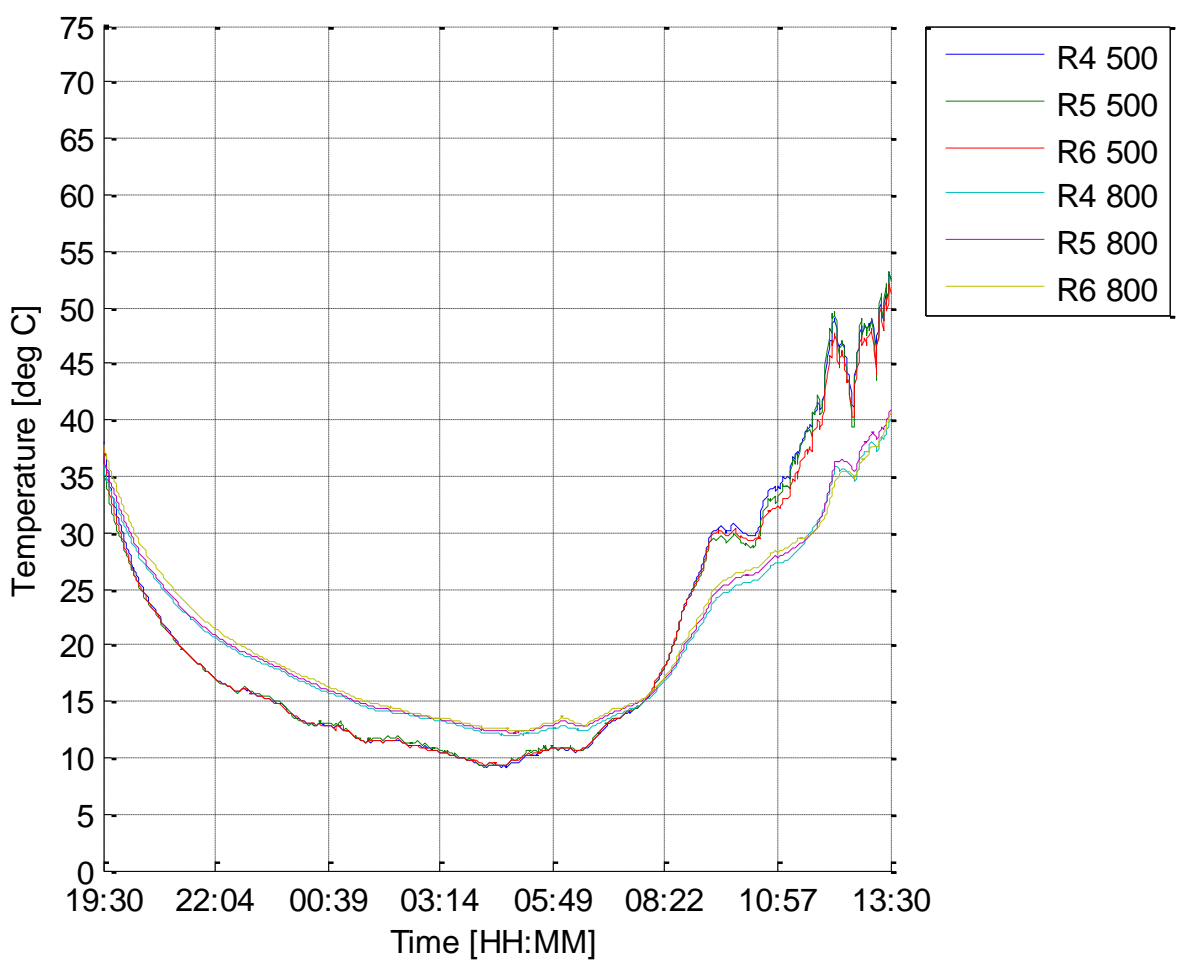

Figure 83 Comparison of RHS Roof Temperatures

In addition, Figure 84 displays the weather data for each day during the analyzed time period (Weather 2010). This weather data included the ambient and dew point temperatures, as well as the barometric pressure and humidity. For the time period shown, the ambient temperature varied from 40 to 58 degrees Celsius with pressure remaining relatively constant and humidity varying from $28 \%$ to $68 \%$. 

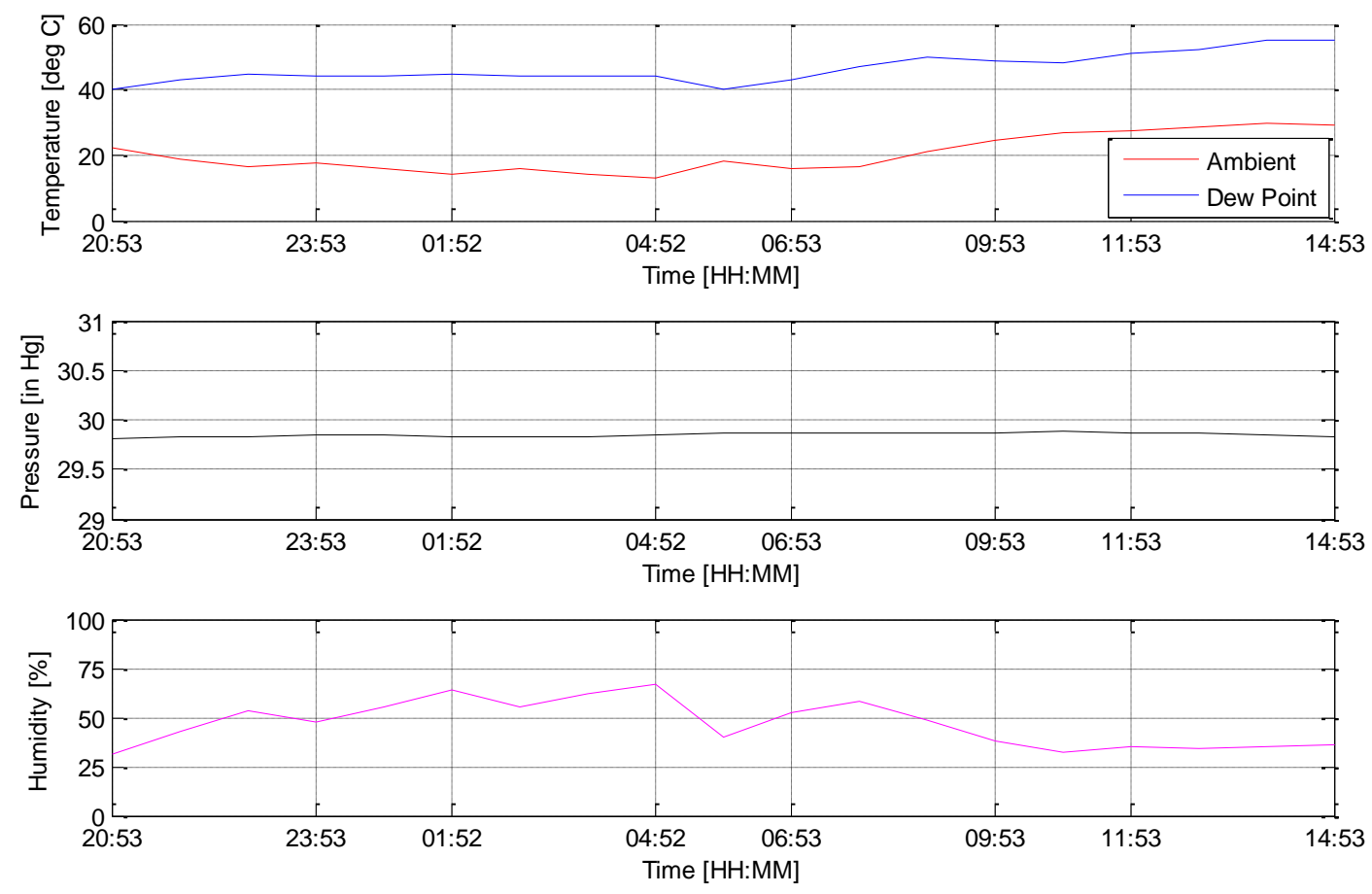

Figure 84 Weather Data (Wunderground $\left.{ }^{\circledR} 2010\right)$

For the second set of environmentally exposed tests, an air velocity transmitter was inserted 6 inches horizontally into the 2 feet stack with a 4 inch air gap. The air transmitter was initially located in the front stack in the morning hours and was moved to back stack in the afternoon hours when the top roof temperatures were approximately equal on the left and right hand sides. This transmitter monitored the exit air velocity of the stack for the second set of tests only. Figure 85 and Figure 86 show the temperatures of the attic for the 500 and 800 units, respectively. Figure 87 and Figure 88 show the temperatures of the roof for the 500 and 800 units, respectively. In addition, Figure 89 and Figure 90 show the temperatures of the topside and underneath the additional roof feature. 


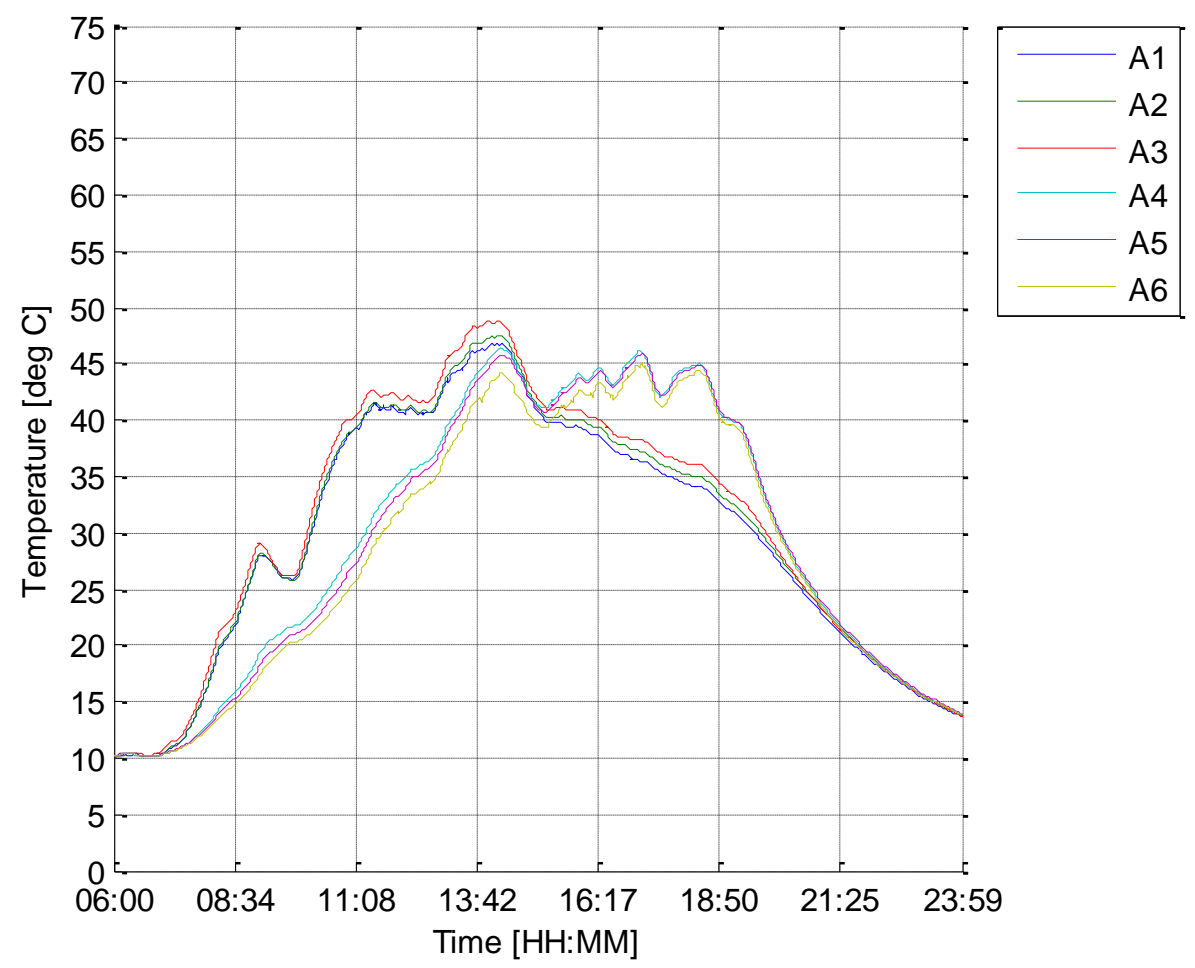

Figure 85 Attic Temperatures (500 Unit)

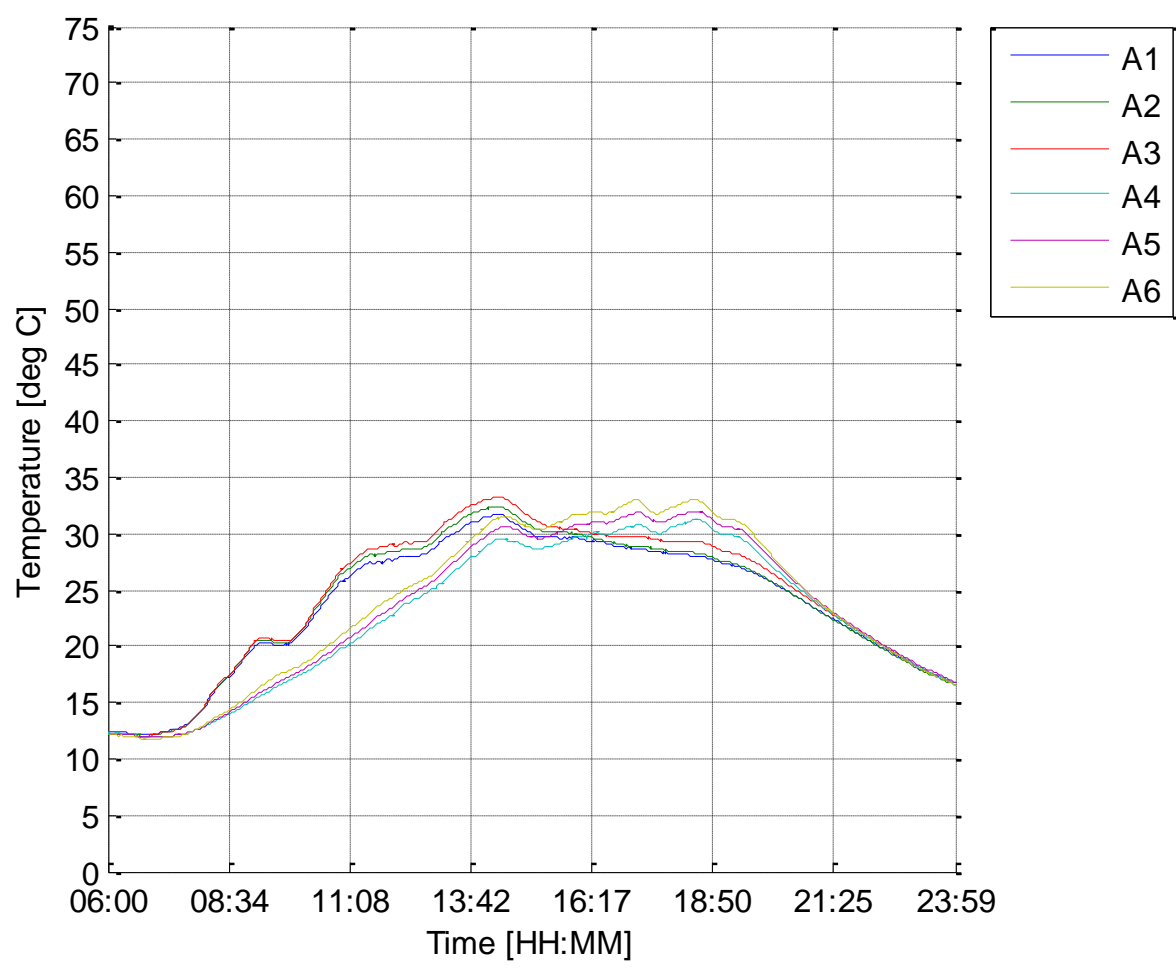

Figure 86 Attic Temperatures (800 Unit) 


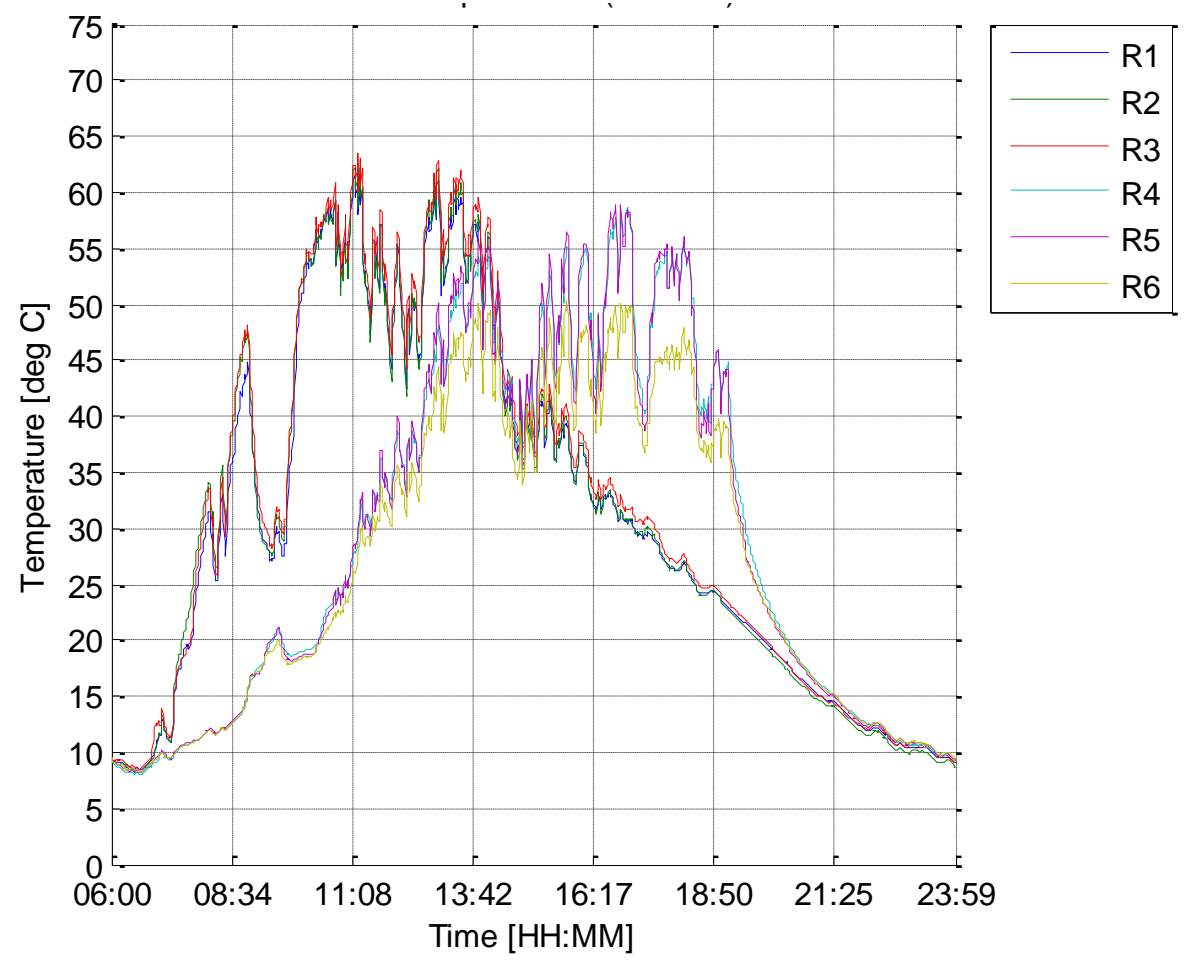

Figure 87 Roof Temperatures (500 Unit)

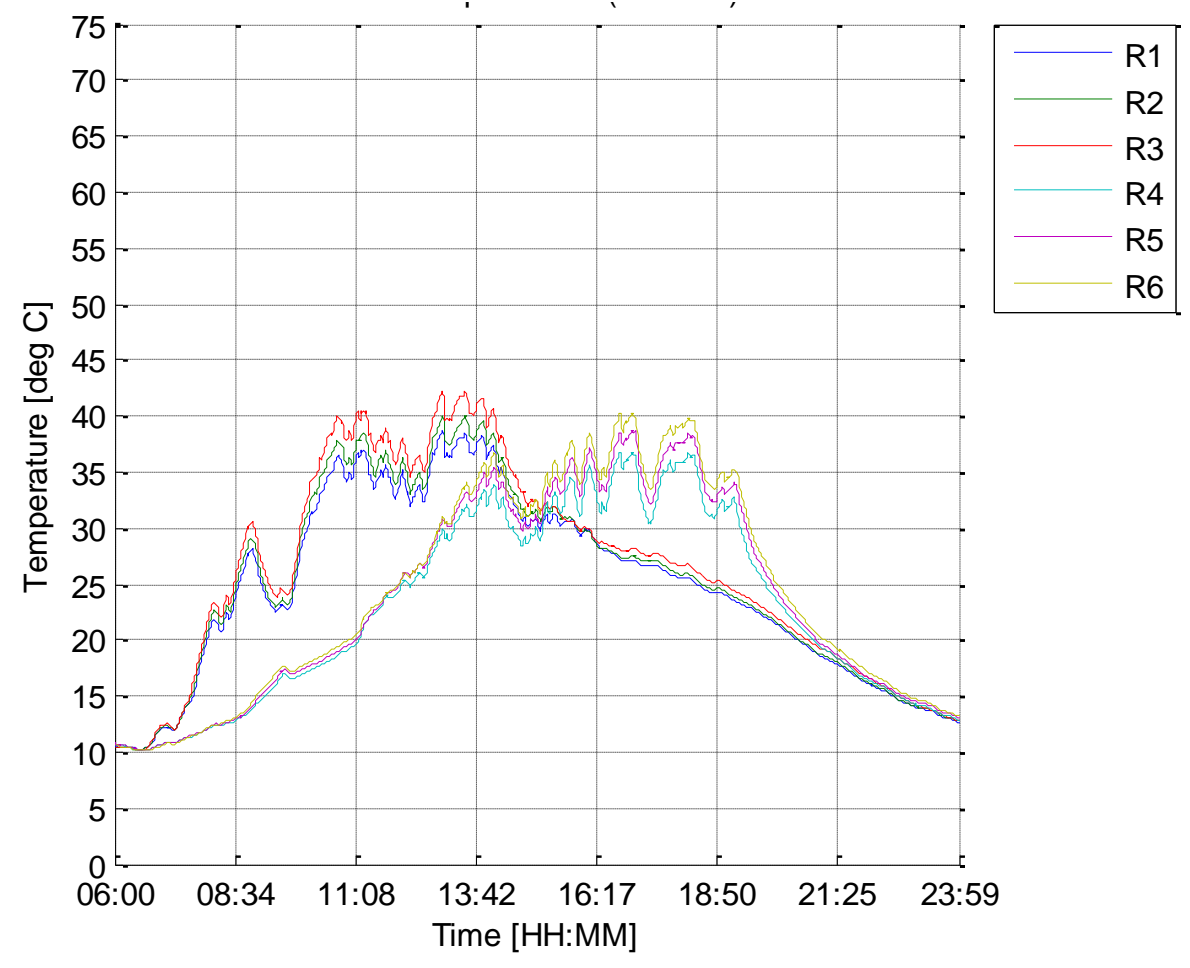

Figure 88 Roof Temperatures (800 Unit) 


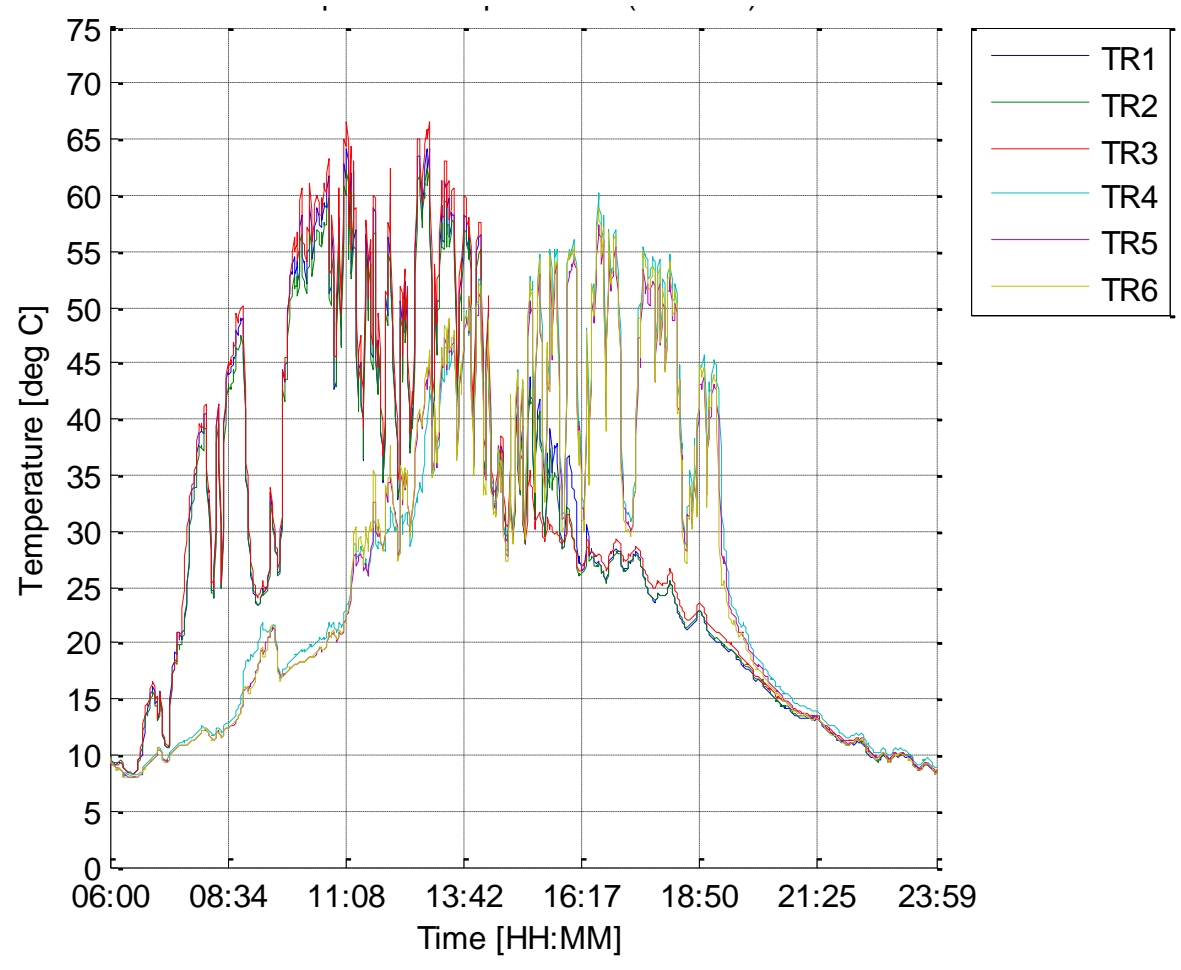

Figure 89 Topside Roof Temperatures (800 Unit)

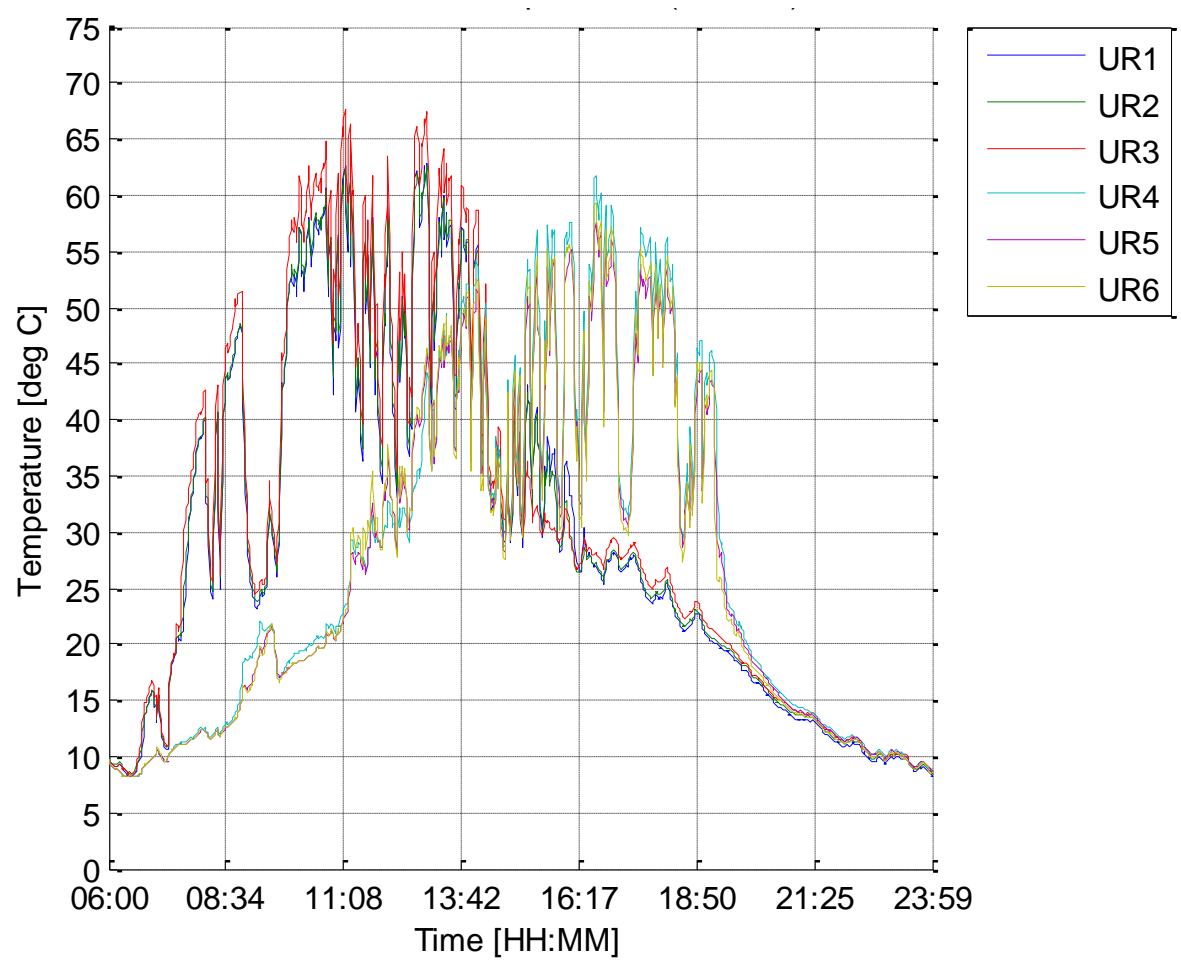

Figure 90 Underneath Roof Temperatures (800 Unit) 
Figure 91 and Figure 92 compare the LHS and RHS of each attic, while Figure 93 and Figure 94 compare the LHS and RHS of each roof. As with the previous set of environmentally exposed units, the 800 unit is significantly cooler than the 500 unit in both the attic and on the exisiting roof.

Figure 95 shows the air velocity in the front stack for the morning hours and the back stack for the afternoon hours for a 4 inch air gap and a two feet stack height. Initially, minimal air flow was present as a result of minimal temperature differences. As the temperatures increased, the air velocity also increased. In addition, Figure 96 shows the weather data for this evaluation. During this time period, ambient temperature increased while humidity decreased.

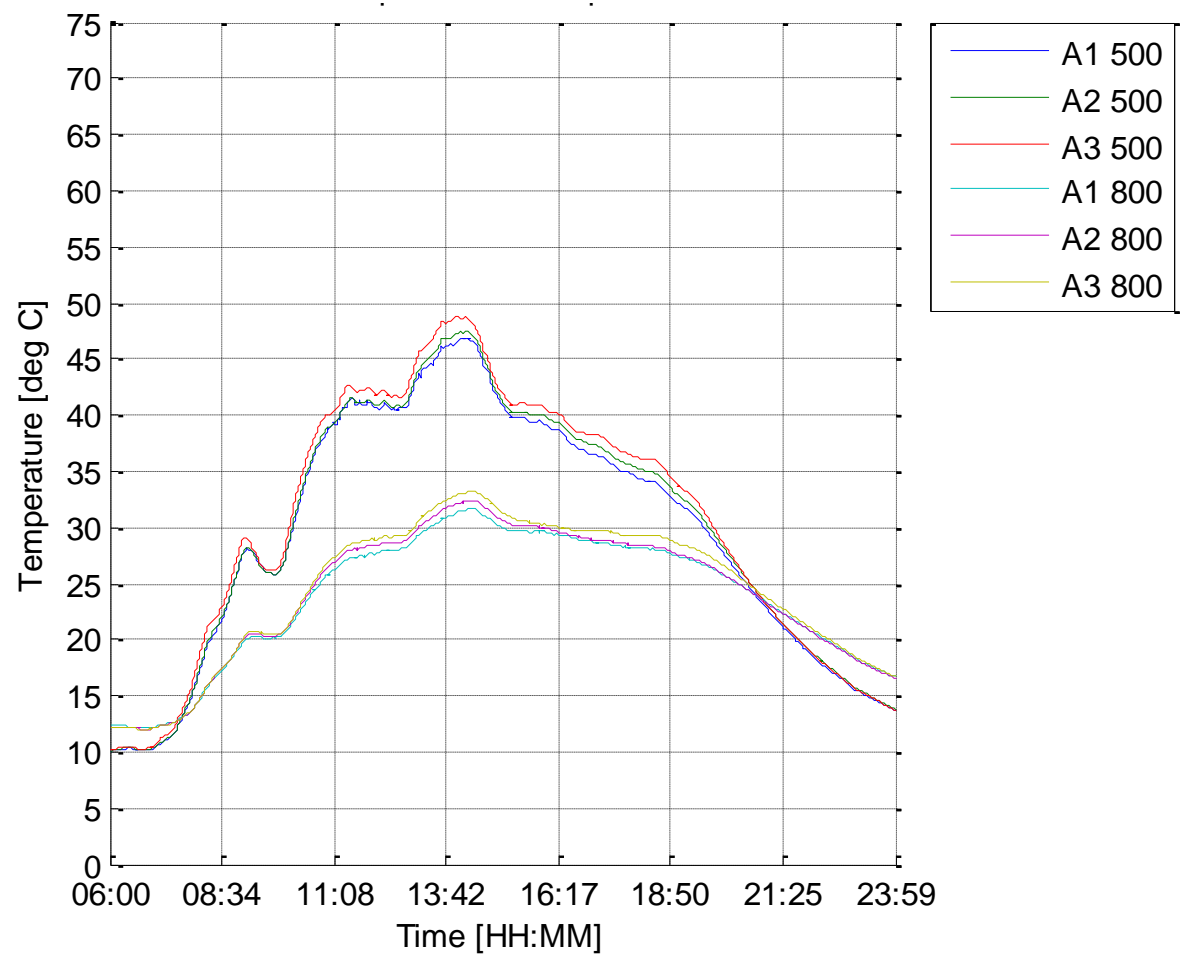

Figure 91 Comparison of LHS Attic Temperatures 


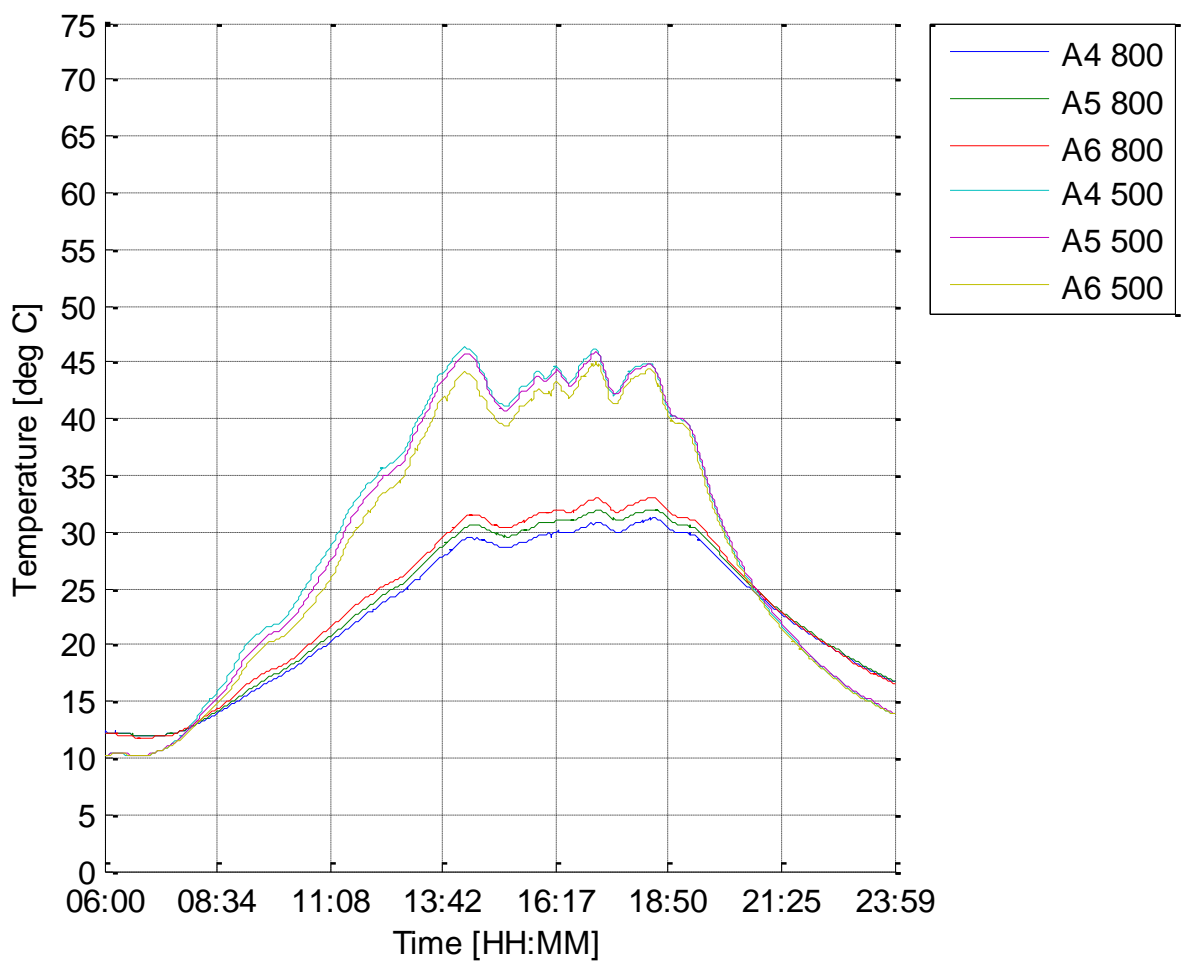

Figure 92 Comparison of RHS Attic Temperatures

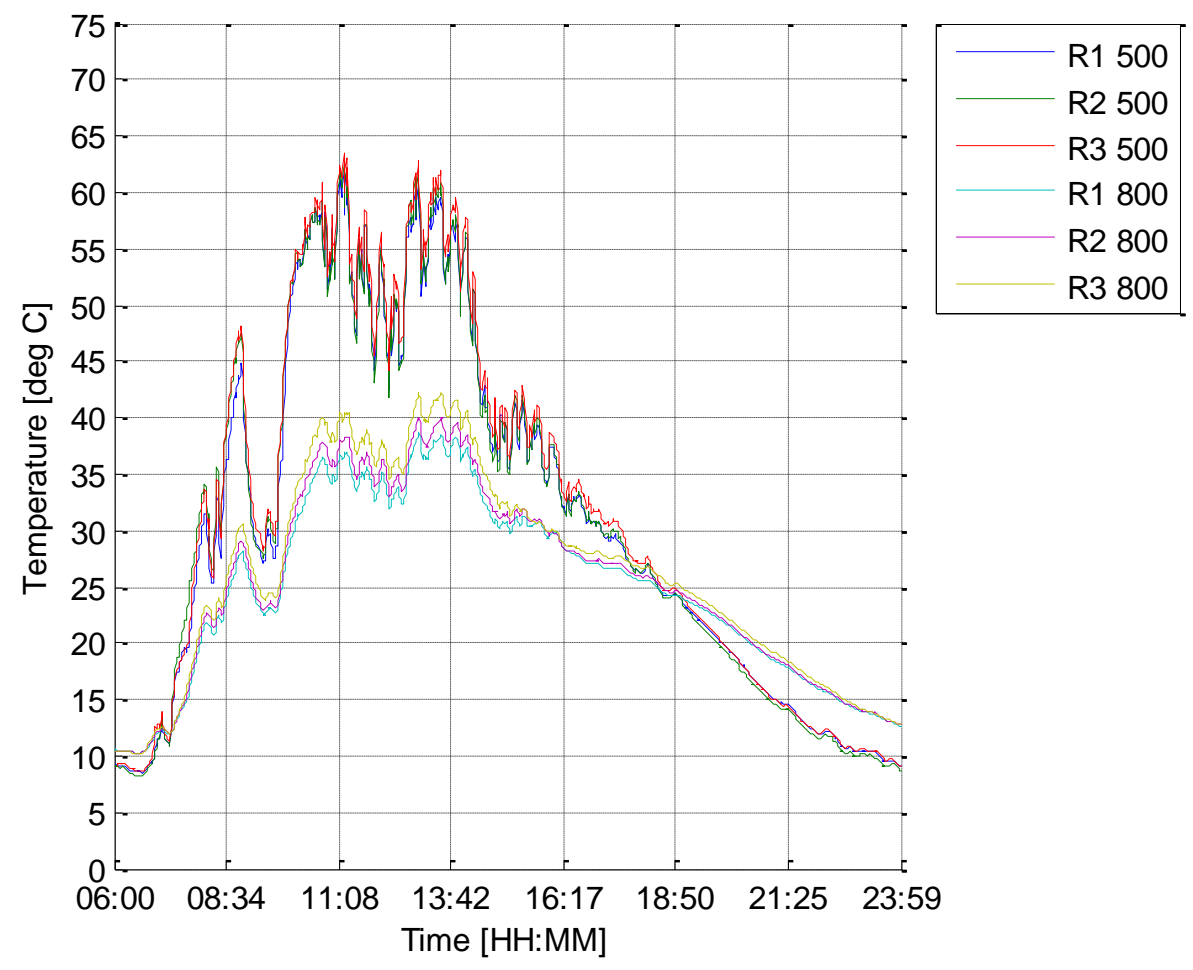

Figure 93 Comparison of LHS Roof Temperatures 


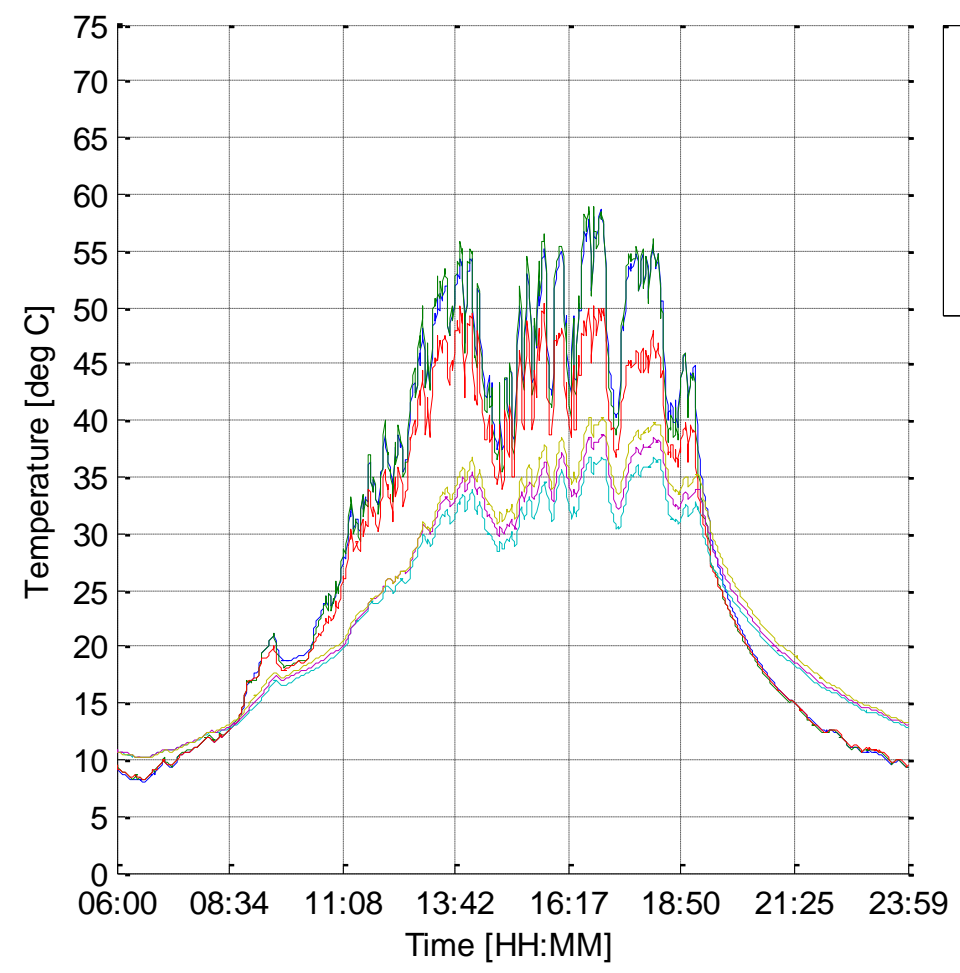

R4 500

R5 500

R6 500

R4 800

R5 800

R6 800

Figure 94 Comparison of RHS Roof Temperatures

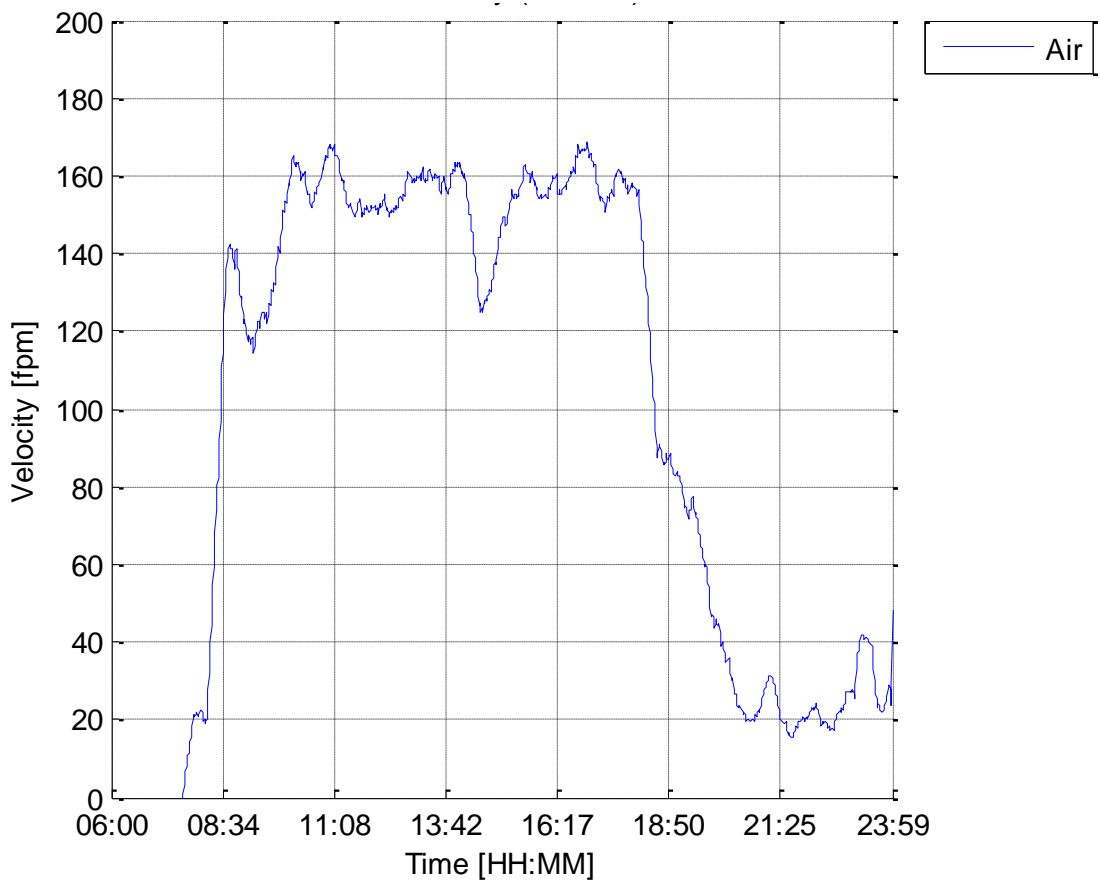

Figure 95 Stack Air Velocity 

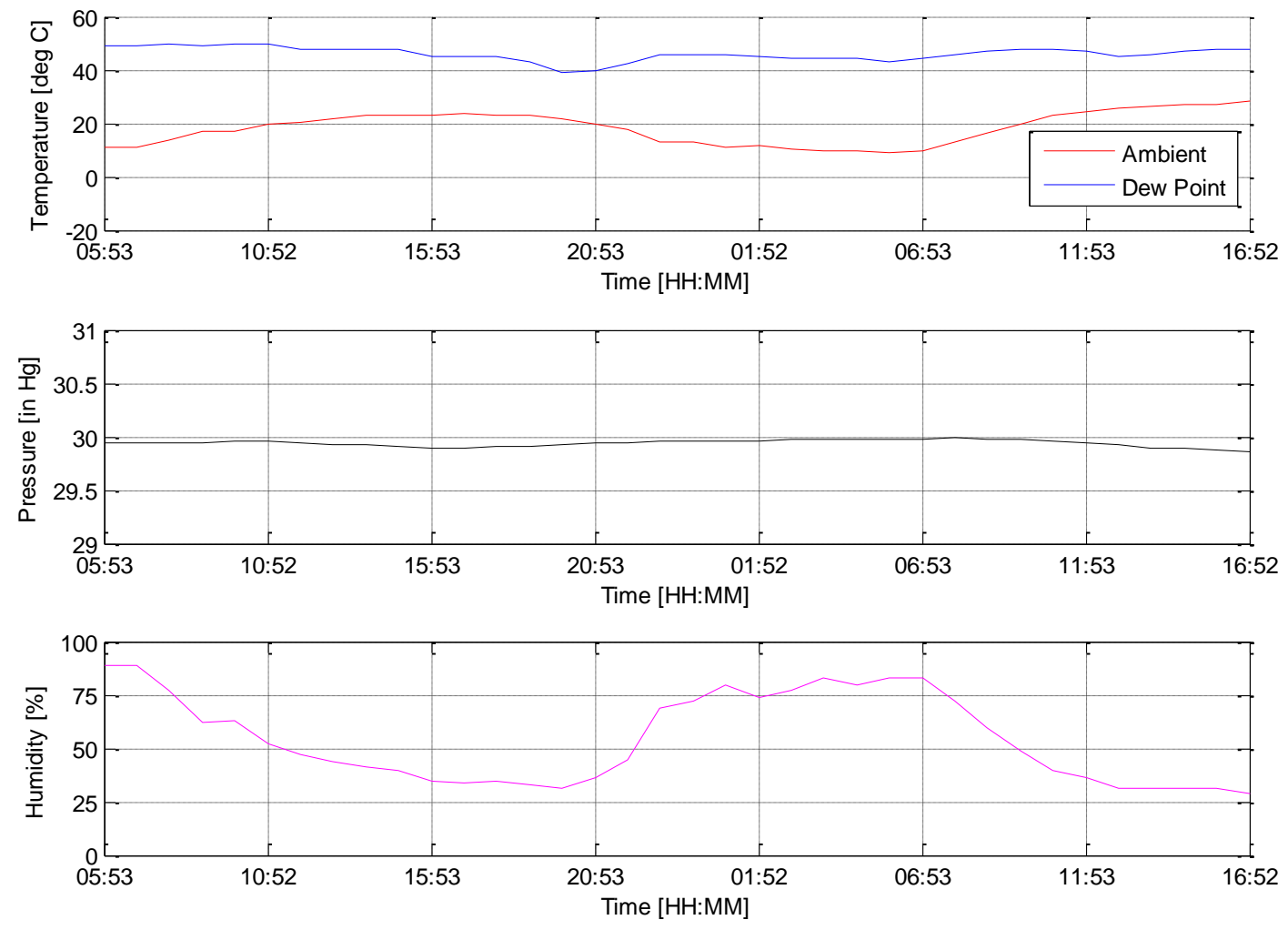

Figure 96 Weather Data (Wunderground ${ }^{\circledR} 2010$ )

A series of tests were performed on each unit in controlled and environmentally exposed environments. Data was collected inside (controlled environment), outside of the WVU Hangar (environmentally exposed) to obtain baseline data, and exposed environmentally with the addition of the heat roof.

While testing under the two baseline environments, it was found that the difference in attic and roof temperatures was minimal. After adding the thermal roof structure, the attic, and roof temperatures were significantly lower in the 800 unit as compared to the 500 unit. A temperature difference of 15-20 degrees Celsius for the both the attic and roof was observed. The results of the experimental analysis show significant decreases in the temperatures of the existing roof and attic temperatures compared to the experimental control unit. 


\subsection{Analytic and Experimental Comparison}

The analytic model was initially run using varying physical parameters, such as the orientation of the roof, exterior roof dimensions, material properties, etc. They were later rerun with the final dimensions and roof orientation of the experimental units.

A comparison between analytic and experimental results was completed. Two air gaps heights of 1.5 and 4.0 inch were evaluated with stack heights of 2 and 4 feet. The maximum attic and roof surface temperatures were averaged on the right hand side of the experimental results. The comparison of the analytic and experimental results is presented in Table 13 and Table 14.

Table 13 Analytic and Experimental Comparison (1.5 inch air gap)

\begin{tabular}{|l|c|c|c|c|}
\hline & \multicolumn{2}{|c|}{ 2 ft Stack } & \multicolumn{2}{c|}{ 4 ft Stack } \\
\hline Sensor Location & Analytic & Experimental & Analytic & Experimental \\
\hline Roof Temperatures $\left[{ }^{\circ} \mathrm{C}\right]$ & 32 & 45 & 31 & 47 \\
\hline Attic Temperatures $\left[{ }^{\circ} \mathrm{C}\right]$ & 29 & 38 & 29 & 38 \\
\hline
\end{tabular}

Table 14 Analytic and Experimental Comparison (4 inch air gap)

\begin{tabular}{|l|c|c|c|c|}
\hline & \multicolumn{2}{|c|}{ 2 ft Stack } & \multicolumn{2}{c|}{ 4 ft Stack } \\
\hline Sensor Location & Analytic & Experimental & Analytic & Experimental \\
\hline Roof Temperatures $\left[{ }^{\circ} \mathrm{C}\right]$ & 30 & 37 & 30 & 38 \\
\hline Attic Temperatures $\left[{ }^{\circ} \mathrm{C}\right]$ & 28 & 29 & 28 & 32 \\
\hline
\end{tabular}

The roof and attic temperatures of the analytic model were lower than the actual experimental results for this research. The difference between the attic and roof temperatures in the analytic model was two to three degrees. However, the experimental model showed a difference of six to nine degrees. Also, the 4 inch air gap resulted in a 7 and 8 degree temperature differential between the roof and attic, while the 1.5 inch air gap showed a much larger differential of 13 and 16 degrees for the 2 and 4 feet stacks, respectively.

The total unit thermal resistance $R_{s}\left[\mathrm{~h} \cdot \mathrm{ft}^{2} \cdot{ }^{\circ} \mathrm{F} / \mathrm{Btu}\right]$ and $\mathrm{U}$-factor of each section $U_{s}$ $\left[\mathrm{Btu} / \mathrm{h} \cdot \mathrm{ft}^{2} \cdot{ }^{\circ} \mathrm{F}\right]$ of the experimental units was determined using Equations (74) and (75) from the R-values presented in Table 15 . The overall thermal resistance $R_{\text {overall }}\left[\mathrm{h} \cdot \mathrm{ft}^{2} \cdot{ }^{\circ} \mathrm{F} / \mathrm{Btu}\right]$ and overall heat transfer coefficient $U_{\text {overall }}\left[\mathrm{Btu} / \mathrm{h} \cdot \mathrm{ft}^{2} \cdot{ }^{\circ} \mathrm{F}\right]$ were determined using Equations (76) and (77). These calculations assumed steady operating conditions, heat transfer is one-dimensional, and thermal properties of the roof and heat transfer coefficients are constant. 


$$
\begin{gathered}
R_{s}=\sum R_{i} \\
U_{s}=\frac{1}{R_{s}} \\
U_{\text {overall }}=\sum f_{\text {area }, i} U_{i} \\
R_{\text {overall }}=\frac{1}{U_{\text {overall }}}
\end{gathered}
$$

\begin{tabular}{|c|c|c|}
\hline Construction & $\begin{array}{c}\text { Between Studs } \\
{\left[\mathbf{h}^{\prime} \cdot \mathbf{f t}^{2} \cdot{ }^{\circ} \mathbf{F} / \text { Btu }\right]}\end{array}$ & $\begin{array}{c}\text { At Studs } \\
{\left[\mathbf{h} \cdot \mathbf{f t}^{2} \cdot{ }^{\circ} \mathbf{F} / \mathbf{B t u}\right]}\end{array}$ \\
\hline Outside surface, $15 \mathrm{mph}$ wind & 0.17 & 0.17 \\
\hline Asphalt shingle roofing & 0.44 & 0.44 \\
\hline Asphalt roll roofing & 0.15 & 0.15 \\
\hline Plywood deck, 5/8 in & 0.78 & 0.78 \\
\hline Non-reflective air space, 3.5 in & 0.86 & - \\
\hline Wood stud, 2 in $\times 4$ in & - & 3.58 \\
\hline Inside surface, 45 degree slope, still air & 0.63 & 0.63 \\
\hline Total unit thermal resistance of each section, $R_{S}$ & 3.03 & 5.75 \\
\hline U-factor of each section $\left[\mathrm{Btu} / \mathrm{h} \cdot \mathrm{ft}^{2} \cdot{ }^{\circ} \mathrm{F}\right]$ & 0.33 & 0.17 \\
\hline Area fraction of each section, $f_{\text {area }}$ & 0.85 & 0.15 \\
\hline Overall U-factor & 0.31 & {$\left[\mathbf{B t u} / \mathbf{h} \cdot \mathbf{f t}^{2} \cdot{ }^{\circ} \mathbf{F}\right]$} \\
\hline Overall unit thermal resistance & 3.26 & {$\left[\mathbf{h} \cdot \mathbf{f t}^{2} \cdot{ }^{\circ} \mathbf{F} / \mathbf{B t u}\right]$} \\
\hline Roof Area, $10 \mathrm{ft} \times 6.83 \mathrm{ft}$ & 68.33 & {$\left[\mathbf{f t}^{2}\right]$} \\
\hline
\end{tabular}

Table 15 R-Values and $U$-Factor

Therefore, the overall unit thermal resistance of the experimental configuration is 3.26 $\mathrm{h} \cdot \mathrm{ft}^{2} \cdot{ }^{\circ} \mathrm{F} / \mathrm{Btu}$ and the overall $\mathrm{U}$-factor is $0.31 \mathrm{Btu} / \mathrm{h} \cdot \mathrm{ft}^{2} \cdot{ }^{\circ} \mathrm{F}$. Note: the wood studs offer much larger thermal resistant to heat flow than the air space between the studs. The heat transfer through the shingled roof to the attic is shown in Table 16 and Table 17 for the 1.5 and 4 inch air gaps, respectively. The heat transfer was calculated using the product of the $\mathrm{R}$-value $\left[\mathrm{h} \cdot \mathrm{ft}^{2} \cdot{ }^{\circ} \mathrm{F} / \mathrm{Btu}\right]$, roof area $\left[\mathrm{ft}^{2}\right]$, and change in temperature between the attic and roof $\left[{ }^{\circ} \mathrm{F}\right]$. 
Table 16 Heat Transfer (1.5 inch air gap)

\begin{tabular}{|l|c|c|c|c|}
\hline & \multicolumn{2}{|c|}{ 2 ft Stack } & \multicolumn{2}{c|}{ 4 ft Stack } \\
\hline Sensor Location & Control & Experimental & Control & Experimental \\
\hline Roof Temperature $\left[{ }^{\circ} \mathrm{F}\right]$ & 144 & 113 & 158 & 117 \\
\hline Attic Temperature $\left[{ }^{\circ} \mathrm{F}\right]$ & 115 & 93 & 127 & 100 \\
\hline Change in Temperature $\left[{ }^{\circ} \mathrm{F}\right]$ & 29 & 20 & 31 & 16 \\
\hline Heat Transfer $[\mathrm{Btu} / \mathbf{h}]$ & $\mathbf{6 0 3}$ & $\mathbf{4 1 5}$ & $\mathbf{6 4 1}$ & $\mathbf{3 3 9}$ \\
\hline
\end{tabular}

Table 17 Heat Transfer (4 inch air gap)

\begin{tabular}{|l|c|c|c|c|}
\hline & \multicolumn{2}{|c|}{ 2 ft Stack } & \multicolumn{2}{c|}{ 4 ft Stack } \\
\hline Sensor Location & Control & Experimental & Control & Experimental \\
\hline Roof Temperature $\left[{ }^{\circ} \mathrm{F}\right]$ & 145 & 99 & 136 & 100 \\
\hline Attic Temperature $\left[{ }^{\circ} \mathrm{F}\right]$ & 104 & 81 & 117 & 90 \\
\hline Change in Temperature $\left[{ }^{\circ} \mathrm{F}\right]$ & 41 & 18 & 20 & 11 \\
\hline Heat Transfer $[\mathrm{Btu} / \mathbf{h}]$ & $\mathbf{8 6 7}$ & $\mathbf{3 7 7}$ & $\mathbf{4 1 5}$ & $\mathbf{2 2 6}$ \\
\hline
\end{tabular}

The 1.5 inch air gap showed a $31 \%$ and $47 \%$ reduction in heat transfer with the 2 and 4 feet stacks, respectively. On the other hand, when the air gap was increased to 4 inches, the reduction in heat transfer was $57 \%$ and $45 \%$ for the two and four feet stacks, respectively.

In the thermal analysis of buildings, the size or capacity of the heating and cooling system and the annual energy consumption are of major interest. The size of heating or cooling systems is based on the most demanding situations under the anticipated worst weather conditions, whereas the annual energy consumption is based on average usage situations under average weather conditions. Therefore the calculation procedure of annual energy usage is quite different than that of design heating or cooling loads.

The simplest and easiest method way of estimating the annual energy consumption of a building is the degree-day method. This steady state approach is based on constant indoor conditions during the heating or cooling season and assumes the efficiency of the heating or cooling equipment is not affected by the variation of outdoor ambient temperatures. The degree day method was used to predict the annual energy savings for a residential home from the experimental results of this research.

Table 18 shows the differences of the heat transfer with varying stack and air gap heights between the control and experimental units. The average of the four scenarios shows the reduced 
amount of energy between the two units. This amount was then divided by the square footage of the experimental unit to determine the energy per square foot. The energy per square foot was then multiplied by the first floor area of the average sized residential home, as shown in Table 19. 


\section{Table 18 Difference in Calculated Heat Transfer}

\begin{tabular}{|c|c|}
\hline & $\begin{array}{c}\text { Heat Transfer } \\
{[\text { [Btu/h] }}\end{array}$ \\
\hline 2 ft stack, 1.5 in air gap & 189 \\
\hline 4 ft stack, 1.5 in air gap & 302 \\
\hline 2 ft stack, 4 in air gap & 490 \\
\hline 4 ft stack, 4 in air gap & 189 \\
\hline Average & $\mathbf{2 9 2}$ \\
\hline
\end{tabular}

The area of an average residential home has between $2,300 \mathrm{ft}^{2}$ and $2,700 \mathrm{ft}^{2}$ of occupied living space that is either cooled or heated. The experimental unit used in this research was a one story, one room building, with a floor area of $64 \mathrm{ft}^{2}$. To extrapolate the energy savings to an average residential home, a footprint of $1,250 \mathrm{ft}^{2}$ (50\% of average area) was used which translated into an estimated energy savings of $5,703 \mathrm{Btu} / \mathrm{h}$. The indoor and outdoor summer design temperatures of $75^{\circ} \mathrm{F}$ and $90^{\circ} \mathrm{F}$ produce a change in temperature of $15^{\circ} \mathrm{F}$. The current electrical energy costs and cooling degree days for the Morgantown, WV area were $\$ 0.07 / \mathrm{kWh}$ and $1,055^{\circ} \mathrm{F}$-day with a $65^{\circ} \mathrm{F}$ base (ASHRAE 1997), respectively. A seasonal energy efficiency ratio of $13 \mathrm{Btu} / \mathrm{h}$ was selected for these calculations since this is the minimum for airconditioners manufactured after 2006. The energy consumed for cooling $E_{c}[\mathrm{~kW} \cdot \mathrm{h}]$ was calculated using Equation (78):

$$
E_{c}=\frac{q_{g}(C D D) 24}{1000(S E E R) \Delta T},
$$

where $q_{g}$ is the design cooling load [Btu/h], $C D D$ is cooling degree days, and $\Delta T$ is the design temperature difference $\left[{ }^{\circ} \mathrm{F}\right]$. Using all the parameters mentioned previously, the reduced energy cooling requirements is $741 \mathrm{~kW} \cdot \mathrm{h}$ which would produce a projected annual savings of $\$ 52$ ( $15 \%$ savings) for a 1,250 $\mathrm{ft}^{2}$ single story, residential home using the degree day method. 
Table 19 Degree Day Method Calculations

\begin{tabular}{|l|c|}
\hline Description & Amount \\
\hline Reduction of Energy $[\mathrm{Btu} / \mathrm{h}]$ & 292 \\
\hline Area of Experimental Unit $\left[\mathrm{ft}^{2}\right]$ & 64 \\
\hline Energy per area $\left[\mathrm{Btu} / \mathrm{h} / \mathrm{ft}^{2}\right]$ & 4.6 \\
\hline First floor area of house $\left[\mathrm{ft}^{2}\right]$ & 1,250 \\
\hline Estimated energy savings $[\mathrm{Btu} / \mathrm{h}]$ & 5,703 \\
\hline Change in temperature $\left[{ }^{\circ} \mathrm{F}\right]$ & 15 \\
\hline Cooling Degree Days & 1,055 \\
\hline SEER [Btu/h/W] & 13 \\
\hline Energy consumed $[\mathrm{kWh}]$ & 741 \\
\hline Electricity Costs $[\$ / \mathrm{kWh}]$ & 0.07 \\
\hline Annual Savings & $\mathbf{\$ 5 2}$ \\
\hline
\end{tabular}

\subsection{Results Summary}

As anticipated and further predicted by the initial modeling, there is a difference in temperature, $\Delta \mathrm{T}$ between the two structures with the addition of the heat roof. Furthermore, while the temperature on the control unit had little fluctuations with location on the outside of the roof (top to bottom), the experimental unit indicated a large variance from top to bottom, as would be expected with the addition of convective flow.

The inside attic temperatures between the two structures were consistent and represented a predictable amount of convective mixing in the attic areas. Note, however that early morning sun exposure showed temperature differentials based primarily on the angle of incidence of the sun with respect to the roof surface.

The addition of the heat roof mitigated fluctuations in the attic temperatures such that for instance the presence of clouds was seen quicker than for the heat roof. Note also that the temperatures at night indicated a reversal in $\Delta \mathrm{T}$ between attics where the heat roof was providing an insulating medium offsetting the effects of the decreasing night time temperature. As soon as the sun cleared the horizon, there was a crossing of these $\Delta \mathrm{T}$ plots and the rest of the day the control remained hotter.

The temperature differential $\Delta \mathrm{T}$ between the two attics was constant with the hypothesis results where the added heat roof provided approximately a $10^{\circ} \mathrm{C}$ to $15^{\circ} \mathrm{C}$ differential between 
the two structures. While it is clear that the cost to install and maintain has not been factored in into the overall cost of such an addition this level of temperature differential will reduce the heat load being absorbed by a cooling system with the reverse, through not as dramatic, during the cooler winter months for heating. 


\section{Conclusions}

A novel type of thermal management system driven by buoyancy effects was evaluated using experimental and analytic techniques. The experimental results clearly indicate that the thermal management system is a viable means to reduce heat flow into attic spaces. This result is also confirmed by the steady state analytic model, although the differences predicted by the analytic model are lower than what was measured experimentally. As the experimental measurements were transient in nature, the experimental temperature differences are expected to be larger than predicted by the analytic model. This is the case when the attic interior temperature has not established steady state conditions.

In addition, the experimental model confirmed as the air gap height is increased, the temperature differential between the shingled roof and attic decreased. Likewise, as the stack height was increased, the temperature differential between the shingled roof and attic decreased due to increased air flow speed which enhances convective heat transfer. As a result, the heat flux into the attic was decreased with the smaller air gap or larger stack heights.

The reduction of heat transfer into the attic, as demonstrated by the experimental model, can translate into energy savings which over a lifetime can be significant. Using the degree-day method and the current electricity costs for the Morgantown, WV area, this resulted in an increased energy savings of $15 \%$. 


\section{RECOMMENDATIONS}

Future research on this passive thermal management system should be considered. Several areas could be addressed including using a solar cell, local weather station, removing the ridge, and modifying the test matrix.

A solar cell, such as the Hydrolynx Model 4015 depicted in Figure 97, could be used to measure the total sun and sky radiation. The sensor responds to a $100 \%$ change in incoming radiation within one millisecond. This sensor is a silicone photovoltaic cell which provides an output signal proportional to solar radiation energy from 0 to $1400 \mathrm{~W} / \mathrm{m}^{2}$. A Pyrex glass dome, sealed with a removable desiccant, protects the silicone cell from dust and moisture.

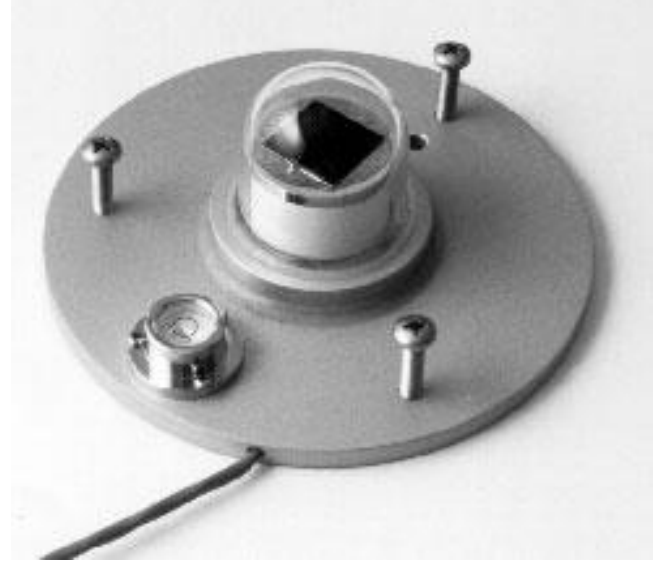

\section{Figure 97 Hydrolynx Model 4015 Solar Photovoltaic Cell}

A weather station, such as the Oregon Scientific Professional Weather Station (Model No.: WMR200A), as pictured in Figure 98, could be used to capture various measurements. This unit can capture over 10 weather measurements wirelessly up to 300 feet away at $433 \mathrm{MHz}$ from the base unit, has its own data logger with an atomic time stamp and operates from $0^{\circ} \mathrm{C}$ to $70^{\circ} \mathrm{C}$. The measurements for this type of research would include the current outdoor temperatures and humidity, wind speed and direction, wind chill, dew point, heat index, barometric pressure. The weather station could be placed near the experimental units, but not close enough to impede the measurements being analyzed and the weather station base unit would be placed inside of the hangar building. 


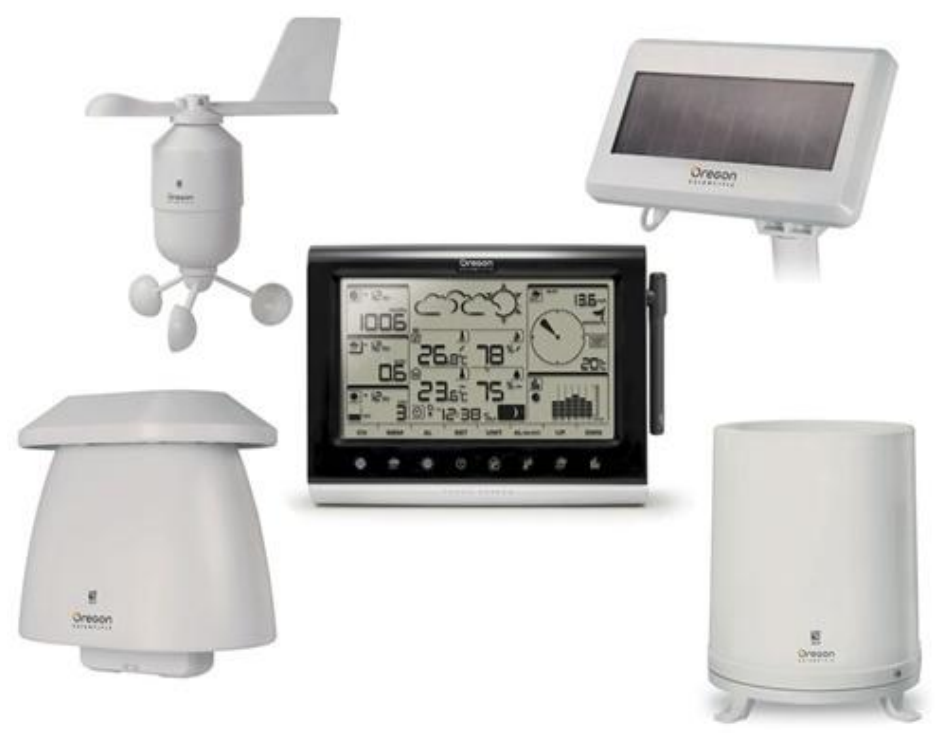

Figure 98 Oregon Scientific Professional Weather Station

To monitor both stacks simultaneously, an additional air velocity sensor would be recommended. In addition, temperature sensors, such as the RTDs used in this research could be installed inside of each stack to monitor the exit air flow temperature.

To increase the airflow and enhance the chimney effect, most of the ridge could be removed in future experimental testing. The increased airflow should carry away the heat produced from the effects of solar radiation in between the existing roof and additional thermal structure. In turn, this will decrease the surface temperature of the existing roof and produce additional airflow inside of the attic reducing the temperature of the attic.

Finally, a different experimental test matrix could be implemented, both experimentally and analytically. This could include testing different paint colors on either side, as well as installing a reflective surface on top of the existing roof. In addition, a different material composition could be tested and analyzed. The various material properties, both thermal and structural, could be evaluated and compared.

Future work should include the development of a transient analytic model to better predict time varying experimental results. Any of these modifications could further enhance the passive thermal management system research. 


\section{REFERENCES}

American Society for Refrigerating and Air-Conditioning Engineers (ASHRAE) Fundamentals Handbook. Atlanta, Georgia. 1997.

Bejan, Adrian. Convection Heat Transfer. John Wiley \& Sons, Inc. $3^{\text {rd }}$ edition. Hoboken, New Jersey. 2004.

Berker, A.R. "Integration des Equations du Movement d'un Fluide Visquex Incompressible." Encyclopedia of Physics. Volume 8, Paer 2, pp 1-384, Springer, Berlin, Germany. 1963.

Berger, A. and M.F. Loutre. Insolation Values for the Climate of the Last 10 Million Years. Quaternary Science Reviews, Volume 10, pp 297-317. 1991.

Bodoia, J.R. and J.F. Osterle. "The Development of Free Convection Between Heated Vertical Plates." Transactions of the American Society of Mechanical Engineers (ASME). pp. 40-44. February 1962.

Carmody, John and Kerry Haglund. "External Shading Devices in Commercial Buildings: The Impact on Energy Use, Peak Demand and Glare Control.” Air Movement and Control Association International (AMCA). 2006.

Cebecci, Turner and Peter Bradshaw. Physical and Computational Aspects of Convective Heat Transfer. Springer-Verlag. New York, New York. 1988

Çengel, Yunus A. Heat and Mass Transfer: A Practical Approach. McGraw-Hill. $3^{\text {rd }}$ edition. New York, New York. 2007.

Çengel, Yunus A. and Robert H. Turner. Fundamentals of Thermal-Fluid Sciences. McGrawHill. $2^{\text {nd }}$ edition. New York, New York. 2005.

Churchill, S.W. and H.H.S. Chu. "Correlating Equations for Laminar and Turbulent Free Convection from a Vertical Plate.” International Journal of Heat Transfer. Volume 18, p 1049. 1975.

“Container Corner Castings.” Pacific Marine \& Industrial. 2007. 29 October 2007 $<$ http://www.pacificmarine.net/containerparts.htm>.

Crawford-Frost, William A. "House-Cooling and Lawn-Sprinkling Device." United States Patent No. 964,464. July 12, 1910.

Department of Energy. “Annual Degree Days to Selected Bases, 1971-2000.” Climatography of the United States No. 81, Supplement Number 2. 2009.

Dominion. "Effective Attic Ventilation.” Accessed November 13, 2008. http://www.dom.com/customer/efficiency/res/pdf/attic_ventilation.pdf. 2008. 
"ECS MOGOS.” Stork. 29 October 2007

$<$ http://www.storkspecialproducts.com/page.html?id=10693>.

eHow. "How to Build a Pitched Roof." http://www.ehow.com/how_2290133_build-pitchroof.html Accessed November 8, 2008.

Elenbaas, W. "Heat Dissipation of Parallel Plates by Free Convection.” Physica 9. pp 1-28. 1942.

Energy Information Administration. Residential Electricity Prices: A Consumer's Guide.

DOE/EIA-X061. www.eia.doe.gov. Accessed October 19, 2008. June 2005.

Energy Star New Homes. US Department of Energy and US Environmental Protection Agency. http://www.energystar.gov. Accessed November 19, 2008.

Energy Efficiency and Renewable Energy. Energy Savings: Tips on Saving Energy and Money at Home. www1.eere.energy.gov/consumer/tips/insulation.html. Accessed January 26, 2010.

Folland, C.K., eds. et al. Observed Climate Variability and Change. In: Climate Change 2001: The Scientific Basis. Contribution of Working Group I to the Third Assessment Report of the Intergovernmental Panel on Climate Change. Cambridge University Press, Cambridge, United Kingdom and New York, New York, USA. 2001.

Fujiii T. and H. Imura. "Natural Convection Heat Transfer from a Plate with Arbitrary Inclination.” International Journal Heat Mass Transfer. Volume 15, p 755. 1972.

Ganesan, P. and G. Palani. "Finite Difference Analysis of Unsteady Natural Convection MHD Flow Past an Inclined Plate with Variable Surface Heat and Mass Flux.” International Journal of Heat and Mass Transfer. Volume 47, Issues 19-20, pp 4449-4457. July 3, 2004.

Gebhart, Benjamin, Jaluria, Yogesh, Mahajan Roop L., and Bahgat Sammakia. Buoyancy Induced Flows and Transport. Hemisphere Publishing Corporation. Washington, District of Columbia. 1988.

Gerhart, Carlton M. "Residential "Air Conditioning System.” United States Patent No. 2,660,863. December 1, 1953.

Heckert, Paul A. "Solar Constant and Variable Sun: Variations in the Sun's Luminosity and the Sunspot Cycle." Accessed on November 18, 2008. Astrophysics. http://astrophysics.suite101.com/article.cfm/solar_constant and variable sun August 4, 2008.

Holder, Leonard H. "Roof Cooling Device.” United States Patent No. 2,266,321. December 16, 1941. 
Kansas State University. "Residential Insulation." Engineering Extension. http://www.oznet.ksu.edu/ Accessed November 14, 2008. January 2000.

Levins, W.P., Karnits, M.A. and D.K. Knight. "Cooling Energy Measurements of Houses with Attics Containing Radiant Barriers.” pp 78-87. 1986.

Lin, Ming-Han. "Numerical Study of Formation of Longitudinal Vortices in Natural Convection Flow Over Horizontal and Inclined Surfaces." International Journal of Heat and Mass Transfer. Volume 44, pp 1759-1766. June 9, 2001.

Love, Tom L. Radiative Heat Transfer. Charles E. Merrill Publishing Co. Columbus, Ohio. 1968.

Lstiburek, J. and J. Carmoody. "Moisture Control Handbook - New, Low-Rise, Residential Construction." ORNL/Sub/89-SD350/1. Oak Ridge National Laboratory. October 1991.

Malhammer, Ake. Thermal Design for Electronics. Version 1.01. Frigus Primor. France. June 5, 2004.

Murray, Alfred T. "Roof Cooling System." United States Patent No. 2,506,936. May 9, 1950.

Myers, Glen E. Analytic Methods in Conduction Heat Transfer. $2^{\text {nd }}$ edition. Thomson-Shore, Inc. 1998.

Naylor, Mark and Kevin C. Farmer. "Sun Damage and Prevention." Electronic Textbook of Dermatology. The Internet Dermatology Society. Accessed October 31, 2008. http://www.telemedicine.org/sundam/sundam2.4.1.html. 1995.

Onur, N., Sivrioglu, M. and M.K. Aktas. "An Experimental Study on the Natural Convection Heat Transfer between Inclined Plates (lower plate isothermally heated and the upper plate thermally insulated as well as unheated)." Heat and Mass Transfer. Volume 32, pp 471-476 Springer-Verlag. 1997.

Parker, Danny. "Technical Support for Development of an Attic Simulation Model for the California Energy Commission.” FSEC-CR-1526-05 Cocoa, Florida. 2005.

Pertl, Emily D. et al. "Feasibility Analysis of an Add-On Roof System for Standard Shipping Containers." AIAA $40^{\text {th }}$ Thermophysics Conference, AIAA Technical Paper No. 2008-4352. Seattle, Washington. June 23-26, 2008.

Reflective Insulation Manufacturers Association (RIMA). "Understanding and Using Reflective Insulation, Radiant Barriers and Radiation Control Coatings." $2^{\text {nd }}$ edition. Phoenix, Arizona. May 2002.

Riemer, Neal M.. "Designing Transportable Collectively Protective Shelters for Thermal Efficiency.” Eglin Air Force Base. Florida. March 2003. 
Robinson, M.L. and Carole Eddington. "Shade Factors in Southern Nevada - Using Trees and Shrubs for Shading Outdoor Spaces.” University of Nevada. SP-01-13. 2001.

Rohde, Robert A. "Global Warming Art.” http://theworldwaterproject.com/water_4process.html. Accessed November 16, 2008.

Schlichting, H. Boundary Layer Theory. McGraw-Hill Book Company, Inc. $4^{\text {th }}$ edition. 1960.

Shah, R.K. and A.L. London. Laminar Low Forced Convection in Ducts, New York, New York. 1978.

Stewart, B.R. "Attic Ventilation for Homes.” www.factsfacts.com. Accessed 19 March 2008.

Stickler, Greg. "Solar Radiation and the Earth System.” National Aeronautics and Space Administration (NASA) Educational Brief. 1999.

Viner, Stephen G. "Evaporative Roof Cooling System.” United States Patent No. 4,761,965. 1988.

Vistanta, R. and D.W. Lankford. "Coupling of Heat Transfer between Two Natural Convection Systems Separated by a Vertical Wall.” International Journal of Heat Mass Transfer. Volume 6. January 1981.

Wiebelt, J.A. Engineering Radiation Heat Transfer. Holt, Rinehart and Winston. New York, New York. 1966.

White, Frank M. Heat and Mass Transfer. Reading, Massachusetts. 1988.

White, Frank M. Viscous Fluid Flow. $2^{\text {nd }}$ edition. Boston, Massachusetts. 1991.

Wilkes, Kenneth E. "Modeling of Residential Attics with Radiant Barriers.” H\&H - Symposium on Improving Building Systems in Hot and Humid Climates. pp 161-168. 1988.

Weather. Historical Weather Data. http://www.wunderground.com . Accessed 18 April 2010. 


\section{APPENDiX A - Mathematica ${ }^{\circledR}$ CODE FOR ANALYTIC Model}

Heat Roof Analysis

$<<$ Units

$<<$ PlotLegends`

Constants, Properties and Nondimensional Numbers

Acceleration due to gravity, $g$

$\mathrm{g}=9.80665$;

Stefan Boltzman Constant, $\sigma$

$\sigma=5.670310^{-8}$;

Universal Gas Constant, $\mathbb{R}$

$\mathbb{R}=8.31447215$;

Properties of Air

Molecular Weight of Dry Air, MAir

MAir $=0.02897$;

Density of Dry Air, $\rho A i r[p, t A b s]$

$\rho$ Air[p_tAbs_]: $=($ MAir $\mathrm{p}) /(\mathbb{R}$ tAbs $)$

Specific Heat Ratio of Dry Air, $\gamma$ Air [tAbs]

$\gamma$ AirK $=$ Interpolation $[\{\{250,300,350,400,450,500,550,600,650,700,750,800,900,1000\}$,

$\left.\{1.401,1.4,1.398,1.395,1.391,1.387,1.381,1.376,1.37,1.364,1.359,1.354,1.344,1.336\}\}^{\top}\right]$;

$\gamma \operatorname{Air}[\mathrm{tAbs}]:=\gamma \operatorname{AirK}[\mathrm{tAbs}]$

$\gamma \operatorname{Air}[250]$

Plot $[\gamma \operatorname{Air}[\mathrm{t}]$

,$\{\mathrm{t}, 250,1000\}$, Axes $\rightarrow$ False,Frame $\rightarrow$ True,PlotStyle $\rightarrow$ Black,FrameLabel $\rightarrow\{\{" \gamma ", "$ " $\},\{"$ Temperature [K]","Specific Heat Ratio of Air"\} \}]

Constant Pressure Specific Heat of Dry Air, CpAir[tAbs]

CpAirK=Interpolation $[\{\{250,300,350,400,450,500,550,600,650,700,750,800,900,1000\}$,

$$
\left.\{1.003,1.005,1.008,1.013,1.02,1.029,1.04,1.051,1.063,1.075,1.087,1.099,1.121,1.142\}\}^{\top}\right] \text {; }
$$

CpAir[tAbs_]:=CpAirK[tAbs] 1000

CpAir[250 ]

Plot[CpAir[t ] , $\{\mathrm{t}, 250,1000\}$, Axes $\rightarrow$ False,Frame $\rightarrow$ True,PlotStyle $\rightarrow$ Black,FrameLabel $\rightarrow\left\{\left\{" C_{p}\right.\right.$ [J/(Kg K)]","'\},\{"Temperature [K]","Constant Pressure Specific Heat of Air"\}\}]

Constant Volume Specific Heat of Dry Air, CvAir[tAbs]

CvAir[tAbs_]:=CpAir[tAbs]-R/MAir

CvAir[300 ]

Plot[CvAir[t ], \{t,250,1000 $\},$ Axes $\rightarrow$ False,Frame $\rightarrow$ True,PlotStyle $\rightarrow$ Black,FrameLabel $\rightarrow\{\{" \mathrm{Cv}$

[J/(Kg K)]","'"\},\{"Temperature [K]","Constant Volume Specific Heat of Air" $\}\}]$

Prandtl Number for Air, prAir[tempAbs]

$\operatorname{prC}=\{\{-40,0.7436\},\{-30,0.7425\},\{-20,0.7408\},\{-10,0.7387\},\{0,0.7362\},\{5,0.7350\}$, $\{10,0.7336\},\{15,0.7323\},\{20,0.7309\},\{25,0.7296\},\{30,0.7282\},\{35,0.7268\},\{40$, $0.7255\},\{45,0.7241\},\{50,0.7228\},\{60,0.7202\},\{70,0.7177\},\{80,0.7154\},\{90,0.7132\}$, $\{100,0.7111\},\{120,0.7073\},\{140,0.7041\}\}$;

$\operatorname{prAirK}[\operatorname{tempK}]]=\operatorname{Fit}[\operatorname{Table}[\{\operatorname{prC}[[i, 1]]+273.15, \operatorname{prC}[[i, 2]]\},\{i, 1$, Length $[\operatorname{prC}]\}],\{1$, tempK\}, tempK]; 
$\operatorname{prAir}[$ tempAbs_] := prAirK[tempAbs]

Plot[prAir[T ], $\{\mathrm{T}, 233,413\}$,

PlotStyle -> Black, Frame -> True, Axes -> False, FrameLabel -> \{"Temperature [K]", "Prandtl

Number"\}]

LogMeanTemperature, $\Delta \operatorname{Tln}[T$, $T$ in, Tout], $\Delta \operatorname{Tln}[\Delta T$ in, $\Delta T$ Tout]

$\triangle \mathrm{T} \ln [\triangle \mathrm{Tin}, \triangle$ Tout $]:=(\triangle$ Tout $-\triangle \mathrm{Tin}) / \log [\triangle \mathrm{T}$ out $/ \triangle \mathrm{Tin}]$

$\triangle \mathrm{T} \ln [$ Ts_Tin_Tout $]:=($ Tin-Tout $) / \log [($ Ts-Tout $) /($ Ts-Tin $)]$

Thermal Conductivity of Air, kAir[tempAbs]

conC $=\{\{-40,0.02057\},\{-30,0.02134\},\{-20,0.02211\},\{-10,0.02288\},\{0,0.02364\},\{5$, $0.02401\},\{10,0.02439\},\{15,0.02476\},\{20,0.02514\},\{25,0.02551\},\{30,0.02588\},\{35$, $0.02625\},\{40,0.02662\},\{45,0.02699\},\{50,0.02735\},\{60,0.02808\},\{70,0.02881\},\{80$, $0.02953\},\{90,0.03024\},\{100,0.03095\},\{120,0.03235\},\{140,0.03374\}\}$;

kAirK $[$ tempK_] $=$ Fit $[$ Table $[\{\operatorname{conC}[[i, 1]]+273.15, \operatorname{conC}[[i, 2]]\},\{i, 1$, Length $[\operatorname{conC}]\}],\{1$, tempK $\}$,te $\mathrm{mpK}]$;

kAir[tempAbs_]:= kAirK[tempAbs]

Plot[kAir[T ], \{T,233,413\},

PlotStyle $\rightarrow$ Black,Frame $\rightarrow$ True,Axes $\rightarrow$ False,FrameLabel $\rightarrow\{$ "Temperature $[\mathrm{K}]$ ","Thermal

Conductivity $\left.\left.[\mathrm{W} /(\mathrm{m} \mathrm{K})]^{\prime \prime}\right\}\right]$

Kinematic Viscosity of Air, vAir[tempAbs]

$\operatorname{kinVC}=\left\{\left\{-40,1.008 * 10^{-5}\right\},\left\{-30,1.087 * 10^{-5}\right\},\left\{-20,1.169 * 10^{-5}\right\},\left\{-10,1.252^{*} 10^{-5}\right\},\left\{0,1.338^{*} 10^{-}\right.\right.$

$\left.{ }^{5}\right\},\left\{5,1.382 * 10^{-5}\right\},\left\{10,1.426^{*} 10^{-5}\right\},\left\{15,1.470 * 10^{-5}\right\},\left\{20,1.516^{*} 10^{-5}\right\},\left\{25,1.562 * 10^{-}\right.$

$\left.{ }^{5}\right\},\left\{30,1.608 * 10^{-5}\right\},\left\{35,1.655^{*} 10^{-5}\right\},\left\{40,1.702 * 10^{-5}\right\},\left\{45,1.750 * 10^{-5}\right\},\left\{50,1.798 * 10^{-}\right.$

$\left.{ }_{5}^{5}\right\},\left\{60,1.896^{*} 10^{-5}\right\},\left\{70,1.995^{*} 10^{-5}\right\},\left\{80,2.097 * 10^{-5}\right\},\left\{90,2.201 * 10^{-5}\right\},\left\{100,2.306^{*} 10^{-}\right.$

$\left.5\},\left\{120,2.522 * 10^{-5}\right\},\left\{140,2.745^{*} 10^{-5}\right\}\right\}$;

$\vee$ AirK $[$ tempK_ $]=$ Fit $[$ Table $[\{\operatorname{kinVC}[[i, 1]]+273.15, \operatorname{kinVC}[[\mathrm{i}, 2]]\},\{\mathrm{i}, 1$, Length $[\operatorname{kinVC}]\}],\{1$, tempK

\} ,tempK] ;

$\vee \operatorname{Air}[$ tempAbs $]:=\vee \operatorname{AirK}[$ tempAbs]

Plot[ $\vee$ Air[T] $10^{5},\{\mathrm{~T}, 233,413\}$,

PlotStyle $\rightarrow$ Black,Frame $\rightarrow$ True,Axes $\rightarrow$ False,FrameLabel $\rightarrow\{$ "Temperature $[\mathrm{K}] "$, "Kinematic

Viscosity $\left.\left.10^{-5}\left[\mathrm{~m}^{2} / \mathrm{s}\right]^{\prime \prime}\right\}\right]$

Film Temperature, $t$ Film[tsAbs,tInfAbs]

tFilm[tempSurfAbs_tempInfAbs_] $=($ tempSurfAbs+tempInfAbs) $/ 2$;

Reynolds Number, rey[charL, vel, vAir]

rey[charL_,vel_, $\vee$ Air_]: $=($ charL vel $) / \vee$ Air

Rayleigh Number, ra[charL,tsAbs,toAbs]

ra[characteristicLength_,tempSurf_,tempo_]: $=\left(\right.$ g characteristicLength ${ }^{3}$

prAir[tFilm[tempSurf,temp $\infty]$ ] (tempSurf-temp $\infty)) /(\mathrm{tFilm}[$ tempSurf,temp $\infty]$

$\checkmark \operatorname{Air}[$ tFilm[tempSurf,temp $\infty]]^{2}$ )

Nusselt Number, nu[charL,tsAbs,tooAbs]

$\mathrm{nu}\left[\mathrm{lc}\right.$,tsAbs_tooAbs_]:=Re[(0.825+(0.387 ra| lc , tsAbs, t Abs $\left.{ }^{\frac{1}{6}}\right) /$

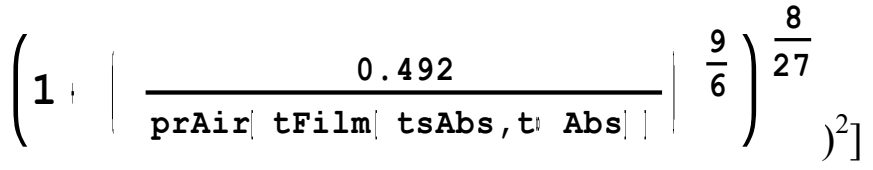

Thermal Circuit Laws 
Series Combination of Resistors, $r s[r 1, r 2]$

rs[r1_,r2_]:=r1+r2;

Parallel Combination of Resistors, $r p[r 1, r 2]$

$\mathrm{rp}\left[\mathrm{r} 1 \_, \mathrm{r} 2 \_\right]:=(\mathrm{r} 1 \mathrm{r} 2) /(\mathrm{r} 1+\mathrm{r} 2)$

Thermal Conduction

Conductive Heat Transfer, $q c[k, a, t 1, t 2]$

$\mathrm{qc}[$ conductance_, area_temp1_temp2] := conductance* area (temp1 - temp2);

Conductive Thermal Resistance, $r c[l, a, k]$

rc[length_,area_conductance_]:=length/(area * conductance);

Thermal Convection

Flat Plate Characteristic Length, fpLc[area,perimiter]

fpLc[area_perimeter_]:=area/perimeter

Convective Heat Transfer Coefficient, $h v$ [charL,tsAbs,tooAbs]

hv[lc_tsAbs_to $\infty$ Abs_]:=((kAir[tFilm[tsAbs,tooAbs]] nu[lc,tsAbs,tooAbs] $) / \mathrm{lc})$

hv2[charL_,vel_tsAbs_,toAbs_]:=((kAir[tFilm[tsAbs,tooAbs]]

nure [charL,vel,tsAbs,toA Abs])/charL)

Convective Thermal Resistance, $r v[h$, area]

$\mathrm{rv}[\mathrm{h}, \mathrm{a}$ ] $]:=1 /(\mathrm{h}$ a);

Convective Thermal Resistance, $r c v$ [a, charL, tsAbs, tooAbs]

rcv[a_,charL_tsAbs_to Abs ]:=1/(a hv[charL,tsAbs,tooAbs])

Thermal Radiation

Radiation Heat Transfer, $\operatorname{qr}[\epsilon$,area, $t 1, t 2]$

$\mathrm{qr}\left[\epsilon_{-}, \mathrm{a}, \mathrm{t} \mathrm{t} \mathrm{Abs}, \mathrm{t} 2 \mathrm{Abs}\right] \mathrm{l}=\in \sigma \mathrm{a}\left(\mathrm{t} 1 \mathrm{Abs}^{4}-\mathrm{t} 2 \mathrm{Abs}^{4}\right)$

$\mathrm{qr}[1,1,350,300]$

Radiation Thermal Resistance, $\operatorname{rr}[a, \sigma, \epsilon, t s A b s, t \infty A b s]$

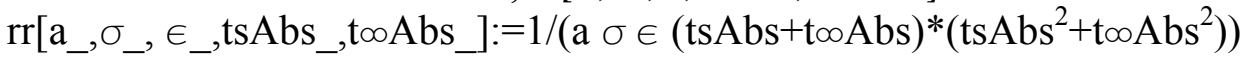

Preliminary

Base Unit

ans $3 \mathrm{c}=$ Join[FindRoot $[\{$

$\mathrm{t} 1==$ Module [

$\{$ rtotal $=(0.218 /$ aroof $)+((($ rcv$[\operatorname{aroof}, \operatorname{charL}, \mathrm{t} 2, \mathrm{t} 3]) \mathrm{rr}[\operatorname{aroof}, \sigma, 0.82, \mathrm{t} 2, \mathrm{t} 3]) /(\mathrm{rcv}[\operatorname{aroof}, \mathrm{charL}, \mathrm{t} 2, \mathrm{t} 3]+$ $\operatorname{rr}[\operatorname{aroof}, \sigma, 0.82, \mathrm{t} 2, \mathrm{t} 3]))+(((\operatorname{rcv}[\operatorname{aroof}, \operatorname{charL}, \mathrm{t} 2, \mathrm{t} 3]) \operatorname{rr}[\operatorname{aroof}, \sigma, 0.82, \mathrm{t} 2, \mathrm{t} 3]) /(\operatorname{rcv}[\operatorname{aroof}, \mathrm{charL}, \mathrm{t} 2, \mathrm{t} 3]+$ $\operatorname{rr}[$ aroof, $\sigma, 0.82, \mathrm{t} 2, \mathrm{t} 3]))+(0.09 /$ aceiling $)+\mathrm{rcv}[$ aceiling, charL $2, \mathrm{t} 5$, troom $]\},($ to rtotal + troom

$((\operatorname{rcv}[\operatorname{aroof}, \operatorname{charL}, \mathrm{t} \infty, \mathrm{t} 1] \operatorname{rr}[\operatorname{aroof}, \sigma, 0.91, \mathrm{t} \infty, \mathrm{t} 1]) /(\operatorname{rcv}[\operatorname{aroof}, \operatorname{charL}, \mathrm{t} \infty, \mathrm{t} 1]+\operatorname{rr}[\operatorname{aroof}, \sigma, 0.91, \mathrm{t} \infty, \mathrm{t} 1]))$

$+((\operatorname{rcv}[\operatorname{aroof}, \operatorname{charL}, \mathrm{t} \infty, \mathrm{t} 1] \operatorname{rr}[\operatorname{aroof}, \sigma, 0.91, \mathrm{t} \infty, \mathrm{t} 1]) /(\operatorname{rcv}[\operatorname{aroof}, \operatorname{charL}, \mathrm{t} \infty, \mathrm{t} 1]+$

$\operatorname{rr}[\operatorname{aroof}, \sigma, 0.91, \mathrm{t} \infty, \mathrm{t} 1])) \mathrm{rtotal}$ qsolar aroof $) /((\operatorname{rcv}[\operatorname{aroof}, \mathrm{charL}, \mathrm{t} \infty, \mathrm{t} 1]$

$\operatorname{rr}[\operatorname{aroof}, \sigma, 0.91, \mathrm{t} \infty, \mathrm{t} 1]) /(\operatorname{rcv}[\operatorname{aroof}, \mathrm{charL}, \mathrm{t} \infty, \mathrm{t} 1]+\operatorname{rr}[\operatorname{aroof}, \sigma, 0.91, \mathrm{t} \infty, \mathrm{t} 1]))+$ rtotal $)$

],

$(\mathrm{t} 1-\mathrm{t} 2) /(0.218 /$ aroof $)=(\mathrm{t} 2-$

t3) $/((\operatorname{rcv}[\operatorname{aroof}, \operatorname{charL}, \mathrm{t} 2, \mathrm{t} 3] \mathrm{rr}[\operatorname{aroof}, \sigma, 0.82, \mathrm{t} 2, \mathrm{t} 3]) /(\operatorname{rcv}[\operatorname{aroof}, \operatorname{charL}, \mathrm{t} 2, \mathrm{t} 3]+\operatorname{rr}[\operatorname{aroof}, \sigma, 0.82, \mathrm{t} 2, \mathrm{t} 3]))$,

$(\mathrm{t} 1-\mathrm{t} 2) /(0.218 /$ aroof $)==(\mathrm{t} 3-\mathrm{t} 4)$

$/((\mathrm{rcv}[$ aceiling,charL2,t3,t4] rr[aceiling, $\sigma, 0.82, \mathrm{t3}, \mathrm{t} 4]) /(\operatorname{rcv}[$ aceiling,charL2,t3,t4]+

$\operatorname{rr}[$ aceiling, $\sigma, 0.82, \mathrm{t} 3, \mathrm{t} 4]))$,

(t1-t2)/(0.218/aroof $)=($ t4-t5)/(0.09/aceiling $)$, 
$(\mathrm{t} 1-\mathrm{t} 2) /(0.218 /$ aroof $)==(\mathrm{t} 5-$

troom $) /((\mathrm{rcv}[$ aceiling,charL2,t5, troom] $\operatorname{rr}[$ aceiling, $\sigma, 0.67, \mathrm{t} 5$, troom $]) /(\mathrm{rcv}[$ aceiling,charL2,t5, troo

$\mathrm{m}]+\operatorname{rr}[$ aceiling, $\sigma, 0.67, \mathrm{t} 5$, troom $]))$

\}

I. $\{$ aroof $\rightarrow 6.35$,aceiling $\rightarrow 5.05$, charL $\rightarrow 2.08$, charL2 $\rightarrow 2.43$, troom $\rightarrow 295$,too $\rightarrow 305$., qsolar $\rightarrow 450$. $\}$, $\{\{\mathrm{t} 1,330\},.\{\mathrm{t} 2,303\},.\{\mathrm{t} 3,302\},.\{\mathrm{t} 4,301\},.\{\mathrm{t} 5,300\}\}$,

AccuracyGoal $\rightarrow$ 7,PrecisionGoal $\rightarrow 7$ ], $\{$ aroof $\rightarrow 6.35$, aceiling $\rightarrow 5.05$, charL $\rightarrow 2.08$, charL $2 \rightarrow 2.43$, troom $\rightarrow 295$.,to $\rightarrow$ 305., qsolar $\rightarrow 450\}$.

\{

$\operatorname{rr}[\operatorname{aroof}, \sigma, 0.91, \mathrm{t} \infty, \mathrm{t} 1], \mathrm{rcv}[\operatorname{aroof}, \operatorname{charL}, \mathrm{t} \infty, \mathrm{t} 1], \mathrm{rcv}[\operatorname{aroof}, \operatorname{charL}, \mathrm{t} 2, \mathrm{t} 3], \mathrm{rcv}[\operatorname{aceiling}, \operatorname{charL}, \mathrm{t} 3, \mathrm{t} 4], \mathrm{rcv}[\mathrm{a}$ ceiling,charL,t5,troom],0.218/aroof,0.09/aceiling\}/.ans3c

\{qsolar aroof, $(\mathrm{t} 1-\mathrm{t} \infty)$ ((rcv[aroof,charL,t $\infty, \mathrm{t} 1] \operatorname{rr}[\operatorname{aroof}, \sigma, 0.91, \mathrm{t} \infty, \mathrm{t} 1]) /(\operatorname{rcv}[\operatorname{aroof}, \mathrm{charL}, \mathrm{t} \infty, \mathrm{t} 1]+$

$\operatorname{rr}[\operatorname{aroof}, \sigma, 0.91, \mathrm{t} \infty, \mathrm{t} 1]))^{-1},(\operatorname{rcv}[\operatorname{aroof}, \operatorname{charL}, \mathrm{t} \infty, \mathrm{t} 1] \operatorname{rr}[\operatorname{aroof}, \sigma, 0.91, \mathrm{t} \infty, \mathrm{t} 1]) /(\operatorname{rcv}[\operatorname{aroof}, \operatorname{charL}, \mathrm{t} \infty, \mathrm{t} 1]+$

$\operatorname{rr}[\operatorname{aroof}, \sigma, 0.91, \mathrm{t} \infty, \mathrm{t} 1])\} /$. ans3c

One Dimensional Flow Estimation

Inlet Outlet Area Ratio Effect, InletOutletEffect[AreaRatio]

prIData $=\{\{1.0,1.0\},\{1.5,1.18\},\{2.0,1.26\},\{3.0,1.34\},\{4.0,1.36\},\{5.0,1.37\},\{6.0,1.38\}\}$;

InletOutletEffect $=$ Interpolation[prIData];

Plot[InletOutletEffect[r]-

$1,\{r, 1,6\}$,Frame $\rightarrow$ True,Axes $\rightarrow$ False,PlotStyle $\rightarrow$ Black,FrameLabel $\rightarrow\{$ "Area Ratio","\% Increase in Flow" $\}]$

Buoyancy Pressure difference, $\triangle P$ Buoyancy[height, pressAbs,tinAbs,toutAbs]

$\triangle \mathrm{PBuoyancy}[\mathrm{h}, \mathrm{P}$, tinAbs_toutAbs_]:=g h $(\mathrm{P}$ MAir)/R (1/tinAbs-1/toutAbs)

$\triangle$ PBuoyancy[3,101000,300,350 ]

Approximate Flow Velocity (ASHRAE 25.13) velBuoyancy[height, tinAbs, toutAbs, Cdischarge $=0.65]$

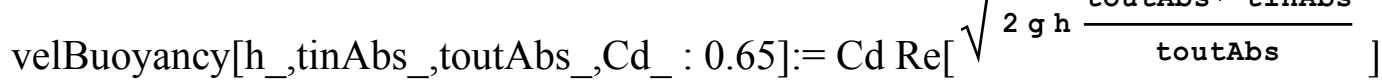

Cooling Air Steady State Temperature, Qflow [tAmb, $\Delta$ Tio, $h, w, a]$

At steady state conditions, ALL the heat, $\mathrm{Q}_{\text {flow }}$, gained through the exterior roof will be carried

away by the air flow, $m=\rho A V$, otherwise the thermally driven flow would increase and steady state would not have been reached.

The flow will increase in temperature by $\Delta \mathrm{T}_{\mathrm{io}}$. Therefore $\mathrm{Q}_{\text {flow }}=\mathrm{C}_{\mathrm{p}} \rho A V \Delta \mathrm{T}_{\text {io }}$ where $\mathrm{V}$ is the velocity calculated from Buoyancy. The resulting equation can be solved for $\Delta \mathrm{T}_{\mathrm{io}}$ Qflow[tAmb_,Tio_h_,w_a_]:=(a/w) CpAir[tAmb $+\triangle$ Tio/2] $\rho \operatorname{Air}[101000$, tAmb $+\triangle$ Tio ] velBuoyancy[h, tAmb, tAmb $+\triangle$ Tio $] \triangle$ Tio

Convective heat transfer in the channel, Qci[tAmv, $\Delta$ Tio,ts, charL]

Qci[tAmb_, $\mathrm{Tio}, \mathrm{ts}, \mathrm{charL}]:=\mathrm{kAir}[\mathrm{tAmb}+\triangle \mathrm{Tio} / 2]$

$\mathrm{nu}[\mathrm{charL}, \mathrm{ts}, \mathrm{tAmb}+\triangle \mathrm{T} \ln [\mathrm{ts}, \mathrm{tAmb}, \mathrm{tAmb}+\triangle \mathrm{Tio}]] / \mathrm{charL} \triangle \mathrm{T} \ln [\mathrm{ts}, \mathrm{tAmb}, \mathrm{tAmb}+\triangle \mathrm{Tio}]$

Convective heat transfer off Exterior roof surface, Qce [tAmb,ts, charL]

Qce[tAmb_ts_,charL_]:=kAir[(tAmb+ts)/2] nu[charL,ts,tAmb]/charL (ts-tAmb)

Qce[300 ,350, Convert[6 Foot,Meter]/Meter]

Total Heat Rejection, HeatRoof[Qsolar, tAmb, charL, chimneyHeight, ridgeLength, gapHeight]

HeatRoof[Qsolar_tAmb_charL_,chimneyHeight_,ridgeLength_,gapHeight_]:= 
Module[ $[\{$

Qs $=$ Convert[Qsolar,Watt/Meter $\left.{ }^{2}\right] \mathrm{Meter}^{2} /$ Watt,

To=Quiet[Convert[tAmb,Kelvin]]/Kelvin,

$\mathrm{cL}=$ Convert $[$ charL,Meter $] /$ Meter,

$\mathrm{h}=$ Convert [chimneyHeight,Meter]/Meter,

$\mathrm{w}=$ Convert[ridgeLength,Meter]/Meter,

$\mathrm{a}=$ Convert[gapHeight,Meter]/Meter,TempRule $\}$,

TempRule=FindRoot $[\{$ Qflow[To, $\triangle$ Tio ,cL,w,a]+Qce[T $\infty, T s, c L]-Q s$, Qflow[T $\infty, \triangle$ Tio

,h,w,a]-Qci[T $\infty, \triangle$ Tio, Ts , cL $]\},\{\{\triangle$ Tio,20. $\},\{$ Ts, 360. $\}\}$,AccuracyGoal $\rightarrow$ 7,PrecisionGoal $\rightarrow 7]$;

$\{$ AirTempRise- $>\triangle$ Tio Kelvin,RoofSurfTemp->Ts Kelvin,AirVelocity->velBuoyancy $[\mathrm{h}, \mathrm{T} \infty$,

To $+\triangle$ Tio] Meter/Second $\} /$. TempRule

]

HeatRoof[450 Watt/Meter ${ }^{2}, 300$ Kelvin,6 Foot,4 Foot,10 Foot,4 Inch]

Buoyancy Velocity Plot

Plot[

$\{$ velBuoyancy[Convert[5 Foot,Meter]/Meter , 300, 300 $+\Delta \mathrm{T}$ ],

velBuoyancy[Convert[7 Foot,Meter]/Meter , 300, 300+ $\Delta \mathrm{T}]$,

velBuoyancy[Convert[9Foot,Meter]/Meter , $300,300+\triangle \mathrm{T}$ ]

\},$\{\triangle \mathrm{T}, 0,30\}$,Frame $\rightarrow$ True,Axes $\rightarrow$ False,

FrameLabel $\rightarrow\{\{" \mathrm{~V}[\mathrm{~m} / \mathrm{s}] "\},,\{" \triangle \mathrm{T}[$ Kelvin]", $\}\}$,

PlotLegend $\rightarrow\{$ Style["5 ft",FontFamily $\rightarrow$ "Times", FontSize $\rightarrow$ 12], Style["7

$\mathrm{ft}$ ",FontFamily $\rightarrow$ "Times", FontSize $\rightarrow$ 12],Style["9 ft",FontFamily $\rightarrow$ "Times", FontSize $\rightarrow$ $12]\}$, LegendPosition $\rightarrow\{0.7,-0.2\}$, LegendSize $\rightarrow\{0.5,0.5\}$, LegendShadow $\rightarrow$ False,

PlotStyle $\rightarrow\{$ Red, Green, Blue, $\}]$

Temperature Rise Plot

Plot $[\{$

AirTempRise/Kelvin/.HeatRoof[Qs Watt/Meter²,300 Kelvin,6 Foot,5Foot,10 Foot,1.5 Inch], AirTempRise/Kelvin/.HeatRoof[Qs Watt/Meter ${ }^{2}, 300$ Kelvin,6 Foot,7 Foot,10 Foot,1.5 Inch], AirTempRise/Kelvin/.HeatRoof[Qs Watt/Meter ${ }^{2}, 300$ Kelvin,6 Foot,9Foot,10 Foot,1.5 Inch], AirTempRise/Kelvin/.HeatRoof[Qs Watt/Meter ${ }^{2}, 300$ Kelvin,6 Foot,5Foot,10 Foot,4. Inch], AirTempRise/Kelvin/.HeatRoof[Qs Watt/Meter ${ }^{2}, 300$ Kelvin,6 Foot,7Foot, 10 Foot,4. Inch], AirTempRise/Kelvin/.HeatRoof[Qs Watt/Meter ${ }^{2}, 300$ Kelvin,6 Foot,9Foot,10 Foot,4. Inch]\}, $\{\mathrm{Q}, 1,600\}$, Frame $\rightarrow$ True,Axes $\rightarrow$ False, FrameLabel $\rightarrow\left\{\{\right.$ "Air $\triangle \mathrm{T}[$ Kelvin $\left.] "\},,\left\{" \mathrm{Q}_{\text {solar }}\left[\mathrm{W} / \mathrm{m}^{2}\right] ",\right\}\right\}$,

PlotLegend $\rightarrow$ \{Style["1.5 in; 5 ft",FontFamily $\rightarrow$ "Times", FontSize $\rightarrow$ 12],Style["1.5 in; 7

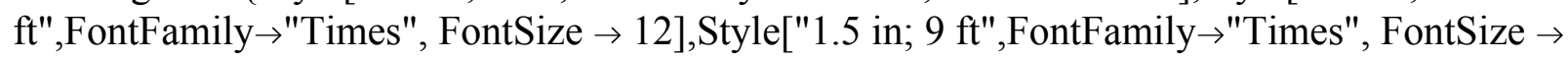

12],Style["4 in; 5 ft",FontFamily $\rightarrow$ "Times", FontSize $\rightarrow$ 12],Style["4 in; 7

$\mathrm{ft}$ ",FontFamily $\rightarrow$ "Times", FontSize $\rightarrow$ 12],Style["4 in; 9 ft",FontFamily $\rightarrow$ "Times", FontSize $\rightarrow$ $12]\}$, LegendPosition $\rightarrow\{0.7,-0.2\}$, LegendSize $\rightarrow\{0.5,0.5\}$, LegendShadow $\rightarrow$ False,

PlotStyle $\rightarrow\{$ Red, Green, Blue, Magenta, Cyan, Black $\}]$

Base unit with heat roof

ans7=FindRoot $[\{$

Module[

$\{$ rtotal3 $=(\operatorname{rcv}[\operatorname{aroof}, \operatorname{charL}, \operatorname{tgas}, \mathrm{t} 1])+(0.218 / \operatorname{aroof})+((\operatorname{rcv}[\operatorname{aroof}, \operatorname{charL}, \mathrm{t} 2, \mathrm{t} 3]) \operatorname{rr}[\operatorname{aroof}, \sigma, 0.82, \mathrm{t} 2, \mathrm{t} 3])$ 
$/(\operatorname{rcv}[\operatorname{aroof}, \mathrm{charL}, \mathrm{t} 2, \mathrm{t} 3]+$

$\operatorname{rr}[$ aroof, $\sigma, 0.82, \mathrm{t} 2, \mathrm{t} 3]))+(((\operatorname{rcv}[$ aceiling, charL2,t3,t4])rr[aceiling, $\sigma, 0.82, \mathrm{t3}, \mathrm{t} 4]) /(\mathrm{rcv}[$ aceiling, charL $2, \mathrm{t3}, \mathrm{t} 4]+\operatorname{rr}[$ aceiling, $\sigma, 0.82, \mathrm{t3}, \mathrm{t} 4]))+(0.09 /$ aceiling $)+(\operatorname{rcv}[$ aceiling, charL2, t5, troom $])\},((\mathrm{t} 0-$

tgas)/(rcv[aroof,charL,t0,tgas])-qflow $+(($ troom-tgas $) /$ rtotal3) $)]==($ too-t0) $) /($ rcv [aroof,charL,too,t0]

$\operatorname{rr}[\operatorname{aroof}, \sigma, 0.97, \mathrm{t} \infty, \mathrm{t} 0]) /(\mathrm{rcv}[\operatorname{aroof}, \mathrm{charL}, \mathrm{t} \infty, \mathrm{t} 0]+\mathrm{rr}[\operatorname{aroof}, \sigma, 0.97, \mathrm{t} \infty, \mathrm{t} 0]))+\mathrm{qsolar}+($ tgas-

t0)/(rcv[aroof, charL, t0, tgas]),

qflow $==\rho$ Air[101000,tout] achannel velBuoyancy[1.53, to, tout, 0.65] CpAir[tout] (tout-t $\infty$ ), qflow $==(\mathrm{t} 0$-tgas $) / \mathrm{rcv}$ [aroof, charL, $\mathrm{t} 0$,tgas] $+(\mathrm{t} 1$-tgas $) / \mathrm{rcv}$ [aroof, charL, tgas, $\mathrm{t} 1]$,

tgas $==\left({ }^{*}\right.$ to $+($ to - tout $) / \log \left[(\right.$ t 0 -tout $) /($ t 0 -t $\left.\infty){ }^{*}\right)($ toottout $) / 2$,

$\left(*\right.$ tgas $==($ too-tout $) / \log [(\mathrm{t} 1$-tout $\left.) /(\mathrm{t} 1-\mathrm{t} \infty)],{ }^{*}\right)$

$(\mathrm{t} 1-\mathrm{t} 2) /(0.218 / \operatorname{aroof})==($ tgas-t1)/(rcv[aroof,charL,tgas,t1]),

$(\mathrm{t} 1-\mathrm{t} 2) /(0.218 /$ aroof $)==(\mathrm{t} 2-$

t3) $/((\operatorname{rcv}[\operatorname{aroof}, \operatorname{charL}, \mathrm{t2}, \mathrm{t3}] \operatorname{rr}[\operatorname{aroof}, \sigma, 0.82, \mathrm{t2}, \mathrm{t3}]) /(\operatorname{rcv}[\operatorname{aroof}, \operatorname{charL}, \mathrm{t} 2, \mathrm{t} 3]+\operatorname{rr}[\operatorname{aroof}, \sigma, 0.82, \mathrm{t2}, \mathrm{t3}]))$, $(\mathrm{t} 1-\mathrm{t} 2) /(0.218 /$ aroof $)=(\mathrm{t} 3-\mathrm{t} 4)$

$/((\mathrm{rcv}$ [aceiling,charL2,t3,t4] rr[aceiling, $\sigma, 0.82, \mathrm{t3}, \mathrm{t4}]) /(\operatorname{rcv}[\operatorname{aceiling}, \operatorname{charL} 2, \mathrm{t} 3, \mathrm{t} 4]+$

$\operatorname{rr}[$ aceiling, $\sigma, 0.82, \mathrm{t} 3, \mathrm{t} 4]))$,

$(\mathrm{t} 1-\mathrm{t} 2) /(0.218 /$ aroof $)==(\mathrm{t} 4-\mathrm{t} 5) /(0.09 /$ aceiling $)$,

$(\mathrm{t} 1-\mathrm{t} 2) /(0.218 /$ aroof $)==(\mathrm{t} 5-$

troom $) /((\mathrm{rcv}[$ aceiling,charL2,t5, troom] $\mathrm{rr}[$ aceiling, $\sigma, 0.67, \mathrm{t5}$, troom $]) /(\mathrm{rcv}[$ aceiling,charL2,t5, troo

$\mathrm{m}]+\operatorname{rr}[$ aceiling, $\sigma, 0.67, t 5$,troom]))

\}

1. \{aroof $\rightarrow 6.35$, aceiling $\rightarrow 5.05$, achannel $\rightarrow 0.31$, charL $\rightarrow 2.08$, charL2 $\rightarrow 2.43$, troom $\rightarrow 295$., $\infty \rightarrow 305$., qsolar $\rightarrow 4506.35\}$,

$\{\{\mathrm{t} 0,350\},.\{$ tout, 340$\},\{\mathrm{tgas}, 335\},\{\mathrm{t} 1,320\},.\{\mathrm{t} 2,315\},.\{\mathrm{t} 3,310\},.\{\mathrm{t} 4,305\},.\{\mathrm{t} 5,300\}$, $\{$ qflow, $300 * 6.35\}\}$,

AccuracyGoal $\rightarrow 7$,PrecisionGoal $\rightarrow 7$ ]

(305-tout)/Log[(t0-tout)/(t0-305)]/.ans7

(t0-tout)/(t0-305)/.ans7

$\{\mathrm{rcv}[\operatorname{aroof}, \mathrm{charL}, \mathrm{to}, \mathrm{t} 0], \mathrm{rcv}[\operatorname{aroof}, \mathrm{charL}, \mathrm{t} 0, \mathrm{tgas}], \mathrm{rcv}[\operatorname{aroof}, \mathrm{charL}, \mathrm{tgas}, \mathrm{t} 1$ ], rcv[aceiling,charL,t2,t3] ,rcv[aceiling,charL,t3,t4],rcv[aceiling,charL,t5,troom],0.218/aroof,0.09/aceiling $\} /$ aroof $\rightarrow 6.35, \mathrm{a}$ ceiling $\rightarrow 5.05$, charL $\rightarrow 1.83$, troom $\rightarrow 295 .$, t $\infty \rightarrow 305$., qsolar $\rightarrow 450.\} /$. ans 7

velBuoyancy[1.53, 305, tout, 0.65$] /$.ans7

qflow/6.35/.ans7 


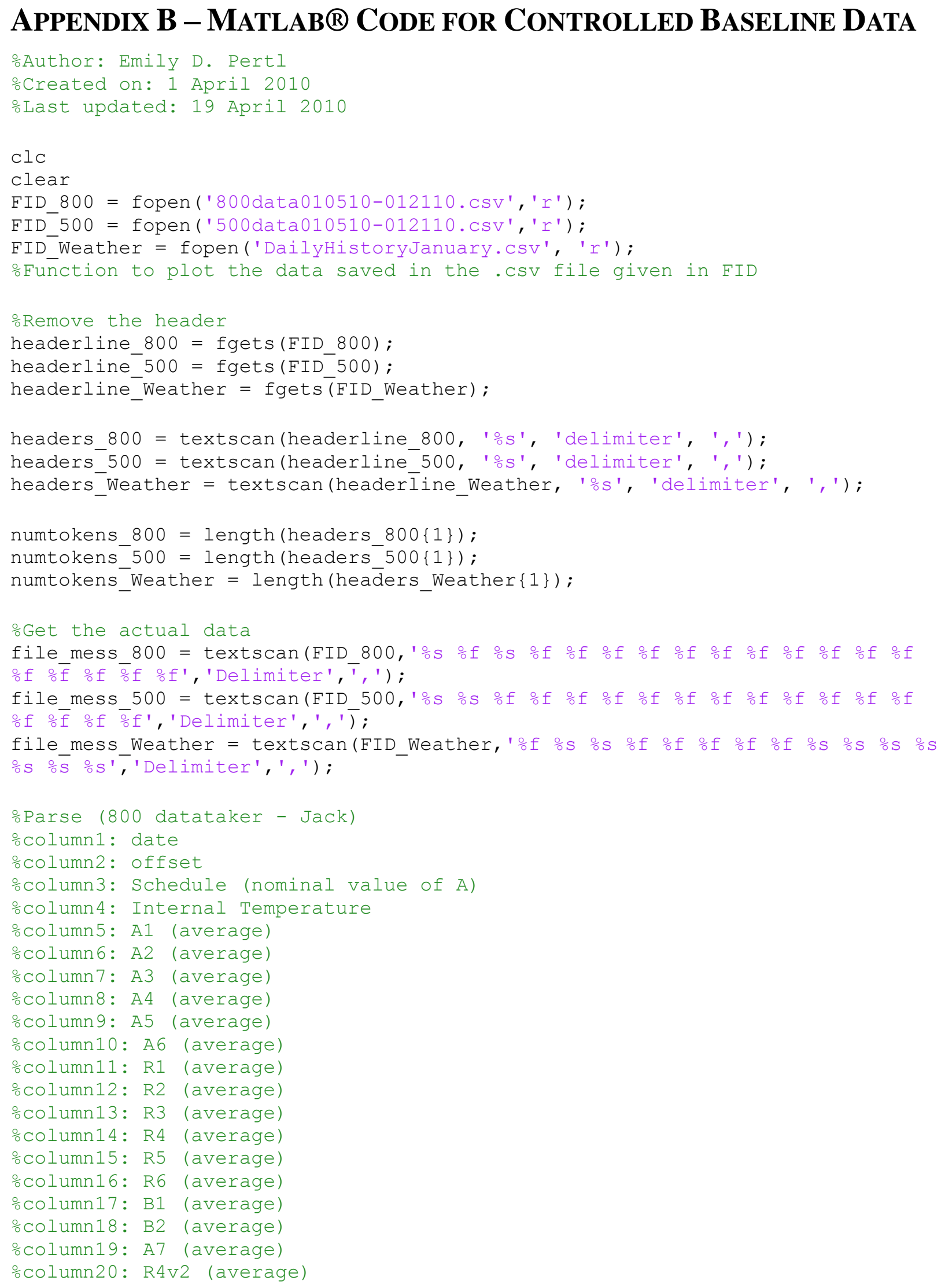




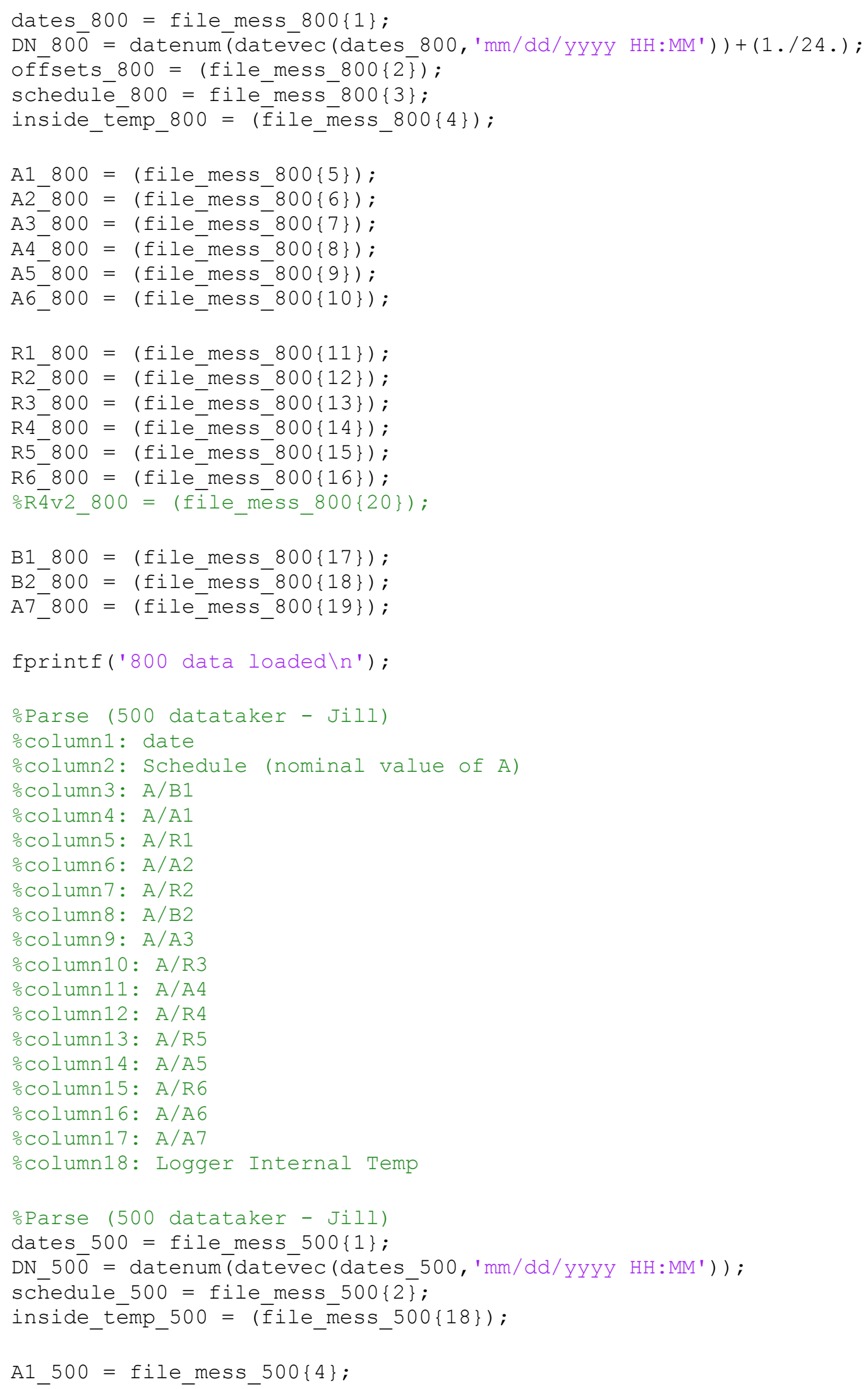




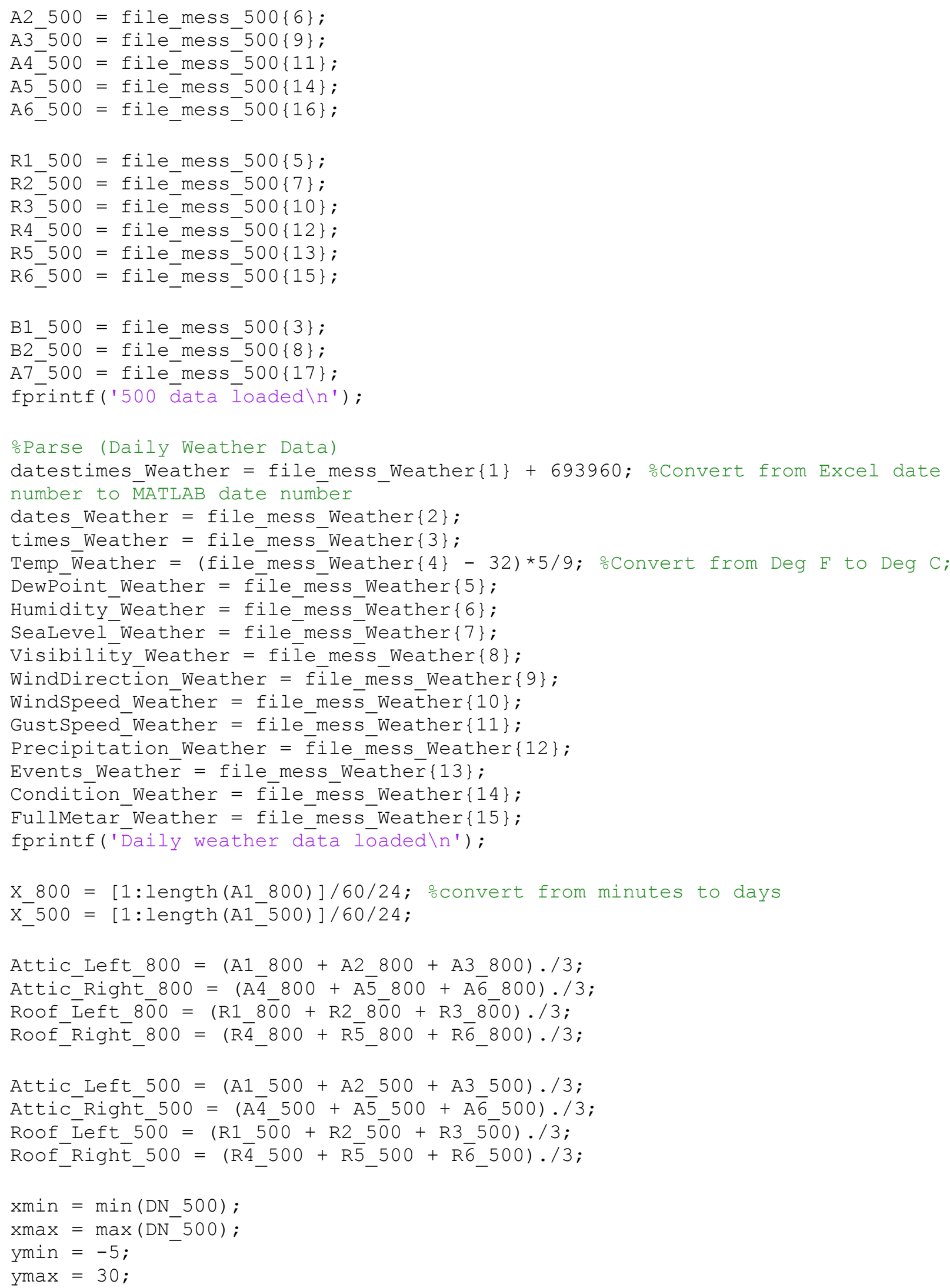




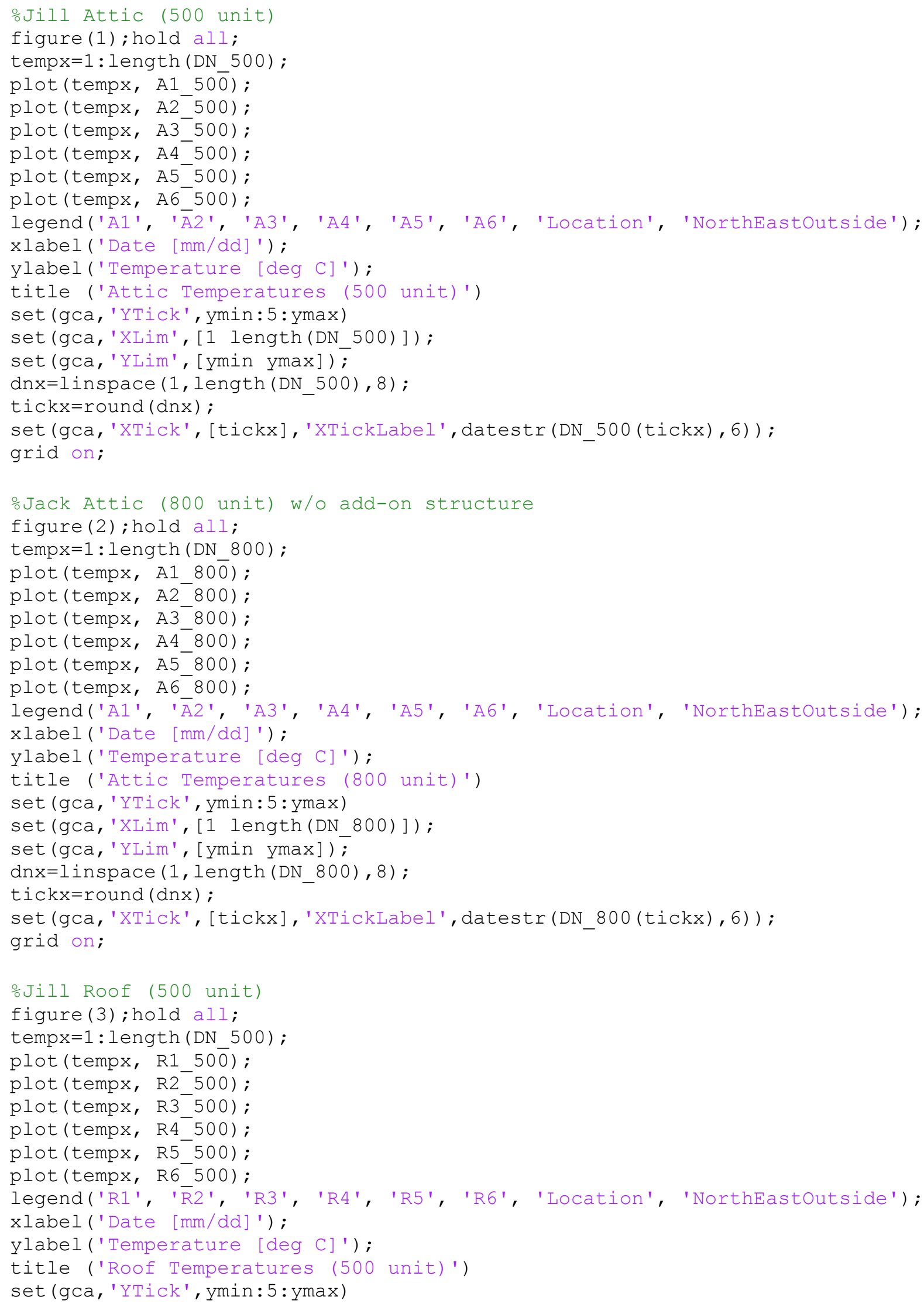




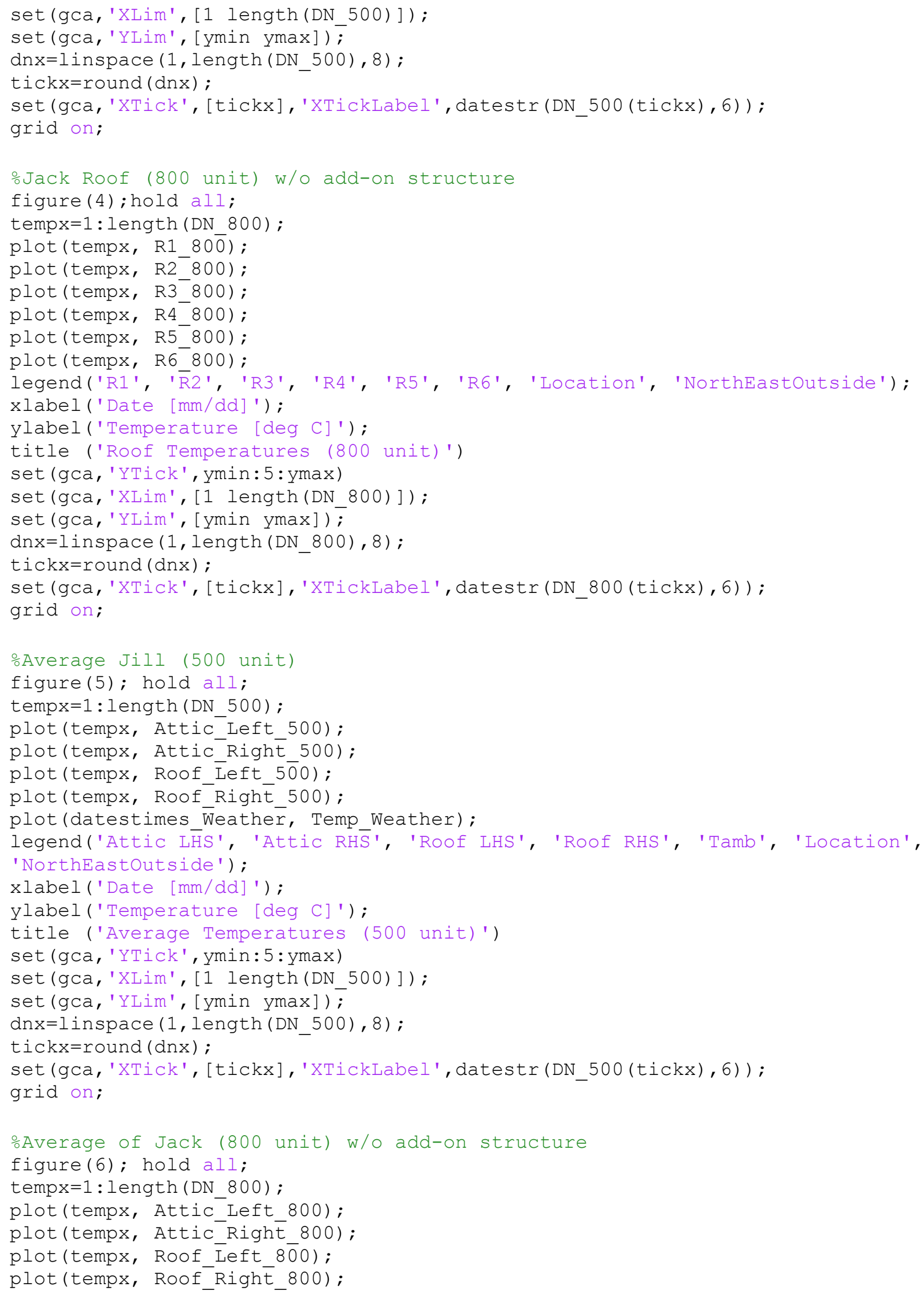




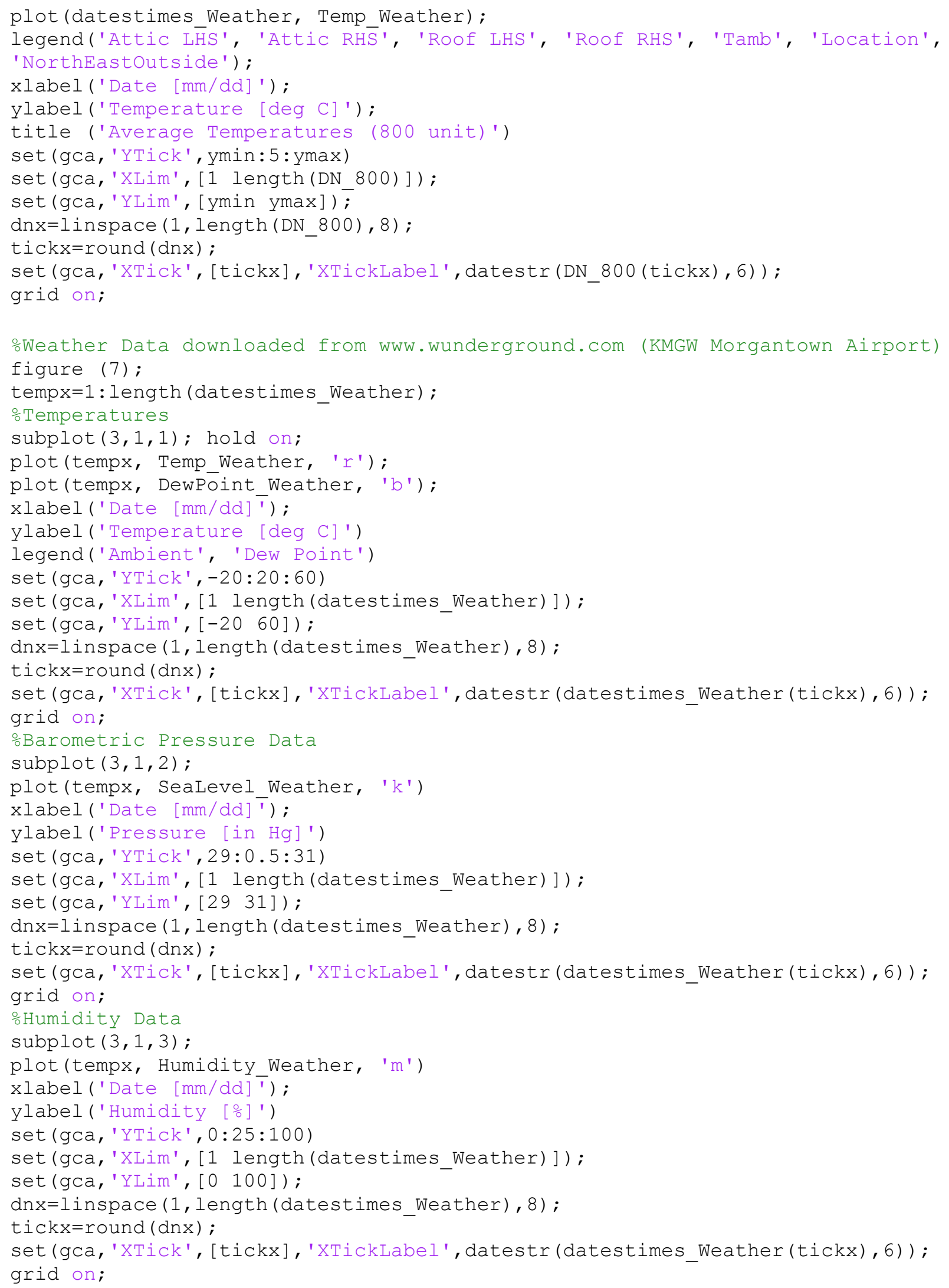




\section{APPENDiX C - MATLAB $®$ CODE FOR ENVIRONMENTAL BASELINE DATA}

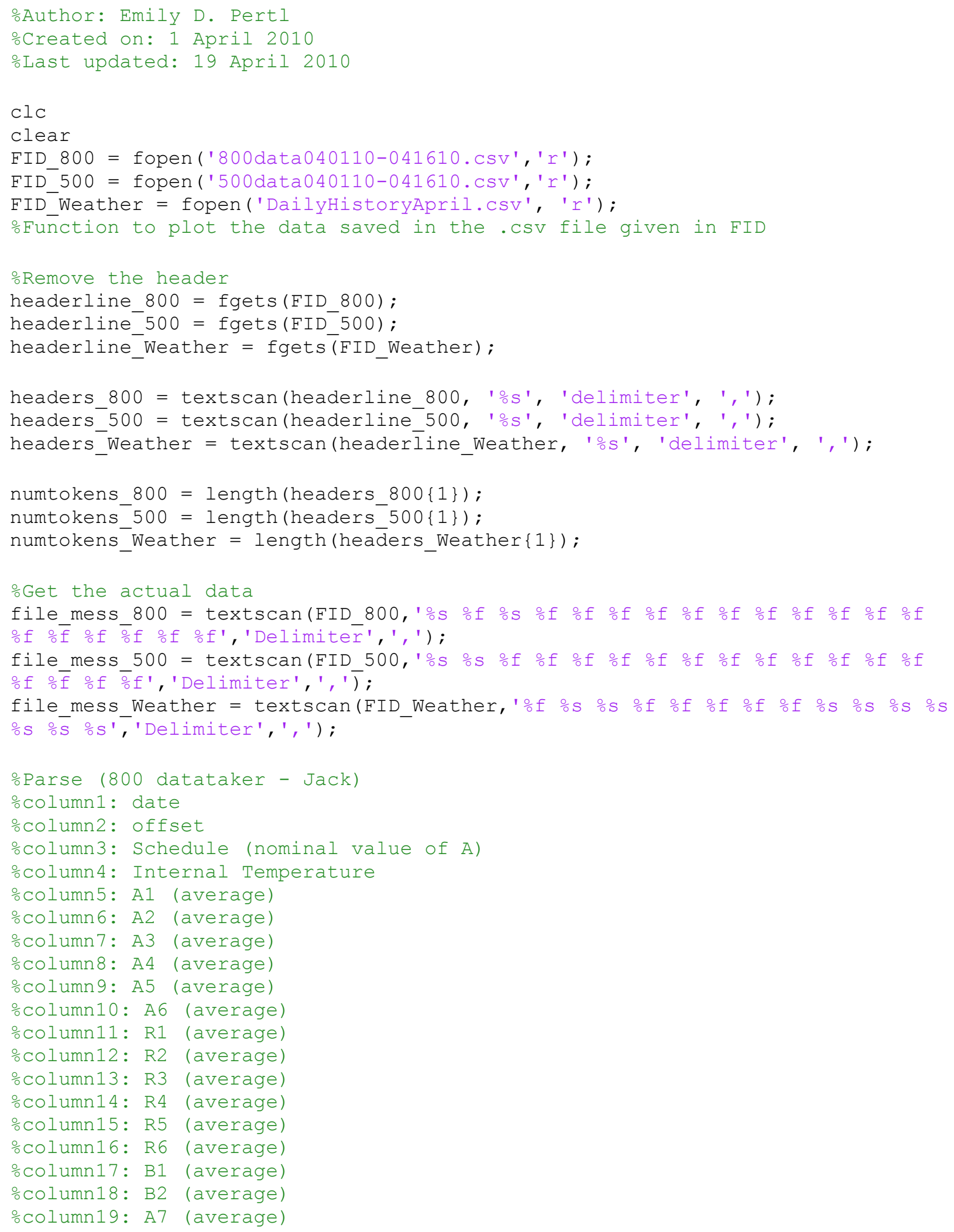




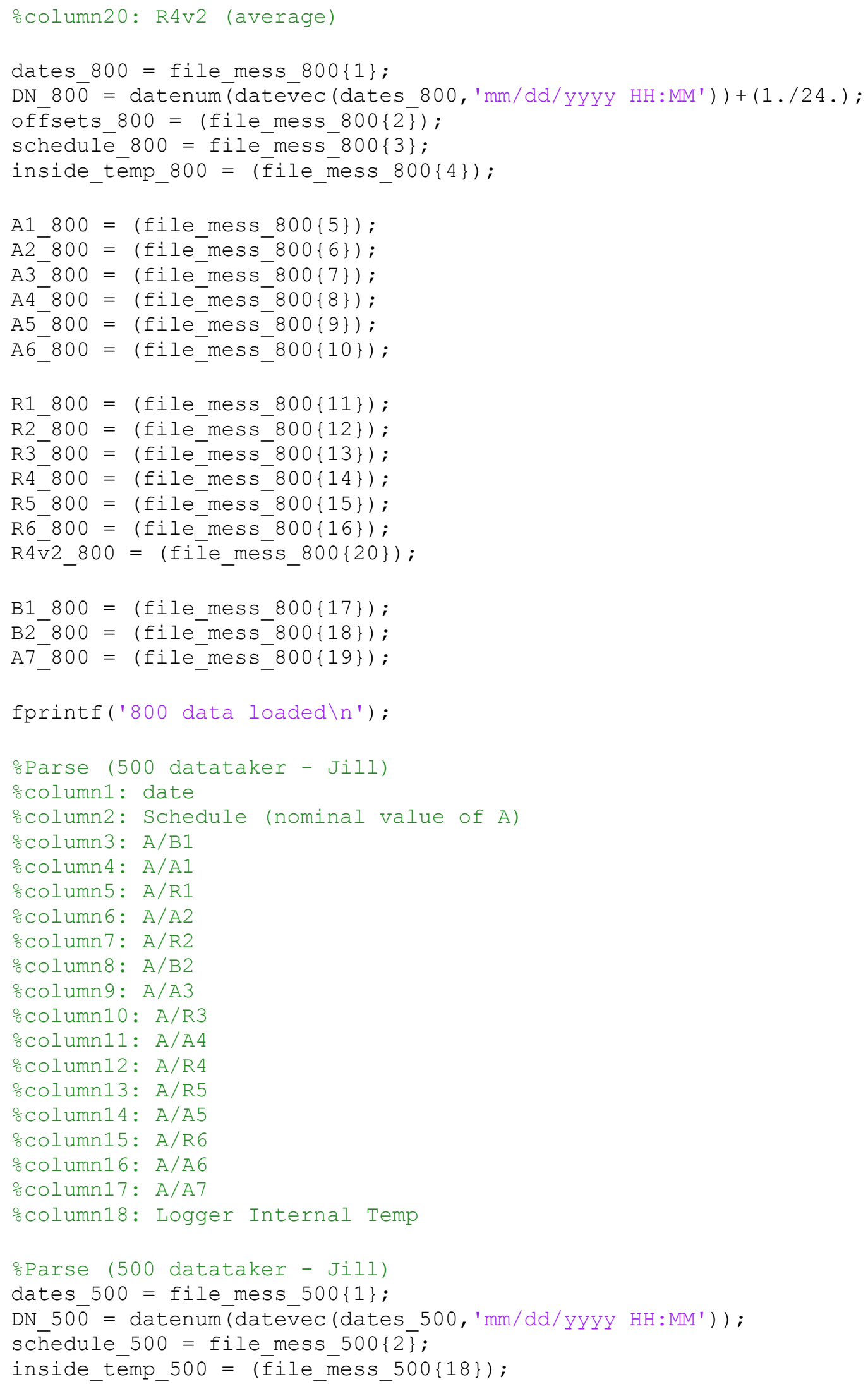




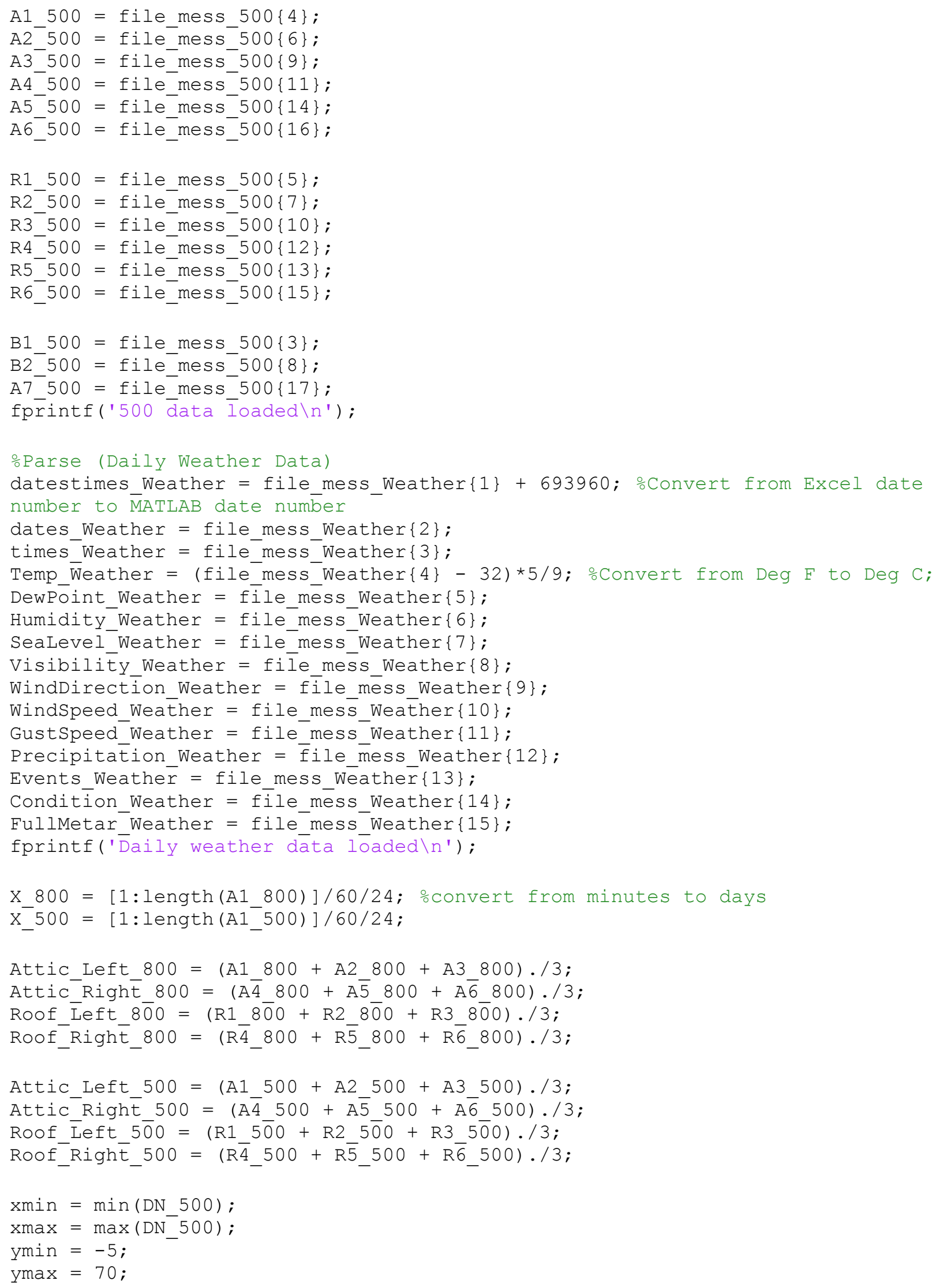




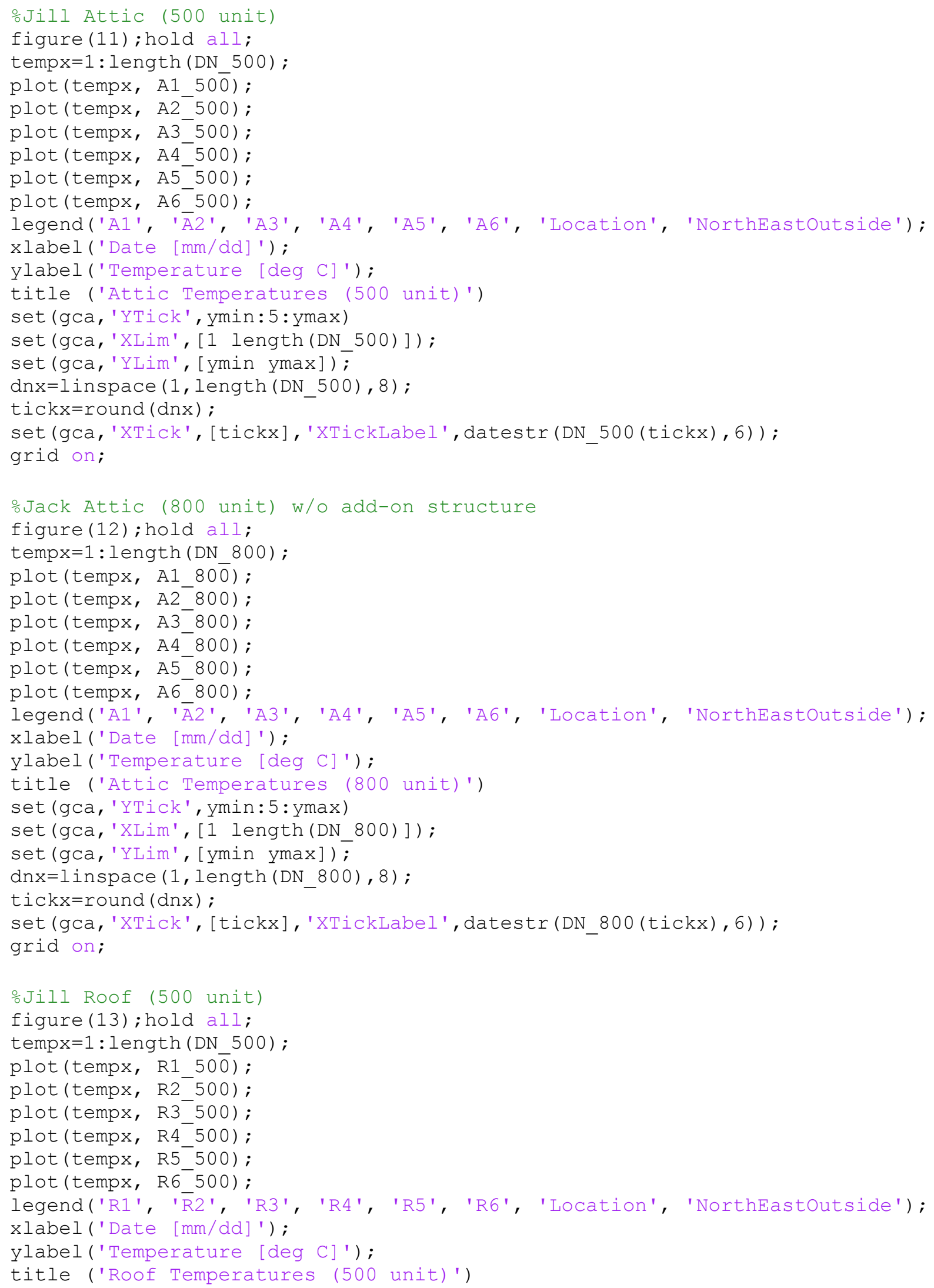




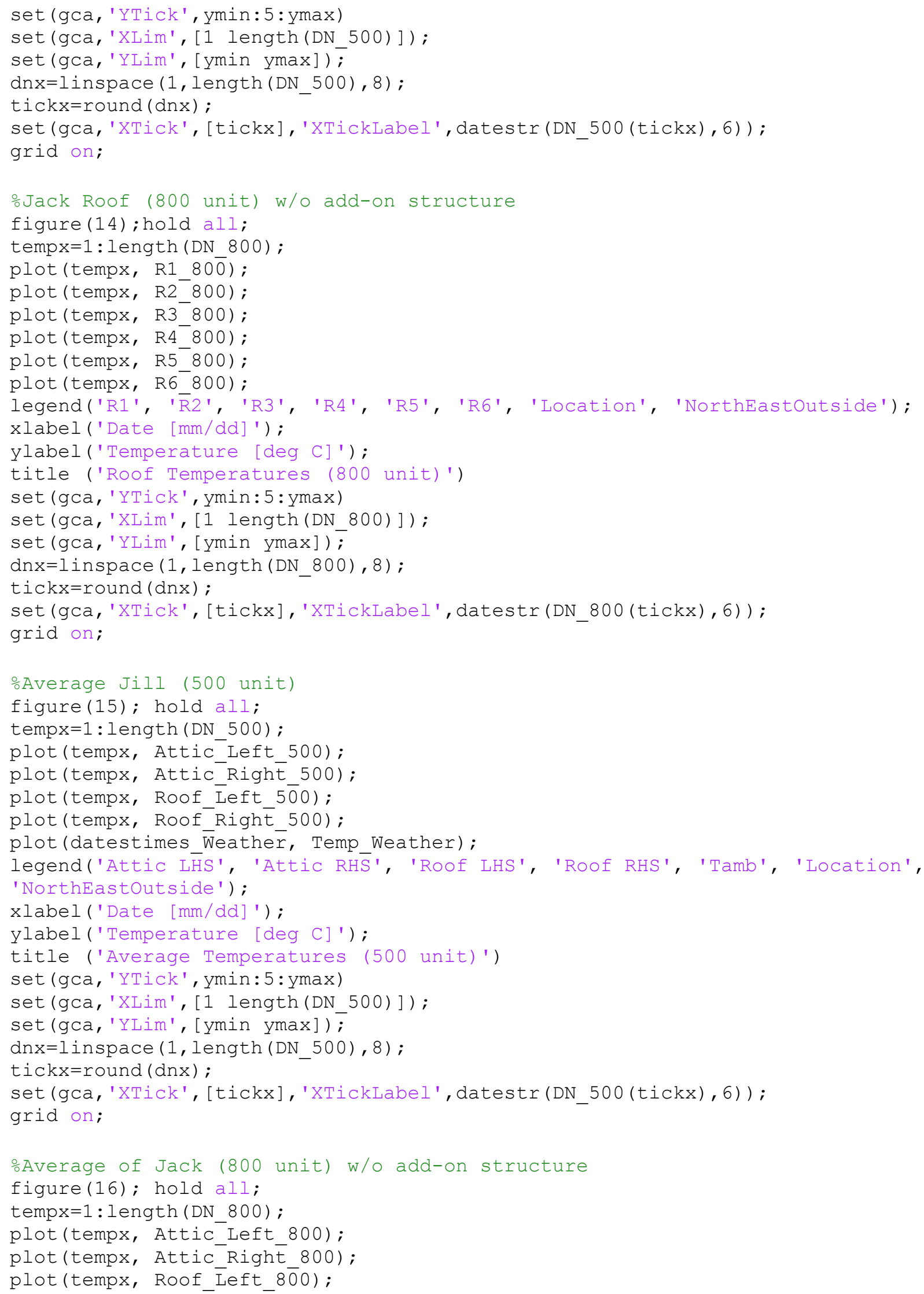




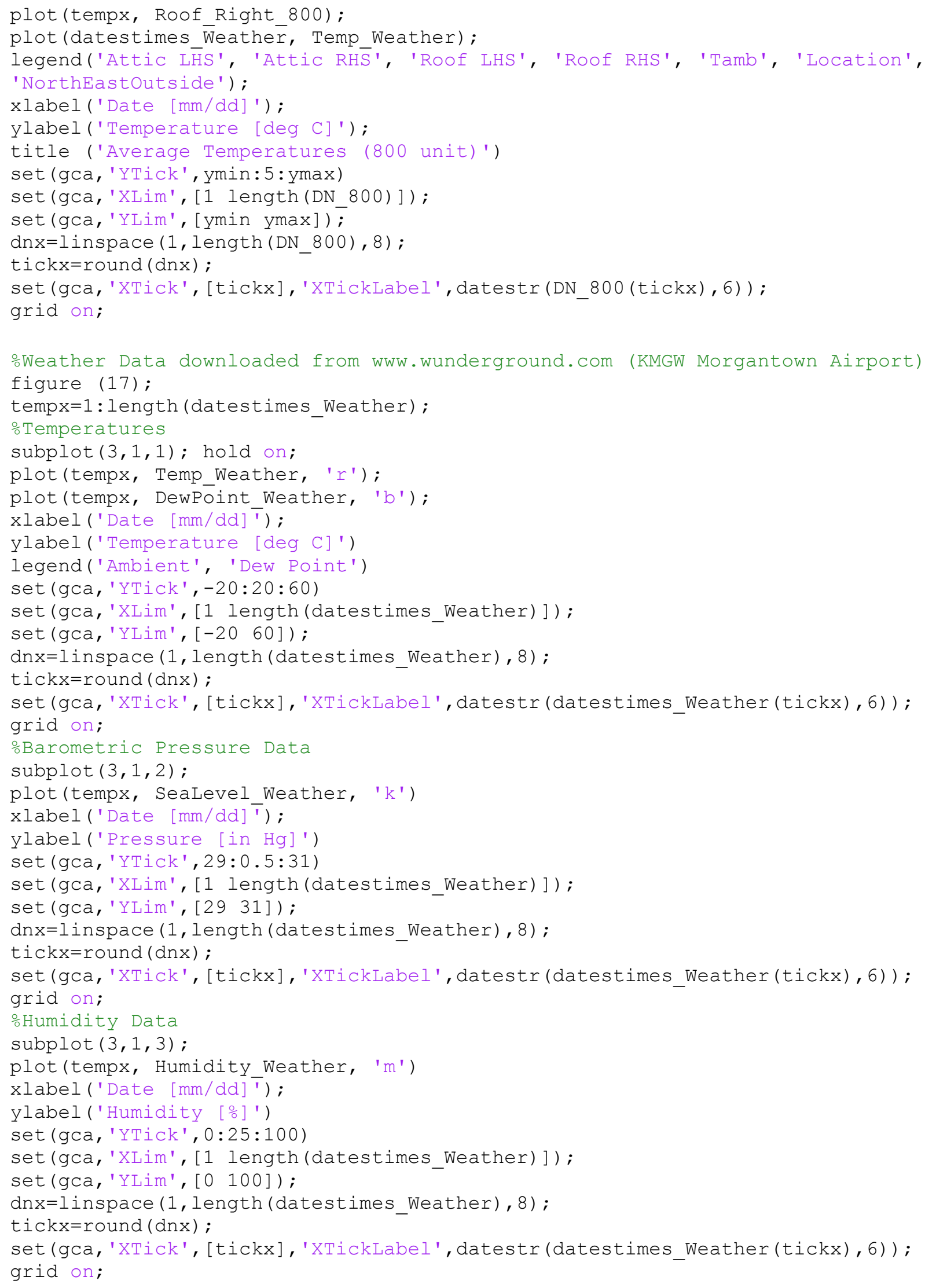




\section{APPENDIX D - MATLAB® CODE FOR ENVIRONMENTALLY EXPOSED DATA}

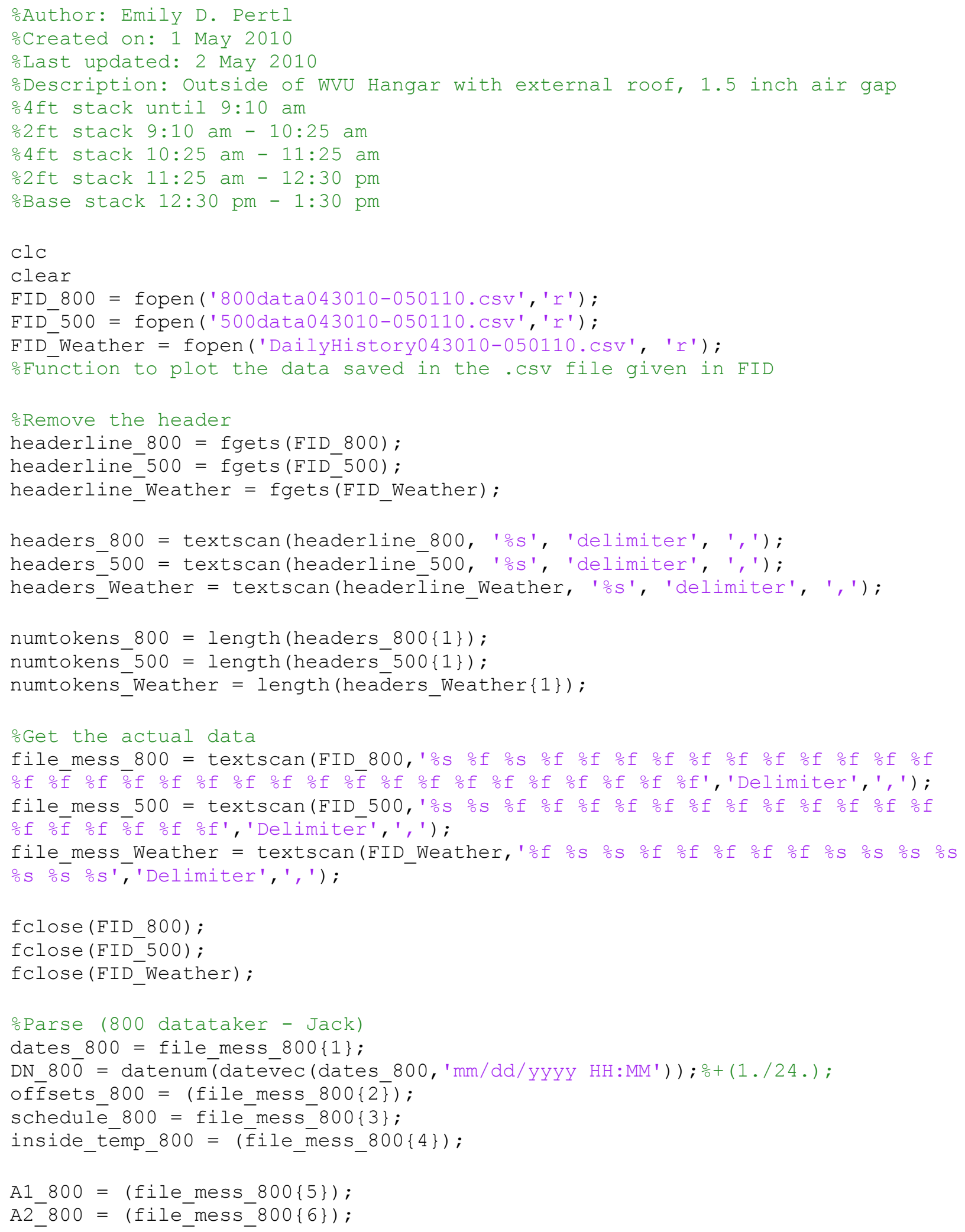




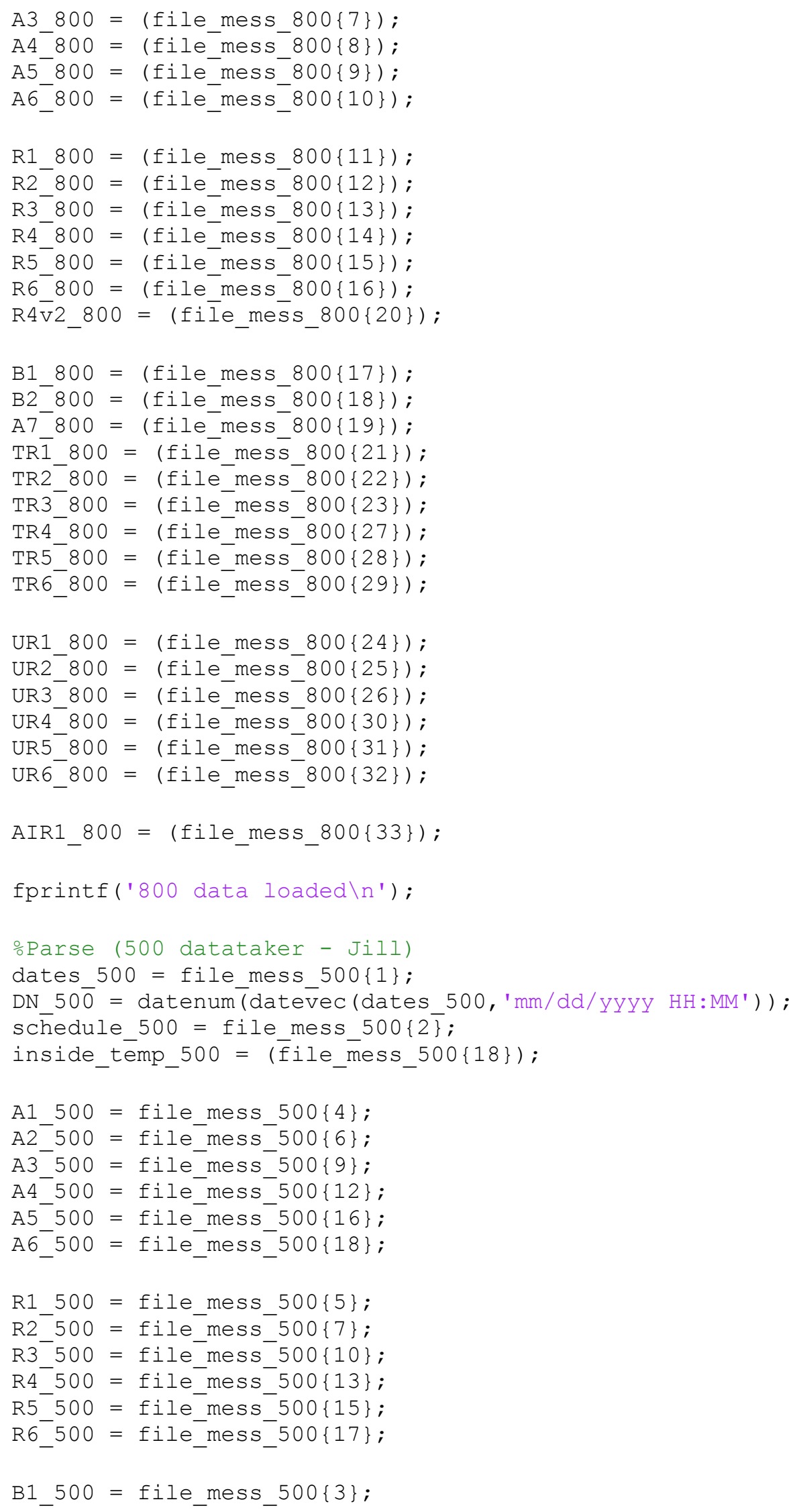




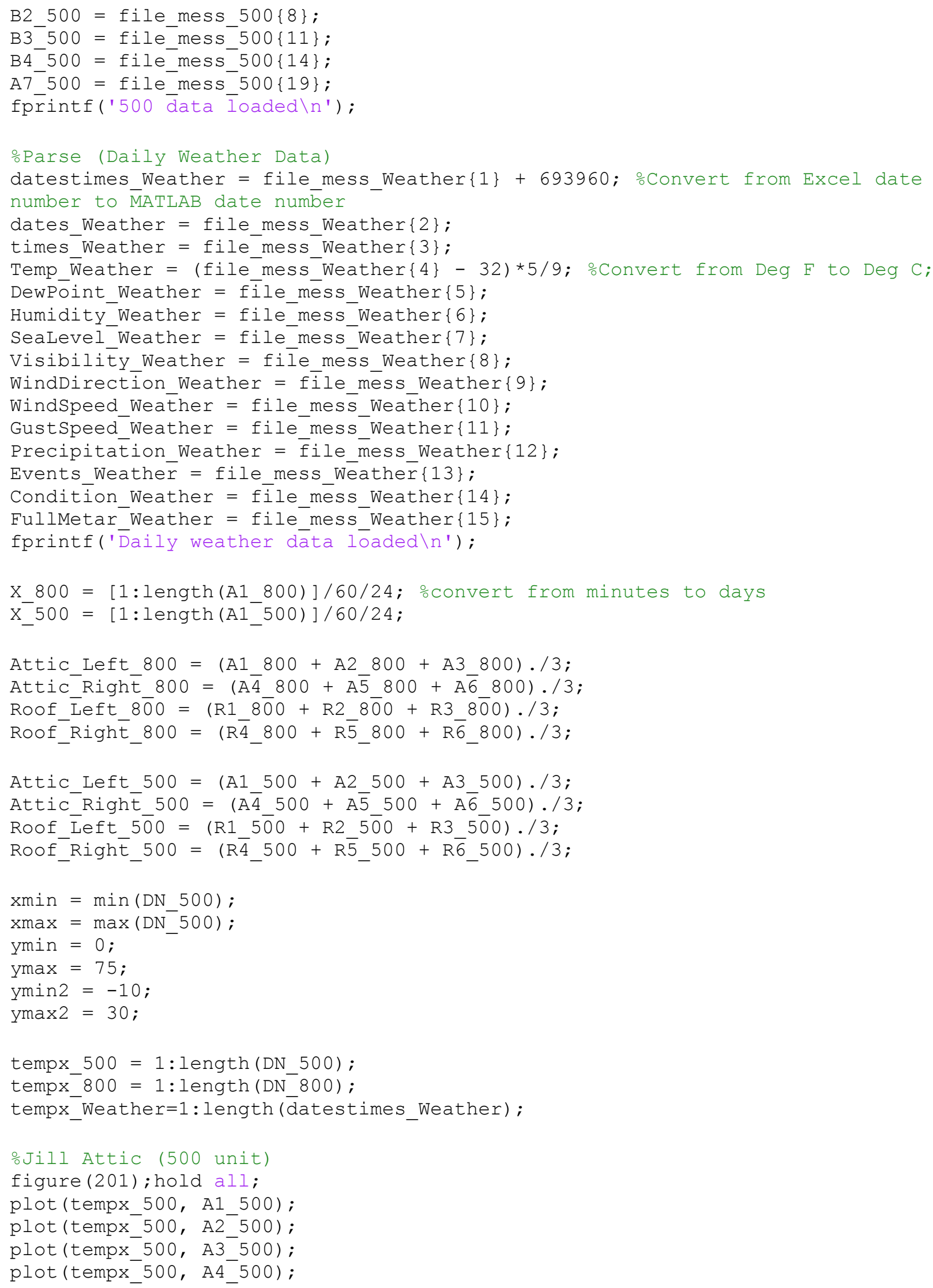




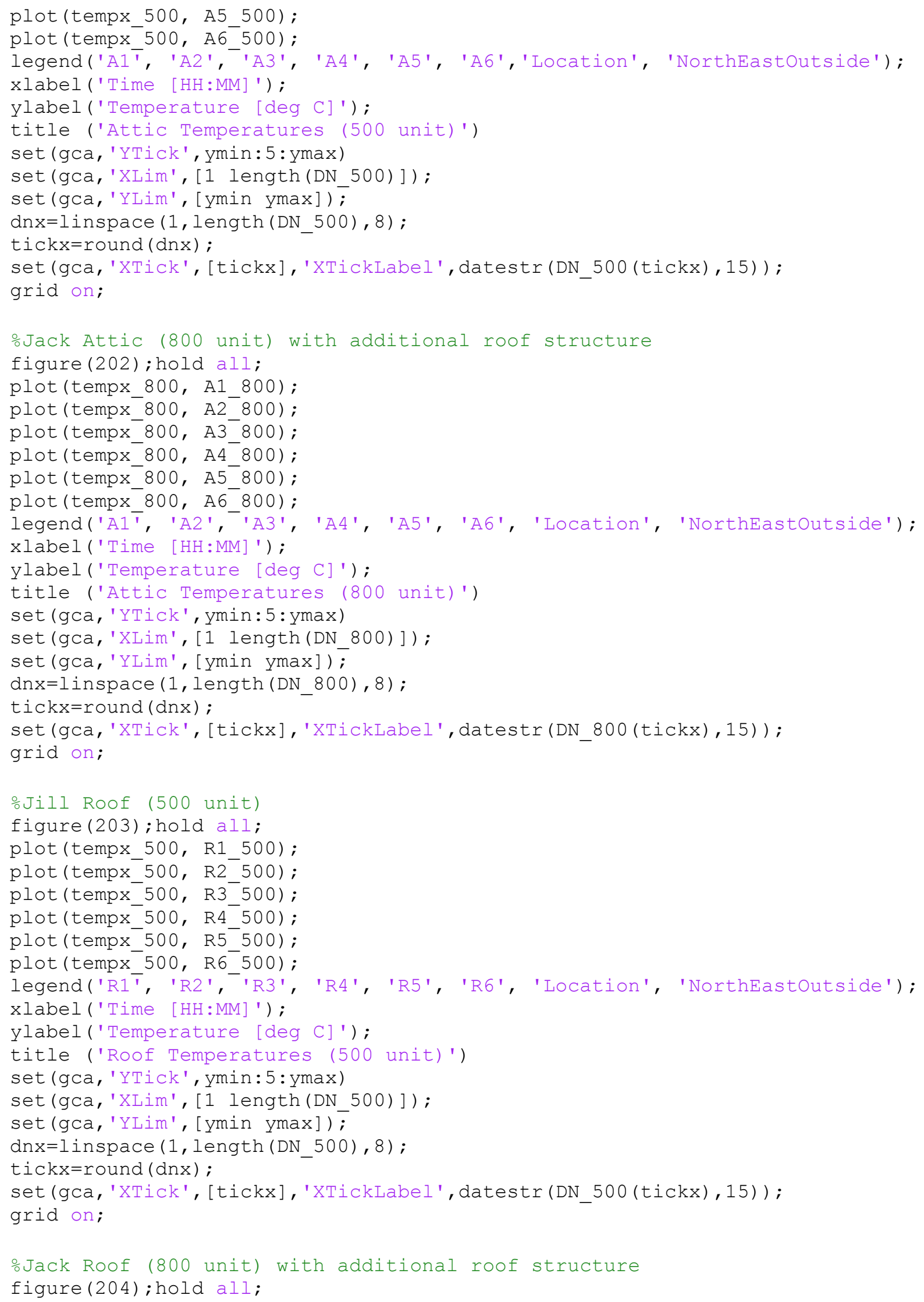




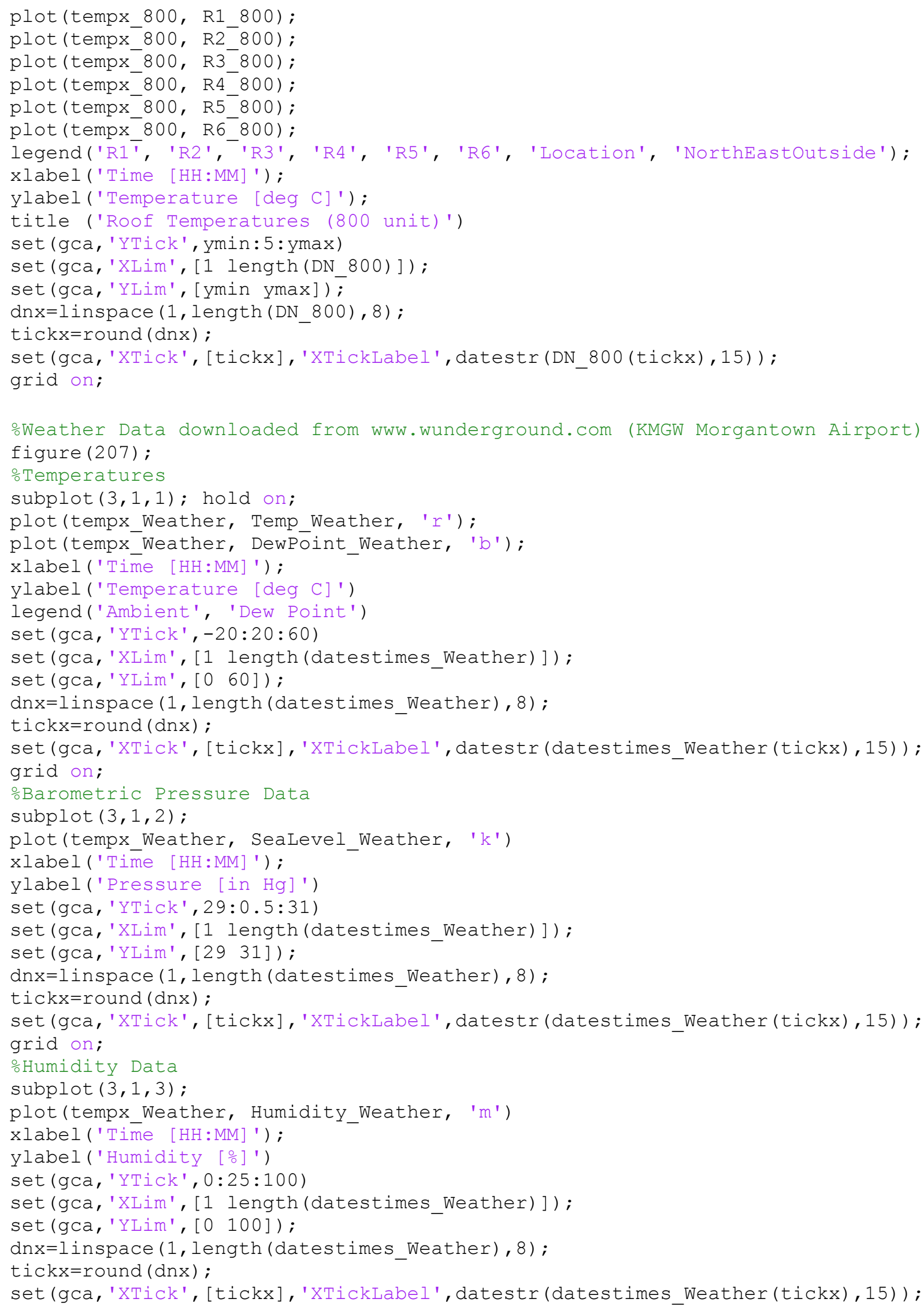




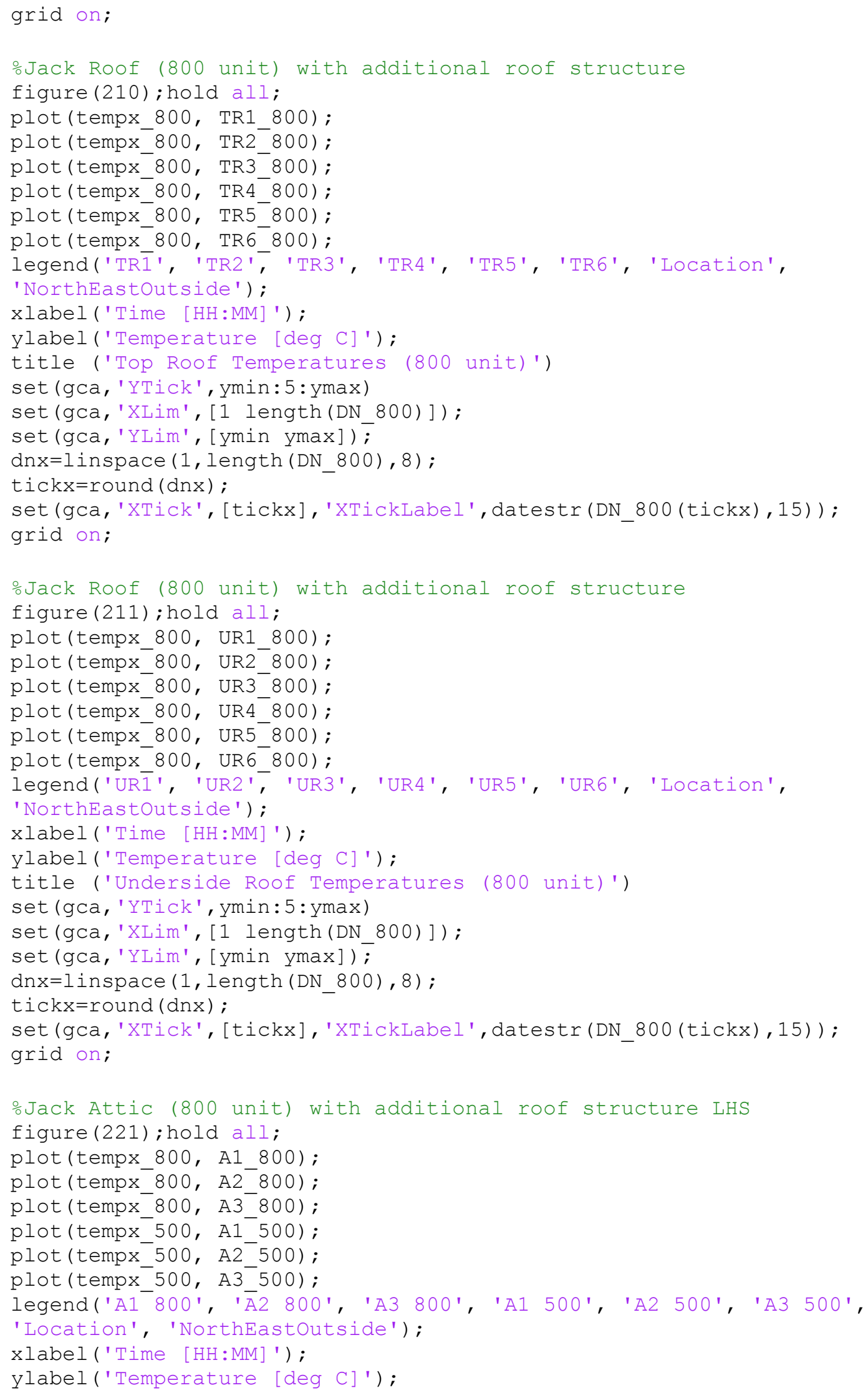




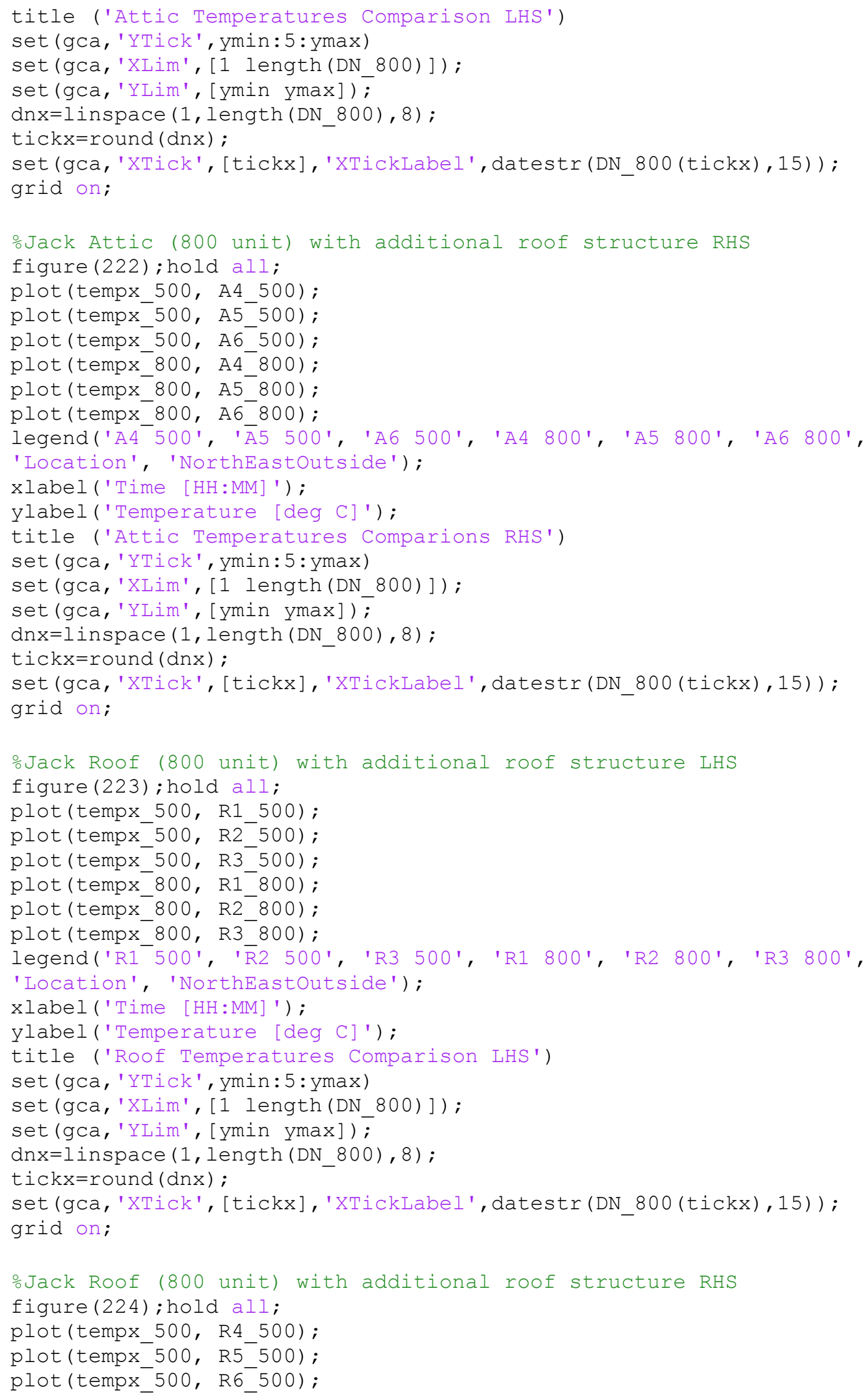




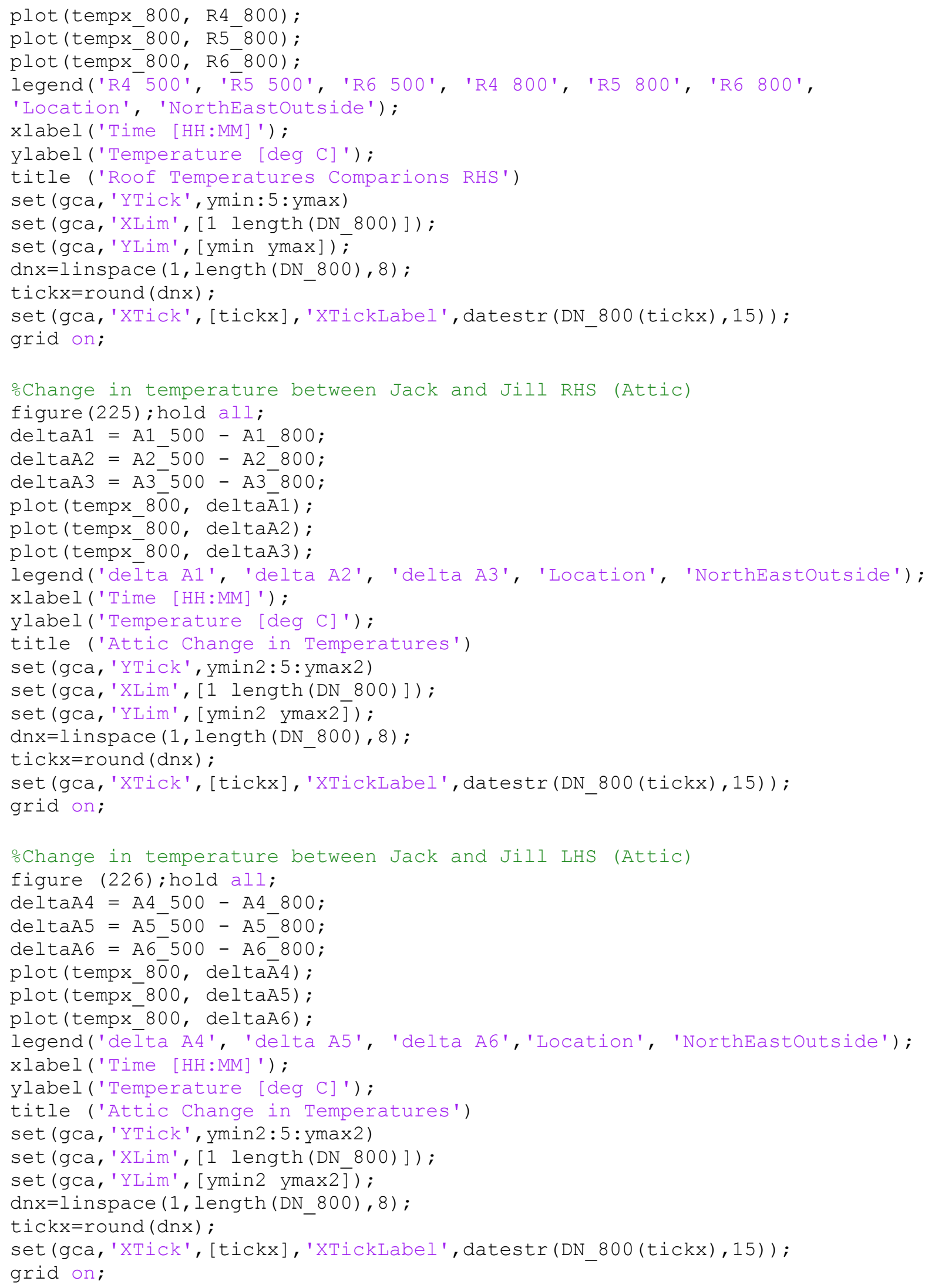




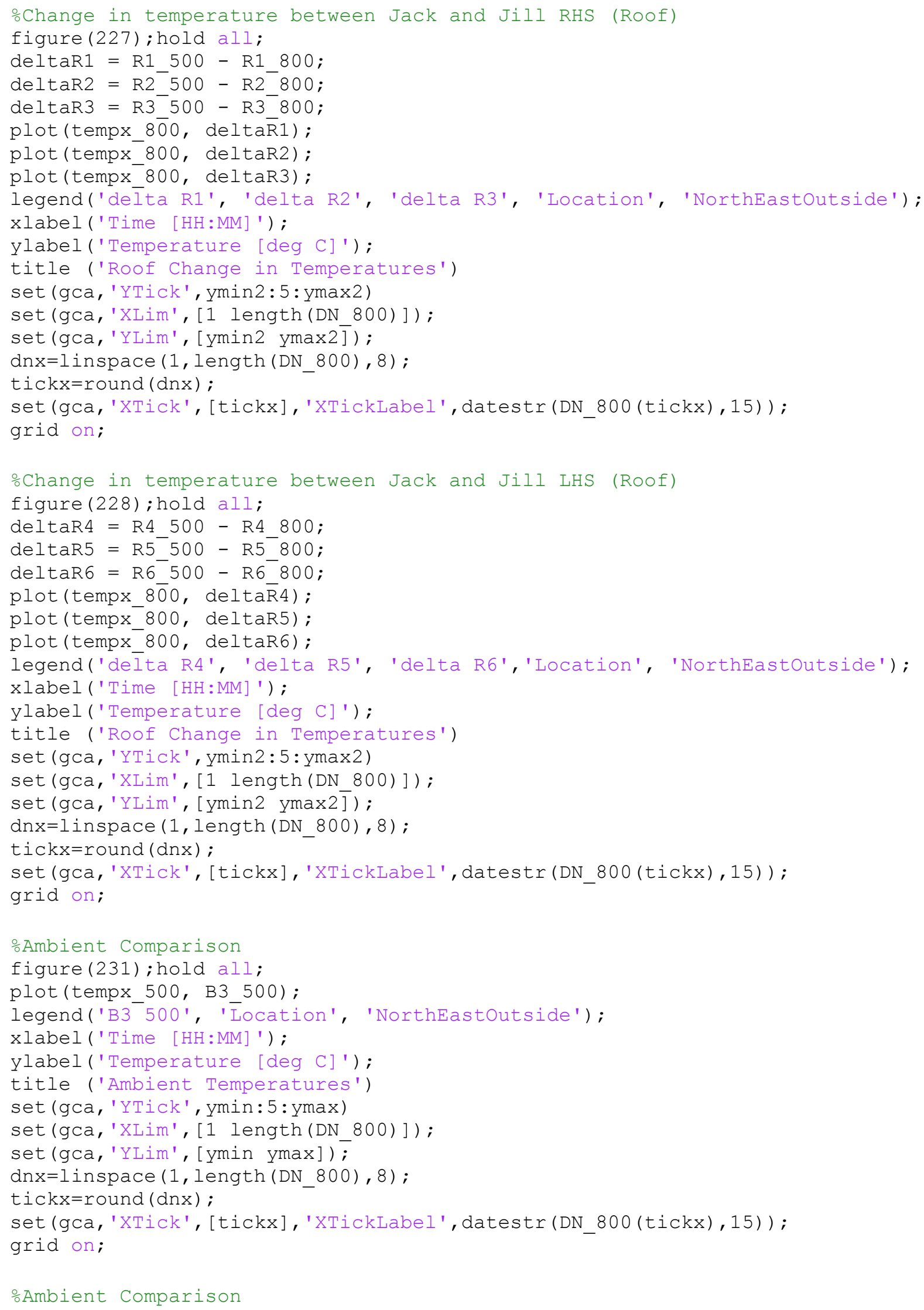




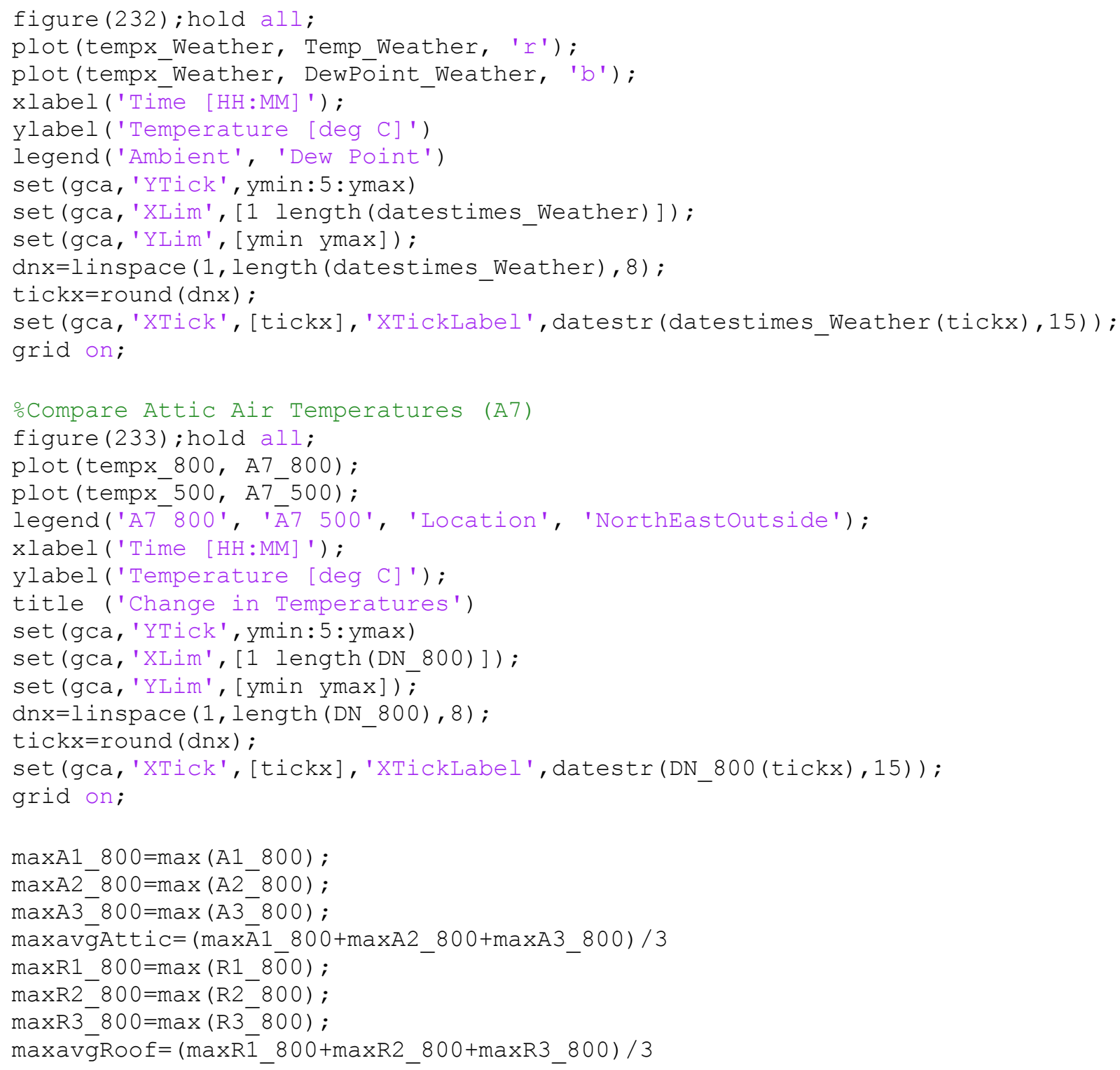

John H. 